\title{
UNDERSTANDING THE CLIMATE EFFECTS OF ANTHROPOGENIC AEROSOLS
}
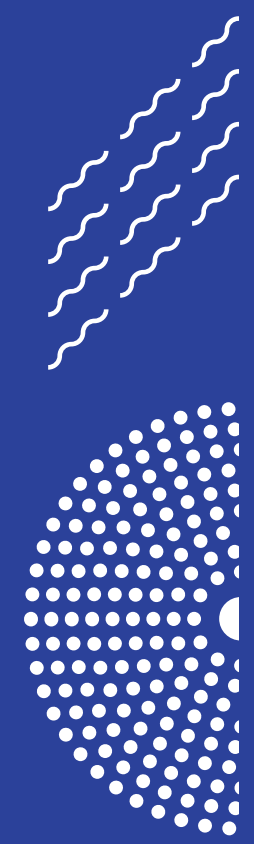
FINNISH METEOROLOGICAL INSTITUTE

CONTRIBUTIONS

No. 176

\title{
Understanding the climate effects of anthropogenic aerosols
}

\author{
Kalle Nordling \\ Institute for Atmospheric and Earth System Research / Physics \\ Faculty of Science \\ University of Helsinki \\ Helsinki, Finland
}

ACADEMIC DISSERTATION in meteorology

To be presented, with the permission of the Faculty of Science of the University of Helsinki, for public criticism in auditorium E204 at Physicum (Gustaf Hällströmin katu 2, Helsinki) on 05.11.2021, at 12 noon.

Finnish Meteorological Institute

Helsinki, 2021 
Supervisors Dr. Joonas Merikanto

Meteorological Research

Finnish Meteorological Institute, Finland

Professor Hannele Korhonen

Meteorological Research

Finnish Meteorological Institute, Finland

Professor Heikki Järvinen

Institute for Atmospheric and Earth System Research

University of Helsinki, Finland

Reviewers Associate Professor Nønne Prisle

Nano and Molecular Systems Research Unit

University of oulu

Associate professor Frida Bender

Department of Meteorology

Stockholm University

Custos Professor Heikki Järvinen

Institute for Atmospheric and Earth System Researc

University of Helsinki, Finland

Opponent Professor Dominick Spracklen

Institute for Climate and Atmospheric Science

School of Earth and Environment

University of leeds

ISBN 978-952-336-143-0 (paperback)

ISBN 978-952-336-142-3 (pdf)

ISSN 0782-6117

prting house

Helsinki 2021 
Published by Finnish Meteorological Institute (Erik Palménin aukio 1), PL 503 00101 Helsinki
Series title, number and report code of publication

Finnish Meteorological Institute

Contributions 176, FMI-CONT-176

Date: 05.11.2021

Author

Kalle Nordling

Title

Understanding the climate effects of anthropogenic aerosols

Abstract

Anthropogenic aerosols alter the climate by scattering and absorbing the incoming solar radiation and by modifying clouds' optical properties, causing a global cooling or warming effect. Anthropogenic aerosols are partly co-emitted with anthropogenic greenhouse gases, and future climate mitigation actions lead to the decline of anthropogenic aerosols' cooling effect. However, the exact cooling effect is still uncertain. Part of this uncertainty is related to the structural differences of current climate models. This work evaluates the present-day anthropogenic aerosol temperature and precipitation effect and factors affecting the model difference. The key objectives of this thesis were: 1) What are the climate effects of present-day anthropogenic aerosols?, 2) What mechanisms drive the model-to-model differences?, and 3) How do future reductions affect local and global climates?

The global models ECHAM6 and NorESM1 were used to evaluate the present-day climate effects with the identical anthropogenic aerosol scheme MACv2-SP. Results reveal that an identical anthropogenic aerosol description does not reduce the uncertainty related to anthropogenic aerosol climate effects, and the difference in the estimated difference is due to model dynamics and oceans. The key mechanism driving the difference in the models was evaluated using data from the Precipitation Driven Model Intercomparison Project (PRMIP). Similar mechanisms drive the model-to-model difference for greenhouse gases and aerosols, where the key drivers are the differences in water vapor, the vertical temperature structure of the atmosphere, and sea ice and snow cover changes. However, on a regional scale, the key drivers differ. Future anthropogenic aerosol effects were evaluated using new CMIP6 data.

This work shows the importance of anthropogenic aerosols for current and future climate change. For a more accurate assessment of climate impacts of anthropogenic aerosols, one needs to also consider remote effects of the local aerosols. The Arctic regions are particularly sensitive to midlatitude aerosols, such as Asian aerosols, which are expected to decline in the next decades. To gain a more accurate estimation of anthropogenic aerosols, it is not sufficient to only focus on composition and geographical distribution of aerosols, as the dynamic response of climate is also important. On global temperature results did not indicate clear aerosols signal, however future temperature development over the Asian regions is modulated by the future Asian aerosol emissions.

\section{Publishing unit}

Finnish Meteorological Institute

\begin{tabular}{ll}
\hline Classification (UDC) & Keywords \\
$551.58,504$ & Climate models, Aerosols, Uncertainty \\
\hline
\end{tabular}

ISSN and series title

0782-6117

Finnish Meteorological Institute Contributions

\begin{tabular}{lll}
\hline ISBN & Language & Pages \\
$978-952-336-143-0$ (paperback) & English & 57 \\
$978-952-336-142-3$ (pdf) & & \\
\hline
\end{tabular}


Julkaisija Ilmatieteen laitos

(Erik Palménin aukio 1), PL 503

00101 Helsinki
Julkaisun sarja, numero ja raporttikoodi

Finnish Meteorological Institute

Contributions 176, FMI-CONT-176

Julkaisuaika: 5.11 .2021

Tekijä

Kalle Nordling

Nimike

Ihmisperäisten pienhiukkasten ilmastovaikutusten mallinnus

Tiivistelmä

Ihmisen aiheuttamat päästöt vaikuttavat ilmastoon monella eri tavalla. Ihmisen aiheuttamien kasvihuonekaasujen lisäksi ihmisen toiminnasta aiheutuva pienhiukkasten määrän lisääntyminen muuttaa ilmakehän koostumusta. Tällä hetikellä pienhiukkaset viilentävät ilmastoa. Ne kuitenkin vaikuttavat suppeammalla alueella kuin kasvihuonekaasut, jonka takia niillä on voimakas paikallinen vaikutus. Kiristyneiden ilmanlaatuvaatimusten takia pienhiukkasten määrä on vähentynyt nopeasti ja niiden koostumus on muuttunut. Tämän takia pienhiukkasten aiheuttamia vaikutuksia nykyilmastoon ja tulevaisuuteen on tärkeää tutkia. Erityisesti viilentävän vaikutuksen tutkiminen on olennaista. Kuitenkaan kaikki pienhiukkaset eivät laske lämpötilaa vaan esimerkiksi musta hiili lämmittää ilmastoa. Kuitenkin pienhiukkasten ilmastovaikutuksiin liitttyy vielä paljon epävarmuuksia ja niiden tutkiminen on tärkeää, jotta yhteiskunnat pystyvät paremmin sopeutumaan pienhiukkasten aiheuttamiin epävarmuuksiin.

Tässä tutkimuksessa hyödynnettiin ECHAM6 ja NorESM1 -ilmastomalleja, joissa on keskenään samanlainen kuvaus ihmisperäisistä pienhiukkasista. Kummassakin mallissa on identtinen kuvaus aerosolien pilvivuorovaikutuksesta. Näiden avulla tutkittiin, mikä on nykypäivän pienhiukkasten ilmastovaikutus. Kasvihuonekaasujen ja erilaisten pienhiukkasten ilmastovaikutuksia sekä ilmastomallien välisiä eroja tutkittiin käyttäen Precipitation Driven Model Intercomparison Project (PDRMIP) aineistoa. Tulevaisuuden pienhiukkasten ilmastovaikutuksia tutkittiin Climate Model Intercomparison Project phase 6 (CMIP6) aineistosta.

Tutkimuksessa havaittiin, että vaikka ilmastomallien ihmisperäisten aerosolien kuvaus oli identtinen, mallit antoivat lievästi erilaisia tuloksia. Mallien väliset erot eivät olleet merkittävästi pienemmät identtisyydestä huolimatta kuin epäidenttisten mallien erot olivat. Ilmastovaikutusten eroihin vaikuttavat ihmisperäisten aerosolien kuvaukse lisäksi se, miten meri on kuvattu malleissa ja miten merijää muuttuu ihmisperäisten aerosolien vaikutuksesta. Globaalilla tasolla mallien väliset erot selittyvät erilaisesta vasteesta ilmakehän pystyrakenteessa ja merijäässä. Vaikka ilmastomalleihin lisätään kasvihuonekaasujen tai aerosolien määrää, erot selittyvät samoilla tekijöillä. Paikallisesti ilmastomallien väliset tulokset taas eroavat merkittävästi myös pilvien erilaisten vaikutusten seurauksena.

Tulevaisuudessa on arvioitu, että pienhiukkasten pitoisuudet pienenevät. Tämä johtuu siitä, että pienhiukkaset syntyvät osittain samoista lähteistä kuin kasvihuonekaasut. Globaalissa lämpötilassa ei havaittu merkittävää vaikutusta, mutta lähitulevaisuudessa aerosolien vaikutus sadannan muutoksessa on merkittävä. Aasiassa aerosoleilla on huomattava vaikutus monsuunisateeseen ja lämpötilaan.

Tämä tutkimus antaa viitteitä siitä, että ilmastomalleissa ihmisperäisten pienhiukkasten ilmastovaikutuksissa merkittävää on pienhiukkasten mahdollisimman tarkan kuvauksen lisäksi ilmakehän ja meren dynaaminen vaste. Mikäli tulevaisuudessa ihmisperäisten aerosolien ilmastovaikutuksia halutaan tarkentaa, pelkästään aerosolien mikrofysiikan tarkempi kuvaus ei ole riittävää vaan tarvitaan ymmärrystä myös ilmakehän dynaamisista vasteista.

Julkaisijayksikkö

Ilmatieteen laitos

\begin{tabular}{lll}
\hline $\begin{array}{l}\text { Luokitus (UDK) } \\
551.58,504\end{array}$ & $\begin{array}{l}\text { Asiasanat } \\
\text { Ilmaston mallinnus, Aerosolit, Epävarmuus }\end{array}$ \\
\hline $\begin{array}{l}\text { ISSN ja avainnimike } \\
0782-6117\end{array}$ & Finnish Meteorological Institute Contributions \\
& & Sivumäärä \\
\hline ISBN & Kieli & 57 \\
$978-952-336-143-0$ (nid.) & Englanti & \\
$978-952-336-142-3$ (pdf) & &
\end{tabular}




\section{Preface}

The research presented here has been carried out in Finnish Meteorological Institute. I'm deeply grateful to the pre-examiners, Prof Nønne Prisle from University of Oulu and Frida Bender from Stockholm University. I deeply thanks the professor Dominick Spracklen from university of leeds for agreening to be an opponent for this thesis.

I'm gratefull to all my supervisors, Hannele Korhonen, Joonas Merikanto and Heikki Järvinen. First for providing this opportunity to work at FMI and second providing huge support for this thesis. Especially Joonas who have had the patient with my texts containing lot of typoes due to severe dyslexia. Also many thanks to our group climate system modeling, especially, Anca, Erika, Jaakko, Tomi, Petri, Antti-Ilari, Declan. I would also thank to collaboration from university of helsinki, Petteri Uotila and Jouni Räisänen. Bjørn Samset, Marianne Tronstad Lund from CICERO and Laura Wilcox from Reading deserves thanks for integrating me to more international research community.

I own thanks also to my friend Heli Seppänen and Petra Laamanen for doing first proof reading of this thesis, and reading all my non-funded grant-applications. Also Nina and Venla whom has listen my presentation rehearsals.

Last I would like to show my gratitude to my wife Kaisu, how has supported me during the whole $\mathrm{PhD}$ process and agreed to move to Oslo with me, and proof reading my applications and other texts, providing opportunity to talk about science and climate in schools. Loving you!

Kalle Nordling

Oslo, 2021 


\section{CONTENTS}

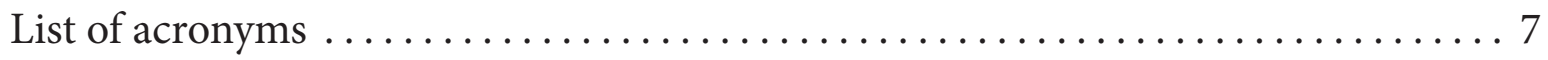

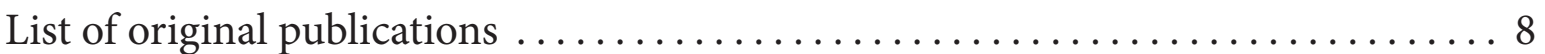

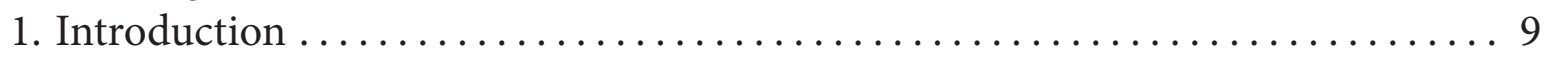

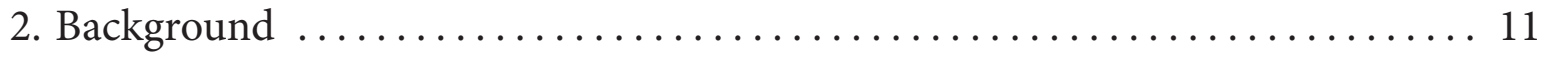

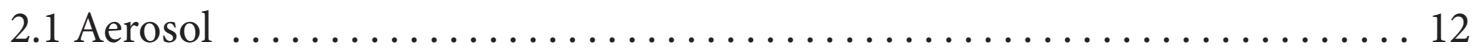

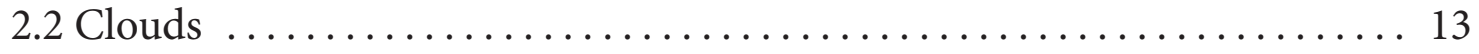

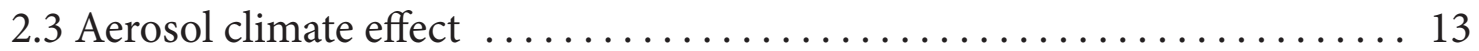

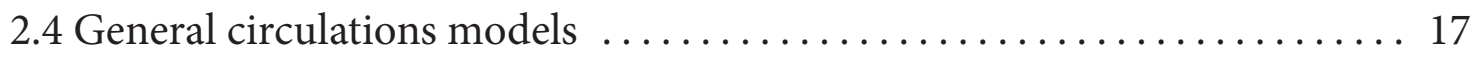

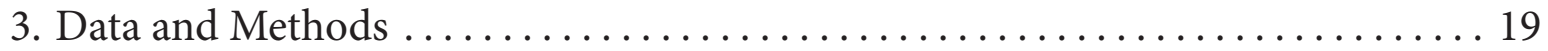

3.1 Climate model simulations and data sets $\ldots \ldots \ldots \ldots \ldots \ldots \ldots \ldots$

3.1.1 Models and performed Simulations ................... 19

3.1.2 PDRMIP and CMIP6 datasets ................... 20

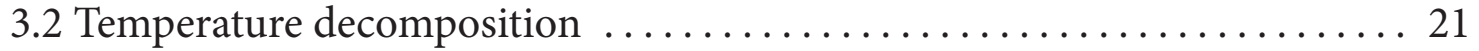

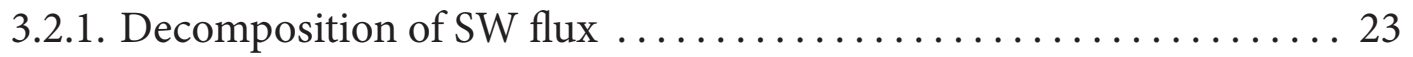

3.2.2. Decomposing LW flux with radiative kernels . . . . . . . . . . . . 25

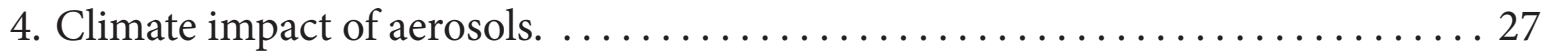

4.1 Global climate impact of present-day aerosols . . . . . . . . . . . . 27

4.2. Climate impact of Asian aerosol emissions . . . . . . . . . . . . . . 29

5. Origin of the temperature response and its uncertainty $\ldots \ldots \ldots \ldots \ldots \ldots \ldots$

6. Future aerosol climate impacts . . . . . . . . . . . . . . . . . 39

6.1 Global effects . . . . . . . . . . . . . . . . . . . . . . . . 39

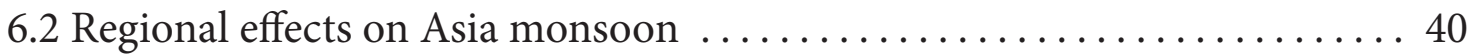

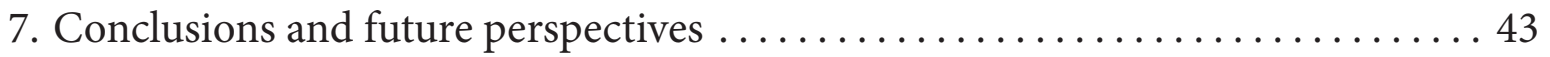

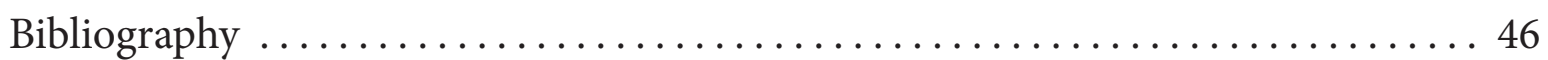




\section{LIST OF ACRONYMS}

CCN Cloud Condencation Nuclei

CDNC Cloud Droplet Number Concentration

CMIP Climate Model Intercomparison Project

ECMWF European Centre for Medium-Range Weather Forecasts

ESM Earth System Model

GCM General Circulation Model

GHG Green House Gas

IN Ice Nuclei

IPCC Intergovernmental Panel on Climate Change

ITCZ Intertropical convergence zone

LW Long Wave

PDRMIP Precipitation Driver Response Model Intercomparison Project

SSP Shared Socioeconomic Pathways

SW Short Wave

TOA Top Of the Atmosphere 


\section{LIST OF ORIGINAL PUBLICATIONS}

I Nordling, K., Korhonen, H., Räisänen, P., Alper, M. E., Uotila, P., O’Donnell, D., and Merikanto, J.: Role of climate model dynamics in estimated climate responses to anthropogenic aerosols. Atmospheric Chemistry and Physics, 19, 9969-9987, doi:10.5194/acp-19-9969-2019

II Wilcox, L. J., Liu, Z., Samset, B. H., Hawkins, E., Lund, M. T., Nordling, K., Undorf, S., Bollasina, M., Ekman, A. M. L., Krishnan, S., Merikanto, J., and Turner, A. G.: Accelerated increases in global and Asian summer monsoon precipitation from future aerosol reductions, Atmospheric Chemistry and Physics , 20, 11955-11977, doi:10.5194/acp-20-11955-2020, 2020.

III Merikanto, J., Nordling, K., Räisänen, P., Räisänen, J., O’Donnell, D., Partanen, A.-I., and Korhonen, H.: How Asian aerosols impact regional surface temperatures across the globe, Atmos. Chem. Phys., 21, 5865-5881, https://doi.org/10.5194/acp-21-5865-2021, 2021.

IV Nordling, K., Korhonen, H., Räisänen, J., Partanen, A.-I., Samset, B., and Merikanto, J.: Understanding the surface temperature response and its uncertainty to $\mathrm{CO} 2, \mathrm{CH} 4$, black carbon and sulfate, Atmos. Chem. Phys. Discuss. [preprint], https://doi.org/10.5194/acp-2021-401, in review, 2021.

Author's contribution to paper I. The author was responsible for the analysis and visualization of the data from the NorESM1 and ECHAM6 models, performing the ECHAM6 simulations, and writing the paper with the help of co-authors. In paper II, the author participated in writing and performed the temperature analysis of the CMIP6 models for four different future emission scenarios. The author also produced the visualization of the temperature data. In paper III, the author was responsible of the data-analysis, writing code for the temperature decomposition, ECHAM6 climate model simulations, and data visualization. In paper IV, the author was responsible for accruing data for six different climate models for five different experiments. The author wrote the data analysis scripts for the temperature decomposition, was responsible for all figures in the text, and wrote the paper with the help of the co-authors. 


\section{INTRODUCTION}

Human activities change the composition of the Earth's atmosphere by increasing greenhouse gas concentrations and by producing short-lived climate pollutants such as aerosols (Zhao et al., 2019). These anthropogenic atmospheric components interact with the climate in different ways. Greenhouse gases make the atmosphere less transparent to thermal infrared radiation, whereas aerosol-climate interactions are more complicated. Aerosols can directly scatter and absorb solar radiation, and they can also change the radiative fluxes indirectly by influencing the optical properties and lifetimes of clouds. Both greenhouse gases and aerosols change the energy balance of Earth, leading to changes in near-surface temperatures via different feedback mechanisms (Myhre et al., 2017). Anthropogenic aerosols play a crucial role in regional climate due to their near-instantaneous response to emission reductions and air quality regulations. However, reliable implementation of aerosol effects into global climate models (GCMs) has been challenging due to an enormous scale difference between the microphysical process and the spatial resolution of the GCMs (Carslaw et al., 2013; McCoy et al., 2020). Furthermore, all relative processes are still not well-understood (Boucher et al., 2013). However, to be able to reproduce the observed climate, models need to include both aerosol effects and GHGs (Bonfils et al., 2020).

Overall, anthropogenic aerosols have global-mean cooling effects. This raises the issue that future reduction of anthropogenic aerosols might exacerbate the climate effects of greenhouse gases (e.g., Navarro et al. (2016); Rotstayn et al. (2013)).It has been estimated that the elimination of aerosols may account for an additional $1.1{ }^{\circ} \mathrm{C}$ degree of greenhouse gas (GHG) driven warming (Samset et al., 2018). This means that

the reduction of anthropogenic aerosols may account for up to half of the total warming in 2100 in scenarios with a moderate GHG increase.

Anthropogenic aerosols have also an important role in driving the precipitation changes (Wilcox et al., 2013; Li et al., 2016; Marvel et al., 2019). Example, studies based on GCMs suggest a global mean increase of precipitation from $0.09 \mathrm{mmd}^{1}$ to 0.16 mmd $^{1}$ (e.g., Westervelt et al. (2015); Rotstayn et al. (2013),). However, climate models are not capturing all observed changes related to precipitation (Agel and Barlow, 2020). On a regional scale, the precipitation changes are strongly influenced by anthropogenic aerosol emissions, especially the decrease in the Asian summer monsoon precipitation. However, current climate models do not capture the observed changes (Salzmann et al., 2014; Bollasina et al., 2011; Jin and Wang, 2017). The rate of change of precipitation per degree of warming is referred to as hydrological sensitivity (Fläschner et al., 2016). The current state of the art GCMs suggests higher hydrological sensitivity for aerosols than GHGs. This means that the reduction of anthropogenic aerosols might be expected to play a more important role in precipitation changes compared to GHG.

The effects of anthropogenic aerosols are felt more strongly on the regional scale 
than the global scale due to their heterogeneous spatial distribution. For example, anthropogenic aerosols have a strong cooling effect over the Arctic compared to the global average (paper III, Navarro et al. (2016); Westervelt et al. (2020)). The emission region of anthropogenic aerosols has a strong influence on the local climate impacts (Westervelt et al., 2020; Persad and Caldeira, 2018; Undorf et al., 2018; Miinalainen et al., 2021). Regions which have historically accounted for the majority of anthropogenic aerosol emissions (i.e., North America, Europe, and China) show the largest cooling effect. Whereas regions where emissions are expected to grow, such as India and East Africa, have a smaller cooling potential (Persad and Caldeira, 2018; Lewinschal et al., 2019; Aamaas et al., 2017).

Despite improvements in model aerosol descriptions, a large amount of uncertainty still exists regarding the climate impacts of anthropogenic aerosols. For example, abrupt removal of all anthropogenic aerosol produces a global average net warming of $0.5{ }^{\circ} \mathrm{C}$ to $1.1{ }^{\circ} \mathrm{C}$ and $1.5 \%$ to $3.1 \%$ increase in precipitation (Samset et al., 2018). Model-to-model spread arises from the chaotic nature of the climate, various descriptions of aerosols and aerosol-cloud interactions, and differences in model dynamics (Wilcox et al., 2015). However, the respective roles of modeled aerosol differences and the chaotic nature of the climate remains unclear. These can be taken into account using large ensemble climate model simulations, which can eliminate the role of climate internal variability (Dittus et al., 2020).

\section{The objectives of this thesis:}

While current warming is a global phenomenon, the regional changes affect societies and people's daily lives the most. This emphasizes the need for understanding the regional climate effects of anthropogenic aerosols as well as the related uncertainties. The aim of this thesis is to answer the following research questions,

- What are the prominent climate effects of present-day anthropogenic aerosols? (Papers I and III)

- What are the primary mechanisms driving the climate effects and model-to-model spread in the temperature response for various different climate forcing agents? (Paper IV)

- What are the primary local and global climate effects of future strong aerosol reduction? (Paper II)

This thesis is organized as follows: section 2 briefly introduces the climate models and the mechanisms of aerosol climate effects. In section 3, the global and regional impact of the removal of anthropogenic aerosols is shown. Section 4 describes the sources of uncertainty in the estimated climate impact of anthropogenic aerosols. Section 5 
discusses anthropogenic aerosols' climate impact in the near future. Finally, all results are summarized and discussed in section 6 with the future perspective of this study. 


\section{BACKGROUND}

\subsection{Aerosols}

Aerosols are small liquid droplets or solid particles suspended in the atmosphere. These small particles are important as they affect health, clouds, meteorology, and climate. Aerosol particles can arise from natural sources such as volcanic activity, dust, sea-spray, anthropogenic sources such as industrial activities, combustion of fuels, biomass burning, traffic, or produced in the atmosphere from the precursor gases (secondary aerosols) as presented in Figure 1 (Seinfeld and Pandis, 2016, p. 97).

Natural sources dominate aerosol emissions. However, in urban regions, anthropogenic emissions exceed natural emissions (Seinfeld and Pandis, 2016; Jacobson, 2005, p. 102, p. 482). Anthropogenic aerosol emissions have increased from the beginning of the industrial revolution to the end of the 20th century. At the beginning of the industrial revolution, most of the anthropogenic aerosol emissions originated from Europe. Gradually emissions from North America started to dominate the total anthropogenic aerosol emissions. Emissions started to decline in Europe and North America from mid-20th century onward due to air quality legislation. The majority of the present-day anthropogenic aerosol emissions originate from the Asian regions. However, due to emission reduction from North America and Europe, global emissions have not increased in the 21st century. (Stevens et al., 2017; Lund et al., 2019; Aas et al., 2019)

The size of atmospheric aerosol particles varies from 1-2 nm molecular clusters (Kulmala et al., 2013; Elm et al., 2020) up to $100 \mu \mathrm{m}$ large particles. After aerosol particles are emitted to the atmosphere, they are transported by the winds. Aerosol lifetime depends highly on the size of the particles. Lifetime of the large aerosol (diameter more than $1 \mu \mathrm{m}$ ) particles is typically days(Croft et al., 2014; Williams et al., 2002). Finer aerosol particles lifetimes varies from days to weeks(Schmale et al., 2011). Aerosols are removed from the atmosphere by precipitation, cloud processes, collision with other particles, or by depositing on existing surfaces(Kristiansen et al., 2012).

The major aerosol species in the atmosphere are sulfate $\left(\mathrm{SO}_{4}\right)$, organic matter, mineral dust, sea salt, and black carbon(Provençal et al., 2017; Seinfeld and Pandis, 2016, p. 102). The most common anthropogenic aerosol species are sulfate originating from sulphur dioxide $\left(\mathrm{SO}_{2}\right)$ and black and organic carbon (BC)(Yang et al., 2020). The anthropogenic $\mathrm{SO}_{2}$ originates mainly from power plants as well as the oil and gas industry as a side product of burning fossil fuelss (Fioletov et al., 2016; McDuffie et al., 2020). The black carbon mainly originates from the incomplete burning of biomass, coal, and liquid fossil fuels (Winiger et al., 2016, 2017).

Climate effects of aerosols highly depend on the composition and size of the particle and emission region (Miinalainen et al., 2021). They can either absorb 


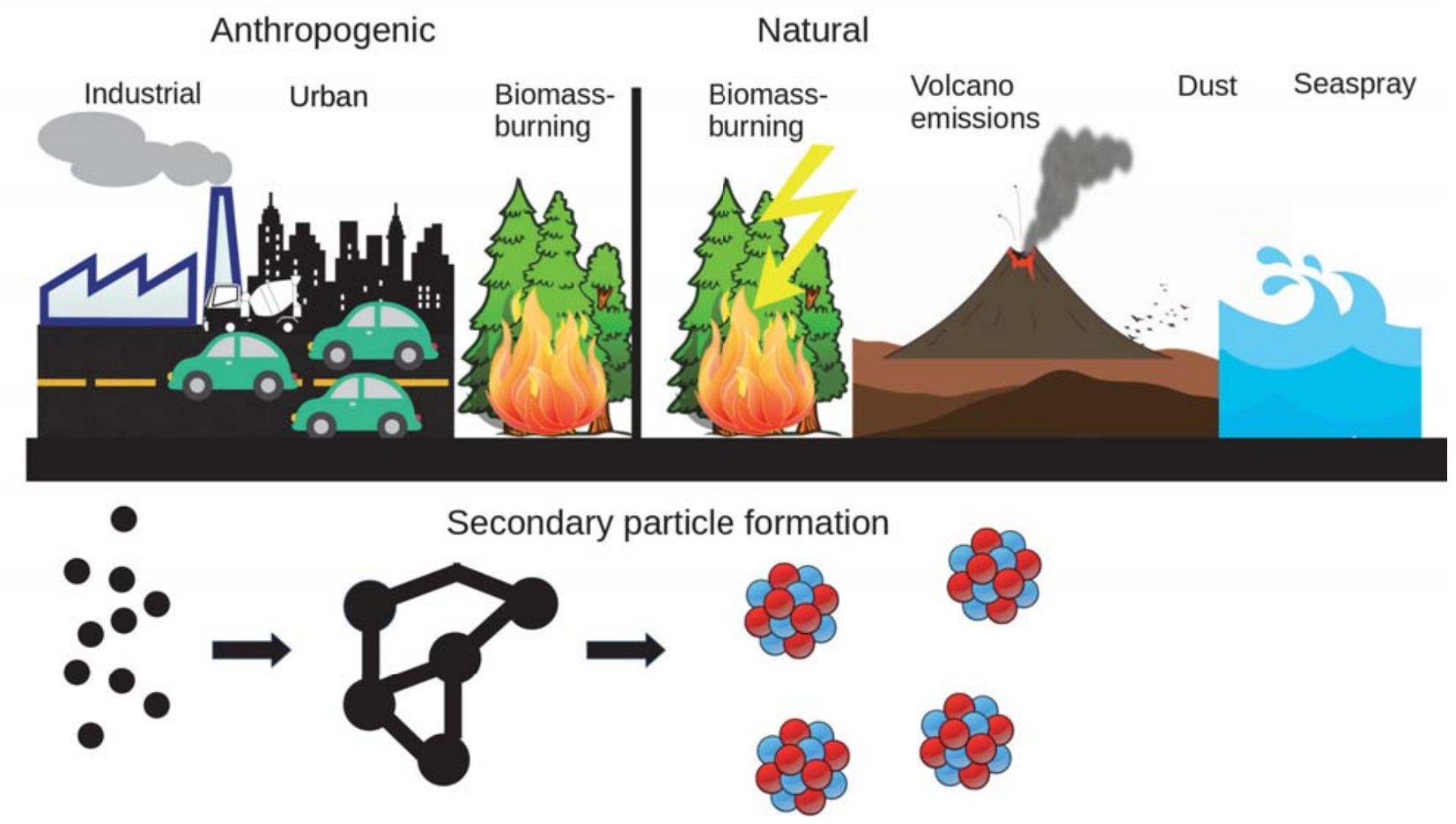

Figure 1: Example of athropogenic and natural sources of aerosol particle.

or scatter the incoming solar and thermal radiation, depending on their chemical compositions. Small particles from 0.1 to 1 micron scatter the incident solar radiation most efficiently. Carbonous particles also absorb the solar radiation, providing additional heat to the atmosphere (Samset et al., 2018). Aerosols can also modify cloud properties, such as cloud albedo, radiation properties, and droplet size.

\subsection{Clouds}

Clouds play an essential role in regulating Earth's climate. Approximately two-thirds of the planet is always covered by clouds (Mace et al., 2009). Warm clouds are formed when water vapor is condensed on the surface of the aerosol particle. Aerosols may form ice clouds in high altitudes where the temperature is below $0^{\circ} \mathrm{C}$ by ether homogeneous freezing. In homogenous freezing, liquid aerosol particles, which are water-saturated, are supersaturated with ice, forming ice crystals. (Koop et al., 2000; M.K. Yau, 1996)

Hence, aerosols are an indispensable element of cloud formation. For this reason, these aerosol particles are also referred to as cloud condensation nuclei $(\mathrm{CCN})$ or ice 
nuclei (IN), depending on the phase of the cloud. The formation of the clouds requires the air to be supersaturated with water. Air is saturated when there is no net transfer of molecules from the liquid surface to the air or vice versa. Hence, air needs to be supersaturated to maintain droplet growth. Supersaturation can be achieved either by cooling the air to its dew point or adding moisture (M.K. Yau, 1996). When the saturated air cools, for example, via updraft and adiabatic cooling, the air becomes supersaturated. Cloud droplets are then formed when enough water is condensed on the aerosol surface (Köhler, 1936). The critical value of CCN's radius for activation highly depends on the chemical composition and size of the aerosol. The larger size of the particle and higher hygroscopicity (chemical composition) lowers the required supersaturation levels (Väisänen et al., 2016; Köhler, 1936; Mochida et al., 2011). The size difference between aerosols, cloud droplets, and raindrops is illustrated in Figure 2.

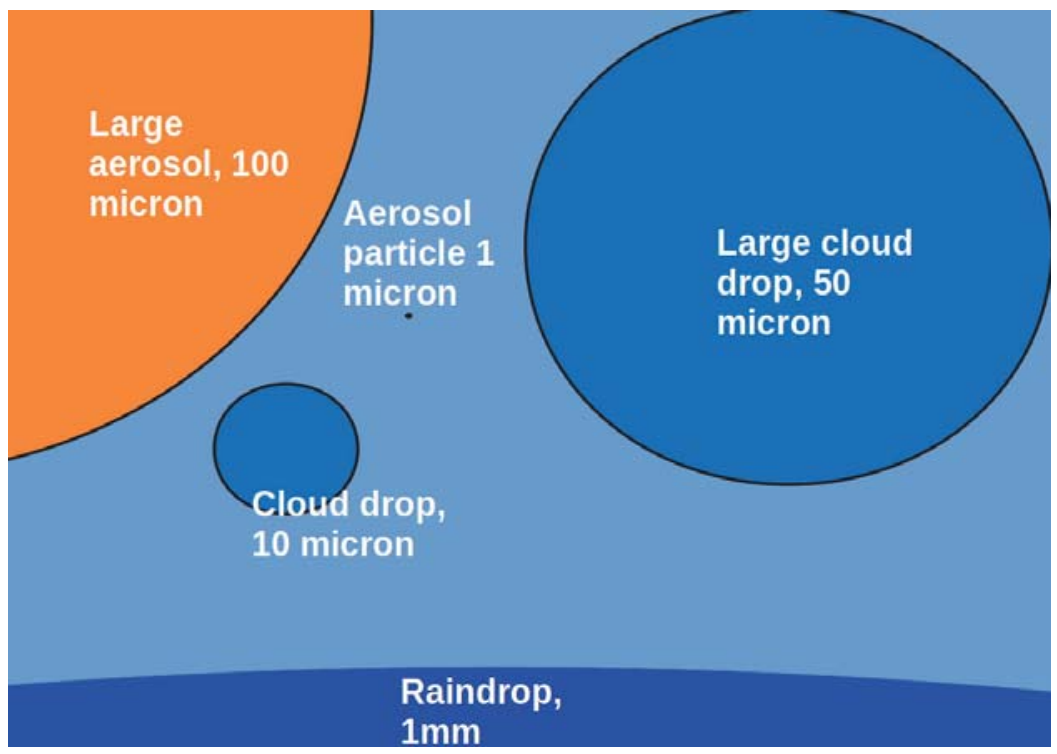

Figure 2: An illustration of the difference in the size of aerosols, cloud droplets, and rain drops.

The climate effects of the clouds depend on their altitude (L'Ecuyer et al., 2019). High altitude clouds consist of ice crystals and efficiently reflect thermal infrared radiation, where low-level clouds reflect the incoming solar radiation but poorly reflect the thermal infrared radiation. In the current climate, the net cloud climate effect is cooling (Loeb et al., 2018; Gryspeerdt et al., 2020). However, current climate models show clear positive net cloud feedback, meaning that the cooling effect of clouds decreases when the climate becomes warmer (Zelinka et al., 2020). Cloud feedback is one of the major uncertainties in GCMs (Cesana and Del Genio, 2021). 


\subsection{Aerosol Climate effect}

Earth's climate is controlled by the energy balance between shortwave radiation originating from the sun and thermal radiation radiated back to space. Figure 3 illustrates the energy flow in Earth's atmosphere. About 30\% of the incoming solar radiation is reflected back to space by clouds and the atmosphere, and the same amount is directly absorbed in the atmosphere. Only $54 \%$ of the incoming solar radiation is absorbed by the Earth's surface (Read et al., 2016) To maintain the energy balance at the top of the atmosphere, the same amount of thermal radiation (longwave radiation) and shortwave radiation needs to be at the top of the atmosphere. The thermal radiation is emitted by the surface and the atmosphere. Not all of the longwave radiation emitted by the surface reaches space. Most of this is absorbed by water vapor and other greenhouse gases and re-emitted to the surface (Seinfeld and Pandis, 2016, p. 42).

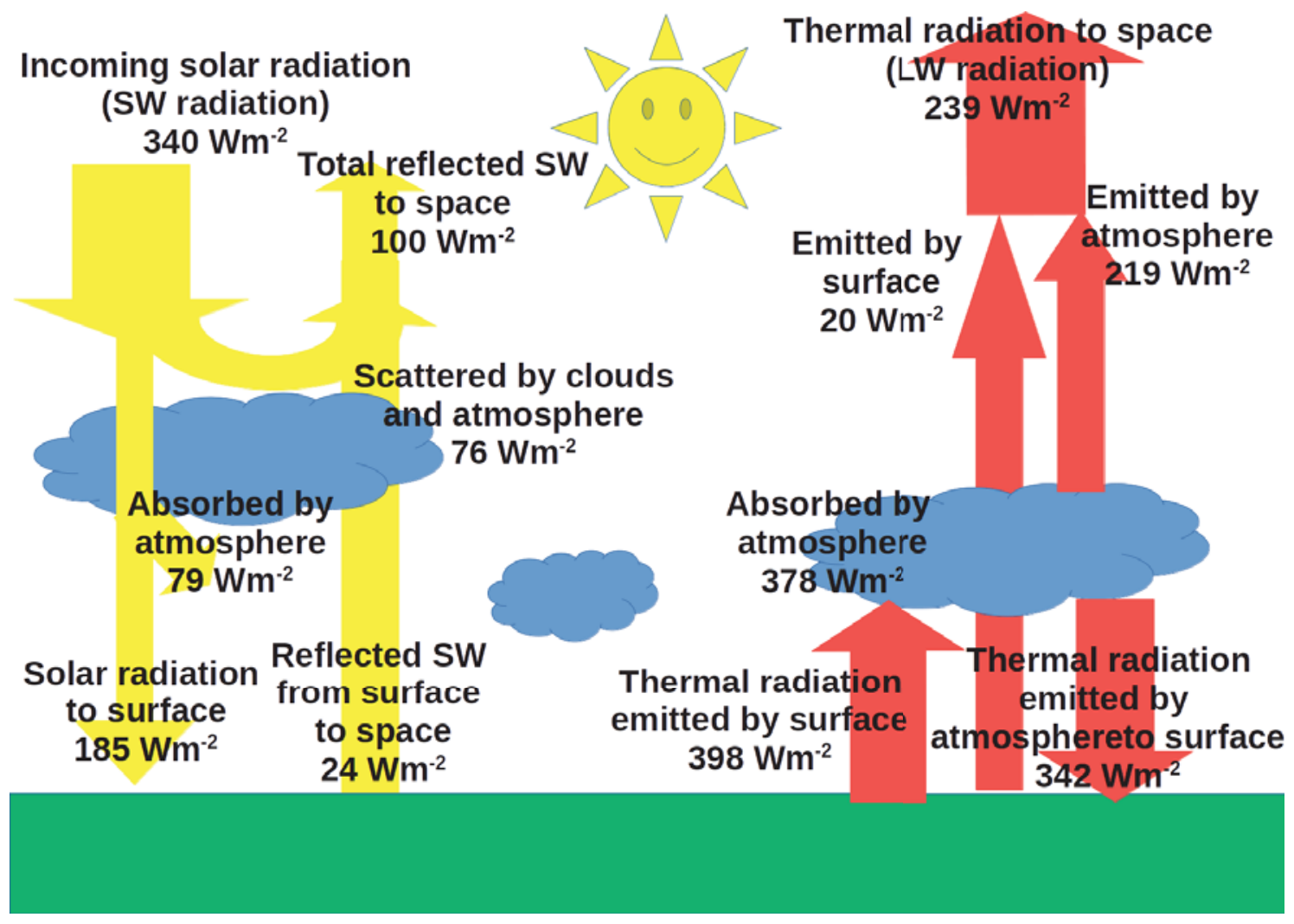

Figure 3: Present-day Earth radiation budget. Values obtained from Read et al. (2016)

If the energy balance is disturbed, for example, by increasing aerosols or greenhouse gases, Earth's temperature will change. For example, if the anthropogenic sulfate concentration is increased, less solar radiation is absorbed by the surface and less thermal radiation is needed to balance the total solar radiation at the top of the atmosphere, due to the fact that sulfate aerosols reflect sunlight back to space. This 
would lead to a decrease in thermal radiation emitted by the surface. This is known as the direct aerosol effect. As another example, if greenhouse gases are increased, less thermal radiation escapes to space, leading to a radiative imbalance at the top of the atmosphere. To account for these imbalances, the surface becomes warmer, increasing outgoing thermal radiation. With higher surface temperature more thermal radiaton is emmited by the surface (Koll and Cronin, 2018). The amount of disruption of the energy balance of given climate forcers (e.g., anthropogenic aerosols or greenhouse gases) is known as radiative forcing. The fifth assessment report (AR5) of the Intergovernmental Panel of Climate Change (IPCC) has estimated the radiative forcing due to human activities to be $2.30 \mathrm{Wm}^{-2}$, ranging from 1.1 to $3.3 \mathrm{Wm}^{-2}$. Most of the radiative forcing originate from well-mixed greenhouse gases $\left(2.83 \mathrm{Wm}^{-2}\right)$. The largest uncertainty is related to the aerosol forcing presented in Figure 4 (Bellouin et al., 2020). Estimated direct aerosol forcing in AR5 is $-0.35 \mathrm{Wm}^{-2}\left(-0.85\right.$ to $\left.0.15^{-2}\right)$, and forcing due to aerosol-cloud interactions is estimated to be $-0.45 \mathrm{Wm}^{-2}\left(-1.2\right.$ to $0.0^{-2}$ ) (Myhre et al., 2013)

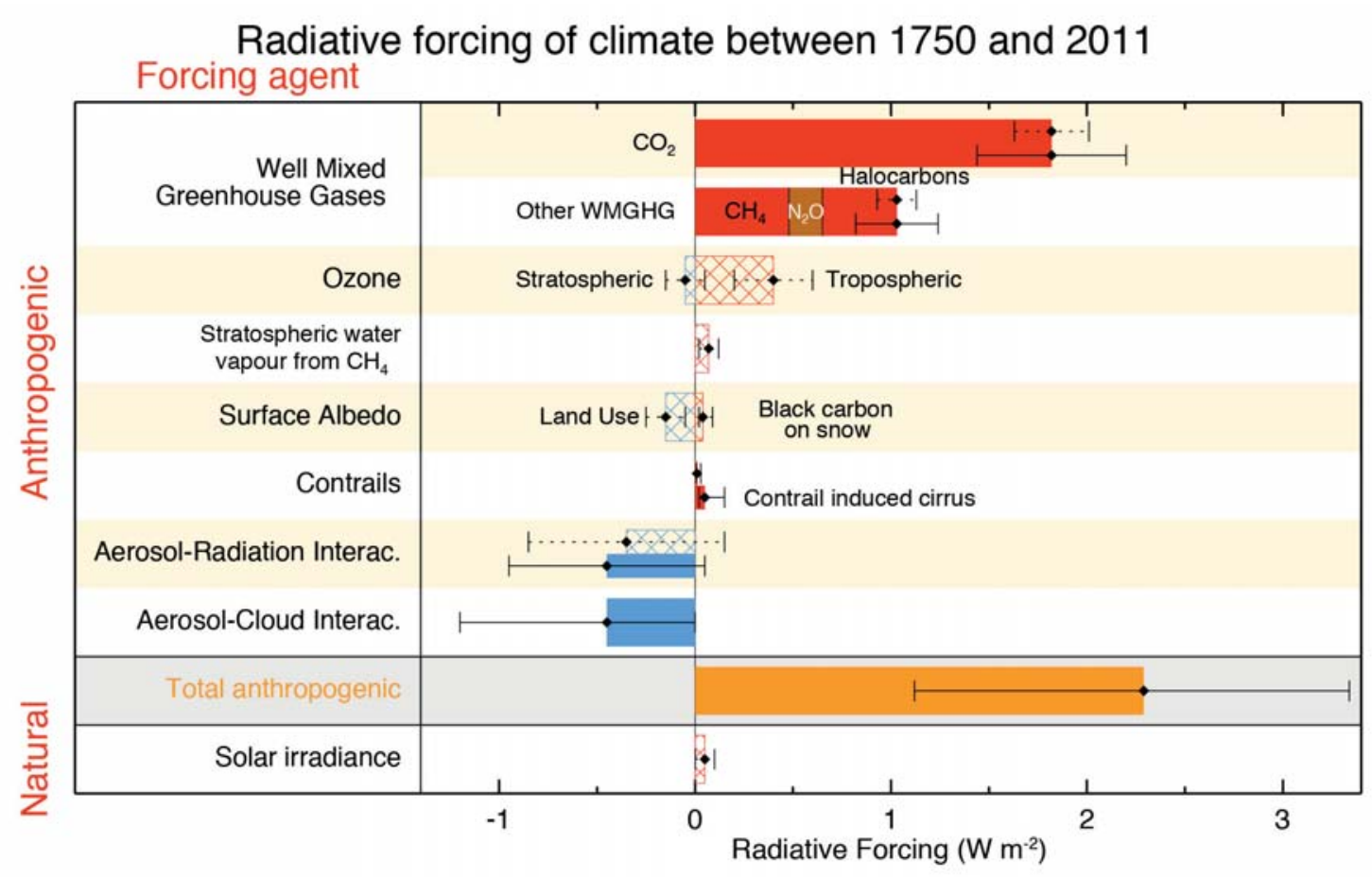

Figure 4: Estimated present-day radiative anthropogenic radiative forcing and estimated uncertainty. Figure adapted from Myhre et al. (2013)

As mentioned previously, aerosols play a crucial role in cloud formation. The next chapter explains in more detail how anthropogenic aerosol emissions alter cloud microphysics and optical properties. Figure 5 illustrates the different mechanisms 
of how increased aerosol concentration in the cloud can alter the optical properties and precipitation formation in the cloud. The first indirect effect, also known as the Twomey effect or cloud albedo effect, is where increased aerosol concentration makes clouds brighter, therefore reflecting more of the incoming solar radiation to space and allowing less radiation to reach Earth's surface. (Twomey, 1959)

Introducing more aerosol particles into the cloud could reduce drizzle production, cloud top height, and cloud lifetime. This is known as the second indirect effect. As aerosols act as CCN, more CCN lead to smaller droplets, suppressing the amount of precipitation (drizzle suppression). Suppressed precipitation formation due to increased aerosol concentration eventually leads to a longer cloud lifetime, where clouds can reflect even more incoming sunlight. An increase in CCN and smaller droplets also alter the vertical mixing in the cloud, leading to an increase in cloud thickness. (Albrecht, 1989; Rosenfeld, 2000; Sarangi et al., 2018) An increase in overall cloud lifetime can also increase overall cloud cover (Kaufman and Koren, 2006). However, the second indirect effect and other adjustments are small compared to the first indirect effect (Douglas and L'Ecuyer, 2020; Glassmeier et al., 2021; Fiedler et al., 2017; Malavelle et al., 2017).

As mentioned previously, aerosol climate effects depend strongly on the chemical composition of the particles. For example, black carbon particles absorb the incoming solar radiation, heating the surrounding air, leading to an additional warming effect. (Johnson et al., 2004) When absorbing aerosols are located in the clouds, they heat and dry the surrounding air, leading to the decrease of cloud cover (semi-direct effect) (Yu et al., 2002). The precise effect of the semi-direct aerosol effect depends highly on the location of the aerosol relative to the cloud. However, when absorbing aerosols are below the cloud, the heating enhances vertical motion, providing more moisture into the cloud and leading to increased cloud cover. When absorbing aerosols are located above, the cloud effects are not as clear as previously mentioned. In the case of a stratocumulus, absorbing aerosols reduce the downwelling solar radiation, leading to decreased evaporation and increasing atmospheric water content. However, reduced solar heating at the surface can cause the opposite effect. (Johnson et al., 2004; Koch and Del Genio, 2010)

\subsection{General Circulations models}

General Circulation Models (GCMs) are a key tool for studying global climate and for making projections of future climate change. These sophisticated tools may include ocean, ice (sea ice and glaciers), atmosphere, and even land models (including the carbon cycle). When the coupled climate model explicitly models the carbon cycle it is referred to as an Earth System Model (ESM). These also include atmospheric composition, trace gases, and aerosols. Climate models work by dividing 


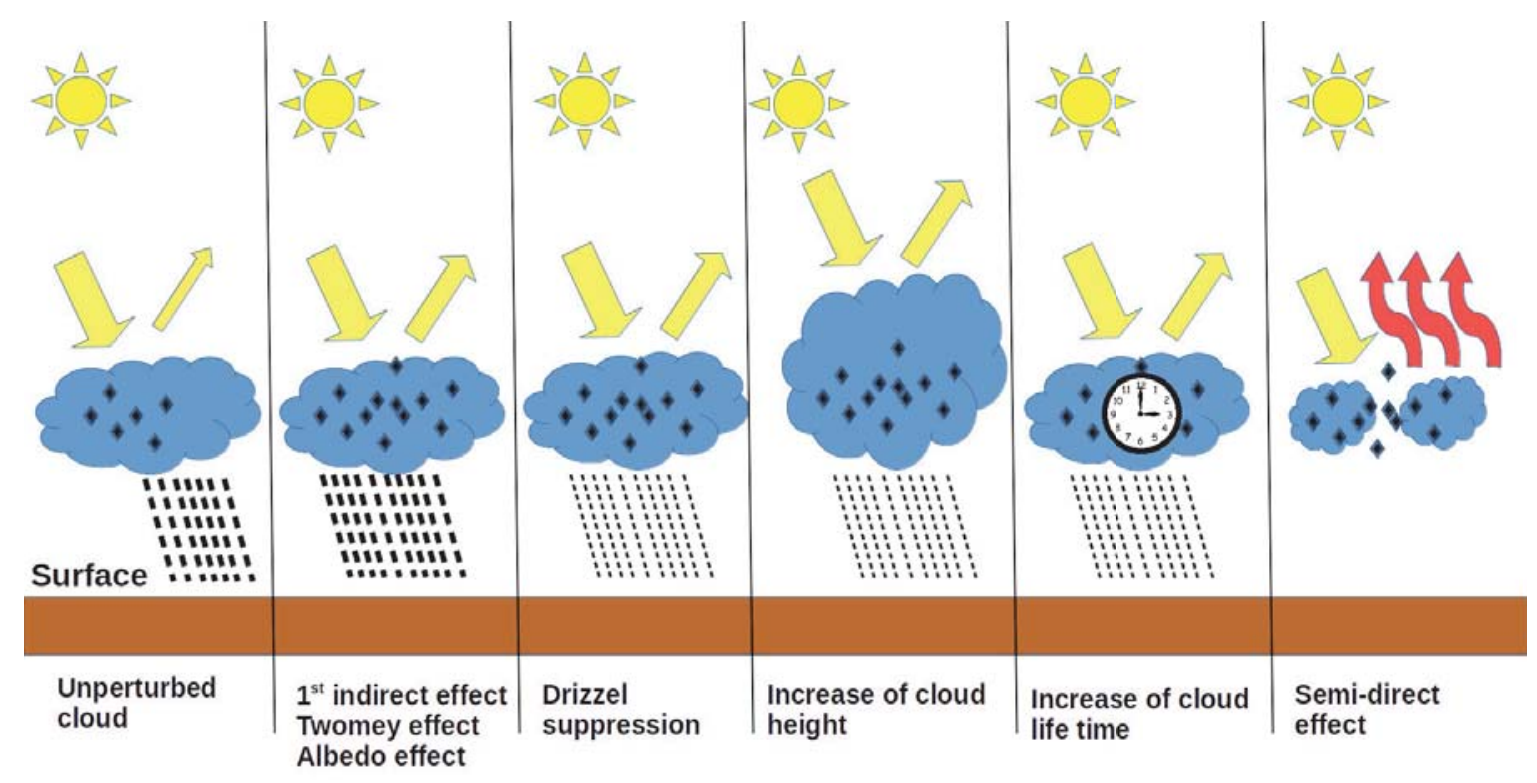

Figure 5: An illustration of cloud-aerosol interactions (aerosol indirect effects). Figure adapted from (Boucher et al., 2013)

Earth's atmosphere into a three-dimensional grid and solving equations describing atmospheric processes in each grid box. The typical spatial resolution (size of the grid box) of current climate models is from $25 \mathrm{~km}$ to $500 \mathrm{~km}$. For processes that take place on a smaller scale than the grid box, the model uses a parametrization to approximate sub-grid scale processes. GCMs divide the time into manageable sections, called timesteps. Typically GCMs perform a calculation for every $30 \mathrm{~min}$. One key source of uncertainty and a limiting factor of climate predictions is different parametrizations used in different models. As GCMs are not perfect, the uncertainty of the models is usually estimated from the spread of an ensemble of models (Hawkins and Sutton, 2009; Lehner et al., 2020). This assumes that all GCMs are independent. However, different GCMs might share same the atmospheric model, and this leads to similar results (Knutti et al., 2013). When comparing multiple models, the model independence is one key factor in how robust the results are. 


\section{Data AND Methods}

One of the goals of this thesis is to study how anthropogenic aerosols affect Earth's climate. In this thesis, two already existing global climate model datasets, CMIP6 and PDRMIP, have been used to perform the analysis. The CMIP6 is newest version from Climate Model Intercomparison Project and the PDRMIP consist of idealized climate model runs for single climate forsing agent. For this thesis separate climate model runs were performed with identical anthropogenic aerosol description. This thesis concentrates on the precipitation and temperature changes due to anthropogenic aerosols and greenhouse gases $\left(\mathrm{CO}_{2}\right.$ and $\left.\mathrm{CH}_{4}\right)$. To assess how the surface temperature changes in more detail, the surface temperature response is also decomposed to its energy balance terms.

\subsection{Climate model simulations and data Sets}

\subsubsection{Models and Performed Simulations}

For papers I and III, 100-year long equilibrium climate simulations with ECHAM6 and NorESM1 GCMs were carried out by implementing, simple athropogenic aerosol description, the second version of the simple plume of the Max Planck Institute (MPI) Aerosol Climatology (MACv2-SP) (Stevens et al., 2017). The ECHAM6 model(Stevens et al., 2013) is a sixth-generation model from MPI, which branches from the early version of the European Centre for Medium-Range Weather Forecasts (ECMWF) model for climate studies. The vertical resolution includes 47 sigma hybrid vertical levels, from surface to $0.01 \mathrm{hPa}$, and the horizontal resolution is $1.9 \times 1.9^{\circ}$ which corresponds to 92 latitude and 192 longitude grid boxes. At the equator this corresponds to a spatial $210 \mathrm{~km}$ resolution. The NorESM1 model is the Norwegian Earth System Model with 1.9x2.5 spatial resolution and 26 sigma hybrid model levels (Bentsen et al., 2013; Iversen et al., 2013; Kirkevåg et al., 2013).This corresponds to a $310 \mathrm{~km}$ spatial resolution at the equator. NorESM1 branches from the Community Climate System Model version 4 (CCSM4) operated at the National Center for Atmospheric Research (NCAR).

The MACv2-SP is a simple representation of the anthropogenic aerosol direct and first indirect effect (Twomey effect, albedo effect). Nine 3-D time-varying Gaussian plumes define the optical properties of anthropogenic aerosols. Anthropogenic aerosol emissions due to biomass burning are presented by four plumes located in South America, South and Central Africa, and the Maritime Continent (Southeast Asia). Industrial plumes are located in Europe, North America, Australia, and South and East Asia. These different types of plumes differ by annual cycle and optical properties to implicitly account for the absorbing aerosols' contribution. The first 
indirect aerosol-cloud effect is parametrized by modifying the model's own cloud droplet number concentration (CDNC) by an empirical relation based on changes in aerosol optical depth. This relation is derived from Moderate Resolution Imaging Spectroradiometer (MODIS) data. (Stevens et al., 2017)

With ECHAM6 and NorESM1, where MACv2-SP aerosol was implemented, a set of simulations were performed for papers I and III. One simulation was performed with all MACv2-SP aerosol plumes, which present present-day aerosol climate effects. Other simulations run included only natural aerosols, and they were used as control runs. Both models were also run with identical radiative forcing. Last simulations were performed with all MACv2-SP aerosol plumes, excluding two Asian industrial plumes, to show present-day Asian aerosol climate effects.

\subsubsection{PDRMIP AND CMIP6 DATASETS}

Paper IV uses data from the Precipitation Driver and Response Model Intercomparison Project (PDRMIP) (Myhre et al., 2017). In PDRMIP, several independent climate models have performed idealized climate forcing experiments. The experiments were carried out by doubling the $\mathrm{CO}_{2}$ concentration, tripling the $\mathrm{CH}_{4}$ concentration, five-folding the sulfate emissions or concentrations, and ten-folding black carbon emissions or concentrations. The experiments are relative to present-day climate or pre-industrial climate. Aerosols are defined either explicitly by emissions or by multiplying the pre-defined concentration field derived from AeroComm Phase II (Myhre et al., 2012). All models included the semi-direct aerosol effect of black carbon, but only NorESM1 and MIROC-SPRINTARS included the aerosol indirect effect from black carbon. All models except NCAR-CESM1-CAM4 and GISS-E2-R include the aerosol-cloud effects from sulfate. Models used in paper IV from the PDRMIP project are listed in table 1.

Paper II uses models from five different CMIP6 experiments (Eyring et al., 2016). The historical experiment covers the years from 1950 to 2014 and four future Shared Socioeconomic Pathways (SSPs), 1-1.9, 2-4.5, 3-7.0, and 5-8.5. Different SSPs represent the range of future aerosol pathways (O’Neill et al., 2016; Rao et al., 2017). All models used from CMIP6 include the first indirect aerosol effect (Twomey effect).

In all future SSPs, the largest reduction of aerosol emissions is located over the Asian regions. In SSP1-1.9, there is a rapid decline of $\mathrm{BC}$ and SO2 emissions from 2020 to 2040. After that, BC emissions are constant and SO2 emissions decline slightly. SSP2-4.5 includes a steady decline of both $\mathrm{BC}$ and SO2 emissions from East Asia and a small initial increase from South Asia, where emissions decline after 2040. In SSP3-7.0, greenhouse gas emissions continue to increase. However, the aerosol emissions peak in 2050 and decline towards the end of the century. SSP5-8.5 is the extreme scenario, where greenhouse gas emissions rapidly increase until 2080 with a modest decline in 


\begin{tabular}{l|llll} 
Model & Aerosols & sulfate/bc & Ocean & ref \\
\hline CanESM2 & E & yes/no & coupled & Arora et al. (2011) \\
\hline NCAR-CESM1-CAM4 & C & no /no & slab ocean & Neale et al. (2010) \\
\hline GISS-E2-R & C & yes/no & coupled & Schmidt et al. (2014) \\
\hline HadGEM2-ES & E & yes/no & coupled & $\begin{array}{l}\text { Collins et al. (2011) } \\
\text { Martin et al. (2011) }\end{array}$ \\
\hline NorESM1 & C & yes/yes & coupled & $\begin{array}{l}\text { Bentsen et al. (2013) } \\
\text { Iversen et al. (2013) } \\
\end{array}$ \\
\hline & & & & Kirkevåg et al. (2013) \\
\hline MIROC-SPRINTARS & E & yes/yes & coupled & $\begin{array}{l}\text { Takemura et al. (2005) } \\
\text { Takemura et al. (2009) } \\
\end{array}$ \\
& & & & Watanabe et al. (2010) \\
\hline
\end{tabular}

Table 1: List of models used in paper III. The aerosols column shows the model aerosol concentration driven by fixed pre-described concentration (C) or via emissions (E). $\mathrm{SO}_{4} / \mathrm{BC}$ columns show if sulfate or black carbon cloud interactions are included in the model.

aerosol emissions towards the end of the century. (Lund et al., 2019)

\subsection{TEMPERATURE DECOMPOSITION}

For studying mechanisms behind aerosol global and regional climate effects, the temperature decomposition method (Räisänen, 2017) is used in paper IV to decompose the climate model output to different local energy balance terms: $\triangle L W, \triangle S W, \triangle S U R F$ and $\triangle C O N V$, where $\triangle L W$ represents the temperature change due to changes in $L W$ radiative fluxes, $\Delta S W$ due to changes in $S W$ radiative fluxes, $\triangle S U R F$ due to change in energy fluxes (latent heat, sensible heat, shortwave and longwave radiation) at the surface, and $\triangle C O N V$ represents combined changes in the energy storage within a local atmospheric column and the atmospheric horizontal energy transport into the column. This method was first introduced by Räisänen and Ylhäisi (2015). Later a more detailed treatment of SW radiation was included by Räisänen (2017) and in paper II a more detailed treatment of LW radiation was added.

The energy balance of an atmospheric column can be described by,

$$
\frac{\partial E}{\partial t}=S W_{T O A}^{\downarrow}-L W_{T O A}^{\uparrow}-G^{\downarrow}+C^{\rightarrow}
$$

where $\frac{\partial E}{\partial t}$ is the change in energy, $S W_{T O A}^{\downarrow}$ is the net incoming shortwave (SW) radiation at top of the atmosphere (TOA), $L W_{T O A}^{\uparrow}$ is the net longwave radiation flux, $C^{\rightarrow}$ is the atmospheric horizontal energy transport into the column, and $G^{\downarrow}$ is the downward heat flux towards the surface defined by, 


$$
G=S W_{S U R F}^{\downarrow}+L W_{S U R F}^{\downarrow}+S H+L H
$$

where $S W_{S U R F}^{\downarrow}$ is the net SW radiation at surface and $L W_{S U R F}^{\downarrow}$ is the net LW radiation at the surface, $S H$ is the sensible heat flux and $L H$ is the latent heat flux. Relating the surface temperature to $L W_{T O A}^{\uparrow}$ by using the Stefan-Boltzmann law,

$$
L W_{T O A}^{\uparrow}=\epsilon_{e f f} \sigma T^{4}
$$

where $\epsilon_{\text {eff } f}$ is an effective planetary emissivity, $\sigma$ is the Boltzmann constant, and $T$ is the surface temperature. As $\epsilon_{e f f}$ is a measure of the atmosphere greenhouse effect, combining equations 1 and 3 gives

$$
\epsilon_{e f f} \sigma T^{4}=S W_{T O A}^{\downarrow}-G^{\downarrow}+\left(C^{\rightarrow}-\frac{\partial E}{\partial t}\right)
$$

In order to obtain an equation for the change in temperature, denoting the change in quantity $X$ (SW, LW, G or C) to be the change between two climate states ( $1=$ baseline, $2=$ perturbed climate), that is, $\Delta X=X_{2}-X_{1}$. The above equation can be writen as

$$
\sigma\left[\epsilon_{e f f}\right] \Delta\left(T^{4}\right)=-\sigma \Delta \epsilon_{e f f}\left[T^{4}\right]+\Delta S W_{T O A}^{\downarrow}-\Delta G^{\downarrow}+\Delta\left(C^{\rightarrow}-\frac{\partial E}{\partial t}\right)
$$

where [] marks the mean state between two climates. By linearizing the left hand side of equation 5 ,

$$
\sigma\left[\epsilon_{e f f}\right] \Delta\left(T^{4}\right) \approx 4 \sigma\left[\epsilon_{e f f}\right]\left[T^{3}\right] \Delta T=D \Delta T
$$

where $D=4 \sigma\left[\epsilon_{e f f}\right]\left[T^{3}\right]$. Now, by combining equations 5,6 and dividing both sides by $D$,

$$
\Delta T=\frac{1}{D}\left(-\sigma \Delta \epsilon_{e f f}\left[T^{4}\right]+\Delta S W+\Delta G^{\downarrow}+\Delta\left(C^{\rightarrow}-\frac{\partial E}{\partial t}\right)\right)
$$

Now, the partial changes in temperature resulting from changes in $\epsilon_{e f f}, S W, \Delta G^{\downarrow}$ and $\Delta\left(C^{\rightarrow}-\frac{\partial E}{\partial t}\right)$ can be writen as

$$
\begin{aligned}
\Delta T_{L W} & =\frac{-\sigma \Delta \epsilon_{e f f}\left[T^{4}\right]}{D}=\Delta L W \\
\Delta T_{S W} & =\frac{\Delta S W_{T O A}^{\downarrow}}{D}=\Delta S W \\
\Delta T_{S U R F} & =\frac{\Delta G^{\downarrow}}{D}=\Delta S U R F \\
\Delta T_{C O N V} & =\frac{C^{\rightarrow}-\frac{\partial E}{\partial t}}{D}=\Delta C O N V
\end{aligned}
$$


Finally, equation 8 reveals the total change in temperature $\Delta T$ as a sum

$$
\Delta T=\Delta L W+\Delta S W+\Delta S U R F+\Delta C O N V
$$

\subsubsection{Decomposition of SW FLUX}

Paper IV includes a more detailed decomposition of the $\Delta S W$ changes at clear-sky conditions, by clouds, and by surface albedo. The SW decomposition is done by the Approximate Partial Radiative Perturbation (APRP) method developed by Taylor et al. (2013), which is based on a simple SW radiation model. The simple model is illustrated in Figure 6. A single layer of atmosphere scatters the downward and upward radiations, but absorbs the incident radiation only in the first transit. From the simplified model, defining the planetary albedo $(A)$ and the ratio of incident surface flux and insolation $\left(\hat{Q}_{s}^{\downarrow}\right)$. Starting by calculating the partly overcast values, the model output of TOA radiative terms can be divided into two terms,

$$
R=(1-c) R_{c l r}+c R_{o c}
$$

where $c$ is the fraction of region occupied $R_{c l r}$ is radiative flux resulting from clear-sky conditions, and $R_{o c}$ is flux resulting from the overcast portion of the regions. Solving the overcast term from equation 10 gives

$$
R_{o c}=\frac{R+(c-1) R_{c l r}}{c}
$$

Overcast fields are calculated for outgoing SW flux at TOA, downwelling SW flux at the surface, and upwelling SW flux at the surface.

The planetary albedo can be calculated by using the relation between insolation (S) and net TOA downward SW flux (Q)

$$
Q=(1-A) S \Rightarrow A=1-\frac{Q}{S}
$$

The surface albedo $\alpha$ is defined by a ratio between the reflected SW radiation $\left(Q_{s}^{\uparrow}\right)$ and the incoming SW radiation $\left(Q_{s}^{\downarrow}\right)$ at the surface

$$
\alpha=\frac{Q_{s}^{\uparrow}}{Q_{s}^{\downarrow}}
$$

and

$$
\hat{Q}_{s}^{\downarrow}=\frac{Q_{s}^{\downarrow}}{S}
$$

The optical properties $1-\mu$ and $\gamma$ can be calculated from the fraction of incoming radiation absorbed by the atmosphere, which is, by definition, the difference between 


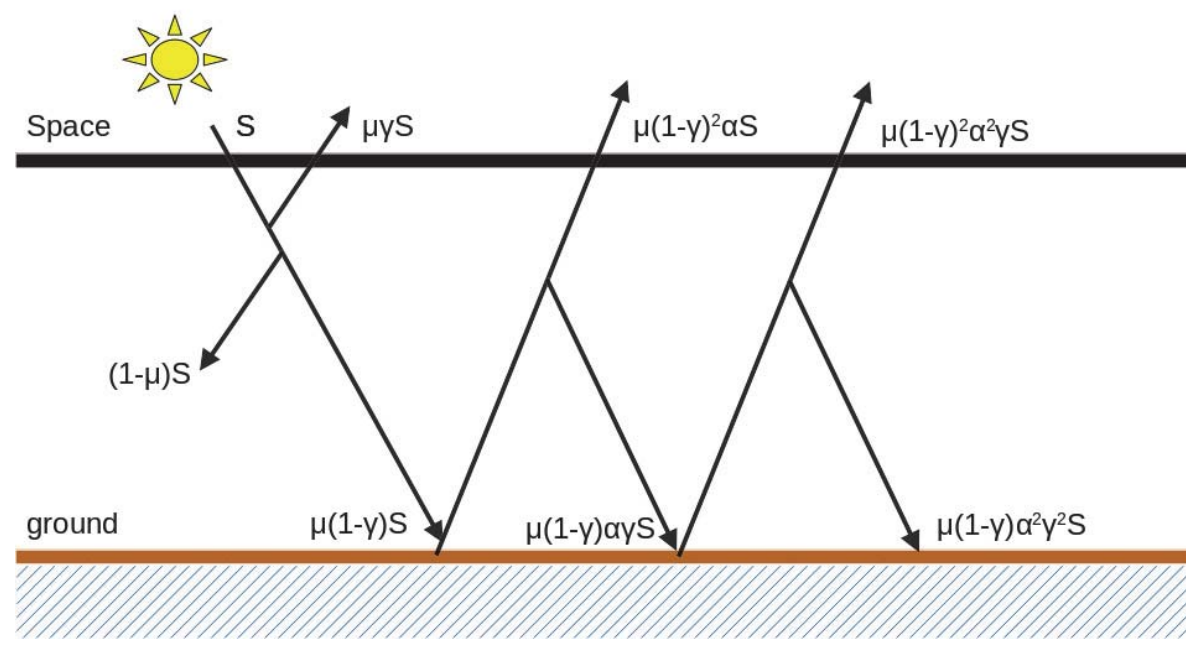

Figure 6: Illustration of the simple shortwave radiation model where $\mathrm{S}$ is the incoming solar radiation, $\gamma$ is the scattering coefficient of the atmosphere and $(1-\mu)$ is atmospheric absorptance.

incoming shortwave radiation absorbed by the surface and the atmosphere and the net flux absorbed by the surface.

$$
1-\mu=\frac{Q}{S}-\frac{Q_{s}^{\downarrow}}{S}(1-\alpha)
$$

Combining equations 12 and 14 gives

$$
\mu=A+\hat{Q}_{s}^{\downarrow}(1-\alpha)
$$

From the simplified model (see Fig. 6) the $\hat{Q}_{s}^{\downarrow}$ can be formulated as

$$
\hat{Q}_{s}^{\downarrow}=\mu(1-\gamma) \sum_{o}^{\infty} \alpha^{i} \gamma^{i}=\frac{\mu(1-\gamma)}{1-\alpha \gamma}
$$

which yields

$$
\gamma=\frac{1-\hat{Q}_{s}^{\downarrow}}{\mu-\alpha \hat{Q}_{s}^{\downarrow}}
$$

using equation $10, \mu, \gamma$ and $\alpha$ can be separately calculated for cloud and non-cloud regions. The APRP methods assumes the noncloud region. The scattering and absorbance coefficients can be calculated for the overcast region as

$$
\begin{aligned}
\left(1-\gamma_{o c}\right) & =\left(1-\gamma_{c l r}\right)\left(1-\gamma_{c l d}\right) \\
\mu_{o c} & =\mu_{c l r} \mu_{c l d}
\end{aligned}
$$


Now the planetary albedo can be expressed as a function of seven variables

$$
A=A\left(c, \alpha_{c l r}, \alpha_{o c}, \mu_{c l r}, \mu_{o c}, \gamma_{c l r}, \gamma_{o c}\right)=(1-c) A_{c l r}+c A_{o c}
$$

where $A_{c l r}$ and $A_{o c}$ can be calculated from the simplified model (see Fig. 6), as

$$
A=\gamma+\mu(1-\gamma)^{2} \alpha \sum_{0}^{\infty} \alpha^{i} \gamma^{i}=\mu \gamma+\frac{\mu \alpha(1-\gamma)^{2}}{1-\alpha \gamma}
$$

The change in shortwave flux decomposes into two components. The first component represents the change in the insolation and the second in the planetary albedo. This can be seen by differentiating equation 12

$$
\Delta Q=\Delta S(1-A)-S \Delta A
$$

Now, the $\Delta A$ in equation 22 can be estimated by decomposing equation 21 to the following form

$$
\Delta A=\frac{\partial A}{\partial \alpha} \Delta \alpha+\frac{\partial A}{\partial \mu} \Delta \mu+\frac{\partial A}{\partial \gamma} \Delta \gamma+\Delta A_{N L}
$$

All terms in equation 23 are calculated both for the clear-sky(clr) as well as cloudy conditions. The last term, $\Delta A_{N L}$ accounts for nonlinear and higher order effects. All right-hand side terms in equation 23 can be computed as follows (only change due to surface albedo is shown)

$$
\begin{aligned}
\frac{\partial A}{\partial \alpha} \Delta \alpha \approx \frac{\Delta A_{\alpha}}{\Delta \alpha} \alpha=\Delta A_{\alpha, c l r} & =A\left(c, \alpha_{c l r, 2}, \alpha_{o c}, \mu_{c l r}, \mu_{o c}, \gamma_{c l r}, \gamma_{o c}\right) \\
- & A\left(c, \alpha_{c l r, 1}, \alpha_{o c}, \mu_{c l r}, \mu_{c l d}, \gamma_{c l r}, \gamma_{c l d}\right)
\end{aligned}
$$

where the subscripts 1 and 2 refer to the control and the perturbation simulations, and the absence of subscript parameters are mean of the control and perturbed values. Finally, the change in shortwave fluxes in equation 9 can be defined as

$$
\Delta S W=\Delta S W_{\alpha}+\Delta S W_{c l r}+\Delta S W_{c l d}+\Delta S W_{i n}+\Delta S W_{N L}
$$

where

$$
\begin{aligned}
\Delta S W_{\alpha} & =\frac{-S}{D} \Delta A_{\alpha, c l r}+\Delta A_{\alpha, o c} \\
\Delta S W_{c l r} & =\frac{-S}{D} \Delta A_{\mu, c l r}+\Delta A_{\gamma, c l r} \\
\Delta S W_{c l d} & =\frac{-S}{D} \Delta A_{\mu, c l d}+\Delta A_{\gamma, c l d}+\Delta A_{c} \\
\Delta S W_{i n} & =\frac{-S}{D} \Delta S(1-A) \\
\Delta S W_{N L} & =\left(\frac{-S}{D} \Delta A\right)-\left(\Delta S W_{\alpha}+\Delta S W_{c l r}+\Delta S W_{c l d}+\Delta S W_{i n}\right)
\end{aligned}
$$




\subsubsection{Decomposing LW fluX with Radiative Kernels}

Similarly to the SW fluxes in paper IV, the change in LW fluxes can be decomposed into clear-sky and cloudy terms

$$
\Delta L W=\Delta L W_{c l r}+\Delta L W_{c l d}
$$

However, by using partition to cloud and non-cloud components as shown in equation 27, cloud components still include changes by non-cloud feedback, that is, changes in water vapor, surface albedo, and temperature. Soden et al. (2008) have shown how radiative kernels can be used to take these non-cloud feedbacks into account. In radiative kernel technique, each state variable (surface temperature, temperature profile, water vapor, and surface albedo) are perturbed by a unit change in a radiative transfer model. Then, the step radiative impact is evaluated. The correction factor accounting for the non-cloud feedbacks is defined as

$$
\begin{aligned}
\Delta L W_{\text {corr }}= & -\left(K_{t_{s}}-K_{T_{s} s}^{c l r}\right) \Delta T \\
& -\int_{p_{s}}^{0}\left(K_{t}-K_{T}^{c l r}\right) \Delta T d p \\
& -\int_{p_{s}}^{0}\left(K_{W}-K_{W}^{c l r}\right) \Delta \ln (q) d p
\end{aligned}
$$

where $K_{t s}, K_{t}$ and $K_{W}$ are radiative kernels for the change in surface temperature, the change in vertical temperature profile, and the change in water vapor

$$
\begin{aligned}
& \Delta L W_{\text {cld }}=\left(\Delta L W_{\text {cld }}-\Delta L W_{\text {corr }}\right) / D \\
& \Delta L W_{c l r}=\left(\Delta L W_{c l r}+\Delta L W_{\text {corr }}\right) / D
\end{aligned}
$$

Above, $L W_{c l r}$ is also corrected so that the kernel correction factor is added to the clear-sky term. Now equation 9 can be written as

$$
\begin{aligned}
\Delta T= & \Delta L W_{c l r}+\Delta L W_{c l d} \\
& +\Delta S W_{c l r}+\Delta S W_{c l d} \\
& +\Delta S W_{\text {Albedo }}+\Delta S U R F+\Delta C O N V
\end{aligned}
$$




\section{Climate impact of aerosols}

Limiting global warming to either 1.5 or $2.0{ }^{\circ} \mathrm{C}$ requires rapid mitigation of anthropogenic emissions. As anthropogenic aerosols partly originate from the same sources as GHGs, concentrations of anthropogenic aerosols are predicted to decline rapidly. Evaluating the net effect of anthropogenic aerosols is important due to differences in patterns of radiative forcing between GHGs and anthropogenic aerosols. This section shows main results from papers I and III, starting from present-day radiative forcing of anthropogenic aerosols, followed by temperature and precipitation changes due to anthropogenic aerosols

\subsection{Global Climate impact of PRESENT-DAy AERosols}

This section covers the main results from paper I. Results are from two independent climate models, ECHAM6 and NorESM1, as discussed in section 3.1.1. Both models included the simple anthropogenic aerosol representation, MACv2-SP. Furthermore, both models were run using identical radiative forcing generated by the ECHAM6 model. First, a comparison of how robust the radiative forcing generated by the MACv2-SP aerosols is, was carried out. As described in section 2.3aerosols alter Earth's climate by perturbing the radiative balance of Earth's atmosphere.

The simple representation of the anthropogenic aerosols shows almost identical global forcing in the ECHAM6 and NorESM1 models, as seen in Figure 7. On a global average, ECHAM6 and NorESM1 generate $-0.64 \mathrm{Wm}^{-2}$ and $-0.69 \mathrm{Wm}^{-2}$ respectively, and the spatial correlation of the forcing is 0.97 . Most of this forcing originates from the Southeast Asia region, where the highest discrepancies of the models' instantaneous forcing are. Slight differences in the generated forcing are due to differences in albedo, clouds, and difference in natural background aerosols (Fiedler et al., 2019). Due to similar forcing, almost identical temperature and precipitation responses should be expected.

On a global average, both models show similar temperature responses due to the addition of the MACv2-SP anthropogenic aerosols. In the ECHAM6 model, MAC2-SP produces a $0.5 \mathrm{~K}$ response, and in NorESM1, $0.48 \mathrm{~K}$. Most of this originates from the Arctic regions, as shown in Figure 8. Model discrepancies do not arise from the slight differences in the forcing, as the NorESM1 model shows an almost identical temperature response when forced directly with the MACv2-SP anthropogenic aerosols or with an identical forcing with the ECHAM6 model. Despite a similar global response, there are significant regional discrepancies between the temperature responses of the ECHAM6 and NorESM1 models. The spatial correlation between ECHAM6 and NorESM1 temperature respose is 0.81 . For example, in ECHAM6, the largest cooling is in the Southeast Asia regions, whereas in the NorESM1 

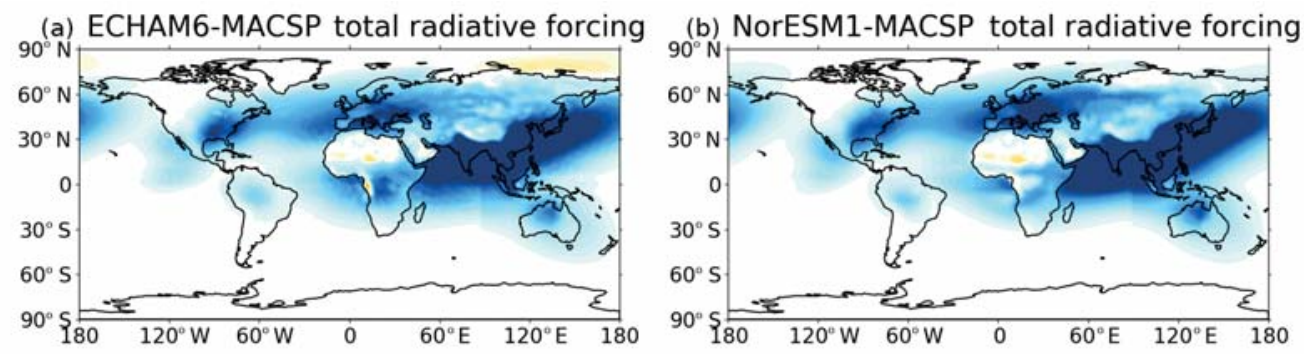

(c) Difference in total radiative forcing: ECHAM6-NorESM1

(d) ECHAM6 - NorESM-EF

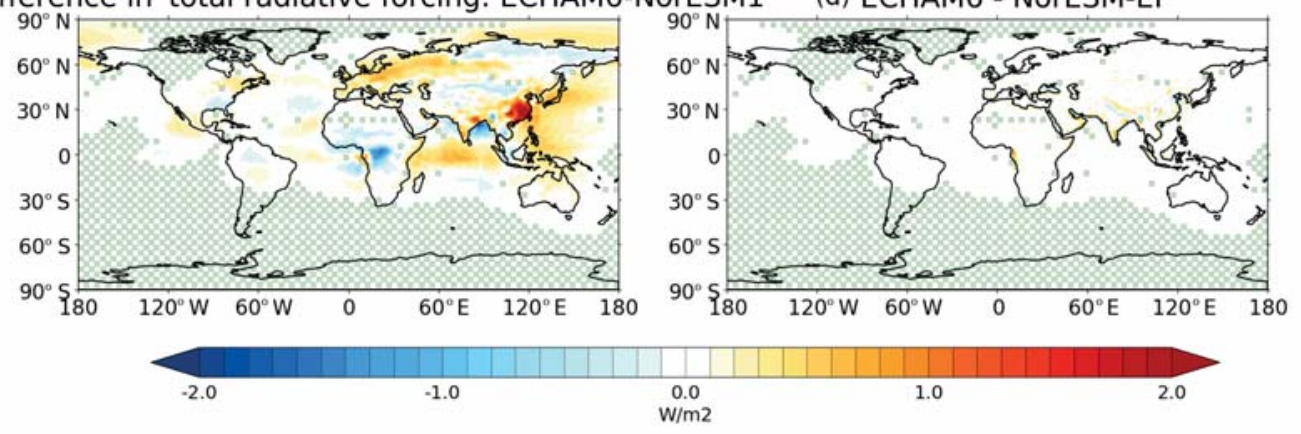

Figure 7: Total instantaneous radiative forcing due to the MACv2-SP anthropogenic aerosols in the ECHAM6 (panel a) and NorESM1 (panel b) models. The difference between the ECHAM6 and NorESM1 forcing (panel c), and the difference between NorESM1 MACv2-SP and NorESM1 with forcing generated by the ECHAM6 model (panel d). Figure obtained from Nordling et al. (2019)

model, the largest cooling is near the Russian Far East and north of Japan. These model differences are related to differences in the sea ice response and cloud responses in the models.

The precipitation response is more uncertain than the temperature response. The spatial correlation between the ECHAM6 and NorESM1 precipitation responses to the addition of MACv2-SP anthropogenic aerosols is 0.47 , significantly lower than with the temperature response (0.81). Both models show a reduction of global precipitation, $-1.79 \%$ in ECHAM6 and $-1.69 \%$ in NorESM1. Figure 8, panel b shows the zonal average precipitation response, and both models show a shift in the Intertropical Convergence Zone (ITCZ). Both models also show a decrease in Asian monsoon precipitation. The Asian summer monsoon (June-August) precipitation decreased $12.8 \%$ and $15.3 \%$ in ECHAM6 and NorESM1, respectively. Similar to the temperature response, slight differences in the forcing do not explain the discrepancies in the precipitation response, as both NorESM1 simulations show an almost identical zonal averaged precipitation response.

To assess the role of the aerosol scheme in estimating the uncertainty of climate 

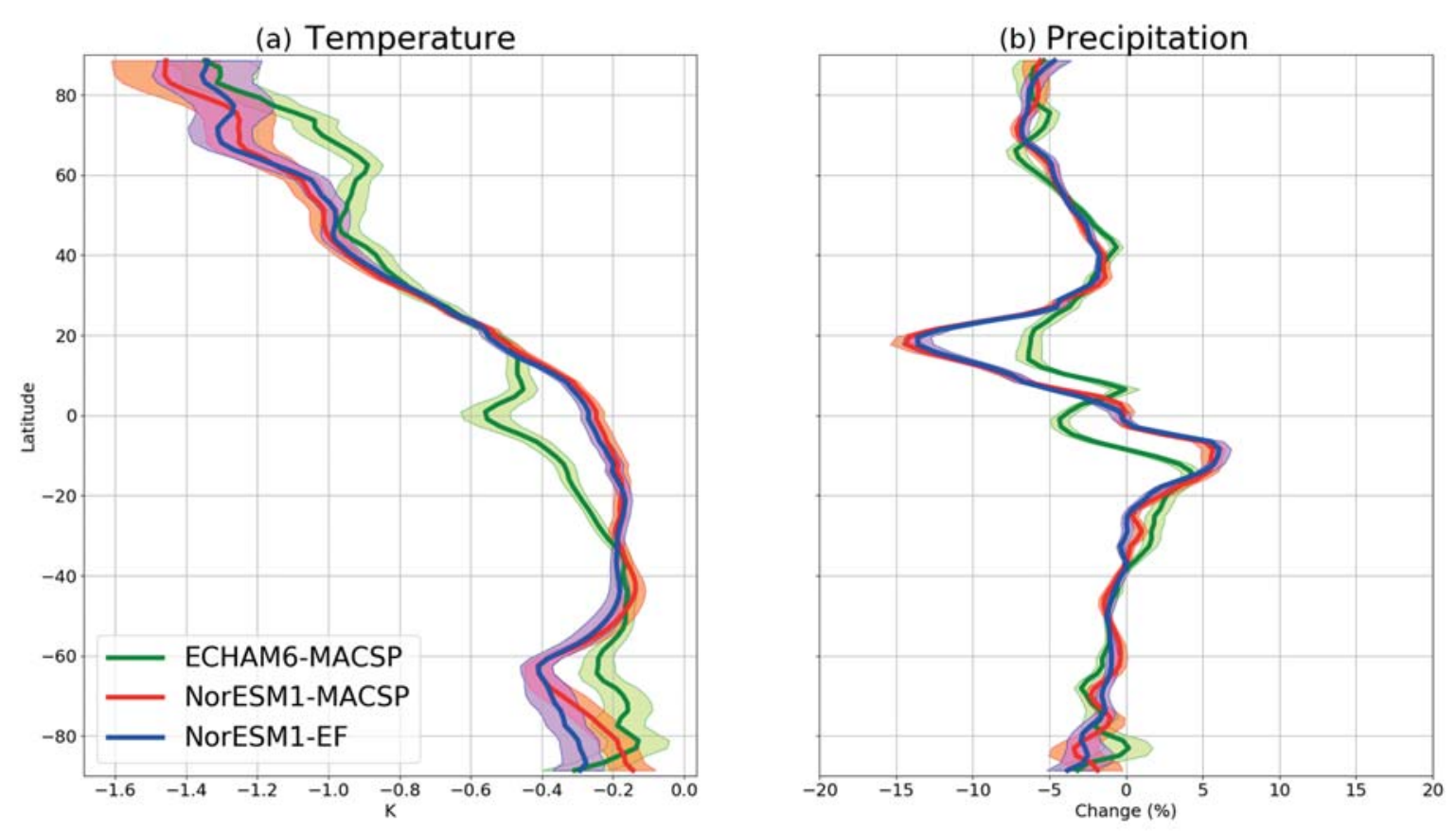

Figure 8: Zonal mean temperature (panel a) and precipitation response (panel b), for both ECHAM6 (green lines) and NorESM1 (red and blue lines) models. Blue lines show response from NorESM1 run where forcing is identical to ECHAM6. The shaded area shows standard error of mean.

effects of anthropogenic aerosols, paper I compared the results described above to similar climate model simulations reported by Samset et al. (2018) for four models with an intrinsic aerosol scheme. Samset et al. (2018) simulations differs from those performed here with ECHAM6 and NorESM1 by having a fully coupled ocean model. Samset et al. (2018) reported a temperature response, due to the removal of anthropogenic aerosols, from -0.5 to $1.1 \mathrm{~K}$ and a precipitation decrease from 1.5 to $3.1 \%$. These numbers are very similar to those found with the MACv2-SP aerosol scheme, and the average spatial correlation for temperature between models with an intrinsic aerosol scheme and models with MACv2-SP aerosols was 0.79 and 0.38 for precipitation. When comparing all models, there was no significant improvement in the spatial agreement of anthropogenic aerosols' climate effect when the same aerosol description was used.

\subsection{Climate impact of Asian aerosol emissions}

IPCC has highlighted in the recent 1.5-degree warming report (Hoegh-Guldberg et al., 2018) South and East Asia with high population density as regions facing significant climate risks in the near future. Most of the present-day aerosols originate from them 

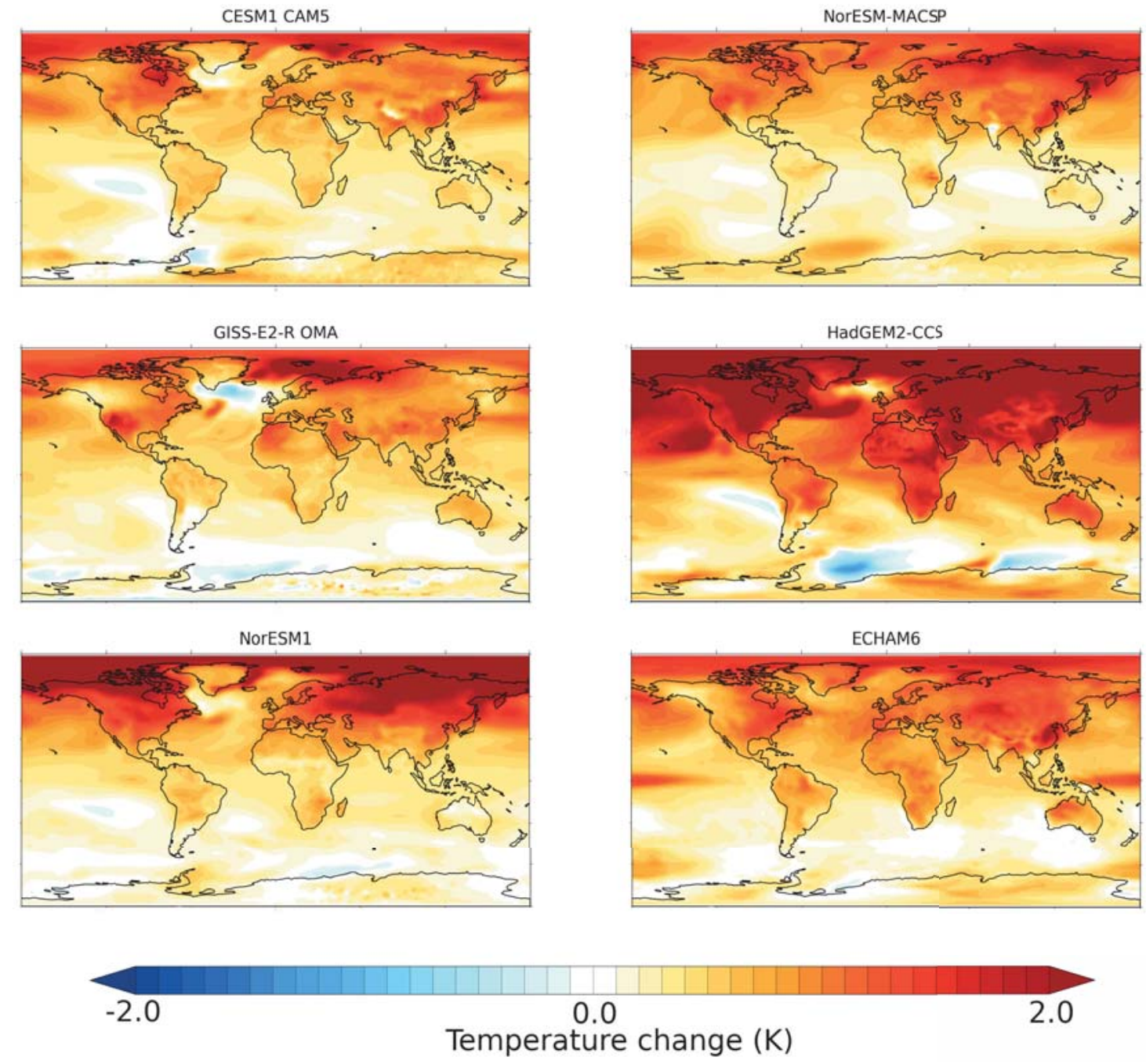

Figure 9: The spatial distribution of six climate models. CESM-CAM5, GISS-E2 OMA, HadGEM2-CCS, and NorESM1 are forced by the models' intrinsic aerosols (obtained from Samset et al. (2018)). ECHAM6 and NorESM-MACSP are forced by MACv2-SP anthropogenic aerosols. 
the Asian regions. These emissions are rapidly changing both in composition and spatial distribution (Myhre et al., 2017), which is predicted to continue in the near future (Samset et al., 2019). Therefore, it is essential to know the climate impacts of aerosols arising solely from Asian emissions.

The surface temperature response of South and East Asian anthropogenic aerosols is studied in paper II, which uses the same models and the same MACv2-SP anthropogenic aerosols as in paper I. Figure 10 shows the total direct and indirect instantaneous forcing caused by the removal of the MACv2-SP Asian anthropogenic aerosols. The instantaneous radiative forcing that stems from present-day anthropogenic aerosols from Asia is $-0.40 \mathrm{Wm}^{2}$, which accounts for $60 \%$ of overall present-day forcing due to the MACv2-SP anthropogenic aerosols. The local forcing reaches over $-8.0 \mathrm{Wm}^{2}$. Both the ECHAM6 and NorESM1 models produce similar global forcing due to the Asian anthropogenic aerosols with a spatial correlation of 0.96 .

Figure 11 shows the annual averages of the temperature response and the decomposed temperature response (see section 3.2. of Asian anthropogenic aerosols. The global mean temperature response is $0.26 \mathrm{~K}$ when the Asian MACv2-SP anthropogenic aerosols are removed. The temperature response from the Asian aerosols is not limited to midlatitudes. A large portion of the global mean temperature response arises from the Arctic region, where the temperature response is created as a result of changes in surface albedo (sea ice and snow cover), energy transport, and changes in LW clear-sky fluxes (laps-rate and water vapor).

Temperature decomposition provides a tool for understanding the underlying mechanisms of temperature change. The direct aerosol forcing changes the SW clear-sky fluxes $\left(S W_{c l r}\right.$ in figure 11) and warms the climate only locally. However, the warming is moderated by cooling due to horizontal energy transport (panel $c$ in Figure 11) and locally enhanced by the combined effects of SW and LW clouds.

The temperature response in high latitudes (from $60^{\circ} \mathrm{N}$ onward) varies highly between seasons. In both models, the warming due to the removal of Asian aerosols is largest in the northern hemisphere. During the Arctic summer, models produce mixed results. However, there is a clear minimum temperature response in the spring. The spring cooling is due to extra heat being absorbed by the ocean $(\triangle S U R F)$.

The strong seasonal Arctic temperature response involves the albedo feedback related to changes in sea ice concentration. The additional ice melt in the Arctic summer and spring increases the open water area, allowing more solar radiation to be absorbed by the oceans, which delays ice formation. This heat is released into the atmosphere during winter. 

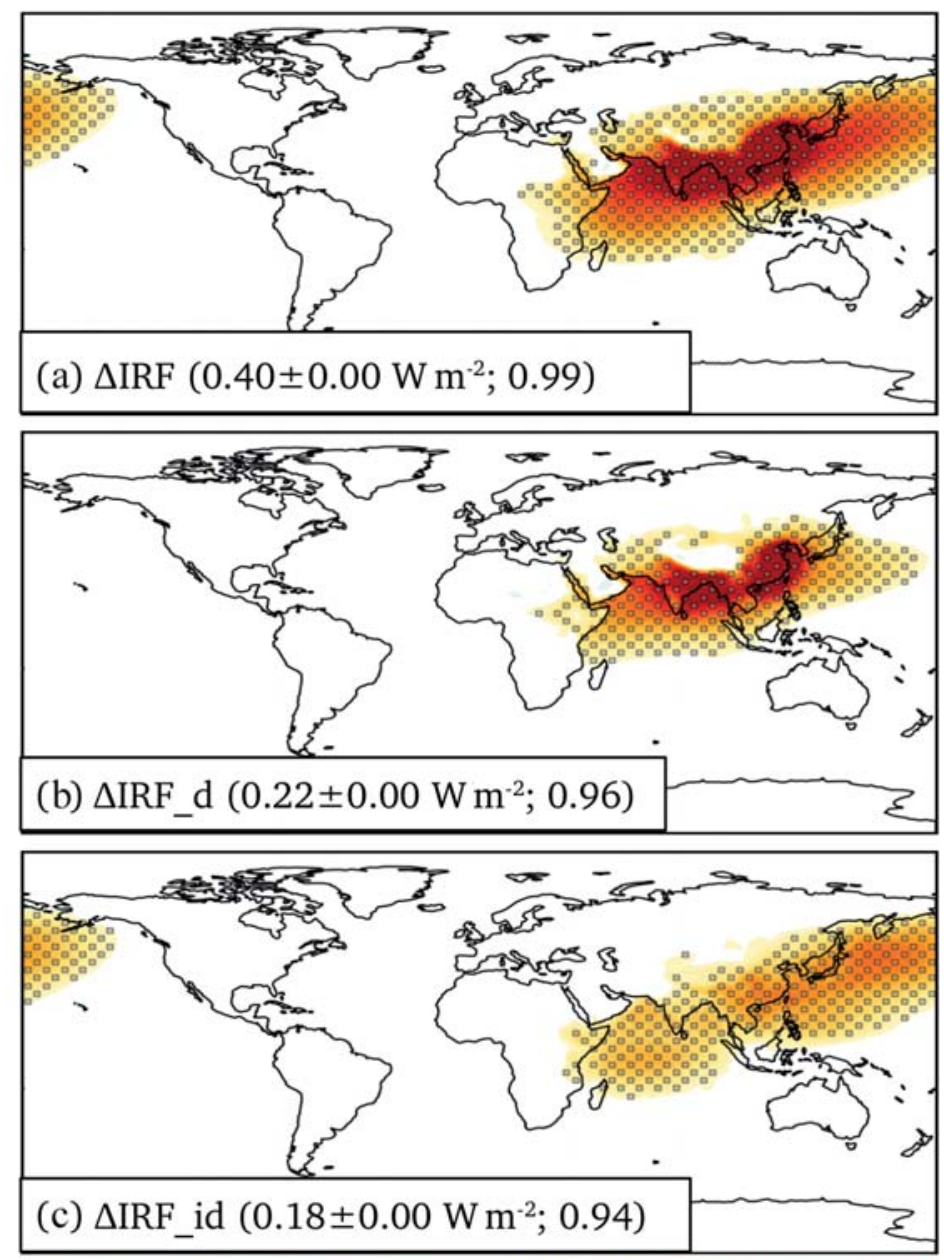

$\begin{array}{lllllllllllllllllllllll}-4.0 & -3.6 & -3.2 & -2.8 & -2.4 & -2.0 & -1.6 & -1.2 & -0.8 & -0.4 & 0.0 & 0.4 & 0.8 & 1.2 & 1.6 & 2.0 & 2.4 & 2.8 & 3.2 & 3.6 & 4.0\end{array}$

$\triangle \mathrm{IRF}\left(\mathrm{W} \mathrm{m}^{-2}\right)$

Figure 10: Mean instantaneous radiative forcing (a), direct aerosol forcing (b), and indirect forcing (c). Figure adapted from paper III 


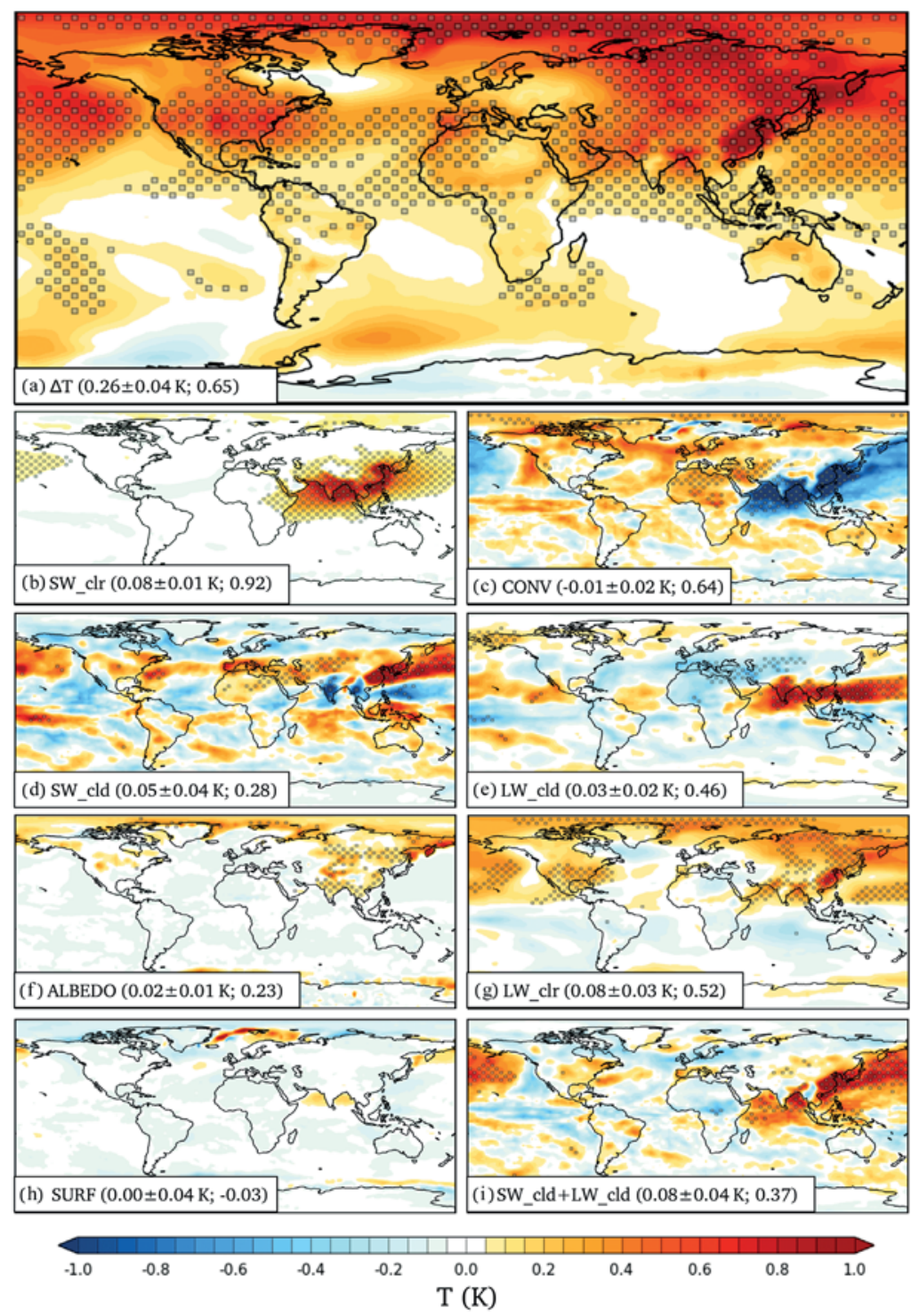

Figure 11: The annual average spatial distribution of the near surface temperature response (panel a), and its energetic components. Figure adapted from paper III. 


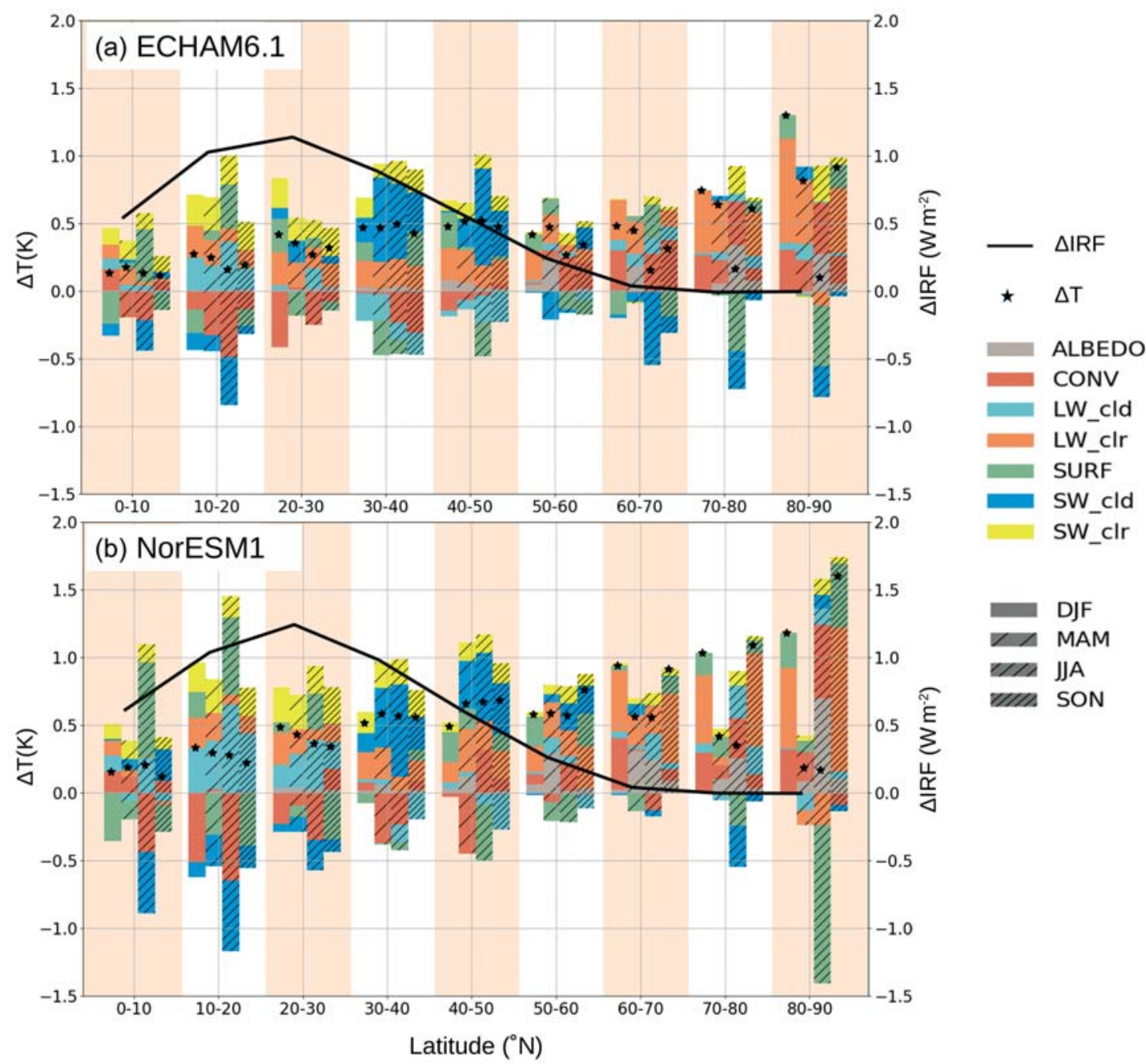

Figure 12: The seasonal cycle of the zonal temperature response to the removal of Asian anthropogenic aerosols. ECHAM6 (a) and NorESM1 (b). The solid line indicates the annual mean instantaneous radiative forcing due to Asian anthropogenic aerosols.Figure adapted from paper III 


\section{ORIgin OF THE TEMPERATURE RESPONSE AND ITS UNCERTAINTY}

In order to reduce the uncertainty in the future projection and to attribute climate impacts of anthropogenic aerosols, the mechanisms behind the surface temperature change need to be understood. The uncertainty in climate projections arise from the structural differences in climate models (Lehner et al., 2020; Hawkins and Sutton, 2009) in a time scale of decades. As shown in the previous section, climate models respond somewhat differently to almost identical external forcing.

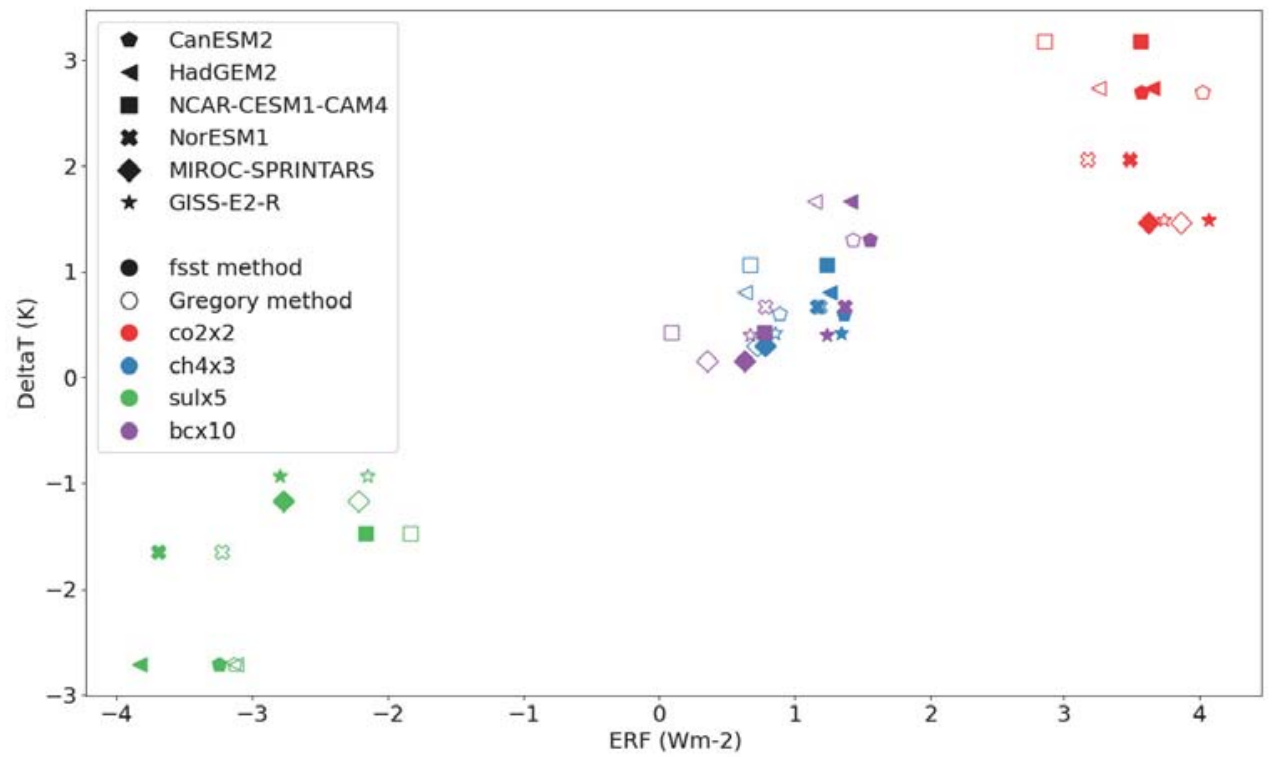

Figure 13: Estimated effective radiative forcing (ERF) for four different climate forcers (CO2, $\mathrm{CH} 4$, sulfate, and black carbon) using six models from the PDRMIP dataset. Filled markers indicate values estimated using fixed-sea-surface simulations, and non-filled markers indicate values estimated using the Gregory method. Figure adapted from paper IV

Figure 13 shows a relation between surface temperature change and forcing generated by $\mathrm{CO}_{2}, \mathrm{CH}_{4}$, sulfate, and black carbon in the PDRMIP experiments. Forcing is calculated by using two different methods. First, the $E R F_{f s s}$ is based on climate model runs with fixed sea surface temperature, allowing only the atmosphere to adjust to the instantaneous forcing. The second method is based on regressing the top-of-atmosphere radiative imbalance against temperature response (Gregory et al., 2004),

$$
N=F-\lambda \Delta T
$$

where $N$ is the TOA imbalance, $F$ is forcing, $\lambda$ is the climate feedback parameter, and $\Delta T$ is global average temperature response. From the regression analysis, we 
can obtain the slope $(\lambda)$ and the intercept term $(F)$. Figure 13 shows that there are only weak correlations between the forcing and the temperature response as well as the model-to-model spread in greenhouse gas forcers $\left(\mathrm{CO}_{2}\right.$ and $\left.\mathrm{CH}_{3}\right)$. However, with aerosol forcing, some correlation exists between forcing and the temperature response.
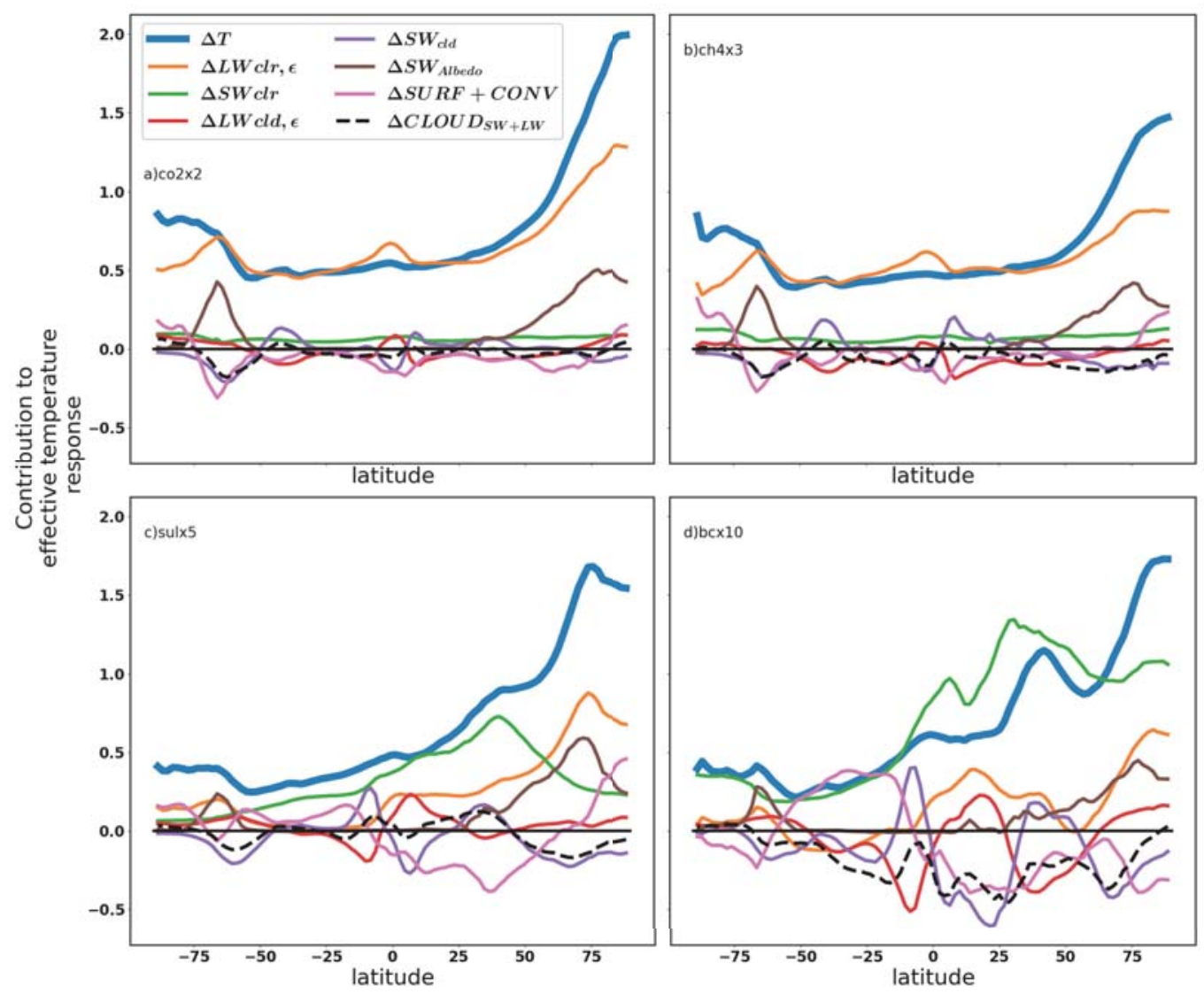

Figure 14: Zonal mean effective temperature response and its energy balance components for four different climate forcing agents $\left(\mathrm{CO}_{2}, \mathrm{CH}_{4}\right.$, sulfate and black carbon).Figure adapted from paper IV

Next, Figure 14 shows the decomposed effective temperature response $(\Delta T$ divided by the ERF) as multi-model means for the four forcing agents. The blue lines in Figure 14 show the zonal mean effective temperature response for each forcer. The greenhouse gases and sulfate produce somewhat similar total effective temperature responses. However, in midlatitudes, sulfate mainly changes the SW fluxes. The black carbon SW contribution exceeds the overall effective temperature response, and it is compensated mainly by the cooling effect of clouds.

One of the main goals of this thesis was to understand where the discrepancies in climate model responses to the same forcing agent arise. Paper IV demonstrates 

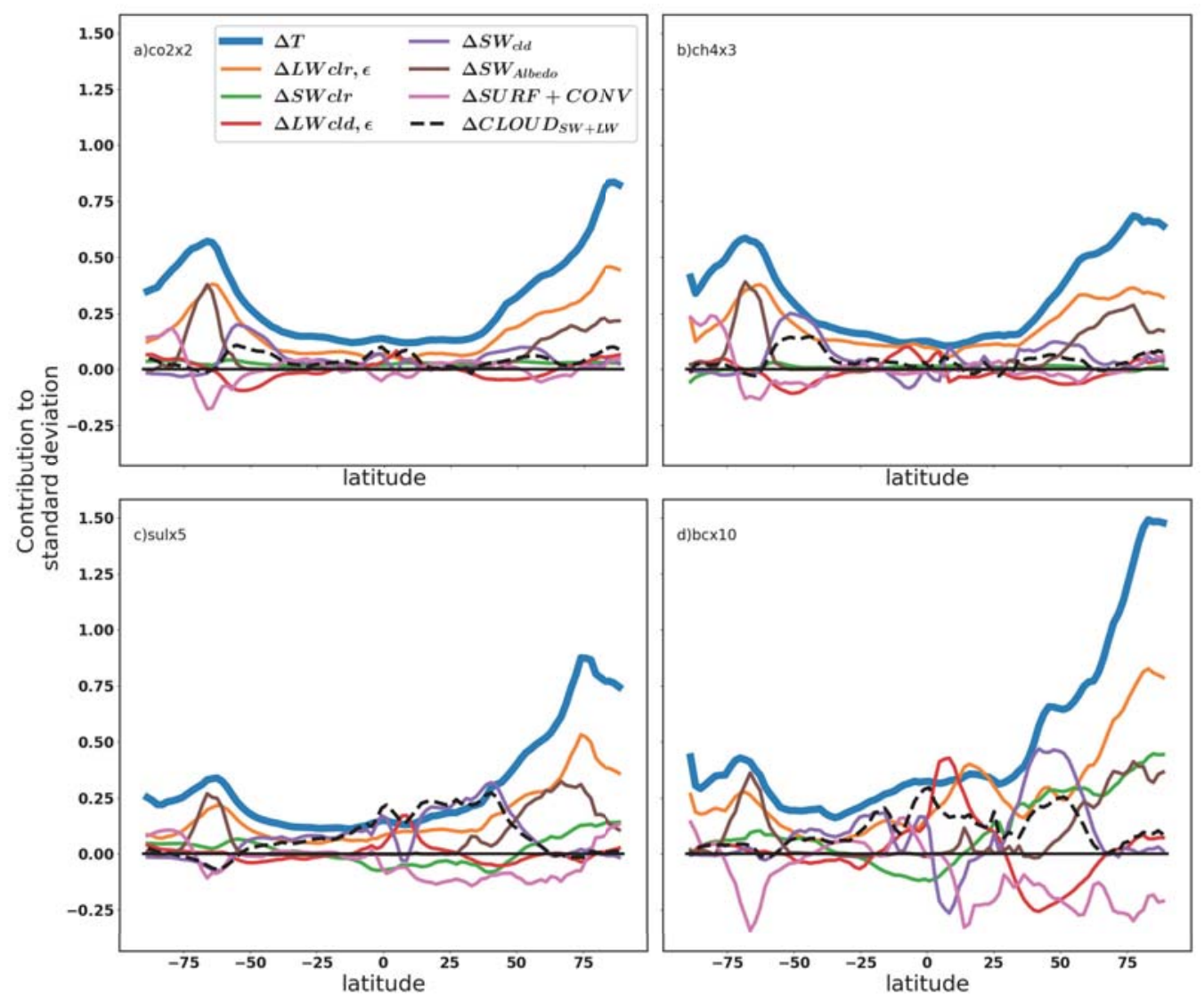

Figure 15: Decomposed model-to-model spread in effective temperature response to its energy balance terms.Figure adapted from paper IV

the use of the temperature decomposition method in understanding the underlying causes in the model-to-model spread. By decomposing the temperature response to its energy balance terms, we can also decompose the standard deviation between models to its energy balance terms. The contribution of the i:th term to the model-to-model standard deviation is defined by

$$
C S D_{i}=\frac{C O V\left(\Delta T, \Delta T_{i}\right)}{\sigma_{\Delta T}}=r_{i} \sigma_{\Delta T_{i}}
$$

where $\operatorname{COV}\left(\Delta T, \Delta T_{i}\right)$ is the covariance between the total effective temperature response and i:th energy balance term, $\sigma_{\Delta T}$ is the standard deviation of temperature response, $r_{i}$ is correlation between temperature and i:th energy balance terms, and $\sigma_{\Delta T_{i}}$ is the standard deviation of $\mathrm{i}$ :th energy balance term.

Figure 15 illustrates the importance of different energy balance terms of zonal mean model-to-model-spread. All forcing agents show somewhat a similar zonal mean 
spread. However, the origin of the spread varies between the forcers. With greenhouse gases (panels $a$ and $b$ in Figure 15), model-to-model spread originates from differences in the LW clear-sky flux responses (orange line) ,i.e., the difference in water vapor and thermal structure of the atmosphere, and the difference in the albedo(brown line), i.e., snow cover and sea ice changes. With aerosols (panels $\mathrm{c}$ and $\mathrm{d}$ in Figure 15), cloud response(black line) also plays a crucial role, especially in the midlatitudes and with the differences in SW clear-sky (i.e., direct aerosol forcing). 


\section{Future Aerosol Climate impacts}

The next sections show how the future changes of aerosol emissions affect the global climate and the Asian monsoon according to CMIP6 models. Figure 16 represents different future emissions pathways in four SSP scenarios used in paper II. There is large spread in future aerosol emission scenarios, largest during 2050, and it is dominated by emissions from East Asia (see Fig. 16).

The SSP1-1.9 scenario shows the most intensive reduction of the anthropogenic aerosols where both $\mathrm{SO}_{2}$ and black carbon emissions decline rapidly at the same time with $\mathrm{CO}_{2}$ emissions. In SSP2-4.5 and SSP3-7.0, there is a more modest decline of anthropogenic aerosol emissions and even a small increase of $\mathrm{SO}_{2}$ emissions from South Asia until 2040. The $\mathrm{CO}_{2}$ emissions increase in SSP5-8.5 and SSP3-7.0 until the end of the century. The rapid decline of anthropogenic aerosols until 2040 may unmask more warming due to $\mathrm{CO}_{2}$ emissions depending on the success of air quality regulations.

\subsection{Global EFFECtS}

Figure 17 llustrates the global temperature response (panel a), precipitation response (panel b), the change in hydrological sensitivity (panel c), and the mean temperature difference between the hemispheres (panel d) for different SSP scenarios and for three different decades in CMIP6 models. The global temperature response to future emission scenarios is primarily dominated by the GHG emissions. In the mid-century SSP2-4.5, SSP3-7.0, and SSP5-8.5, temperature anomalies relative to 1980-2014 are significantly larger than for SSP1-1.9. This indicates a weak anthropogenic aerosol fingerprint in future global temperature development.

However, there is a signal from anthropogenic aerosols in the precipitation response and the change in hydrological sensitivity (Fig. 17, panels b and c). The SSP1-1.9 scenario shows a significantly larger precipitation anomaly than other SSPs. The precipitation increase is driven by the GHGs in 2045-2054, where a rapid decrease of anthropogenic aerosols in 2025-2034 shows a more extensive anomaly than other SSPs. In hydrological sensitivity, the anthropogenic aerosol signal is more prominent. In 2035-2044, the hydrological sensitivity anomaly in SSP1-1.9 is significantly larger than in SSP3-7.0 and in 2045-2054 significantly larger than any other SSP. Anthropogenic aerosols are a dominant driver for the chagne in interhemispheric temperature gradient until 2050. The interhemispheric temperature gradient is an essential driver of the ITCZ position and controls regional precipitation and monsoon precipitation (Ayantika et al., 2021). However, there is a large inter-model spread in the interhemispheric temperature gradient. 

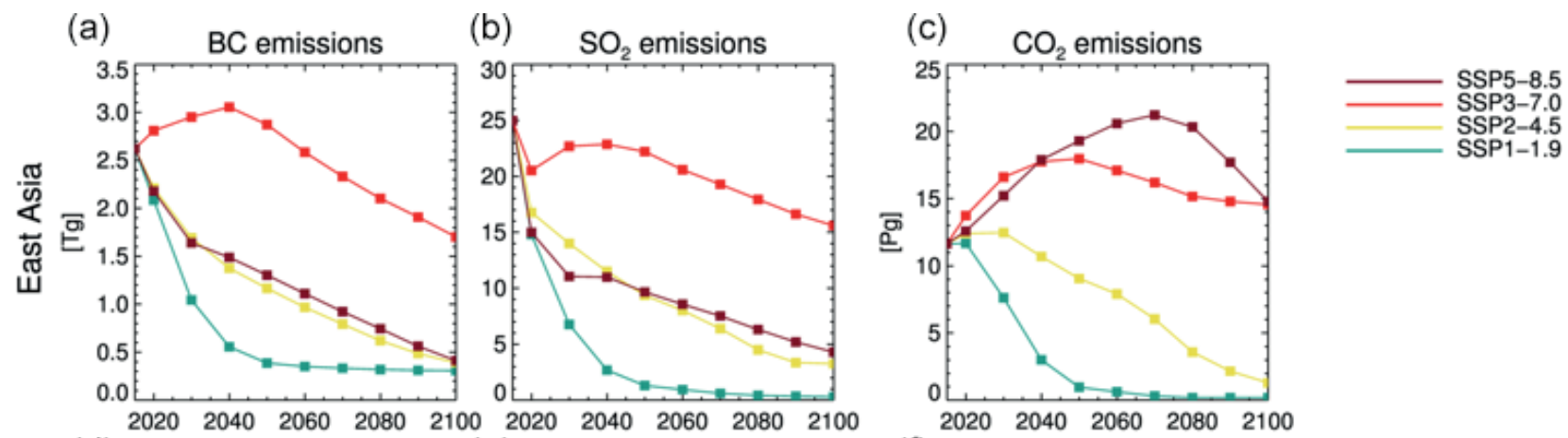

(d)

(e)

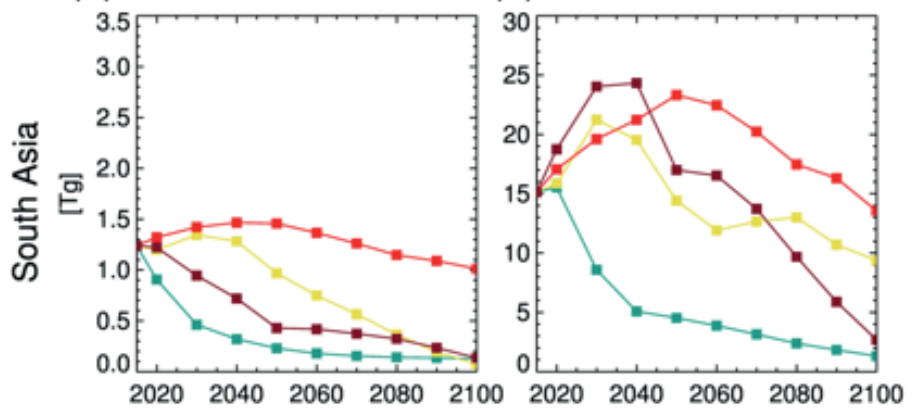

(f)

(g)

(h)
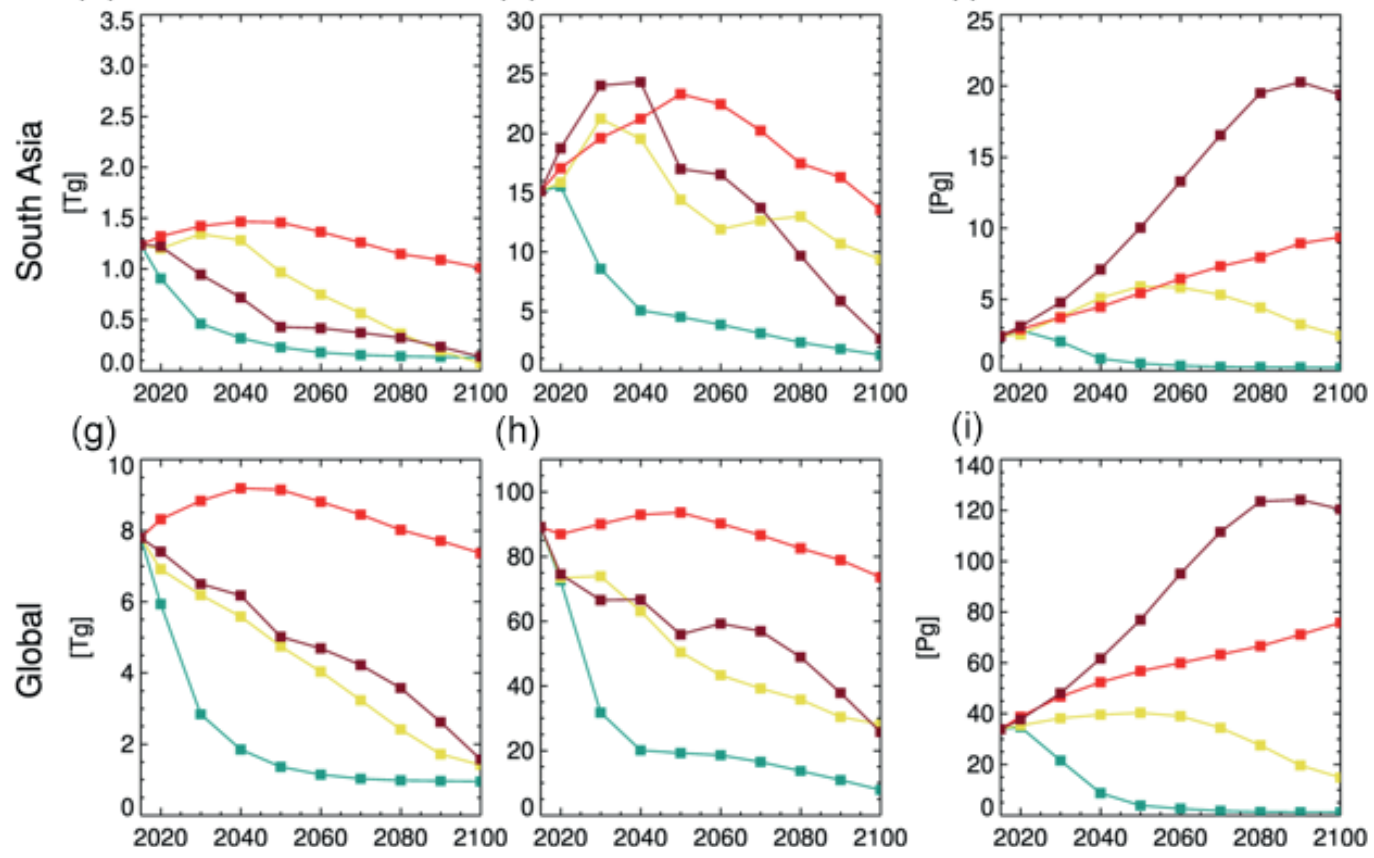

(i)

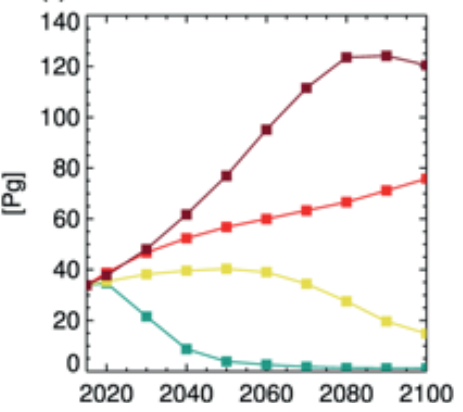

Figure 16: Future emissions of black carbon (a), sulfur dioxide (b), and carbon dioxide(c) in the future emission scenarios, SSP1-1.9, SSP2-4.5, SSP3-7.0, and SSP5-8.5 for East Asia (a-c), South Asia (d-f), and Global (g-i). Figure adapted from Wilcox et al. (2020)

\subsection{Regional EFFECTS ON ASIAN SUMMER MONSOON}

Up to $80 \%$ of annual precipitation in South Asia is provided by the summer monsoon. It has an enormous impact on health, agriculture, and water resources (Webster et al., 1998). Figure 18 shows the regional response in temperature, precipitation, and hydrological sensitivity in $1980-2014$ for Asia $\left(67.5-145^{\circ} \mathrm{E}, 5-47.5^{\circ} \mathrm{N}\right)$, East Asia $\left(20-40^{\circ} \mathrm{N}, 100-120^{\circ} \mathrm{E}\right)$, and South Asia $\left(5-25^{\circ} \mathrm{N}, 55-95^{\circ} \mathrm{E}\right)$ in CMIP6 models. The reduction of anthropogenic aerosols in SSP1-1.9 scenarios enhances warming in the Asian region until 2035 when the aerosol cooling effect is reduced, especially over land regions. The increase of anthropogenic aerosol emissions in SSP3-7.0 moderates the warming despite the increase of $\mathrm{CO}_{2}$ emissions. 

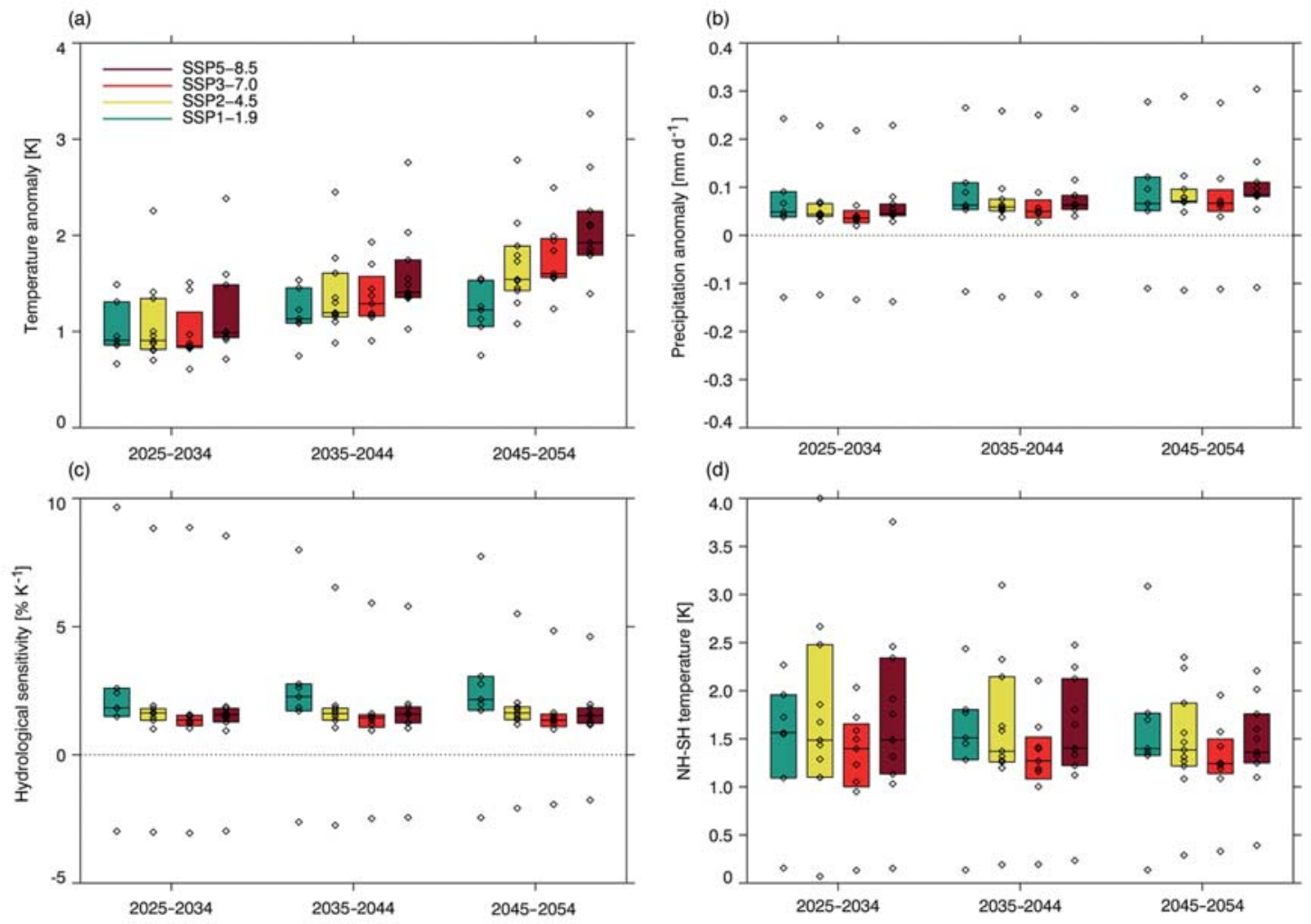

Figure 17: Globally averaged temperature and precipitation changes in future SSP scenarios.Figure adapted from pape Wilcox et al. (2020)

In the precipitation response to future anthropogenic aerosol emissions, the pattern is more persistent. The most extensive increase in precipitation response is in the SSP1-1.9 scenario from 2025 until 2045 over Asia. At the same time, the smallest increase in precipitation is in SSP3-7.0. The same aerosol-dominated pattern can be seen in hydrological sensitivity, where changes are dominated by the decrease of anthropogenic aerosols in SSP1-1.9. However, the pattern is not clear in the 2045-2055 period over south Asia. 

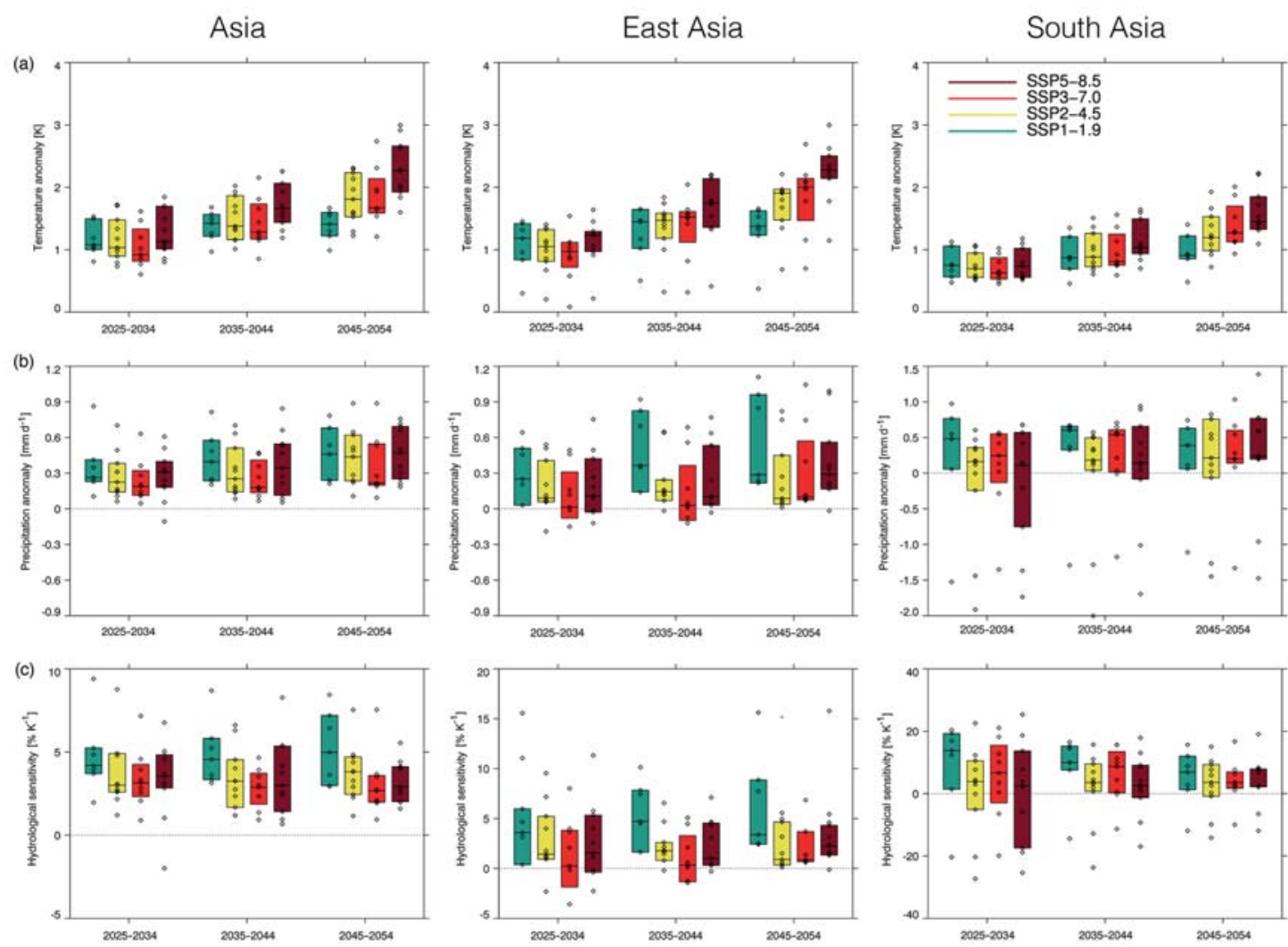

Figure 18: Regional mean for JJA-mean temperature anomaly (row a), precipitation (row b), and hydrological sensitivity (row c). Figure adapted from paper Wilcox et al. (2020) 


\section{Conclusions AND FUtURE PERSPECTIVES}

Climate models are one of the key tools in studying climate and climate change. However, they exhibit uncertainties arising from future emission scenarios, structural differences, internal climate variability, and model initialization. The aim of this thesis was to answer following questions.

- What are the most prominent climate effects of present-day anthropogenic aerosols? (Papers I and III)?

- What are the primary mechanisms driving the climate effects and model-to-model spread in the temperature response for various different climate forcing agents? (Paper IV)

- What are the primary local and global climate effects of future strong aerosol reduction?(Paper II)

As presented in paper I, two independent climate models indicate that present-day aerosols cool Earth's climate around $0.5^{\circ} \mathrm{C}$ on global average. The identical anthropogenic aerosol description, which includes the first indirect cloud effect, did not reduce the dissimilarities in the geographical distribution of temperature and precipitation response compared to models with intrinsic aerosol schemes. The slight dissimilarities in the generated aerosol forcing are not responsible for these pattern differences as even identical aerosol forcing did not reduce the dissimilarities. This indicates that the geographical distribution differences of temperature and precipitation response are driven by the model dynamics. The atmosphere circulation response is not the only driver of the model discrepancies, as the different ocean models have a large impact on regional climate responses between different models (Deser et al., 2016; Kay et al., 2016). However, the exact role of the ocean remains unclear (Krishnan et al., 2020).

Paper III concentrated on the anthropogenic aerosol temperature response solely arising from Asian present-day emissions. Most of the present-day anthropogenic aerosol forcing is due to emissions from Asian regions. These partly mask the warming due to GHG emissions, similarly to global emissions in paper I. The most prominent temperature response in the wintertime Arctic regions stems from changes in sea ice concentration. However, it has been shown that Arctic amplification may occur even if sea ice remains constant (Pithan and Mauritsen, 2014).The Arctic is particularly sensitive to future climate change, and current models exhibit large uncertainty in the Arctic (Cai et al., 2021), which it is dominated by local cloud feedbacks (Stuecker et al., 2018). Hence, it is important to understand the uncertainty and future climate change in the Arctic. Similarly to paper I the results in paper III 
show a robust temperature response resulting from present-day Asian anthropogenic aerosols. Furthermore, paper III shows mechanisms behind the temperature response and its model difference, which highlights the importance of local feedbacks, similarly to Stuecker et al. (2018); Pithan and Mauritsen (2014).

Different anthropogenic aerosol species affect the climate in different ways. Paper IV illustrates how the temperature responses from sulfate and BC differ from those from GHG emissions. The main driver of the model-to-model differences in GHG climate response and aerosols is the response in vertical temperature distribution and water vapor. On the regional scale, clouds and direct aerosols, forcing also plays an important role. Previously the model-to-model spread has been attributed mainly to cloud feedback (Zelinka et al., 2020; Zhao et al., 2016; Dong et al., 2020). Results in paper IV provide somewhat divergent results as they show that model-to-model differences are dominated by clear-sky, and not cloud responses. This is mainly due to forcing and adjustments counteracting some of the differences in the forcing and feedbacks (Hu et al., 2020; Wang and Huang, 2020; Kramer et al., 2019).

Understanding how aerosols (anthropogenic or natural) interact with climate is crucial to understanding future climate change. Despite future reduction of anthropogenic aerosols, natural aerosols may increase due to warming from GHGs, leading to changes in natural aerosol concentrations, which contributes to transient and equilibrium climate sensitivities, and may affect specific climate targets such as 1.5 (Meehl et al., 2020; Matthews et al., 2021; Rogelj et al., 2019). For example, anthropogenic aerosols have an important role in constraining the equilibrium climate sensitivity (Fletcher et al., 2018; Paulot et al., 2020). Paper IV shows the mechanisms that drive the model-to-model differences in annual mean temperature responses. However, paper IV lacks knowledge of the driving mechanisms on the seasonal and monthly time scales. One option to reduce the model-to-model spread is to improve the models' radiative transfer codes (Soden et al., 2018). Ongoing research activities are working on quantifying how Earth responds to different types of radiative forcing and where the model biases originate from (Pincus et al., 2016).

The last research question of this thesis is about future aerosol effects in different future emission scenarios (paper II). Until 2050 the global precipitation changes are dominated by future aerosol emission reductions. The most prominent effects are found in the Asian summer monsoon, where, in the near future, aerosols might dominate the precipitation and temperature change.

Lastly, I will discuss of some of the future perspectives of this thesis. First, as shown in section 5, aerosols have a profound role in model uncertainty on the regional scale. Particularly, more realistic and physics-based cloud-aerosol interactions in global circulation models could reduce this uncertainty. For example, utilizing machine learning techniques and large eddy simulations (LES) to construct an emulator can 
emulate the essential cloud-aerosols process. A similar technique can be used to reduce uncertainties related to, for example, sea ice change due to anthropogenic aerosols.

Second, to gain a more profound understanding of future temperature change, model-to-model variability, and natural climate variability, the temperature decomposition method presented in paper IV provides a valuable tool. As shown in paper IV, the same forcing agents produce somewhat different effective radiative forcing in current climate models, but, even more importantly models respond differently to this forcing. RFMIP (Pincus et al., 2016) provides valuable data for assessing the question why models respond differently to similar radiative forcing. This could reveal the key mechanisms behind model uncertainties, which dominate the climate projection in time scales of decades, which is the relevant time scale for policy makers. 


\section{REFERENCES}

Aamaas, B., T. K. Berntsen, J. S. Fuglestvedt, K. P. Shine, and W. J. Collins, 2017: Regional temperature change potentials for short-lived climate forcers based on radiative forcing from multiple models. Atmospheric Chemistry and Physics, 17(17), 10795-10809.

Aas, W., A. Mortier, V. Bowersox, R. Cherian, G. Faluvegi, H. Fagerli, J. Hand, Z. Klimont, C. Galy-Lacaux, C. M. Lehmann, et al., 2019: Global and regional trends of atmospheric sulfur. Scientific reports, 9(1), 1-11.

Agel, L., and M. Barlow, 2020: How well do cmip6 historical runs match observed northeast us precipitation and extreme precipitation-related circulation? Journal of Climate, 33(22), 9835-9848.

Albrecht, B. A., 1989: Aerosols, cloud microphysics, and fractional cloudiness. Science, 245(4923), 1227-1230.

Arora, V., J. Scinocca, G. Boer, J. Christian, K. Denman, G. Flato, V. Kharin, W. Lee, and W. Merryfield, 2011: Carbon emission limits required to satisfy future representative concentration pathways of greenhouse gases. Geophysical Research Letters, 38(5).

Ayantika, D., R. Krishnan, M. Singh, P. Swapna, N. Sandeep, A. Prajeesh, and R. Vellore, 2021: Understanding the combined effects of global warming and anthropogenic aerosol forcing on the south asian monsoon. Climate Dynamics, 56(5), 1643-1662.

Bellouin, N., J. Quaas, E. Gryspeerdt, S. Kinne, P. Stier, D. Watson-Parris, O. Boucher, K. S. Carslaw, M. Christensen, A.-L. Daniau, et al., 2020: Bounding global aerosol radiative forcing of climate change. Reviews of Geophysics, 58(1), e2019RG000660.

Bentsen, M., I. Bethke, J. B. Debernard, T. Iversen, A. Kirkevåg, Ø. Seland, H. Drange, C. Roelandt, I. A. Seierstad, C. Hoose, et al., 2013: The norwegian earth system model, noresm1-m-part 1: description and basic evaluation of the physical climate. Geoscientific Model Development, 6(3), 687-720.

Bollasina, M. A., Y. Ming, and V. Ramaswamy, 2011: Anthropogenic aerosols and the weakening of the south asian summer monsoon. science, 334(6055), 502-505.

Bonfils, C. J., B. D. Santer, J. C. Fyfe, K. Marvel, T. J. Phillips, and S. R. Zimmerman, 2020: Human influence on joint changes in temperature, rainfall and continental aridity. Nature Climate Change, 10(8), 726-731. 
Boucher, O., D. Randall, P. Artaxo, C. Bretherton, G. Feingold, P. Forster, V.-M. Kerminen, Y. Kondo, H. Liao, U. Lohmann, P. Rasch, S. K. Satheesh, S. Sherwood, B. Stevens, and X. Zhang, 2013: Clouds and Aerosols. Climate Change 2013: The Physical Science Basis. Contribution of Working Group I to the Fifth Assessment Report of the Intergovernmental Panel on Climate Change.

Cai, Z., Q. You, F. Wu, H. W. Chen, D. Chen, and J. Cohen, 2021: Arctic warming revealed by multiple cmip6 models: evaluation of historical simulations and quantification of future projection uncertainties. Journal of Climate, 34(12), 4871-4892.

Carslaw, K. S., L. A. Lee, C. L. Reddington, K. J. Pringle, A. Rap, P. M. Forster, G. W. Mann, D. V. Spracklen, M. T. Woodhouse, L. A. Regayre, and J. R. Pierce, 2013: Large contribution of natural aerosols to uncertainty in indirect forcing. Nature, 503(7474), 67-71.

Cesana, G. V., and A. D. Del Genio, 2021: Observational constraint on cloud feedbacks suggests moderate climate sensitivity. Nature Climate Change 1-6.

Collins, W., N. Bellouin, M. Doutriaux-Boucher, N. Gedney, P. Halloran, T. Hinton, J. Hughes, C. Jones, M. Joshi, S. Liddicoat, et al., 2011: Development and evaluation of an earth-system model-hadgem2. Geoscientific Model Development, 4(4), 1051-1075.

Croft, B., J. Pierce, and R. Martin, 2014: Interpreting aerosol lifetimes using the geos-chem model and constraints from radionuclide measurements. Atmospheric Chemistry and Physics, 14(8), 4313-4325.

Deser, C., L. Sun, R. A. Tomas, and J. Screen, 2016: Does ocean coupling matter for the northern extratropical response to projected arctic sea ice loss? Geophysical Research Letters, 43(5), 2149-2157.

Dittus, A. J., E. Hawkins, L. J. Wilcox, R. T. Sutton, C. J. Smith, M. B. Andrews, and P. M. Forster, 2020: Sensitivity of historical climate simulations to uncertain aerosol forcing. Geophysical Research Letters, 47(13), e2019GL085806.

Dong, Y., K. C. Armour, M. D. Zelinka, C. Proistosescu, D. S. Battisti, C. Zhou, and T. Andrews, 2020: Intermodel spread in the pattern effect and its contribution to climate sensitivity in cmip5 and cmip6 models. Journal of Climate, 33(18), 7755-7775.

Douglas, A., and T. L'Ecuyer, 2020: Quantifying cloud adjustments and the radiative forcing due to aerosol-cloud interactions in satellite observations of warm marine clouds. Atmospheric Chemistry and Physics, 20(10), 6225-6241. 
Elm, J., J. Kubečka, V. Besel, M. J. Jääskeläinen, R. Halonen, T. Kurtén, and H. Vehkamäki, 2020: Modeling the formation and growth of atmospheric molecular clusters: A review. Journal of Aerosol Science, 149, 105621.

Eyring, V., S. Bony, G. A. Meehl, C. A. Senior, B. Stevens, R. J. Stouffer, and K. E. Taylor, 2016: Overview of the coupled model intercomparison project phase 6 (cmip6) experimental design and organization. Geoscientific Model Development, 9(5), 1937-1958.

Fiedler, S., S. Kinne, W. T. K. Huang, P. Räisänen, D. O’Donnell, N. Bellouin, P. Stier, J. Merikanto, T. v. Noije, R. Makkonen, et al., 2019: Anthropogenic aerosol forcing-insights from multiple estimates from aerosol-climate models with reduced complexity. Atmospheric Chemistry and Physics, 19(10), 6821-6841.

Fiedler, S., B. Stevens, and T. Mauritsen, 2017: On the sensitivity of anthropogenic aerosol forcing to model-internal variability and parameterizing a t womey effect. Journal of Advances in Modeling Earth Systems, 9(2), 1325-1341.

Fioletov, V. E., C. A. McLinden, N. Krotkov, C. Li, J. Joiner, N. Theys, S. Carn, and M. D. Moran, 2016: A global catalogue of large so 2 sources and emissions derived from the ozone monitoring instrument. Atmospheric Chemistry and Physics, 16(18), 11497-11519.

Fläschner, D., T. Mauritsen, and B. Stevens, 2016: Understanding the intermodel spread in global-mean hydrological sensitivity. Journal of Climate, 29(2), 801-817.

Fletcher, C. G., B. Kravitz, and B. Badawy, 2018: Quantifying uncertainty from aerosol and atmospheric parameters and their impact on climate sensitivity. Atmospheric Chemistry and Physics, 18(23), 17529-17543.

Glassmeier, F., F. Hoffmann, J. S. Johnson, T. Yamaguchi, K. S. Carslaw, and G. Feingold, 2021: Aerosol-cloud-climate cooling overestimated by ship-track data. Science, 371(6528), 485-489.

Gregory, J. M., W. Ingram, M. Palmer, G. Jones, P. Stott, R. Thorpe, J. Lowe, T. Johns, and K. Williams, 2004: A new method for diagnosing radiative forcing and climate sensitivity. Geophysical research letters, 31(3).

Gryspeerdt, E., J. Mülmenstädt, A. Gettelman, F. F. Malavelle, H. Morrison, D. Neubauer, D. G. Partridge, P. Stier, T. Takemura, H. Wang, et al., 2020: Surprising similarities in model and observational aerosol radiative forcing estimates. Atmospheric chemistry and physics, 20(1), 613-623. 
Hawkins, E., and R. Sutton, 2009: The potential to narrow uncertainty in regional climate predictions. Bulletin of the American Meteorological Society, 90(8), 1095-1108.

Hoegh-Guldberg, O., D. Jacob, M. Bindi, S. Brown, I. Camilloni, A. Diedhiou, R. Djalante, K. Ebi, F. Engelbrecht, J. Guiot, et al., 2018: Impacts of 1.5 c global warming on natural and human systems. Global warming of 1.5 C. An IPCC Special Report.

Hu, X., H. Fan, M. Cai, S. A. Sejas, P. Taylor, and S. Yang, 2020: A less cloudy picture of the inter-model spread in future global warming projections. Nature communications, 11(1), 1-11.

Iversen, T., M. Bentsen, I. Bethke, J. Debernard, A. Kirkevåg, Ø. Seland, H. Drange, J. Kristjansson, I. Medhaug, M. Sand, et al., 2013: The norwegian earth system model, noresm 1-m-part 2: climate response and scenario projections. Geoscientific Model Development, 6(2), 389-415.

Jacobson, M. Z., 2005: Fundamentals of Atmospheric Modeling. Cambridge University Press, 2 edition.

Jin, Q., and C. Wang, 2017: A revival of indian summer monsoon rainfall since 2002. Nature Climate Change, 7(8), 587-594.

Johnson, B., K. Shine, and P. Forster, 2004: The semi-direct aerosol effect: Impact of absorbing aerosols on marine stratocumulus. Quarterly Journal of the Royal Meteorological Society, 130(599), 1407-1422.

Kaufman, Y. J., and I. Koren, 2006: Smoke and pollution aerosol effect on cloud cover. Science, 313(5787), 655-658.

Kay, J. E., C. Wall, V. Yettella, B. Medeiros, C. Hannay, P. Caldwell, and C. Bitz, 2016: Global climate impacts of fixing the southern ocean shortwave radiation bias in the community earth system model (cesm). Journal of Climate, 29(12), 4617-4636.

Kirkevåg, A., T. Iversen, Ø. Seland, C. Hoose, J. Kristjánsson, H. Struthers, A. M. Ekman, S. Ghan, J. Griesfeller, E. D. Nilsson, et al., 2013: Aerosol-climate interactions in the norwegian earth system model-noresm1-m. Geoscientific Model Development, 6(1), 207-244.

Knutti, R., D. Masson, and A. Gettelman, 2013: Climate model genealogy: Generation cmip5 and how we got there. Geophysical Research Letters, 40(6), 1194-1199. 
Koch, D., and A. Del Genio, 2010: Black carbon semi-direct effects on cloud cover: review and synthesis. Atmospheric Chemistry and Physics, 10(16), 7685-7696.

Köhler, H., 1936: The nucleus in and the growth of hygroscopic droplets. Transactions of the Faraday Society, 32, 1152-1161.

Koll, D. D., and T. W. Cronin, 2018: Earth's outgoing longwave radiation linear due to h2o greenhouse effect. Proceedings of the National Academy of Sciences, 115(41), 10293-10298.

Koop, T., B. Luo, A. Tsias, and T. Peter, 2000: Water activity as the determinant for homogeneous ice nucleation in aqueous solutions. Nature, 406(6796), 611-614.

Kramer, R. J., B. J. Soden, and A. G. Pendergrass, 2019: Evaluating climate model simulations of the radiative forcing and radiative response at earth's surface. Journal of Climate, 32(13), 4089-4102.

Krishnan, S., A. M. Ekman, H.-C. Hansson, I. Riipinen, A. Lewinschal, L. J. Wilcox, and T. Dallafior, 2020: The roles of the atmosphere and ocean in driving arctic warming due to european aerosol reductions. Geophysical Research Letters, 47(7), e2019GL086681.

Kristiansen, N. I., A. Stohl, and G. Wotawa, 2012: Atmospheric removal times of the aerosol-bound radionuclides $137 \mathrm{cs}$ and 131 i measured after the fukushima dai-ichi nuclear accident-a constraint for air quality and climate models. Atmospheric Chemistry and Physics, 12(22), 10759-10769.

Kulmala, M., J. Kontkanen, H. Junninen, K. Lehtipalo, H. E. Manninen, T. Nieminen, T. Petäjä, M. Sipilä, S. Schobesberger, P. Rantala, et al., 2013: Direct observations of atmospheric aerosol nucleation. Science, 339(6122), 943-946.

Lehner, F., C. Deser, N. Maher, J. Marotzke, E. M. Fischer, L. Brunner, R. Knutti, and E. Hawkins, 2020: Partitioning climate projection uncertainty with multiple large ensembles and cmip5/6. Earth System Dynamics, 11(2), 491-508.

Lewinschal, A., A. M. Ekman, H.-C. Hansson, M. Sand, T. K. Berntsen, and J. Langner, 2019: Local and remote temperature response of regional so 2 emissions. Atmospheric Chemistry and Physics, 19(4), 2385-2403.

Li, Z., W.-M. Lau, V. Ramanathan, G. Wu, Y. Ding, M. Manoj, J. Liu, Y. Qian, J. Li, T. Zhou, et al., 2016: Aerosol and monsoon climate interactions over asia. Reviews of Geophysics, 54(4), 866-929. 
Loeb, N. G., D. R. Doelling, H. Wang, W. Su, C. Nguyen, J. G. Corbett, L. Liang, C. Mitrescu, F. G. Rose, and S. Kato, 2018: Clouds and the earth's radiant energy system (ceres) energy balanced and filled (ebaf) top-of-atmosphere (toa) edition-4.0 data product. Journal of Climate, 31(2), 895-918.

Lund, M. T., G. Myhre, and B. H. Samset, 2019: Anthropogenic aerosol forcing under the shared socioeconomic pathways. Atmospheric Chemistry and Physics, 19(22), $13827-13839$.

L'Ecuyer, T. S., Y. Hang, A. V. Matus, and Z. Wang, 2019: Reassessing the effect of cloud type on earth's energy balance in the age of active spaceborne observations. part i: Top of atmosphere and surface. Journal of Climate, 32(19), 6197-6217.

Mace, G. G., Q. Zhang, M. Vaughan, R. Marchand, G. Stephens, C. Trepte, and D. Winker, 2009: A description of hydrometeor layer occurrence statistics derived from the first year of merged cloudsat and calipso data. Journal of Geophysical Research: Atmospheres, 114(D8).

Malavelle, F. F., J. M. Haywood, A. Jones, A. Gettelman, L. Clarisse, S. Bauduin, R. P. Allan, I. H. H. Karset, J. E. Kristjánsson, L. Oreopoulos, et al., 2017: Strong constraints on aerosol-cloud interactions from volcanic eruptions. Nature, 546(7659), 485-491.

Martin, G., N. Bellouin, W. Collins, I. Culverwell, P. Halloran, S. Hardiman, T. Hinton, C. Jones, R. McDonald, A. McLaren, et al., 2011: The hadgem2 family of met office unified model climate configurations, geosci. model dev., 4, 723-757, doi: 10.5194.

Marvel, K., B. I. Cook, C. J. Bonfils, P. J. Durack, J. E. Smerdon, and A. P. Williams, 2019: Twentieth-century hydroclimate changes consistent with human influence. Nature, 569(7754), 59-65.

Matthews, H. D., K. B. Tokarska, J. Rogelj, C. J. Smith, A. H. MacDougall, K. Haustein, N. Mengis, S. Sippel, P. M. Forster, and R. Knutti, 2021: An integrated approach to quantifying uncertainties in the remaining carbon budget. Communications Earth \& Environment, 2(1), 1-11.

McCoy, I. L., D. T. McCoy, R. Wood, L. Regayre, D. Watson-Parris, D. P. Grosvenor, J. P. Mulcahy, Y. Hu, F. A.-M. Bender, P. R. Field, et al., 2020: The hemispheric contrast in cloud microphysical properties constrains aerosol forcing. Proceedings of the National Academy of Sciences, 117(32), 18998-19006.

McDuffie, E. E., S. J. Smith, P. O'Rourke, K. Tibrewal, C. Venkataraman, E. A. Marais, B. Zheng, M. Crippa, M. Brauer, and R. V. Martin, 2020: A global anthropogenic 
emission inventory of atmospheric pollutants from sector-and fuel-specific sources (1970-2017): an application of the community emissions data system (ceds). Earth System Science Data, 12(4), 3413-3442.

Meehl, G. A., C. A. Senior, V. Eyring, G. Flato, J.-F. Lamarque, R. J. Stouffer, K. E. Taylor, and M. Schlund, 2020: Context for interpreting equilibrium climate sensitivity and transient climate response from the cmip6 earth system models. Science Advances, 6(26), eaba1981.

Miinalainen, T., H. Kokkola, K. E. Lehtinen, and T. Kühn, 2021: Comparing the radiative forcings of the anthropogenic aerosol emissions from chile and mexico. Journal of Geophysical Research: Atmospheres e2020JD033364.

M.K. Yau, R. R. R., 1996: A Short Course in Cloud Physics. International Series in Natural Philosophy. Butterworth-Heinemann, 3 edition.

Mochida, M., C. Nishita-Hara, H. Furutani, Y. Miyazaki, J. Jung, K. Kawamura, and M. Uematsu, 2011: Hygroscopicity and cloud condensation nucleus activity of marine aerosol particles over the western north pacific. Journal of Geophysical Research: Atmospheres, 116(D6).

Myhre, G., W. Aas, R. Cherian, W. Collins, G. Faluvegi, M. Flanner, P. Forster, Ø. Hodnebrog, Z. Klimont, M. T. Lund, et al., 2017: Multi-model simulations of aerosol and ozone radiative forcing due to anthropogenic emission changes during the period 1990-2015. Atmospheric Chemistry and Physics, 17(4), 2709-2720.

Myhre, G., P. Forster, B. Samset, Ø. Hodnebrog, J. Sillmann, S. Aalbergsjø, T. Andrews, O. Boucher, G. Faluvegi, D. Fläschner, et al., 2017: Pdrmip: A precipitation driver and response model intercomparison project-protocol and preliminary results. Bulletin of the American Meteorological Society, 98(6), 1185-1198.

Myhre, G., B. Samset, M. Schulz, Y. Balkanski, S. Bauer, T. Berntsen, H. Bian, N. Bellouin, M. Chin, T. Diehl, et al., 2012: Radiative forcing of the direct aerosol effect from aerocom phase ii simulations. Atmospheric Chemistry \& Physics Discussions, 12(8).

Myhre, G., D. Shindell, F.-M. Bréon, W. Collins, J. Fuglestvedt, J. Huang, D. Koch, J.-F. Lamarque, D. Lee, B. Mendoza, T. Nakajima, A. Robock, G. Stephens, T. Takemura, and $\mathrm{H}$. Zhang, 2013: Anthropogenic and natural radiative forcing. Cambridge University Press, Cambridge, UK, 659-740.

Navarro, J. A., V. Varma, I. Riipinen, Ø. Seland, A. Kirkevåg, H. Struthers, T. Iversen, H.-C. Hansson, and A. M. Ekman, 2016: Amplification of arctic warming by past air pollution reductions in europe. Nature Geoscience, 9(4), 277-281. 
Neale, R. B., C.-C. Chen, A. Gettelman, P. H. Lauritzen, S. Park, D. L. Williamson, A. J. Conley, R. Garcia, D. Kinnison, J.-F. Lamarque, et al., 2010: Description of the ncar community atmosphere model (cam 5.0). NCAR Tech. Note NCAR/TN-486+ STR, 1(1), 1-12.

Nordling, K., H. Korhonen, P. Räisänen, M. E. Alper, P. Uotila, D. O’Donnell, and J. Merikanto, 2019: Role of climate model dynamics in estimated climate responses to anthropogenic aerosols. Atmospheric Chemistry and Physics, 19(15), 9969-9987.

O’Neill, B. C., C. Tebaldi, D. P. v. Vuuren, V. Eyring, P. Friedlingstein, G. Hurtt, R. Knutti, E. Kriegler, J.-F. Lamarque, J. Lowe, et al., 2016: The scenario model intercomparison project (scenariomip) for cmip6. Geoscientific Model Development, 9(9), 3461-3482.

Paulot, F., D. Paynter, M. Winton, P. Ginoux, M. Zhao, and L. W. Horowitz, 2020: Revisiting the impact of sea salt on climate sensitivity. Geophysical Research Letters, 47(3), e2019GL085601.

Persad, G. G., and K. Caldeira, 2018: Divergent global-scale temperature effects from identical aerosols emitted in different regions. Nature communications, 9(1), 1-9.

Pincus, R., P. M. Forster, and B. Stevens, 2016: The radiative forcing model intercomparison project (rfmip): experimental protocol for cmip6. Geoscientific Model Development, 9(9), 3447-3460.

Pithan, F., and T. Mauritsen, 2014: Arctic amplification dominated by temperature feedbacks in contemporary climate models. Nature Geoscience, 7(3), 181-184.

Provençal, S., P. Kishcha, A. M. da Silva, E. Elhacham, and P. Alpert, 2017: Aod distributions and trends of major aerosol species over a selection of the world's most populated cities based on the 1 st version of nasa's merra aerosol reanalysis. Urban climate, 20, 168-191.

Räisänen, J., 2017: An energy balance perspective on regional co 2-induced temperature changes in cmip5 models. Climate dynamics, 48(9-10), 3441-3454.

Räisänen, J., and J. S. Ylhäisi, 2015: Co 2-induced climate change in northern europe: Cmip2 versus cmip3 versus cmip5. Climate Dynamics, 45(7-8), 1877-1897.

Rao, S., Z. Klimont, S. J. Smith, R. Van Dingenen, F. Dentener, L. Bouwman, K. Riahi, M. Amann, B. L. Bodirsky, D. P. van Vuuren, et al., 2017: Future air pollution in the shared socio-economic pathways. Global Environmental Change, 42, 346-358. 
Read, P., J. Barstow, B. Charnay, S. Chelvaniththilan, P. Irwin, S. Knight, S. Lebonnois, S. Lewis, J. Mendonça, and L. Montabone, 2016: Global energy budgets and 'trenberth diagrams' for the climates of terrestrial and gas giant planets. Quarterly Journal of the Royal Meteorological Society, 142(695), 703-720.

Rogelj, J., P. M. Forster, E. Kriegler, C. J. Smith, and R. Séférian, 2019: Estimating and tracking the remaining carbon budget for stringent climate targets. Nature, 571(7765), 335-342.

Rosenfeld, D., 2000: Suppression of rain and snow by urban and industrial air pollution. Science, 287(5459), 1793-1796.

Rotstayn, L., M. A. Collier, A. Chrastansky, S. Jeffrey, and J.-J. Luo, 2013: Projected effects of declining aerosols in rcp4. 5: unmasking global warming? Atmospheric Chemistry and Physics, 13(21), 10883-10905.

Salzmann, M., H. Weser, and R. Cherian, 2014: Robust response of asian summer monsoon to anthropogenic aerosols in cmip5 models. Journal of Geophysical Research: Atmospheres, 119(19), 11-321.

Samset, B. H., M. T. Lund, M. Bollasina, G. Myhre, and L. Wilcox, 2019: Emerging asian aerosol patterns. Nature Geoscience, 12(8), 582-584.

Samset, B. H., M. Sand, C. Smith, S. Bauer, P. Forster, J. Fuglestvedt, S. Osprey, and C.-F. Schleussner, 2018: Climate impacts from a removal of anthropogenic aerosol emissions. Geophysical Research Letters, 45(2), 1020-1029.

Samset, B. H., C. W. Stjern, E. Andrews, R. A. Kahn, G. Myhre, M. Schulz, and G. L. Schuster, 2018: Aerosol absorption: Progress towards global and regional constraints. Current climate change reports, 4(2), 65-83.

Sarangi, C., V. P. Kanawade, S. N. Tripathi, A. Thomas, and D. Ganguly, 2018: Aerosol-induced intensification of cooling effect of clouds during indian summer monsoon. Nature communications, 9(1), 1-9.

Schmale, J., J. Schneider, G. Ancellet, B. Quennehen, A. Stohl, H. Sodemann, J. F. Burkhart, T. Hamburger, S. R. Arnold, A. Schwarzenboeck, S. Borrmann, and K. S. Law, 2011: Source identification and airborne chemical characterisation of aerosol pollution from long-range transport over greenland during polarcat summer campaign 2008. Atmospheric Chemistry and Physics, 11(19), 10097-10123.

Schmidt, G. A., M. Kelley, L. Nazarenko, R. Ruedy, G. L. Russell, I. Aleinov, M. Bauer, S. E. Bauer, M. K. Bhat, R. Bleck, et al., 2014: Configuration and assessment of the 
giss modele2 contributions to the cmip5 archive. Journal of Advances in Modeling Earth Systems, 6(1), 141-184.

Seinfeld, J. H., and S. N. Pandis, 2016: Atmospheric chemistry and physics: from air pollution to climate change. John Wiley \& Sons.

Soden, B. J., W. D. Collins, and D. R. Feldman, 2018: Reducing uncertainties in climate models. Science, 361(6400), 326-327.

Soden, B. J., I. M. Held, R. Colman, K. M. Shell, J. T. Kiehl, and C. A. Shields, 2008: Quantifying climate feedbacks using radiative kernels. Journal of Climate, 21(14), 3504-3520.

Stevens, B., S. Fiedler, S. Kinne, K. Peters, S. Rast, J. Müsse, S. J. Smith, and T. Mauritsen, 2017: Macv2-sp: A parameterization of anthropogenic aerosol optical properties and an associated twomey effect for use in cmip6. Geoscientific Model Development, 10(1), 433-452.

Stevens, B., M. Giorgetta, M. Esch, T. Mauritsen, T. Crueger, S. Rast, M. Salzmann, H. Schmidt, J. Bader, K. Block, et al., 2013: Atmospheric component of the mpi-m earth system model: Echam6. Journal of Advances in Modeling Earth Systems, 5(2), $146-172$.

Stuecker, M. F., C. M. Bitz, K. C. Armour, C. Proistosescu, S. M. Kang, S.-P. Xie, D. Kim, S. McGregor, W. Zhang, S. Zhao, et al., 2018: Polar amplification dominated by local forcing and feedbacks. Nature Climate Change, 8(12), 1076-1081.

Takemura, T., M. Egashira, K. Matsuzawa, H. Ichijo, R. O'ishi, and A. Abe-Ouchi, 2009: A simulation of the global distribution and radiative forcing of soil dust aerosols at the last glacial maximum. Atmospheric Chemistry \& Physics, 9(9).

Takemura, T., T. Nozawa, S. Emori, T. Y. Nakajima, and T. Nakajima, 2005: Simulation of climate response to aerosol direct and indirect effects with aerosol transport-radiation model. Journal of Geophysical Research: Atmospheres, 110(D2).

Taylor, P. C., M. Cai, A. Hu, J. Meehl, W. Washington, and G. J. Zhang, 2013: A decomposition of feedback contributions to polar warming amplification. Journal of Climate, 26(18), 7023-7043.

Twomey, S., 1959: The nuclei of natural cloud formation part ii: The supersaturation in natural clouds and the variation of cloud droplet concentration. Geofisica pura e applicata, 43(1), 243-249. 
Undorf, S., D. Polson, M. Bollasina, Y. Ming, A. Schurer, and G. Hegerl, 2018: Detectable impact of local and remote anthropogenic aerosols on the 20th century changes of west african and south asian monsoon precipitation. Journal of Geophysical Research: Atmospheres, 123(10), 4871-4889.

Väisänen, O., A. Ruuskanen, A. Ylisirniö, P. Miettinen, H. Portin, L. Hao, A. Leskinen, M. Komppula, S. Romakkaniemi, K. E. Lehtinen, et al., 2016: In-cloud measurements highlight the role of aerosol hygroscopicity in cloud droplet formation. Atmospheric Chemistry and Physics, 16(16), 10385-10398.

Wang, Y., and Y. Huang, 2020: Understanding the atmospheric temperature adjustment to co2 perturbation at the process level. Journal of Climate, 33(3), 787-803.

Watanabe, M., T. Suzuki, R. O'ishi, Y. Komuro, S. Watanabe, S. Emori, T. Takemura, M. Chikira, T. Ogura, M. Sekiguchi, et al., 2010: Improved climate simulation by miroc5: mean states, variability, and climate sensitivity. Journal of Climate, 23(23), 6312-6335.

Webster, P. J., V. O. Magana, T. Palmer, J. Shukla, R. Tomas, M. Yanai, and T. Yasunari, 1998: Monsoons: Processes, predictability, and the prospects for prediction. Journal of Geophysical Research: Oceans, 103(C7), 14451-14510.

Westervelt, D., L. Horowitz, V. Naik, J.-C. Golaz, and D. Mauzerall, 2015: Radiative forcing and climate response to projected 21st century aerosol decreases. Atmospheric Chemistry and Physics, 15(22), 12681-12703.

Westervelt, D. M., N. R. Mascioli, A. M. Fiore, A. J. Conley, J.-F. Lamarque, D. T. Shindell, G. Faluvegi, M. Previdi, G. Correa, and L. W. Horowitz, 2020: Local and remote mean and extreme temperature response to regional aerosol emissions reductions. Atmospheric Chemistry and Physics, 20(5), 3009-3027.

Wilcox, L., E. Highwood, B. Booth, and K. Carslaw, 2015: Quantifying sources of inter-model diversity in the cloud albedo effect. Geophysical Research Letters, 42(5), $1568-1575$.

Wilcox, L. J., E. J. Highwood, and N. J. Dunstone, 2013: The influence of anthropogenic aerosol on multi-decadal variations of historical global climate. Environmental Research Letters, 8(2), 024033.

Wilcox, L. J., Z. Liu, B. H. Samset, E. Hawkins, M. T. Lund, K. Nordling, S. Undorf, M. Bollasina, A. M. Ekman, S. Krishnan, et al., 2020: Accelerated increases in global and asian summer monsoon precipitation from future aerosol reductions. Atmospheric Chemistry and Physics, 20(20), 11955-11977. 
Williams, J., M. d. Reus, R. Krejci, H. Fischer, and J. Ström, 2002: Application of the variability-size relationship to atmospheric aerosol studies: estimating aerosol lifetimes and ages. Atmospheric Chemistry and Physics, 2(2), 133-145.

Winiger, P., A. Andersson, S. Eckhardt, A. Stohl, and Ö. Gustafsson, 2016: The sources of atmospheric black carbon at a european gateway to the arctic. Nature communications, 7(1), 1-8.

Winiger, P., A. Andersson, S. Eckhardt, A. Stohl, I. P. Semiletov, O. V. Dudarev, A. Charkin, N. Shakhova, Z. Klimont, C. Heyes, et al., 2017: Siberian arctic black carbon sources constrained by model and observation. Proceedings of the National Academy of Sciences, 114(7), E1054-E1061.

Yang, Y., S. Lou, H. Wang, P. Wang, and H. Liao, 2020: Trends and source apportionment of aerosols in europe during 1980-2018. Atmospheric Chemistry and Physics, 20(4), 2579-2590.

Yu, H., S. Liu, and R. Dickinson, 2002: Radiative effects of aerosols on the evolution of the atmospheric boundary layer. Journal of Geophysical Research: Atmospheres, 107(D12), AAC-3.

Zelinka, M. D., T. A. Myers, D. T. McCoy, S. Po-Chedley, P. M. Caldwell, P. Ceppi, S. A. Klein, and K. E. Taylor, 2020: Causes of higher climate sensitivity in cmip6 models. Geophysical Research Letters, 47(1), e2019GL085782.

Zhao, A., D. S. Stevenson, and M. A. Bollasina, 2019: Climate forcing and response to greenhouse gases, aerosols, and ozone in cesm1. Journal of Geophysical Research: Atmospheres, 124(24), 13876-13894.

Zhao, M., J.-C. Golaz, I. M. Held, V. Ramaswamy, S.-J. Lin, Y. Ming, P. Ginoux, B. Wyman, L. Donner, D. Paynter, et al., 2016: Uncertainty in model climate sensitivity traced to representations of cumulus precipitation microphysics. Journal of Climate, 29(2), 543-560. 

(C) 2019 Atmos. Chem. Phys.,

Reprinted, with permission, from

The ACP, 19, 9969-9987,

doi:10.5194/acp-19-9969-2019 



\title{
Role of climate model dynamics in estimated climate responses to anthropogenic aerosols
}

\author{
Kalle Nordling $^{1}$, Hannele Korhonen ${ }^{1}$, Petri Räisänen ${ }^{1}$, Muzaffer Ege Alper ${ }^{1}$, Petteri Uotila ${ }^{2}$, Declan O’Donnell ${ }^{1}$, and \\ Joonas Merikanto ${ }^{1}$ \\ ${ }^{1}$ Finnish Meteorological Institute, Helsinki, Finland \\ ${ }^{2}$ INAR/Physics, University of Helsinki, Helsinki, Finland
}

Correspondence: Kalle Nordling (kalle.nordling@fmi.fi)

Received: 21 December 2018 - Discussion started: 14 January 2019

Revised: 5 June 2019 - Accepted: 6 July 2019 - Published: 9 August 2019

\begin{abstract}
Significant discrepancies remain in estimates of climate impacts of anthropogenic aerosols between different general circulation models (GCMs). Here, we demonstrate that eliminating differences in model aerosol or radiative forcing fields results in close agreement in simulated globally averaged temperature and precipitation responses in the studied GCMs. However, it does not erase the differences in regional responses. We carry out experiments of equilibrium climate response to modern-day anthropogenic aerosols using an identical representation of anthropogenic aerosol optical properties and the first indirect effect of aerosols, MACv2-SP (a simple plume implementation of the second version of the Max Planck Institute Aerosol CLimatology), in two independent climate models (NorESM, Norwegian Earth System Model, and ECHAM6). We find consistent global average temperature responses of -0.48 $( \pm 0.02)$ and $-0.50( \pm 0.03) \mathrm{K}$ and precipitation responses of $-1.69( \pm 0.04) \%$ and $-1.79( \pm 0.05) \%$ in NorESM1 and ECHAM6, respectively, compared to modern-day equilibrium climate without anthropogenic aerosols. However, significant differences remain between the two GCMs' regional temperature responses around the Arctic circle and the Equator and precipitation responses in the tropics. The scatter in the simulated globally averaged responses is small in magnitude when compared against literature data from modern GCMs using model intrinsic aerosols but same aerosol emissions $-(0.5-1.1) \mathrm{K}$ and $-(1.5-3.1) \%$ for temperature and precipitation, respectively). The Pearson correlation of regional temperature (precipitation) response in these literature model experiments with intrinsic aerosols is 0.79 (0.34). The corresponding correlation coefficient for NorESM1 and
\end{abstract}

ECHAM6 runs with identical aerosols is $0.78(0.41)$. The lack of improvement in correlation coefficients between models with identical aerosols and models with intrinsic aerosols implies that the spatial distribution of regional climate responses is not improved via homogenizing the aerosol descriptions in the models. Rather, differences in the atmospheric dynamic and snow/sea ice cover responses dominate the differences in regional climate responses. Hence, even if we would have perfect aerosol descriptions inside the global climate models, uncertainty arising from the differences in circulation responses between the models would likely still result in a significant uncertainty in regional climate responses.

\section{Introduction}

Making reliable predictions on future changes in regional climates is crucial for estimating how climate change will impact people and societies (Hawkins et al., 2016), but there are still large uncertainties related to climate change predictions on regional scales (Giorgi and Francisco, 2000; Feser et al., 2011). Anthropogenic aerosol particles can be an important driver for regional climate change due to the nearinstantaneous response of local aerosol concentrations to changes in emissions, their direct radiative properties and their ability to modify cloud microphysical processes. However, reliable implementation of aerosol effects into global climate models has been challenging. Several aerosol processes are still not well understood (Boucher et al., 2013), and there exists an enormous scale difference between the

Published by Copernicus Publications on behalf of the European Geosciences Union. 
microphysical processes and the resolution of global-scale models (Carslaw et al., 2013).

Varying descriptions of aerosols and aerosol-cloud interactions cause a wide spread in aerosol radiative forcing and climate impacts between different general circulation models (GCMs) (Wilcox et al., 2015). Shindell et al. (2015) compared historical Coupled Model Intercomparison Project phase 5 (CMIP5) runs with and without anthropogenic forcing from aerosols, ozone and land use. The forcing showed a very large spatial variation with globally averaged values that ranged between 0.15 and $-1.44 \mathrm{Wm}^{-2}$ (the aerosol contribution being between -0.29 and $\left.-1.44 \mathrm{Wm}^{-2}\right)$. The combined changes in aerosol, ozone and land use produced globally averaged transient temperature responses between 0.00 and $-1.33 \mathrm{~K}$ over the 20 th century, with the spatial pattern of the temperature response varying significantly between the models. Overall, the inclusion of aerosols in CMIP5 models nevertheless improved the historical temperature trends compared to observations. This applied particularly to models including sophisticated parameterizations for aerosol cloud droplet activation (Ekman, 2014).

Besides reducing the global temperature, anthropogenic aerosols are also known to reduce global precipitation (Ramanathan, 2005) and to significantly modify the Asian monsoon (Bollasina et al., 2011; Salzmann et al., 2014). Wang (2015) demonstrated that among CMIP5 models the changes in anthropogenic aerosols dominated the total precipitation changes from the pre-industrial era to the present day. Most of this change was caused by the remote impact of aerosols rather than by direct effects on local cloud processes and cloud optical depth in all but heavily aerosol-loaded regions, such as in the Indian monsoon region. Also, for precipitation changes, an improved representation of aerosol-cloud interactions was found to be the key factor in reproducing consistent distributions of past precipitation change.

Improvements in model aerosol descriptions have not succeeded to remove the large uncertainty in aerosol climate effects. After CMIP5, the most representative multi-model results on aerosol climate impacts have been provided by Samset et al. (2018). They compared the equilibrium climate responses for complete removals of model intrinsic anthropogenic aerosols among four state-of-the-art fully coupled climate models, with aerosol emissions from CMIP5 (Lamarque et al., 2010). In their study, removing the aerosols produced global-mean temperature increases between 0.5 and $1.1 \mathrm{~K}$ and precipitation increases between $1.5 \%$ and $3.1 \%$. In another recent study, Kasoar et al. (2016) reduced anthropogenic $\mathrm{SO}_{2}$ emissions from China in three independent climate models. There, identical emission reductions lead to simulated changes in aerosol optical depth and shortwave radiative flux over China that varied by up to a factor of 6 between the models. The three models also exhibited large differences in their global and regional temperature responses. However, it is unclear to which degree the existing spread in aerosol climate impacts among current climate models re- sults from differences in modeled aerosols or from differences in model dynamical responses to aerosols. Only standardized aerosol perturbations across different models can entangle these sources of uncertainties in aerosol climate effects (Stier et al., 2013).

Here, we explore how robust the aerosol climate response would be in modern GCMs if the anthropogenic aerosols and their cloud interactions could be modeled exactly. To assess this question, we carry out long equilibrium climate simulations with fixed greenhouse gas concentrations and prescribed aerosol fields using the MACv2-SP (a simple plume implementation of the second version of the Max Planck Institute Aerosol CLimatology) aerosol description (Stevens et al., 2017) in two modern GCMs, NorESM1 (Norwegian Earth System Model) and ECHAM6. MACv2-SP is partly based on observational data and provides a simple representation of global aerosol optical properties. It also includes a simple empirical fit for aerosol-cloud-albedo effects. These experiments allow us to single out the contribution of climate model dynamics to the intermodel differences in the response to anthropogenic aerosols. We will compare our results against the dataset by Samset et al. (2018) to investigate the robustness of global and regional climate responses in modern climate models using interactive or prescribed aerosols.

\section{Methods}

\subsection{Applied climate models and setup}

We carry out modern-day equilibrium climate simulations with two independent climate models, ECHAM6.1 and NorESM1. ECHAM6.1 (Stevens et al., 2013) is the sixth generation of the ECHAM general circulation model developed in the Max Planck Institute with 47 sigma hybrid vertical levels, with the model top at $0.01 \mathrm{hPa}$ and a horizontal resolution of $1.9^{\circ} \times 1.9^{\circ}$. The original ECHAM model branched from an early version of the European Centre for MediumRange Weather Forecasts (ECMWF) model for climate studies. NorESM1 is the Norwegian Earth system model with 26 sigma hybrid vertical levels (the highest model level at $2.9 \mathrm{hPa}$ ) and $1.9^{\circ} \times 2.5^{\circ}$ horizontal resolution (Bentsen et al., 2013; Iversen et al., 2013; Kirkevåg et al., 2013). NorESM1 is based on the Community Climate System Model version 4 (CCSM4) operated at the National Center for Atmospheric Research (NCAR). Thus, the two models applied in our study do not share a common development history. Here, both models were run with identical fixed modern-day greenhouse gas concentrations. Oceans were simulated with the intrinsic slab ocean configurations of the models. This idealization removes the effect of natural and aerosol-induced variations in ocean circulation and restricts our study to the response in atmospheric circulation, oceanic heat exchange and sea ice dynamics only. 


\subsection{Standardized aerosol representation}

MACv2-SP is a standardized representation of anthropogenic aerosol radiative effects, accounting for the direct radiative as well as the cloud albedo effect of anthropogenic aerosol (Stevens et al., 2017). However, the cloud lifetime effect is not taken into account. Anthropogenic aerosols are represented by nine 3-D time-varying Gaussian plumes defining the aerosol optical depth, single scattering albedo and asymmetry parameter. Four of these plumes represent aerosol emissions from biomass burning and the other five are associated with industrial emissions. The industrial plumes originate from Europe, North America, east Asia, south Asia and Australia, and the biomass plumes from north Africa, South America, south central Africa and the Maritime Continent (Fig. 1 and Table 1 in Stevens et al., 2017). The plumes differ in their annual cycle and optical properties, and have a realistic horizontal and vertical structure that represents the transports of aerosols with prevailing winds. The aerosol properties are based on aerosol climatology by Kinne et al. (2013), derived from groundbased Sun photometer networks (AERONET) merged onto background maps from global models participating in the Aerosol Model Intercomparison Project (AeroCom). The cloud albedo effect in MACv2-SP is parameterized by modifying the model-intrinsic natural cloud droplet number concentration (CDNC) via a relation based on the total change in aerosol optical depth (AOD). This parametrization is derived from Moderate Resolution Imaging Spectroradiometer (MODIS) data. MACv2-SP allows for a simple and observation-based representation of the changes in aerosol optical properties and cloud droplet number concentrations due to anthropogenic aerosols.

\subsection{Model experiments and analysis}

Sets of 100-year equilibrium climate runs for the year 2005 were conducted with both models, with the last 60 years used for the analysis. (1) The control run (CTRL) included only natural aerosols and was constructed from two runs for each model with small initial condition perturbations. (2) The MACSP run included both natural and anthropogenic aerosols for the year 2005. In addition, for NorESM1, a third run (EF) was carried out. This run employed the timevarying 3-D aerosol radiative forcing field computed from the ECHAM6's MACSP run. A more detailed description of the implementation is given in the Appendix A. A summary of the runs is given in Table 1.

Based on these runs, the following three experiments were defined to estimate the effect of anthropogenic aerosols: ECHAM6-MACSP (the difference between the MACSP and CTRL runs for ECHAM6), NorESM1-MACSP (MACSP minus CTRL for NorESM1) and NorESM1-EF (EF minus CTRL for NorESM1). The analysis of the results was based on monthly-mean values of data and focused on the effects
Table 1. Summary of the performed model runs.

\begin{tabular}{lll}
\hline Runs & Forcing & Models \\
\hline CTRL & Natural aerosols & ECHAM6, NorESM1 \\
MACSP & MACv2-SP and natural aerosols & ECHAM6, NorESM1 \\
EF & Forcing field from ECHAM6 & NorESM1 \\
\hline
\end{tabular}

of MACv2-SP aerosols on near-surface temperature, precipitation, surface albedo and total cloud cover. The statistical significance of the responses was evaluated using a Student's $t$ test with an auto-correlation correction according to Zwiers and von Storch (1995). The response uncertainties in global-mean values were estimated by the standard error of means taking into account lag-1 auto-correlation according to Zwiers and von Storch (1995). The instantaneous radiative forcing was calculated using double radiation calls with and without MACv2-SP aerosols during the slab ocean runs.

\section{Results}

\subsection{Aerosol radiative forcing}

The total radiative forcing from the MACv2-SP anthropogenic aerosol description was found to be very similar for the two models (see Fig. 1). For ECHAM6, the MACv2SP aerosol scheme produces a $-0.64 \mathrm{Wm}^{-2}$ global average total shortwave radiative forcing at the top of the atmosphere (TOA) for the year 2005 , with $-0.35 \mathrm{Wm}^{-2}$ arising from direct and $-0.29 \mathrm{Wm}^{-2}$ from indirect radiative forcing. For NorESM1, the same aerosol scheme produces a slightly higher global radiative forcing of $-0.69 \mathrm{Wm}^{-2}$ at TOA, with $-0.36 \mathrm{Wm}^{-2}$ direct and $-0.33 \mathrm{Wm}^{-2}$ indirect radiative forcing. Figure $\mathrm{C} 1$ shows the maps of aerosol direct and indirect radiative forcing in the two models as calculated here. The largest difference in the total forcing was found over southeast Asia (up to $3.20 \mathrm{Wm}^{-2}$ ), where also the largest absolute forcing was found in both models. Fiedler et al. (2019) have calculated both the MACv2-SP effective radiative forcing and the instantaneous radiative forcing using double radiation calls with fixed sea surface temperature for the two climate models used here. They showed that with fixed sea surface temperature the MACv2-SP aerosols produce an instantaneous radiative forcing of -0.60 and $-0.68 \mathrm{Wm}^{-2}$ in ECHAM6 and NorESM1, respectively. The correlation coefficient for the regional total forcing in the two models due to MACv2-SP is 0.97 , and 0.90 for direct and 0.89 indirect forcing only. Thus, the regional differences in direct and indirect forcing somewhat compensate for each other.

We used a Gaussian process emulation technique (O'Hagan, 2006) to assess the causes for the regional differences in aerosol radiative forcing (see Appendix B for details). Our analysis showed that differences in cloud cover and surface albedo can explain nearly all of the variance 

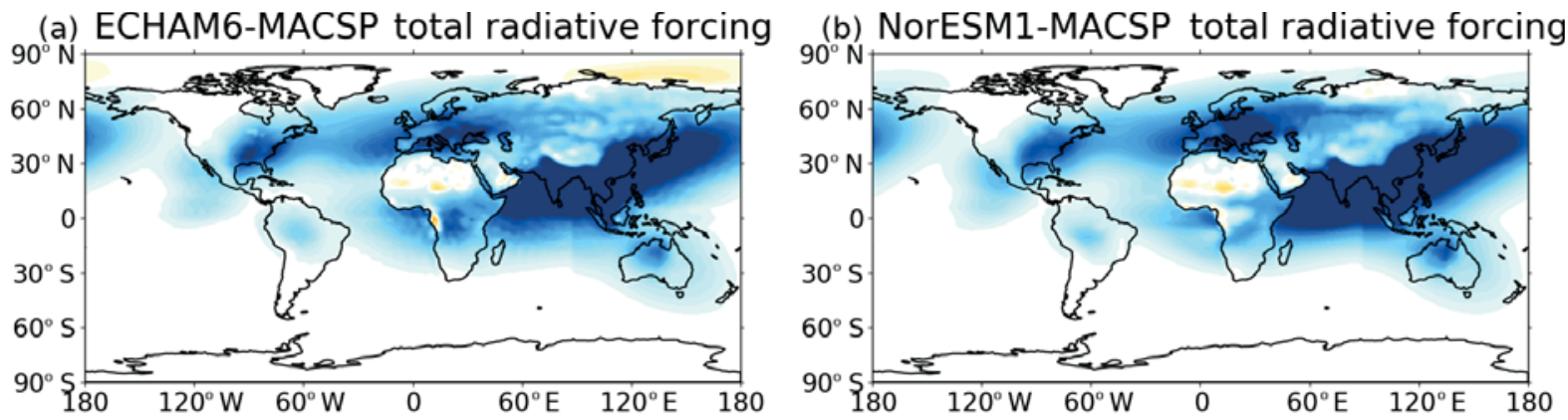

(c) Difference in total radiative forcing: ECHAM6-NorESM1
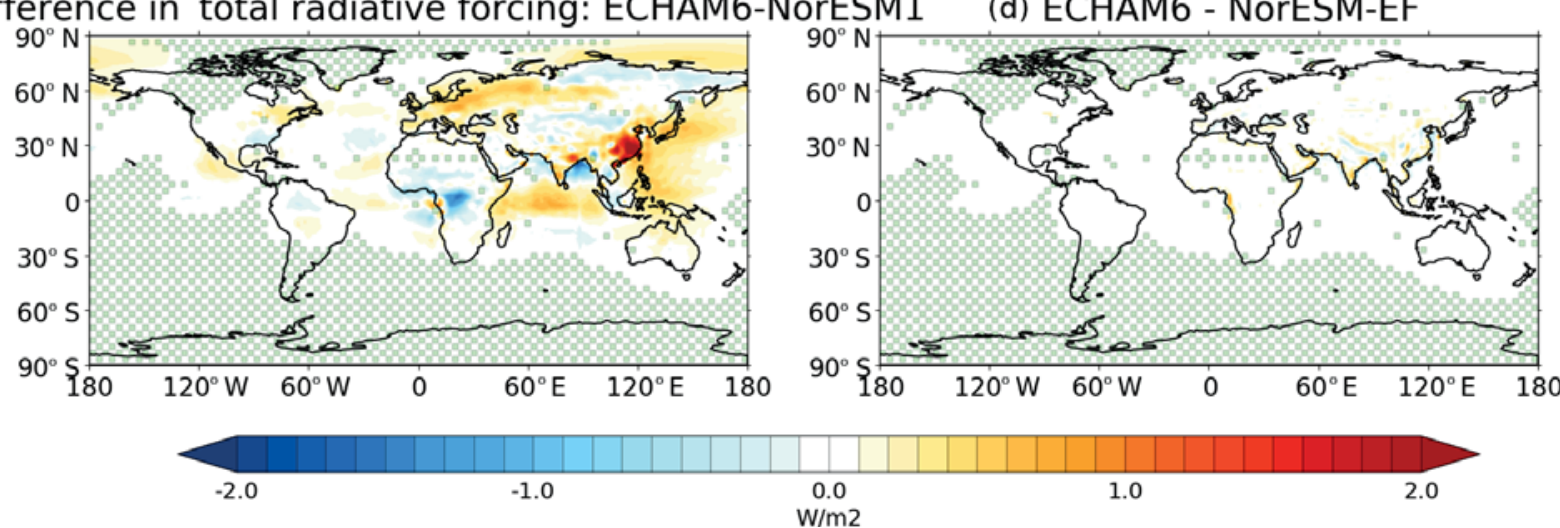

Figure 1. The total radiative forcing at top of the atmosphere produced by MACv2-SP aerosols. Panel (a) shows the forcing in ECHAM6MACSP experiment and (b) in NorESM1-MACSP experiment. Panels (c) and (d) show the difference in forcing between the two models and difference between ECHAM-MACSP and NorESM1-EF runs. Small green circles mask the areas where results are not statistically significant at the $p<0.05$ level.

in the difference in total instantaneous shortwave radiative forcing between ECHAM6 and NorESM1. Our sensitivity analysis reveals that in the regions with the largest radiative forcing (close to the center of the MACv2-SP plumes) the difference in model cloud cover dominates the difference in model shortwave forcing. In contrast, in regions with low aerosol radiative forcing, the differences in surface albedo dominate the differences in forcing. We note that these results apply only to fixed aerosol fields produced by the MACv2-SP representation. Previous research shows that the aerosol radiative forcing can also depend on the meteorology (surface winds and precipitation) produced by the models, partly driven by the natural variability of the climate system (Fiedler et al., 2019).

\subsection{Climate response to the addition of anthropogenic aerosols}

\subsubsection{Temperature}

We obtain a robust global temperature response of $-0.5 \mathrm{~K}$ due to the inclusion of MACv2-SP anthropogenic aerosols in both models. For the ECHAM6-MACSP experiment, the global-mean near-surface temperature response is -0.50 $( \pm 0.03) \mathrm{K}$, with regional values ranging from +0.30 to $-2.10 \mathrm{~K}$. For the NorESM1-MACSP experiment, the globalmean value is $-0.48( \pm 0.02) \mathrm{K}$ and the regional values range between +0.39 and $-2.28 \mathrm{~K}$.

Figure 2 shows the regional temperature response to the inclusion of anthropogenic MACv2-SP aerosols. The spatial correlation between ECHAM6-MACSP and NorESM1MACSP experiments is 0.81 for full experiments with $60+$ 120 years of MACSP and CTRL runs in both models. The largest cooling in ECHAM6 is located in southeast Asia, whereas in NorESM1 the largest cooling is found near the Russian Far East and north of Japan, with a second minimum over the Greenland Sea. Small positive temperature responses are found close to the Antarctic coast in both models, but these temperature responses are not statistically significant and are related to natural variations in sea ice. We found some significant correlation between the regional aerosol forcing and regional temperature response in both models: 0.39 in ECHAM6 and 0.29 in NorESM1, respectively. Among the CMIP5 model considered in Shindell et al. (2015), the multi-model mean regional correlation between 
the combined effective aerosol and ozone forcing and temperature response was slightly negative $(-0.1)$, varying between negative values in some models and positive values among others.

Figure $3 \mathrm{a}$ shows the zonal-mean temperature responses obtained from ECHAM6-MACSP and NorESM1-MACSP experiments. These experiments show a moderate cooling due to anthropogenic aerosols across the Southern Hemisphere latitudes, whereas in the Northern Hemisphere the cooling response clearly strengthens towards the high latitudes. The modeled regional temperature responses between ECHAM6 and NorESM1 simulations disagree the most in mid- and high-latitude regions, as seen in Fig. 2c. In highlatitude regions, temperature differences are associated with surface albedo responses (snow/sea ice) between the models (see Fig. C2). Changes in surface albedo are known to amplify changes in Arctic temperatures (albedo feedback). Hence, differences in snow and sea ice responses may partly explain the difference in temperature responses in the high latitudes. This feedback, together with ocean circulation feedback, also dominates at high latitudes the regional differences in temperature responses to homogeneous greenhouse gas forcing among different climate models (Shindell et al., 2015).

\subsubsection{Precipitation}

The inclusion of anthropogenic aerosols results in a similar global reduction of precipitation in all experiments, with ECHAM6-MACSP showing a change of $-1.79 \pm 0.05 \%$ and NorESM1-MACSP showing a change of $-1.69 \pm 0.04 \%$ in annual precipitation (Table 2). The regional changes of the precipitation patterns are shown in Fig. 4. The spatial correlation between the precipitation responses in the full ECHAM6-MACSP and NorESM1-MACSP experiments is 0.47 , which is much lower than the corresponding correlation for temperature. In addition, while the temperature responses are negative almost globally, both positive and negative responses occur for precipitation, with relatively sharp edges between regions with different signs of changes. While similar large-scale features of precipitation changes can be seen in both models, their dislocation leads to a weaker regional correlation than for the temperature response. In both models, the relative changes in the convective precipitation are larger than the relative changes in large-scale precipitation. Also consistently across the two models, the seasonal response in the total precipitation is similar, with the largest changes in June-July-August (see Table C1). Both models consistently show an overall drying of the Northern Hemisphere, with some statistically significant regional increases in precipitation over northwest Africa.

Both models show a maximum reduction in total precipitation around $15-20^{\circ} \mathrm{N}$ and a maximum increase around 10 $15^{\circ} \mathrm{S}$, associated with an asymmetric response in Hadley circulation across the Equator (see Figs. $3 b$ and 4). Changes
Table 2. Summary of modern-day global-mean change of temperature and precipitation. Standard errors of means are shown in brackets.

\begin{tabular}{lrr}
\hline & Near-surface temperature & Precipitation $(\%)$ \\
\hline ECHAM6-MACSP & $-0.50( \pm 0.03)$ & $-1.79( \pm 0.05)$ \\
NorESM1-MACSP & $-0.48( \pm 0.02)$ & $-1.69( \pm 0.04)$ \\
NorESM-EF & $-0.49( \pm 0.01)$ & $-1.82( \pm 0.04)$ \\
\hline
\end{tabular}

in precipitation in the tropics are also related to changes in vertical motion in the same region (see Fig. C4). This is suggestive of a southward shift of the Intertropical Convergence Zone (ITCZ) associated with a change in hemispheric temperature gradient (Broccoli et al., 2006). The inclusion of anthropogenic aerosols results in decreased precipitation in the South Asian monsoon region (defined here as the land region over $5-25^{\circ} \mathrm{N}, 65-110^{\circ} \mathrm{E}$ ) (Fig. 3). In June-August, the monsoon precipitation decreased by $12.8 \%$ in the ECHAM6MACSP and $15.3 \%$ in the NorESM1-MACSP experiments. Reduction of monsoon precipitation due to the anthropogenic aerosols has also been reported in several previous studies (Ganguly et al., 2012; Li et al., 2018b; Polson et al., 2014; Bollasina et al., 2011). In contrast with the seasonal cycle in temperature response, the largest precipitation response occurs in Northern Hemisphere summer during the Asian monsoon season. The two models show a different response over the West African monsoon region $\left(5^{\circ} \mathrm{S}-25^{\circ} \mathrm{N}, 20^{\circ} \mathrm{W}-\right.$ $20^{\circ} \mathrm{E}$ ), with the NorESM1-MACSP experiment showing a statistically significant reduction in precipitation of $-5.3 \%$, while the ECHAM6-MACSP experiment does not show a significant change $(-1.8 \%)$. In the vicinity of the Australian continent, the ECHAM6-MACSP experiment shows an area of increased precipitation extending from the Indian Ocean to western Australia, while in the NorESM1-MACSP experiment, the increase is located entirely over the Indian Ocean.

There appear to be several causes for the differences in the precipitation response between the two models. For instance, there is a relationship between the difference of the regional precipitation response and the difference in vertical velocity response (correlation coefficient 0.44 between Figs. $4 \mathrm{c}$ and $\mathrm{C} 4 \mathrm{c}$ ). However, it cannot be concluded that change in precipitation is caused by the change in vertical velocity. Probably, both the changes in vertical velocity and precipitation are related to changes in circulation. Also the difference in the initial equilibrium state of precipitation patterns correlates weakly with the difference in the precipitation response (correlation coefficient 0.23 ). Furthermore, differences in the cloud cover responses (see Fig. C3) are also related to differences in precipitation responses (correlation coefficient 0.32 ). The vertical velocity correlates also with the total cloud cover response (correlation coefficient 0.41 ). 
(a) ECHAM6-MACSP temperature response
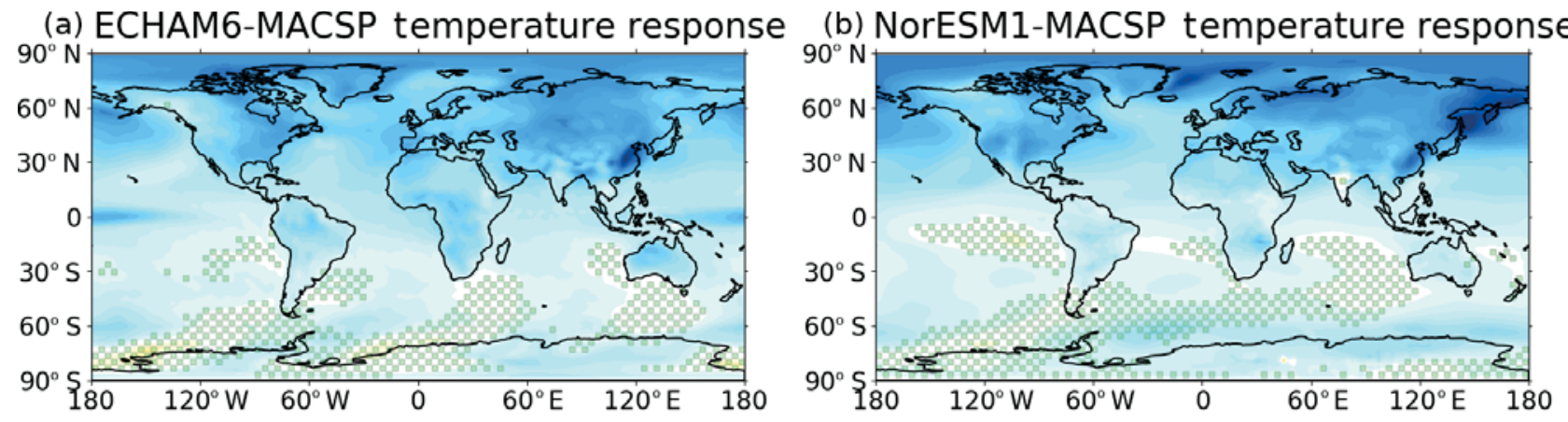

(c) Difference in ECHAM6-NorESM1

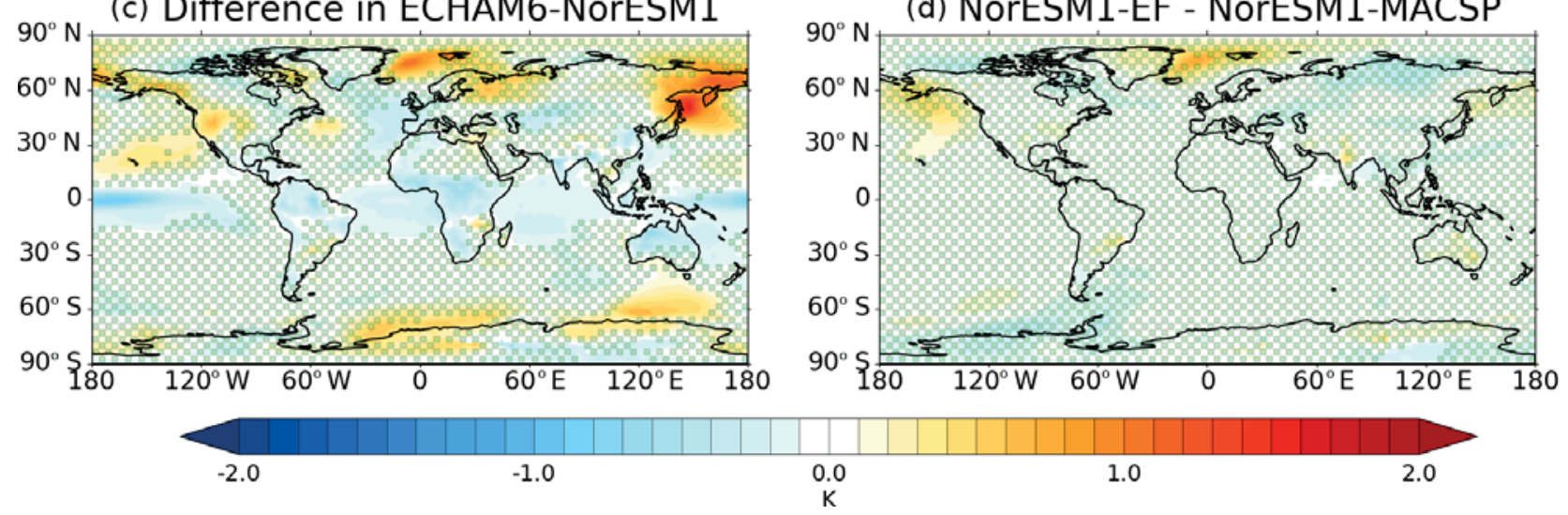

Figure 2. Near-surface temperature response to the addition of anthropogenic (MACv2-SP) aerosols. Panel (a) shows the response for ECHAM6-MACSP experiment and (b) for NorESM1-MACSP experiment. Panels (c) and (d) show the difference in the responses between the two models and difference between NorESM1-MACSP and NorESM1-EF. Small green circles mask the areas where results are not statistically significant at the $p<0.05$ level.
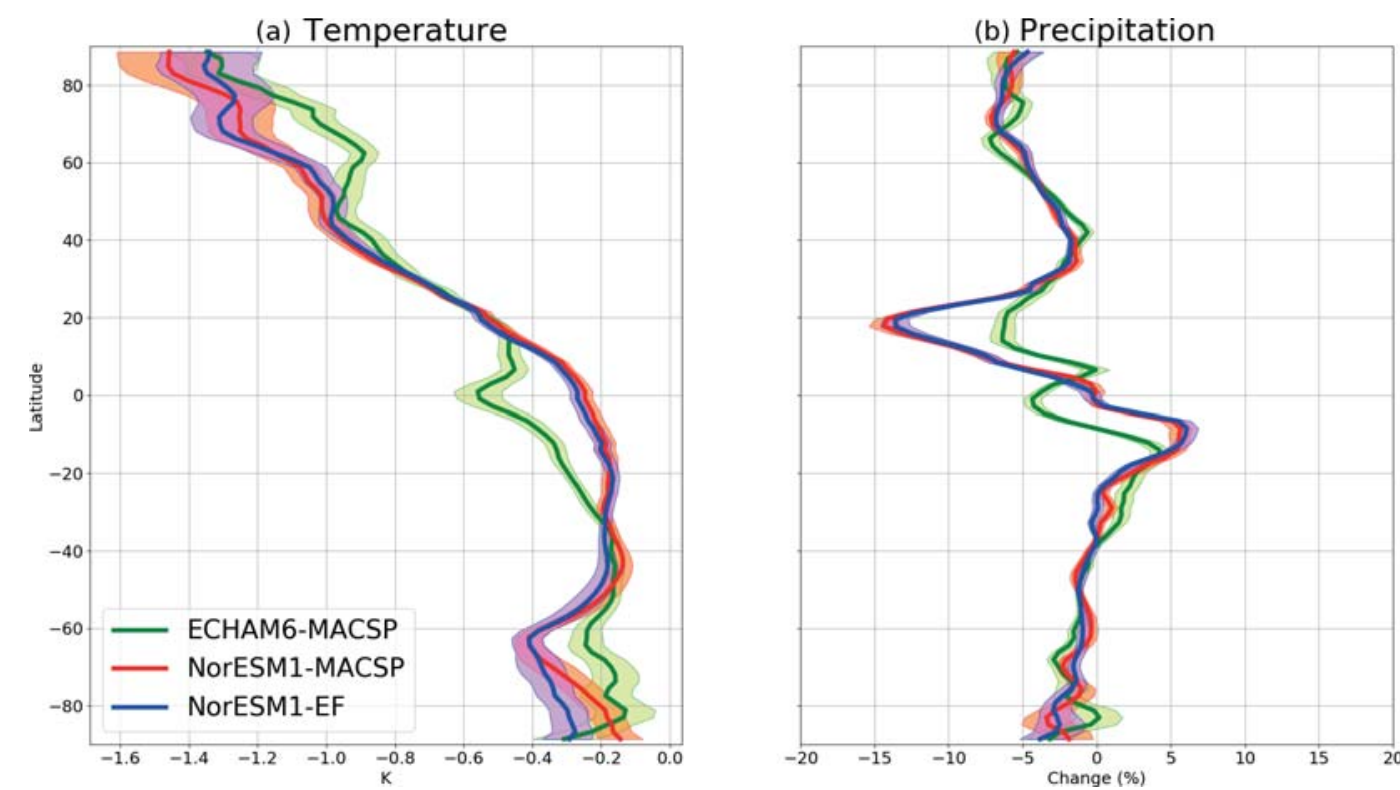

Figure 3. Impact of MACSP anthropogenic aerosols on zonal-mean temperature (K) and precipitation (\%) in ECHAM6-MACSP, NorESM1MACSP and NorESM1-EF experiments. The shaded area shows the standard error of the mean as a function of latitude. 
(a) ECHAM6-MACSP precipitation response

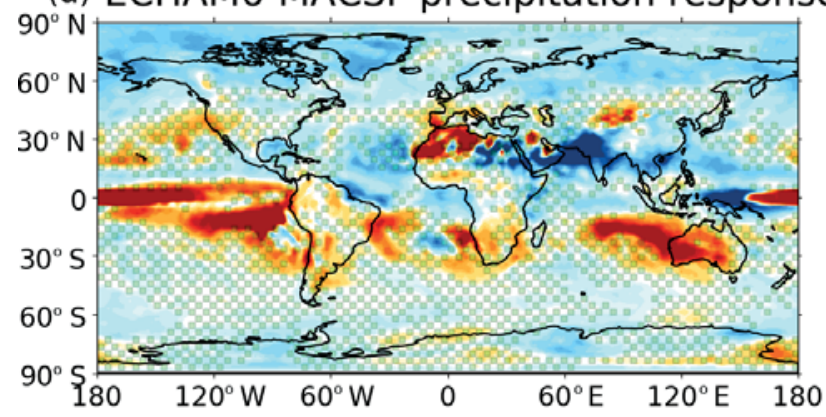

(c) Difference in ECHAM6-NorESM1

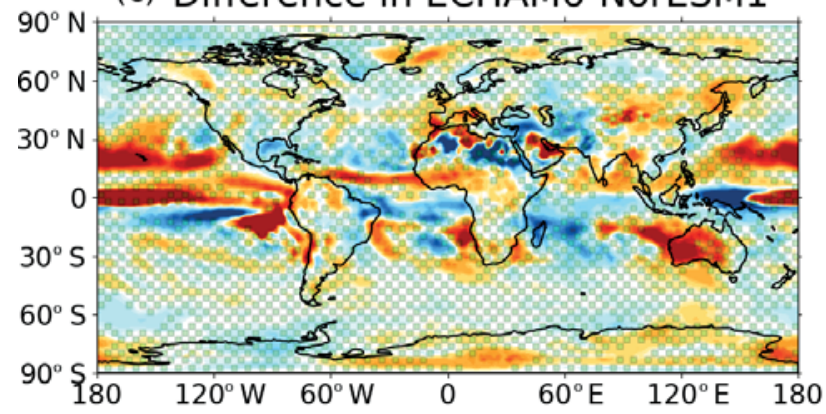

(b) NorESM1-MACSP precipitation response

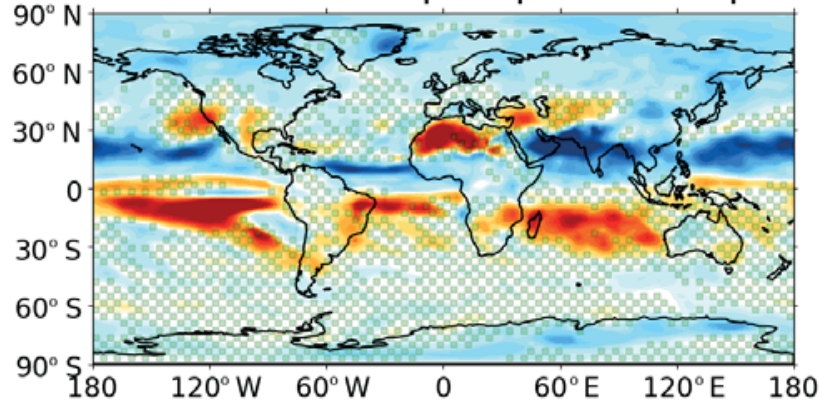

(d) NorESM1-EF - NorESM1-MACSP

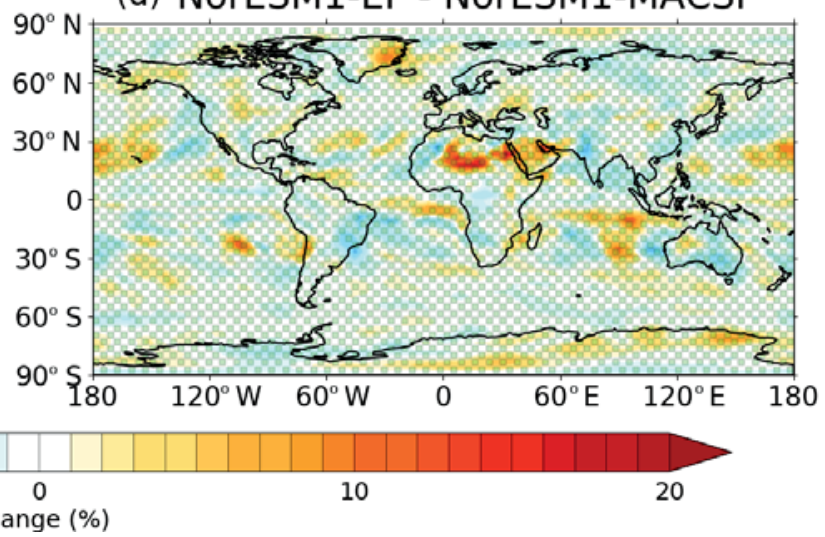

Figure 4. Panel (a) shows the ECHAM6-MACSP experiment precipitation response to adding MACv2-SP aerosols and (b) shows the same for the NorESM1-MACSP experiment. Panels (c) and (d) show the intermodel difference in precipitation response and difference between NorESM1-MACSP and NorESM1-EF. The green dots mark the regions where the MACv2-SP aerosols do not have a statistically significant impact at the $p<0.05$ level.

\subsubsection{Comparison between the NorESM1-MACSP and NorESM1-EF experiments}

We now briefly discuss the differences between the NorESM1-MACSP and NorESM1-EF experiments. As noted in Sect. 2.3, the difference between these experiments is that in NorESM1-MACSP, the radiative forcing due to the MACv2-SP aerosols is computed using NorESM1's own meteorology and own radiation scheme, while in NorESM1EF, forcing from ECHAM6's MACSP run is applied. The forcing results are shown in Fig. 1d. The minor differences seen in Fig. 1d are related to interpolating the radiative forcing between ECHAM6 and NorESM1 horizontal grids. The general finding here is that the results for these two experiments are very similar. The global-mean temperature response is $-0.48( \pm 0.02) \mathrm{K}$ for NorESM1-MACSP and $-0.49( \pm 0.01) \mathrm{K}$ for NorESM1-EF, while the global-mean precipitation responses are $-1.69( \pm 0.04) \%$ and -1.82 $( \pm 0.04) \%$. Also, the zonal-mean and regional temperature and precipitation responses in NorESM1-MACSP and NorESM1-EF are very similar (Figs. 2d, 3 and 4d). The spatial correlation in response between the full NorESM1MACSP and NorESM1-EF experiments is as high as 0.97 for temperature and 0.95 for precipitation, which are much higher than the correlations between NorESM1-MACSP and ECHAM6-MACSP responses (0.81 and 0.47). Indeed, with the exception of the global-mean precipitation response, for which the ECHAM6-MACSP value $(-1.79 \pm 0.05 \%)$ falls between NorESM1-MACSP and NorESM1-EF, the responses in the two NorESM1 experiments are closer to each other than the ECHAM6-MACSP response. Therefore, it can be concluded that the differences in the effects of MACv2SP aerosols between ECHAM6 and NorESM1 are mainly related to differences in the model circulation responses, not to the differences in the aerosol forcing fields.

\subsection{Comparison to models with interactive aerosols}

Finally, we compare the obtained equilibrium temperature and precipitation responses with prescribed MACv2-SP aerosols in ECHAM6 and NorESM1 against those equilibrium climate responses from four fully coupled climate models (CESM1, GISS, HadGEMS2 and NorESM1) with intrinsic aerosol schemes but the same aerosol emissions, reported by Samset et al. (2018). In the four models considered by Samset et al. (2018), the global average temperature 
responses were $-(0.5,0.5,1.1$ and 0.6$) \mathrm{K}$, and precipitation responses were $-(1.5 \%, 1.8 \%, 2.6 \%$ and $3.1 \%)$, respectively. We obtain similar temperature responses of $-(0.48-$ $0.50) \mathrm{K}$ and precipitation responses of $-(1.69-1.82) \%$ using the prescribed MACv2-SP aerosol description.

Tables 3 and 4 show the correlation coefficients for regional climate responses between all experiments in our datasets and the Samset et al. (2018) datasets. The correlations are calculated for equilibrium climate runs with equal time averaging over 50 years with and without anthropogenic aerosols both for our datasets and the Samset et al. (2018) datasets. Note that these coefficients do not depend on the magnitude of the average responses in the models but only on the relative regional distributions of the responses. Perhaps surprisingly, the average correlation coefficient for regional temperature response between interactive aerosol models (i.e., the Samset et al., 2018 models), 0.79, is almost identical to the correlation between our prescribed aerosol models (0.78). Also, the average correlation coefficient between experiments using interactive aerosols and a fully coupled ocean model (Samset et al., 2018) and experiments using prescribed aerosols and a slab ocean model (our models) is 0.76 , nearly the same as for the fully coupled interactive aerosol models only. The similar regional correlation between different experiments is remarkable considering large differences in the aerosol descriptions between the different models. It appears that the differences in aerosol descriptions do not dominate the differences in regional temperature response. The average correlation coefficient for regional precipitation changes within Samset et al. (2018) models with intrinsic aerosol descriptions is 0.34 , while it is 0.41 within our models with prescribed aerosols. The average correlation coefficient for regional precipitation changes between the Samset et al. (2018) models with fully coupled ocean and our models with a slab ocean is 0.39 , which is similar to the mean correlation within the Samset et al. (2018) models.

The correlation coefficient between NorESM1 experiments using different aerosol descriptions and ocean models is now only $0.33 / 0.38$. Thus, differences in aerosol descriptions, ocean models and atmospheric responses all contribute to differences in regional precipitation responses. The correlation coefficients for precipitation responses are, however, more uncertain than those for temperature responses, due to a stronger impact of natural variability.

Even long equilibrium climate runs cannot fully eliminate the natural climate variability on a regional level. With our full dataset (60 years of MACSP runs +120 years of the CTRL run), we obtain a spatial correlation of 0.47 between NorESM1-MACSP and ECHAM6-MACSP precipitation responses, a slight improvement over the correlation coefficient of $0.41( \pm 0.02)$ for $50+50$-year datasets. The spatial correlation for temperature improves from $0.78( \pm 0.02)$ to 0.81 . The fully coupled ocean models in the Samset et al. (2018) dataset also feature long-term internal variability in the ocean states that adds to the level of natural variation with

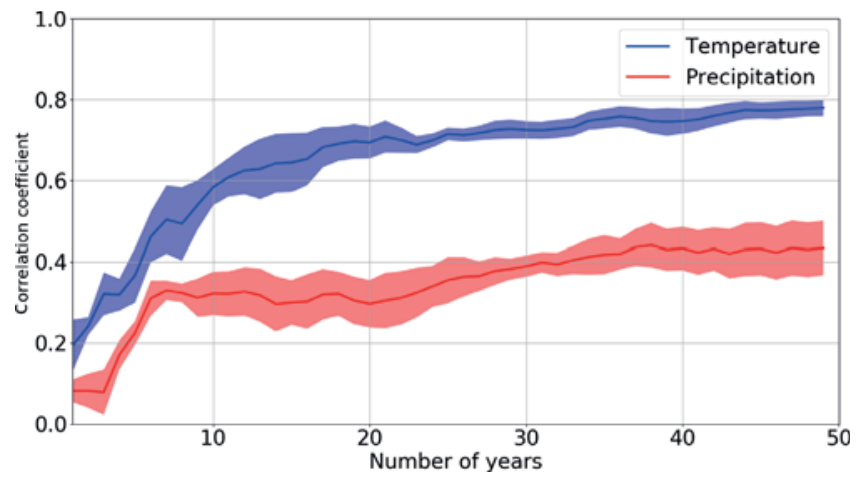

Figure 5. Correlation coefficient of temperature (precipitation) response as a function of the number of averaged years. Blue (red) is the correlation between the temperature responses to MACv2-SP aerosols in the two models. The shaded area shows the variation between different control runs. The same number of years is used for the CTRL run and MACSP run.

respect to our models with simpler slab ocean representations used in this paper. Therefore, we would expect the Samset et al. (2018) data to include more noise than our results with slab ocean configurations. Furthermore, it is important to note that differences in the ocean descriptions are known to have a large impact in the regional climate responses between different models (Deser et al., 2016; Kay et al., 2016). Overall, we would expect that due to these differences the climate signals obtained from fully coupled models would intrinsically correlate less well with each other than those from models with slab ocean configurations. Somewhat surprisingly, this turns out not to be the case.

The dependence of the calculation of time-averaged correlation coefficients on the simulation length for our data is shown in Fig. 5. There, the blue and red shaded regions represent the level of expected variation in the regional correlation coefficients between two climate models obtained from equilibrium model experiments with and without anthropogenic aerosols. We obtained a correlation coefficient of 0.78 with a standard deviation of \pm 0.02 for temperature response and $0.41( \pm 0.02)$ for precipitation after 50 years of simulation, these periods being representative for the Samset experiments but neglecting the impact of long-term ocean variations. The corresponding correlation coefficients for full model runs $(60+120$ years of simulation) are 0.47 for precipitation and 0.81 for temperature.

\section{Conclusions}

We have provided results here on the equilibrium climate response of modern-day anthropogenic aerosols using two different climate models, ECHAM6 and NorESM1, with the MACv2-SP (Stevens et al., 2017) anthropogenic aerosol representations. The results were obtained both using the same representations of aerosol optical properties and cloud- 
Table 3. Intermodel correlations of regional temperature response for the Samset et al. (2018) models and our models. The average correlation coefficient between the Samset et al. (2018) models is 0.79 with a standard deviation of 0.05; the average correlation coefficient between the models used in this study and the Samset et al. (2018) models is 0.76 . The correlations are calculated for 50 years with and 50 years without anthropogenic aerosols. Correlation for our whole dataset $(60+120$ years $)$ is shown in brackets. The range is the standard deviation between results obtained for two different CTRL runs.

\begin{tabular}{lrrrrrr}
\hline & CESM1 & GISS & HadGEM2 & NorESM1 & ECHAM6-MACSP & NorESM1-MACSP \\
\hline GISS & 0.74 & & & & & \\
HadGEMS2 & 0.83 & 0.79 & & & \\
NorESM1 & 0.82 & 0.71 & 0.87 & & & \\
\hline This study & & & & & \\
\hline ECHAM6-MACSP & $0.75 \pm 0.01$ & $0.72 \pm 0.02$ & $0.75 \pm 0.01$ & $0.74 \pm 0.02$ & & \\
NorESM1-MACSP & $0.80 \pm 0.01$ & $0.68 \pm 0.01$ & $0.79 \pm 0.0$ & $0.85 \pm 0.01$ & $0.78 \pm 0.02(0.81)$ & $0.96 \pm 0.0(0.97)$ \\
NorESM1-EF & $0.81 \pm 0.00$ & $0.7 \pm 0.01$ & $0.77 \pm 0.0$ & $0.80 \pm 0.02$ & $0.78 \pm 0.02(0.82)$ & $0.96 \pm$ \\
\hline
\end{tabular}

Table 4. Intermodel correlations of regional precipitation response for the Samset et al. (2018) models and our models. The average correlation coefficient between the models is 0.34 with a standard deviation of 0.10 ; the average correlation coefficient between the models used in this study and the Samset et al. (2018) models is 0.38 . The correlations are calculated for 50 years with and 50 years without anthropogenic aerosols. The range of the correlation coefficient shows the standard deviations between results obtained for two different CTRL runs. The correlation for our whole dataset $(60+120$ years $)$ is shown in brackets.

\begin{tabular}{lrrrrrr}
\hline & CESM1 & GISS & HadGEM2 & NorESM1 & ECHAM6-MACSP & NorESM1-MACSP \\
\hline GISS & 0.38 & & & & & \\
HadGEMS2 & 0.42 & 0.43 & & & \\
NorESM1 & 0.39 & 0.12 & 0.31 & & & \\
\hline This study & & & & & & \\
\hline ECHAM6-MACSP & $0.42 \pm 0.03$ & $0.28 \pm 0.03$ & $0.36 \pm 0.03$ & $0.12 \pm 0.07$ & & \\
NorESM1-MACSP & $0.5 \pm 0.05$ & $0.34 \pm 0.03$ & $0.49 \pm 0.0$ & $0.38 \pm 0.03$ & $0.41 \pm 0.02(0.47)$ & $0.85 \pm 0.08(0.95)$ \\
NorESM1-EF & $0.54 \pm 0.00$ & $0.41 \pm 0.0$ & $0.48 \pm 0.0$ & $0.33 \pm 0.0$ & $0.41 \pm 0.02(0.47)$ & $0.85 \pm$ \\
\hline
\end{tabular}

albedo effect and for identical instantaneous aerosol radiative forcing fields in the models.

The MACv2-SP aerosols produced a very similar total instantaneous anthropogenic aerosol radiative forcing in the two models $\left(-0.64 \mathrm{Wm}^{-2}\right.$ in the ECHAM6-MACSP and $-0.69 \mathrm{Wm}^{-2}$ in the NorESM1-MACSP experiments). We found that there are differences up to $3.2 \mathrm{Wm}^{-2}$ in the instantaneous regional aerosol forcing between the models when using the same aerosol representation. These differences can mostly be explained via differences in cloud fields and surface albedo in the models.

The addition of MACv2-SP anthropogenic aerosols produced very similar global average responses on temperature, $-0.48( \pm 0.02)$ and $-0.50( \pm 0.03) \mathrm{K}$, and precipitation, $-1.69( \pm 0.04) \%$ and $-1.79( \pm 0.05) \%$ in the NorESM1MACSP and ECHAM6-MACSP experiments, respectively. The largest disagreement in regional temperature response was found at high-latitude regions associated with largest differences in surface albedo feedback (snow/sea ice), while the largest differences in regional precipitation response were located mainly in the tropics. These key regional differences remained even when using exactly the same aerosol radia- tive forcing fields in both models. Several previous studies have discussed that the main driver for ITCZ shift is the Northern Hemisphere cooling due to anthropogenic aerosols (Broccoli et al., 2006; Hwang et al., 2013; Wang, 2015). Chiang and Bitz (2005) showed with the Community Climate Model version 3 a connection between ITCZ shift and added Arctic ice cover. Based on these previous studies, it seems plausible that different responses in Arctic sea ice and snow cover in ECHAM6-MACSP and in the two NorESM1 experiments result in different high-latitude temperature responses, which in turn are reflected as differences in the ITCZ shift that drives the precipitation change at low latitudes. However, it should be noted that the ITCZ shift is also sensitive to the type of ocean model used, and slab ocean models tend to exaggerate the change in ITCZ (Kay et al., 2016).

We compared our results using uniform aerosol representations to a set of four current climate models using their intrinsic aerosol representations but the same aerosol emissions, reported by Samset et al. (2018). Among the Samset et al. (2018) models, the global responses to additions of anthropogenic aerosol varied between -0.5 and $-1.1 \mathrm{~K}$ for temperature and between $-1.5 \%$ and $-3.1 \%$ for precipita- 
tion. However, the correlation coefficients for regional distributions of climate responses, averaged over equal run length, were nearly as good among our experiments with prescribed aerosols and slab ocean representation ( 0.78 for temperature and 0.41 for precipitation) and among the Samset et al. experiments with model-intrinsic aerosols and the fully coupled ocean representation ( 0.79 for temperature and 0.34 for precipitation).

The lack of improvement in the correlation coefficients suggests that differences in aerosol descriptions are not the only cause of regional differences in climate signals between the models. Rather, the differences in model circulation responses appear to dominate the differences in regional climate responses. Figure C5 shows the average $850 \mathrm{hPa}$ wind responses for the ECHAM6-MACSP and NorESM1MACSP experiments for Northern Hemisphere winter. The responses in the circulation fields vary significantly between the two models, with an annual average correlation coefficient of only 0.18 (DJF: -0.03; MAM: 0.07; JJA: 0.15; SON: 0.19). The lack of robustness in atmospheric circulation responses between different climate models has been previously discussed by Shepherd (2014) for CMIP5 Representative Concentration Pathway (RCP) 8.5 scenarios and by Li et al. (2018a) for HAPPI (Half a degree Additional warming, Prognosis and Projected Impact) 1.5 and $2.0 \mathrm{~K}$ warming scenarios. Shepherd (2014) argued that the differences in circulation responses cause variation in the regional temperature and precipitation responses in future climate scenarios. Li et al. (2018a) showed that model consensus for circulation response is low even for atmosphere-only models forced with same time-varying sea surface temperature (SST) and sea ice, anthropogenic greenhouse gases, ozone, land use, land cover and aerosols. Both in Shepherd (2014) and Li et al. (2018a) data, the NH wintertime circulation response over the North Atlantic disagrees significantly between models. Also for ECHAM6-MACSP and NorESM1-MACSP, the circulation response over the North Atlantic shows differences in magnitude and pattern. Differences are also seen over the North Pacific region. Combined with the difference in the sea ice and surface albedo change in the North Pacific, these circulation changes can drive the temperature response differences in the region.
Our results imply that in current global climate models the regional aerosol climate impacts cannot be better constrained by further improving aerosol descriptions alone. More extensive model comparisons are needed to explain the model discrepancies in response to aerosol forcing. Improvements on the dynamical cores, physical parameterizations and ocean models are needed to narrow down model uncertainties in the regional aerosol climate responses.

Data availability. Data and scripts are available at https://etsin. fairdata.fi/dataset/7cf4b0d1-7789-4756-b7bc-3964d0646a4c (Nordling et al., 2019). 


\section{Appendix A: NorESM-EF technical description}

The NorESM1-EF run employed radiative forcing extracted from the ECHAM6-MACSP run. First, multi-year monthly means of MACv2-SP aerosol radiative forcing (for TOA and surface radiative fluxes and atmospheric heating rates) were computed for ECHAM6-MACSP. Second, these values were interpolated to the NorESM1 horizontal and vertical grid and normalized by the monthly-mean incoming solar radiation at model top. Third, during the NorESM1-EF run, the normalized forcing was multiplied by the TOA incoming solar radiation at each radiation time step, and it was added to the radiative fluxes and heating rates computed without MACv2$\mathrm{SP}$ aerosols.

This treatment ensures that the diurnal cycle of the aerosol forcing is approximately correct; in particular, there is no aerosol forcing during the night. However, the computed forcing is independent of the clouds simulated by NorESM1. Thus, while the aerosol radiative forcing is computed correctly in a monthly-mean sense, its sub-monthly correlation with clouds is ignored. In principle, this could impact the differences between NorESM1-EF and ECHAM6-MACSP. The impact is, however, most likely small. If neglecting the sub-monthly correlation between clouds and aerosol forcing were to have a substantial impact on the climate response to MACv2-SP aerosols, this should also show up in the differences between NorESM1-EF and NorESM1MACSP. Yet, the differences between NorESM1-EF and NorESM1-MACSP are very small (Tables 2 and C1), in fact much smaller than the corresponding differences between ECHAM6-MACSP and either NorESM1-EF or NorESM1MACSP. This strongly suggests that the differences between NorESM1-EF and ECHAM6-MACSP are primarily caused by the use of a different climate model rather than by the subtle differences in radiative forcing.

\section{Appendix B: Sensitivity analysis of model aerosol forcing}

We used a Gaussian process emulation technique (O'Hagan, 2006) to evaluate the regional differences in aerosol radiative forcing. First, we simply assume that the forcing difference depends only on the differences in model output values and not on the actual values themselves. Second, we selected the differences in modeled output (total cloud cover, surface albedo, precipitation, surface temperature, surface wind $u$ component) as trial sets for these values. These can be described via a relation $Y=\eta(\boldsymbol{X})$, where $\boldsymbol{X}=[\Delta \alpha, \Delta \beta, \ldots, \xi]$, where $\alpha$ and $\beta$ are total cloud cover and surface albedo, and $\xi$ is a pure noise (Gaussian) variable. Next, the function $\boldsymbol{Y}=\eta(\boldsymbol{X})$ is inferred using a Gaussian process prior emulator for a part of the yearly averaged radiative forcing data (in our case, 40 years). Each variable is assigned a sensitivity index which describes the relative sensitivity of $\boldsymbol{Y}$ to that variable. The sensitivity analysis of the estimated $\boldsymbol{Y}$ function was done by using the extended Fourier amplitude sensitivity test (FAST) (Saltelli et al., 1999). As an end result, FAST assesses the contributions of each emulator input variable (components of $\left.\boldsymbol{X}=\left(\boldsymbol{X}_{i}\right)\right)$ to the variance in emulator output variable $(Y)$, where it is assumed the input variables $\boldsymbol{X}_{i}$ have an independent and identical distribution uniform prior. The inferred function $\boldsymbol{Y}$ is finally validated by comparing the emulated forcing field against validation data separate from the training data (here, 20 years long, constructed from 20-year monthly values). 


\section{Appendix C}

(a) ECHAM6-MACSP direct forcing

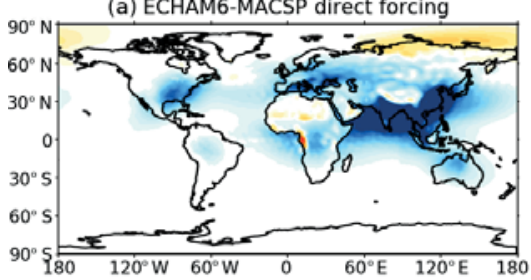

(d) ECHAM6-MACSP indirect forcing

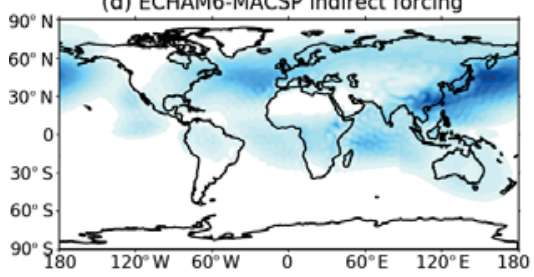

(b) NorESM1-MACSP direct forcing

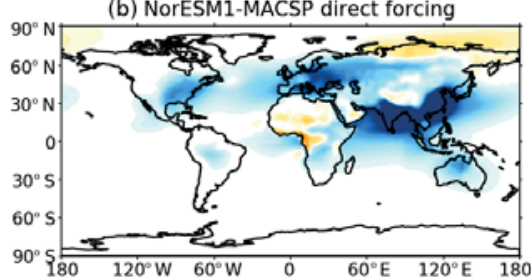

(e) NorESM1-MACSP indirect forcing

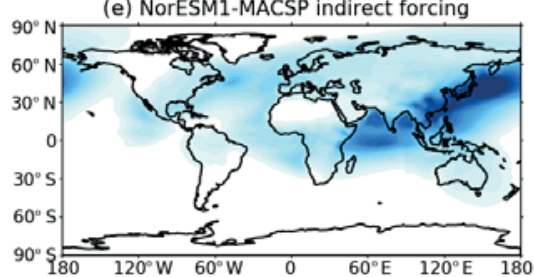

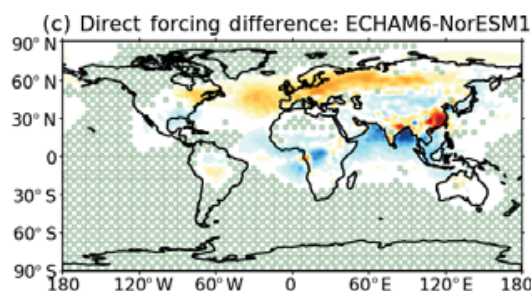

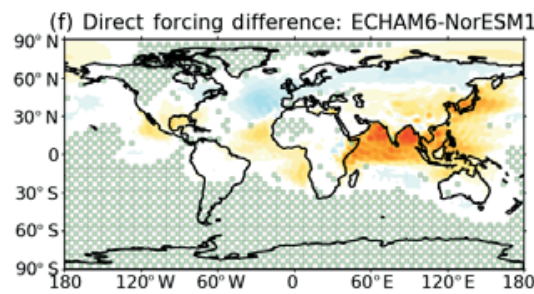

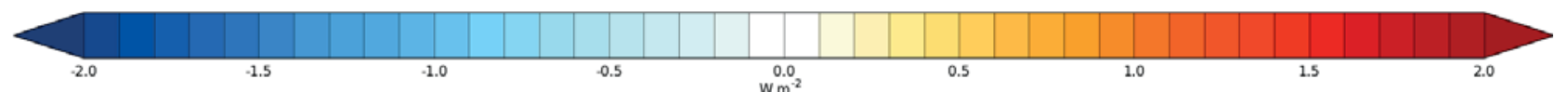

Figure C1. Instantaneous radiative forcing by anthropogenic (MACv2-SP) aerosols. Panels (a), (b), (c) show the direct radiative forcing, and (d), (e), (f) show the indirect radiative forcing produced by MACv2-SP. Green masking in panels (c) and (f) indicates areas where the difference between the models in the instantaneous radiative forcing is not statistically significant $(p>0.05)$. 
(a) ECHAM6-MACSP surface albedo response

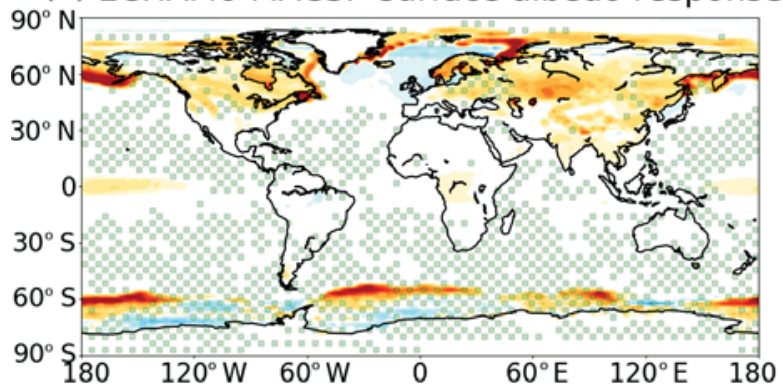

(b) NorESM1-MACSP surface albedo response

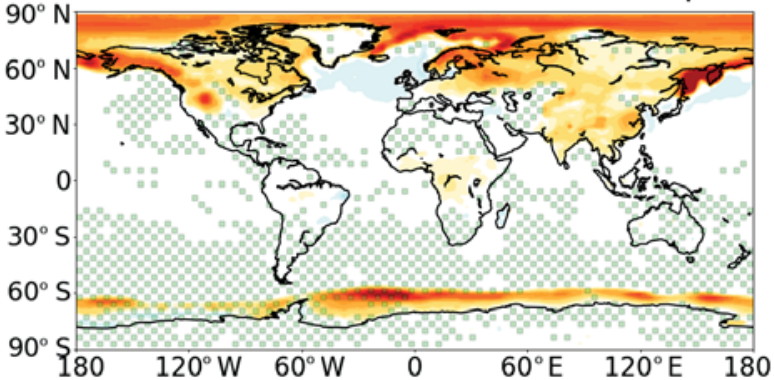

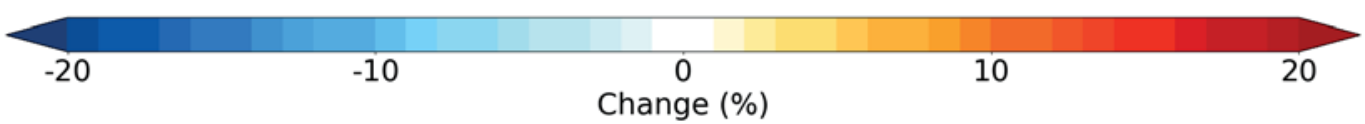

(c) Difference in surface albedo response: ECHAM6-NorESM1

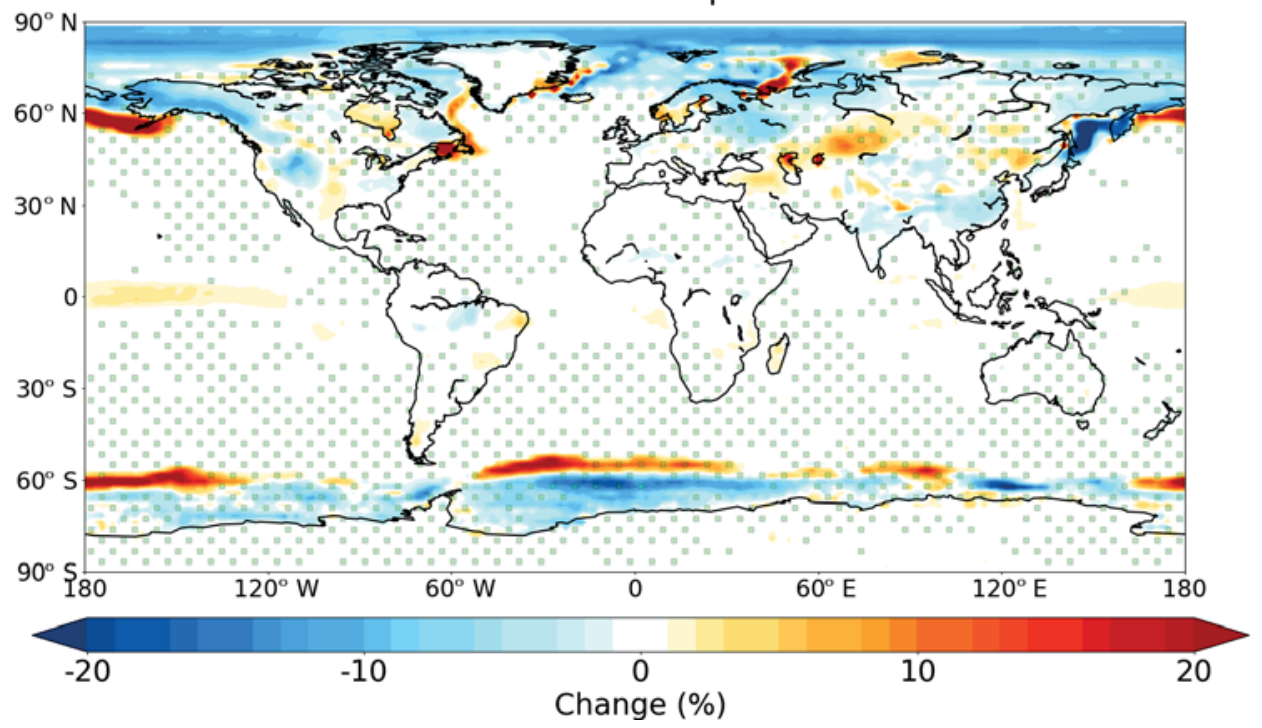

Figure C2. Surface albedo response to the addition of anthropogenic aerosols. (a) Response in the ECHAM6-MACSP experiment; (b) response in the NorESM1-MACSP experiment; (c) the difference in surface albedo response: ECHAM6-MACSP experiment minus NorESM1-MACSP experiment. The green dots represent the area where anthropogenic aerosols do not have a statistically significant impact at the $p<0.05$ level (in panel c) or where the difference between the models is not statistically significant (in panels $\mathbf{a}$ and $\mathbf{b}$ ). 
(a) ECHAM6-MACSP total cloud cover response

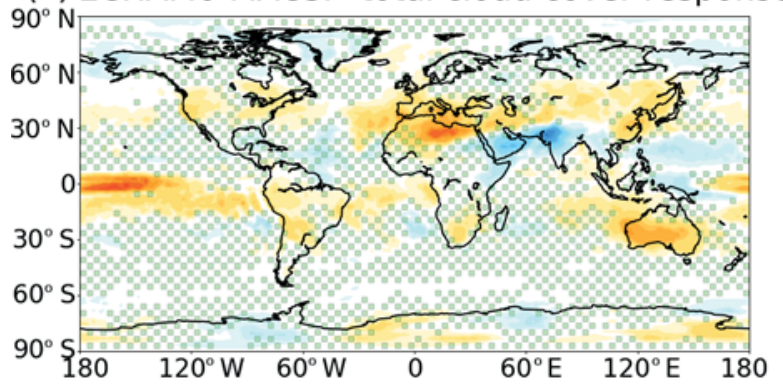

(b) NorESM1-MACSP total cloud cover response
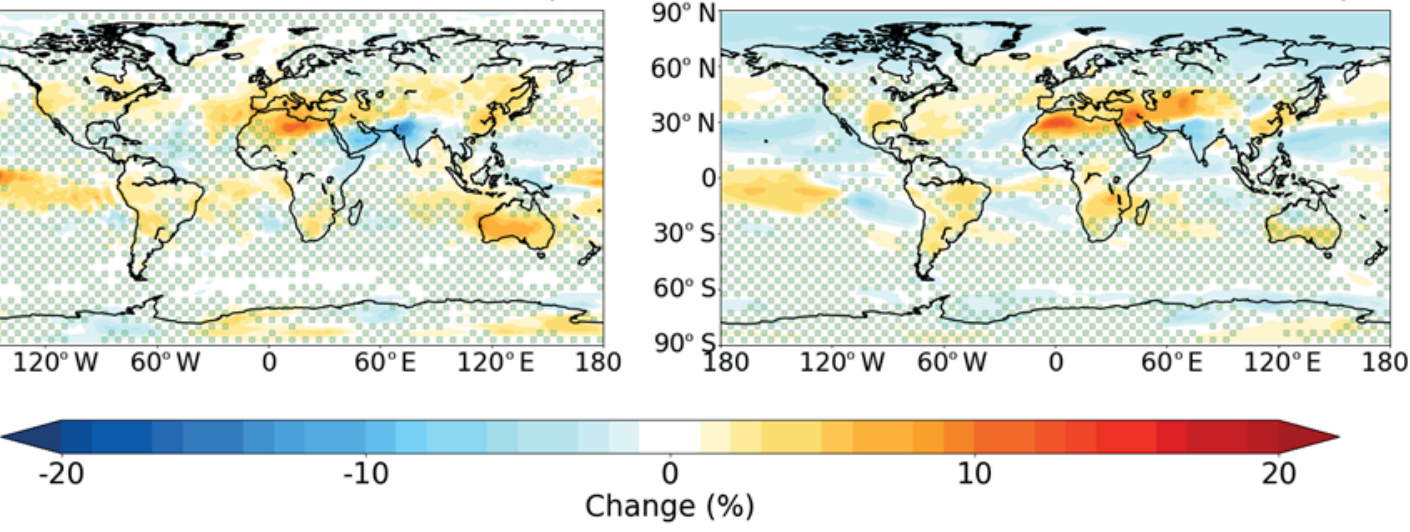

(c) Difference in total cloud cover response: ECHAM6-NorESM1

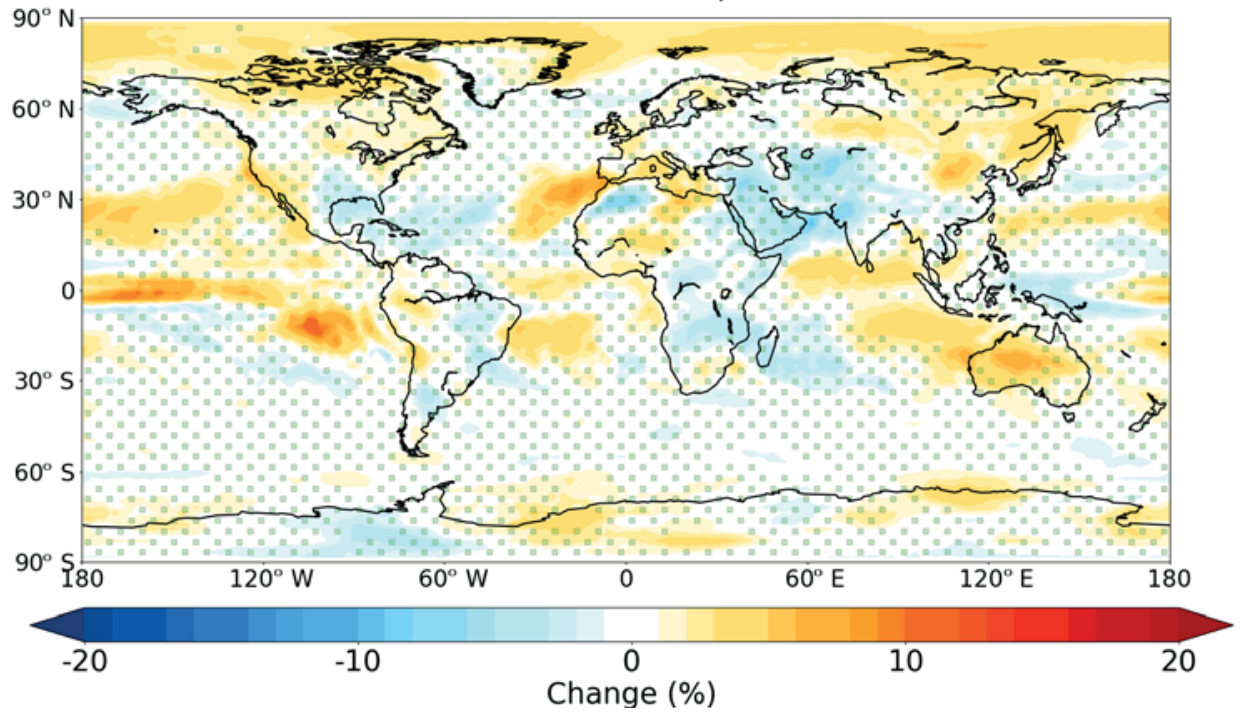

Figure C3. Total cloud cover response to the addition of anthropogenic aerosols. (a) Response in the ECHAM6-MACSP experiment; (b) response in the NorESM1-MACSP experiment; (c) the difference in responses between the experiments. The green dots represent the area where anthropogenic aerosols do not have a statistically significant impact at the $p<0.05$ level (in panel c) or where the difference between the models is not statistically significant (in panels $\mathbf{a}$ and $\mathbf{b}$ ). 
(a) ECHAM6-MACSP vertical velocity

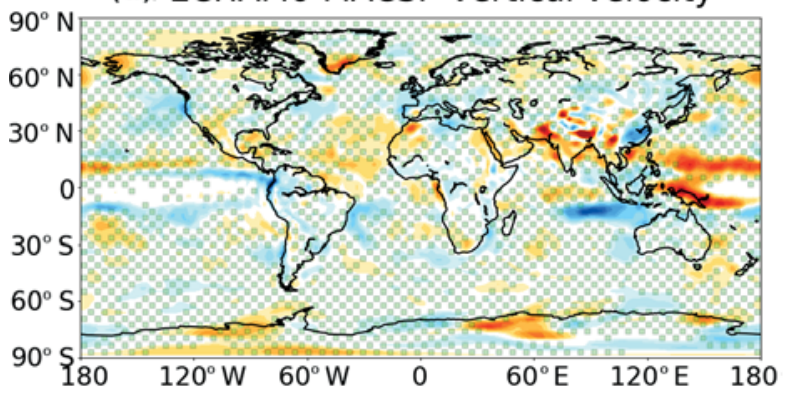

(b) NorESM1-MACSP vertical velocity

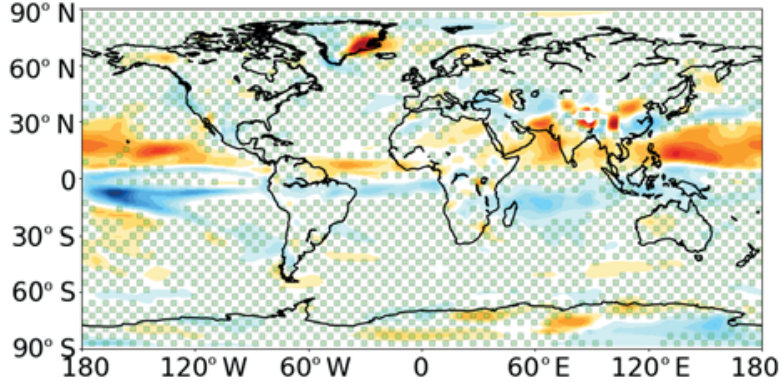

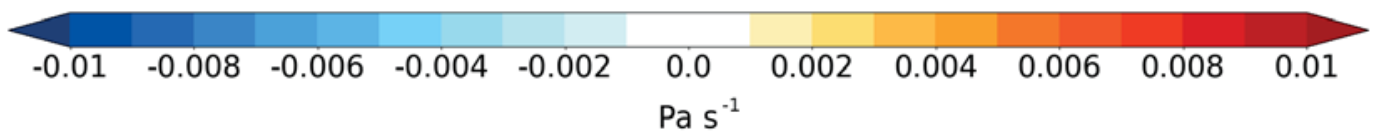

(c) Difference in vertical velocity response: ECHAM6-NorESM1

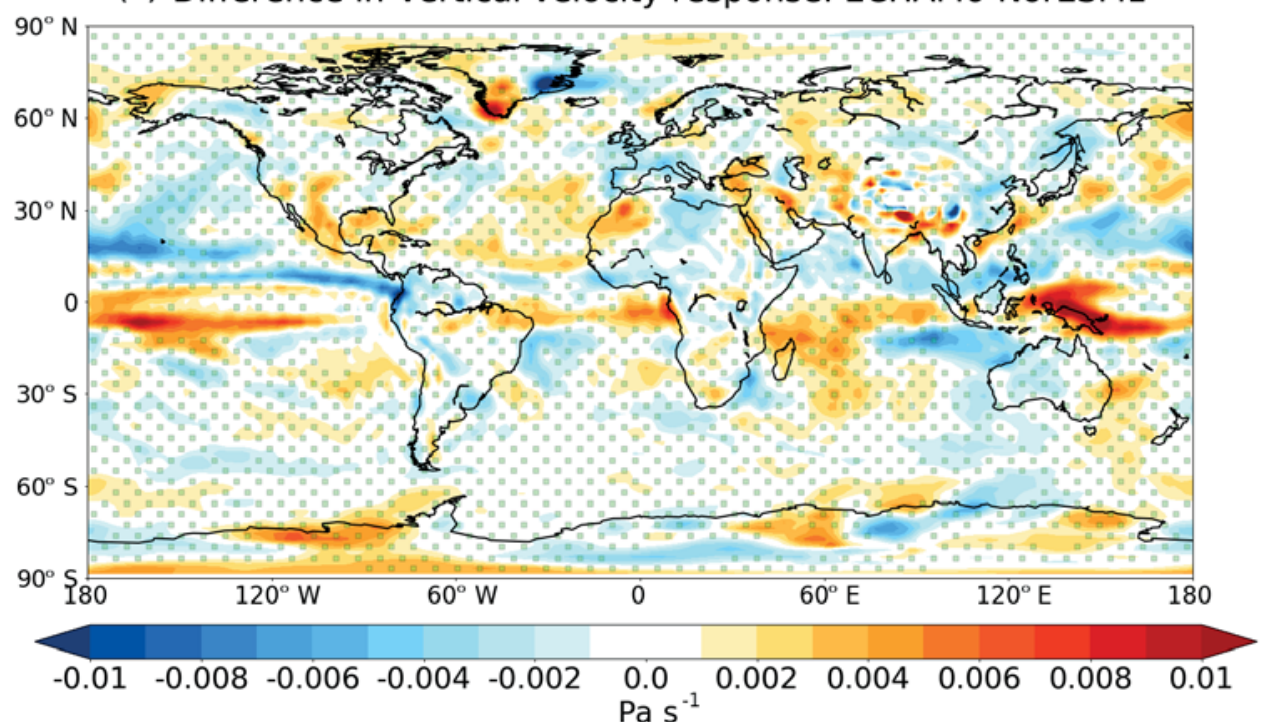

Figure C4. Vertical motion response at the $600 \mathrm{hPa}$ level to the addition of anthropogenic aerosols. (a) Response in the ECHAM6MACSP experiment; (b) response in the NorESM1-MACSP experiment; (c) the difference in responses between the experiments. The green dots represent the area where anthropogenic aerosols do not have a statistically significant impact at the $p<0.05$ level (in panel c) or where the difference between the models is not statistically significant (in panels $\mathbf{a}$ and $\mathbf{b}$ ). 
(a) ECHAM DJF

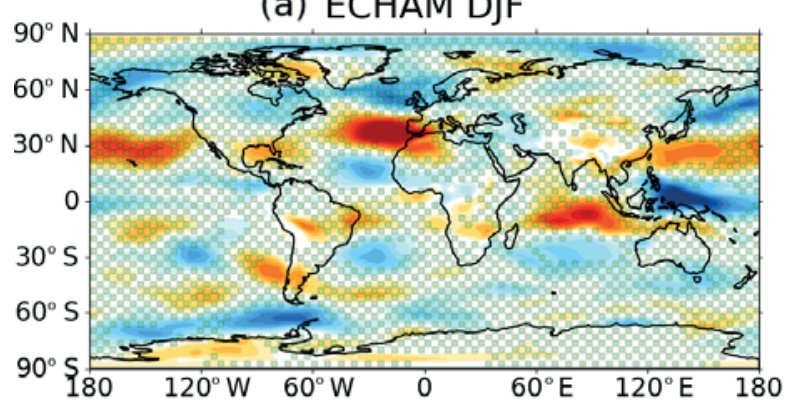

(b) NorESM1 DJF

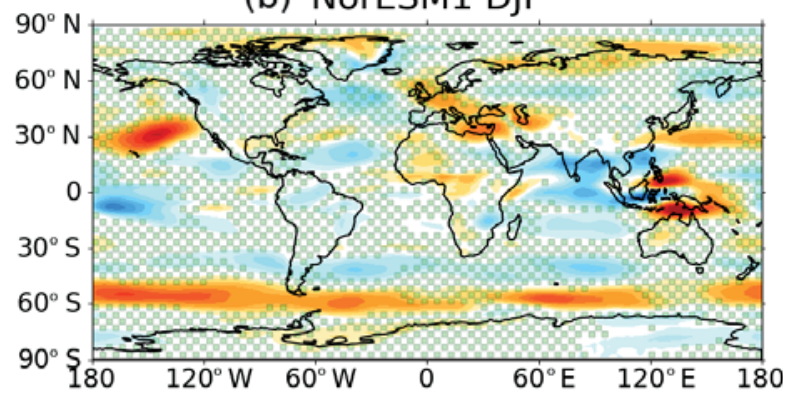

(c) NorESM-ECHAM DJF

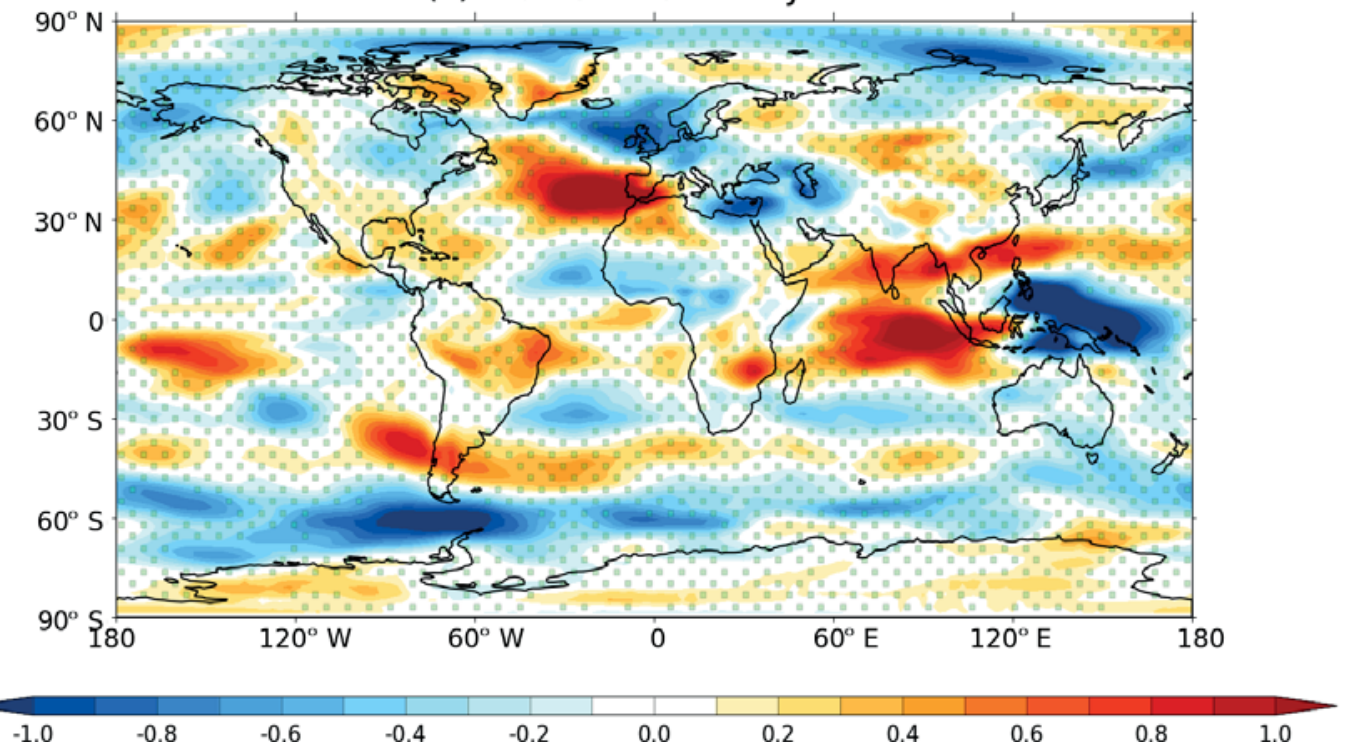

Figure C5. Lower tropospheric $(850 \mathrm{hPa})$ zonal wind response to adding MACv2-SP anthropogenic aerosols for Northern Hemisphere winter. The green dots represent the area where anthropogenic aerosols do not have a statistically significant impact at the $p<0.05$ level (in panel $\mathbf{c}$ ) or where the difference between the models is not statistically significant (in panels $\mathbf{a}$ and $\mathbf{b}$ ). The units are in $\mathrm{ms}^{-1}$. 
Table C1. Summary of global-mean change of temperature and precipitation due to modern-day anthropogenic aerosols. Error bars are the standard error of means.

\begin{tabular}{lrrrrr}
\hline & \multicolumn{5}{c}{ Near-surface temperature } \\
\cline { 2 - 6 } & DJF & MAM & JJA & SON & Annual \\
\hline ECHAM6-MACSP & $-0.54( \pm 0.03)$ & $-0.50( \pm 0.03)$ & $-0.44( \pm 0.02)$ & $-0.51( \pm 0.02)$ & $-0.50( \pm 0.03)$ \\
NorESM1-MACSP & $-0.49( \pm 0.02)$ & $-0.46( \pm 0.02)$ & $-0.45( \pm 0.01)$ & $-0.51( \pm 0.02)$ & $-0.48( \pm 0.02)$ \\
NorESM1-EF & $-0.51( \pm 0.02)$ & $-0.47( \pm 0.01)$ & $-0.46( \pm 0.01)$ & $-0.50( \pm 0.01)$ & $-0.49( \pm 0.01)$ \\
\hline Total precipitation $(\%)$ & & & & \\
\hline ECHAM6-MACSP & $-1.45( \pm 0.07)$ & $-1.82( \pm 0.07)$ & $-2.11( \pm 0.08)$ & $-1.79( \pm 0.07)$ & $-1.79( \pm 0.05)$ \\
NorESM1-MACSP & $-1.62( \pm 0.07)$ & $-1.53( \pm 0.07)$ & $-2.08( \pm 0.07)$ & $-1.52( \pm 0.06)$ & $-1.69( \pm 0.04)$ \\
NorESM1-EF & $-1.7( \pm 0.05)$ & $-1.68( \pm 0.05)$ & $-2.17( \pm 0.07)$ & $-1.71( \pm 0.04)$ & $-1.82( \pm 0.04)$ \\
\hline Large-scale precipitation $(\%)$ & & & & \\
\hline ECHAM6-MACSP & $-1.62( \pm 0.22)$ & $-1.65( \pm 0.12)$ & $-1.22( \pm 0.2)$ & $-0.77( \pm 0.16)$ & $-1.31( \pm 0.1)$ \\
NorESM1-MACSP & $-0.58( \pm 0.21)$ & $-0.83( \pm 0.18)$ & $-2.74( \pm 0.23)$ & $-1.03( \pm 0.16)$ & $-1.28( \pm 0.09)$ \\
NorESM1-EF & $-0.74( \pm 0.18)$ & $-0.98( \pm 0.15)$ & $-2.77( \pm 0.22)$ & $-1.03( \pm 0.09)$ & $-1.37( \pm 0.08)$ \\
\hline Convective precipitation $(\%)$ & & & & \\
\hline ECHAM6-MACSP & $-1.36( \pm 0.12)$ & $-1.91( \pm 0.11)$ & $-2.56( \pm 0.1)$ & $-2.34( \pm 0.1)$ & $-2.05( \pm 0.06)$ \\
NorESM1-MACSP & $-2.27( \pm 0.14)$ & $-1.93( \pm 0.13)$ & $-1.71( \pm 0.11)$ & $-1.82( \pm 0.09)$ & $-1.93( \pm 0.08)$ \\
NorESM1-EF & $-2.28( \pm 0.11)$ & $-2.08( \pm 0.09)$ & $-1.83( \pm 0.08)$ & $-2.12( \pm 0.09)$ & $-2.08( \pm 0.06)$ \\
\hline
\end{tabular}


Author contributions. KN performed ECHAM6 simulations with help from JM, PR and DO'D. PR performed all NorESM1 simulations. MEA advised on the sensitivity analysis. PU advised on the data analysis. The manuscript was written by $\mathrm{KN}$ and JM, with contributions from all authors. HK came up with the initial research idea and JM coordinated the project.

Competing interests. The authors declare that they have no conflict of interest.

Acknowledgements. This project has been funded by the European Research Council (ERC) under the European Union's Horizon 2020 research and innovation program under grant agreement no. 646857, and by the Academy of Finland (project 287440). Petteri Uotila was supported by the EC Marie Curie Support Action LAWINE (grant 707262). The authors would also like to thank Bjørn Hallvard Samset for providing data of fully coupled model runs, Stephanie Fiedler for providing MACv2-SP code for ECHAM6.1 and two reviewers for reviewing this paper.

Financial support. This research has been supported by the Academy of Finland (grant no. 287440), the EC Marie Curie Support Action LAWINE (grant no. 707262) and the European Research Council (grant no. 646857).

Review statement. This paper was edited by Peter Haynes and reviewed by Peter Haynes and one anonymous referee.

\section{References}

Bentsen, M., Bethke, I., Debernard, J. B., Iversen, T., Kirkevåg, A., Seland, ø., Drange, H., Roelandt, C., Seierstad, I. A., Hoose, C., and Kristjánsson, J. E.: The Norwegian Earth System Model, NorESM1-M - Part 1: Description and basic evaluation of the physical climate, Geosci. Model Dev., 6, 687-720, https://doi.org/10.5194/gmd-6-687-2013, 2013.

Bollasina, M. A., Ming, Y., and Ramaswamy, V.: Anthropogenic Aerosols and the Weakening of the South Asian Summer Monsoon, Science, 334, 502-505, 2011.

Boucher, O., Randall, D., Artaxo, P., Bretherton, C., Feingold, G., Forster, P., Kerminen, V.-M., Kondo, Y., Liao, H., Lohmann, U., Rasch, P., K. Satheesh, S., Sherwood, S., Stevens, B., and Zhang, X.: Clouds and Aerosols, in: Climate Change 2013: The Physical Science Basis, Contribution of Working Group I to the Fifth Assessment Report of the Intergovernmental Panel on Climate Change, edited by: Stocker, T. F., Qin, D., Plattner, G.-K., Tignor, M., Allen, S. K., Boschung, J., Nauels, A., Xia, Y., Bex, V., and Midgley, P. M., Cambridge University Press, Cambridge, United Kingdom and New York, NY, USA

Broccoli, A. J., Dahl, K. A., and Stouffer, R. J.: Response of the ITCZ to Northern Hemisphere cooling, Geophys. Res. Lett., 33, L01702, https://doi.org/10.1029/2005GL024546, 2006.
Carslaw, K. S., Lee, L. A., Reddington, C. L., Pringle, K. J., Rap, A., Forster, P. M., Mann, G. W., Spracklen, D. V., Woodhouse, M. T., Regayre, L. A., and Pierce, J. R.: Large contribution of natural aerosols to uncertainty in indirect forcing, Nature, 503, 67-71, https://doi.org/10.1038/nature12674, 2013.

Chiang, J. C. H. and Bitz, C. M.: Influence of high latitude ice cover on the marine Intertropical Convergence Zone, Clim. Dynam., 25, 477-496, https://doi.org/10.1007/s00382-005-0040-5, 2005.

Deser, C., Sun, L., Tomas, R. A., and Screen, J.: Does ocean coupling matter for the northern extratropical response to projected Arctic sea ice loss?, Geophys. Res. Lett., 43, 2149-2157, https://doi.org/10.1002/2016GL067792, 2016.

Ekman, A. M. L.: Do sophisticated parameterizations of aerosolcloud interactions in CMIP5 models improve the representation of recent observed temperature trends?, J. Geophys. Res.Atmos., 119, 817-832, https://doi.org/10.1002/2013JD020511, 2014.

Feser, F., Rockel, B., von Storch, H., Winterfeldt, J., Zahn, M., Feser, F., Rockel, B., Storch, H. v., Winterfeldt, J., and Zahn, M.: Regional Climate Models Add Value to Global Model Data: A Review and Selected Examples, B. Am. Meteorol. Soc., 92, 1181-1192, https://doi.org/10.1175/2011BAMS3061.1, 2011.

Fiedler, S., Kinne, S., Huang, W. T. K., Räisänen, P., O’Donnell, D., Bellouin, N., Stier, P., Merikanto, J., van Noije, T., Makkonen, R., and Lohmann, U.: Anthropogenic aerosol forcing insights from multiple estimates from aerosol-climate models with reduced complexity, Atmos. Chem. Phys., 19, 6821-6841, https://doi.org/10.5194/acp-19-6821-2019, 2019.

Ganguly, D., Rasch, P. J., Wang, H., and Yoon, J.-H.: Climate response of the South Asian monsoon system to anthropogenic aerosols, J. Geophys. Res.-Atmos., 117, https://doi.org/10.1029/2012JD017508, 2012.

Giorgi, F. and Francisco, R.: Uncertainties in regional climate change prediction: a regional analysis of ensemble simulations with the HADCM2 coupled AOGCM, Clim. Dynam., 16, 169182, https://doi.org/10.1007/PL00013733, 2000.

Hawkins, E., Smith, R. S., Gregory, J. M., and Stainforth, D. A.: Irreducible uncertainty in near-term climate projections, Clim. Dynam., 46, 3807-3819, https://doi.org/10.1007/s00382-015-2806$8,2016$.

Hwang, Y.-T., Frierson, D. M. W., and Kang, S. M.: Anthropogenic sulfate aerosol and the southward shift of tropical precipitation in the late 20th century, Geophys. Res. Lett., 40, 2845-2850, https://doi.org/10.1002/grl.50502, 2013.

Iversen, T., Bentsen, M., Bethke, I., Debernard, J. B., Kirkevåg, A., Seland, Ø., Drange, H., Kristjansson, J. E., Medhaug, I., Sand, M., and Seierstad, I. A.: The Norwegian Earth System Model, NorESM1-M - Part 2: Climate response and scenario projections, Geosci. Model Dev., 6, 389-415, https://doi.org/10.5194/gmd-6-389-2013, 2013.

Kasoar, M., Voulgarakis, A., Lamarque, J.-F., Shindell, D. T., Bellouin, N., Collins, W. J., Faluvegi, G., and Tsigaridis, K.: Regional and global temperature response to anthropogenic $\mathrm{SO}_{2}$ emissions from China in three climate models, Atmos. Chem. Phys., 16, 9785-9804, https://doi.org/10.5194/acp-169785-2016, 2016.

Kay, J. E., Wall, C., Yettella, V., Medeiros, B., Hannay, C., Caldwell, P., Bitz, C., Kay, J. E., Wall, C., Yettella, V., Medeiros, B., Hannay, C., Caldwell, P., and Bitz, C.: Global Climate Impacts 
of Fixing the Southern Ocean Shortwave Radiation Bias in the Community Earth System Model (CESM), J. Clim., 29, 46174636, https://doi.org/10.1175/JCLI-D-15-0358.1, 2016.

Kinne, S., O'Donnel, D., Stier, P., Kloster, S., Zhang, K., Schmidt, H., Rast, S., Giorgetta, M., Eck, T. F., and Stevens, B.: MAC-v1: A new global aerosol climatology for climate studies, J. Adv. Model. Earth Sy., 5, 704-740, https://doi.org/10.1002/jame.20035, 2013.

Kirkevåg, A., Iversen, T., Seland, Ø., Hoose, C., Kristjánsson, J. E., Struthers, H., Ekman, A. M. L., Ghan, S., Griesfeller, J., Nilsson, E. D., and Schulz, M.: Aerosol-climate interactions in the Norwegian Earth System Model - NorESM1-M, Geosci. Model Dev., 6, 207-244, https://doi.org/10.5194/gmd-6207-2013, 2013.

Lamarque, J.-F., Bond, T. C., Eyring, V., Granier, C., Heil, A., Klimont, Z., Lee, D., Liousse, C., Mieville, A., Owen, B., Schultz, M. G., Shindell, D., Smith, S. J., Stehfest, E., Van Aardenne, J., Cooper, O. R., Kainuma, M., Mahowald, N., McConnell, J. R., Naik, V., Riahi, K., and van Vuuren, D. P.: Historical (1850-2000) gridded anthropogenic and biomass burning emissions of reactive gases and aerosols: methodology and application, Atmos. Chem. Phys., 10, 7017-7039, https://doi.org/10.5194/acp-10-7017-2010, 2010.

Li, C., Michel, C., Seland Graff, L., Bethke, I., Zappa, G., Bracegirdle, T. J., Fischer, E., Harvey, B. J., Iversen, T., King, M. P., Krishnan, H., Lierhammer, L., Mitchell, D., Scinocca, J., Shiogama, H., Stone, D. A., and Wettstein, J. J.: Midlatitude atmospheric circulation responses under 1.5 and $2.0{ }^{\circ} \mathrm{C}$ warming and implications for regional impacts, Earth Syst. Dynam., 9, 359-382, https://doi.org/10.5194/esd-9-359-2018, 2018a.

Li, X., Ting, M., and Lee, D. E.: Fast Adjustments of the Asian Summer Monsoon to Anthropogenic Aerosols, Geophys. Res. Lett., 45, 1001-1010, https://doi.org/10.1002/2017GL076667, 2018 b.

Nordling, K., Merikanto, J., Räisänen, P., Korhonen, H., Uotila, P., O'Donnell, D., and Alper, M. E.: RECIA, available at: https://etsin.fairdata.fi/dataset/ 7cf4b0d1-7789-4756-b7bc-3964d0646a4c last access: 12 July 2019.

O'Hagan, A.: Bayesian analysis of computer code outputs: A tutorial, Reliab. Eng. Syst. Safe., 91, 1290-1300, https://doi.org/10.1016/J.RESS.2005.11.025, 2006.

Polson, D., Bollasina, M., Hegerl, G. C., and Wilcox, L. J.: Decreased monsoon precipitation in the Northern Hemisphere due to anthropogenic aerosols, Geophys. Res. Lett., 41, 6023-6029, https://doi.org/10.1002/2014GL060811, 2014.

Ramanathan, P. J., Crutzen J. T., and Kiehl, D. R.: Aerosols, Climate, and the Hydrological Cycle, Science, 294, 2119-2124, 2005.
Saltelli, A., Tarantola, S., and Chan, K. P.-S.: A Quantitative Model-Independent Method for Global Sensitivity Analysis of Model Output, Technometrics, 41, 39-56, https://doi.org/10.2307/1270993, 1999.

Salzmann, M., Weser, H., and Cherian, R.: Robust response of Asian summer monsoon to anthropogenic aerosols in CMIP5 models, J. Geophys. Res.-Atmos., 119, 321-11, https://doi.org/10.1002/2014JD021783, 2014.

Samset, B. H., Sand, M., Smith, C. J., Bauer, S. E., Forster, P. M., Fuglestvedt, J. S., Osprey, S., and Schleussner, C.F.: Climate Impacts From a Removal of Anthropogenic Aerosol Emissions, Geophys. Res. Lett., 45, 1020-1029, https://doi.org/10.1002/2017GL076079, 2018.

Shindell, D. T., Faluvegi, G., Rotstayn, L., and Milly, G.: Spatial patterns of radiative forcing and surface temperature response, J. Geophys. Res.-Atmos., 120, 5385-5403, https://doi.org/10.1002/2014JD022752, 2015.

Stevens, B., Giorgetta, M., Esch, M., Mauritsen, T., Crueger, T., Rast, S., Salzmann, M., Schmidt, H., Bader, J., Block, K., Brokopf, R., Fast, I., Kinne, S., Kornblueh, L., Lohmann, U., Pincus, R., Reichler, T., and Roeckner, E.: Atmospheric component of the MPI-M Earth System Model: ECHAM6, J. Adv. Model. Earth Sy., 5, 146-172, https://doi.org/10.1002/jame.20015, 2013.

Stevens, B., Fiedler, S., Kinne, S., Peters, K., Rast, S., Müsse, J., Smith, S. J., and Mauritsen, T.: MACv2-SP: a parameterization of anthropogenic aerosol optical properties and an associated Twomey effect for use in CMIP6, Geosci. Model Dev., 10, 433 452, https://doi.org/10.5194/gmd-10-433-2017, 2017.

Stier, P., Schutgens, N. A. J., Bellouin, N., Bian, H., Boucher, O., Chin, M., Ghan, S., Huneeus, N., Kinne, S., Lin, G., Ma, X., Myhre, G., Penner, J. E., Randles, C. A., Samset, B., Schulz, M., Takemura, T., Yu, F., Yu, H., and Zhou, C.: Host model uncertainties in aerosol radiative forcing estimates: results from the AeroCom Prescribed intercomparison study, Atmos. Chem. Phys, 13, 3245-3270, https://doi.org/10.5194/acp-13-3245-2013, 2013.

Wang, C.: Anthropogenic aerosols and the distribution of past large-scale precipitation change, Geophys. Res. Lett., 42, 1087610884, https://doi.org/10.1002/2015GL066416, 2015.

Wilcox, L. J., Highwood, E. J., Booth, B. B. B., and Carslaw, K. S.: Quantifying sources of inter-model diversity in the cloud albedo effect, Geophys. Res. Lett., 42, 1568-1575, https://doi.org/10.1002/2015GL063301, 2015.

Zwiers and von Storch: Taking Serial Correlation into Account in Tests of the Mean, J. Clim., 8, 336-351, 1995. 

(C) 2021 Atmos. Chem. Phys.,

Reprinted, with permission, from ACP , 20, 11955-11977, doi:10.5194/acp-20-11955-2020 



\title{
Accelerated increases in global and Asian summer monsoon precipitation from future aerosol reductions
}

\author{
Laura J. Wilcox ${ }^{1,2}$, Zhen Liu ${ }^{3}$, Bjørn H. Samset ${ }^{4}$, Ed Hawkins ${ }^{1,2}$, Marianne T. Lund ${ }^{4}$, Kalle Nordling ${ }^{5}$, \\ Sabine Undorf ${ }^{6}$, Massimo Bollasina ${ }^{3}$, Annica M. L. Ekman ${ }^{6}$, Srinath Krishnan ${ }^{6}$, Joonas Merikanto ${ }^{5}$, and \\ Andrew G. Turner ${ }^{1,2}$ \\ ${ }^{1}$ National Centre for Atmospheric Science, University of Reading, Reading, UK \\ ${ }^{2}$ Department of Meteorology, University of Reading, Reading, UK \\ ${ }^{3}$ School of Geosciences, Grant Institute, University of Edinburgh, Edinburgh, UK \\ ${ }^{4}$ CICERO Center for International Climate Research, Oslo, Norway \\ ${ }^{5}$ Finnish Meteorological Institute, Helsinki, Finland \\ ${ }^{6}$ Department of Meteorology, Stockholm University, Stockholm, Sweden
}

Correspondence: Laura Wilcox (1.j.wilcox@reading.ac.uk)

Received: 22 December 2019 - Discussion started: 30 January 2020

Revised: 18 August 2020 - Accepted: 28 August 2020 - Published: 26 October 2020

\begin{abstract}
There is a large range of future aerosol emissions scenarios explored in the Shared Socioeconomic Pathways (SSPs), with plausible pathways spanning a range of possibilities from large global reductions in emissions by 2050 to moderate global increases over the same period. Diversity in emissions across the pathways is particularly large over Asia. Rapid reductions in anthropogenic aerosol and precursor emissions between the present day and the 2050s lead to enhanced increases in global and Asian summer monsoon precipitation relative to scenarios with weak air quality policies. However, the effects of aerosol reductions do not persist to the end of the 21 st century for precipitation, when instead the response to greenhouse gases dominates differences across the SSPs. The relative magnitude and spatial distribution of aerosol changes are particularly important for South Asian summer monsoon precipitation changes. Precipitation increases here are initially suppressed in SSPs 2$4.5,3-7.0$, and 5-8.5 relative to SSP1-1.9 when the impact of remote emission decreases is counteracted by continued increases in South Asian emissions.
\end{abstract}

\section{Introduction}

Anthropogenic aerosols can affect climate either by scattering or absorbing solar radiation or by changing cloud prop- erties (Boucher et al., 2013). Overall, aerosols have a globalmean cooling effect, manifested, for example, in a slower rate of global warming in the mid-20th century concurrent with rapid increases in aerosol burden (Wilcox et al., 2013; Jones et al., 2013; Hegerl et al., 2019). This has raised the question of whether the warming associated with present-day and future reductions in anthropogenic aerosol might exacerbate the climate impacts brought about by continued increases in greenhouse gas (GHG) emissions.

Many studies have demonstrated the potential for an enhanced future warming from aerosol reductions in global climate models driven by plausible reductions in the emissions of anthropogenic aerosol and their precursors (e.g. Chalmers et al., 2012; Levy et al., 2013; Rotstayn et al., 2013; Acosta Navarro et al., 2017). In recent years, emission scenarios have typically been taken from either the Representative Concentration Pathways (RCPs; Moss et al., 2010; van Vuuren et al., 2011) used in the 5th Coupled Model Intercomparison Project (CMIP5; Taylor et al., 2012) or the more diverse ECLIPSE (Klimont et al., 2017) aerosol pathways: CLE (Current LEgislation) and MFR (Maximum Feasible Reduction). Estimates based on transient simulations with CMIP5 generation models suggest that future aerosol reductions may result in warming of up to $1.1 \mathrm{~K}$ in addition to any GHG-driven warming (e.g. Rotstayn et al., 2013; Levy et al., 2013; Acosta Navarro et al., 2017). This indicates that

Published by Copernicus Publications on behalf of the European Geosciences Union. 
reduced anthropogenic aerosol emissions may account for up to half of the total warming by 2100 in scenarios with moderate GHG increases. Similar magnitudes are also seen in studies using equilibrium experiments (Kloster et al., 2010), studies using reduced complexity models (Hienola et al., 2018), and studies assuming a complete removal of anthropogenic aerosol (Samset et al., 2018; Nordling et al., 2019).

The important role of anthropogenic aerosol in driving precipitation changes has also been documented, including the possible contribution to the spin-down in the global water cycle in the mid-20th century (Liepert et al., 2004; Wilcox et al., 2013; Wu et al., 2013). A greater response of global mean precipitation to anthropogenic aerosol changes compared to GHGs is expected since aerosol has a stronger effect on atmospheric shortwave transmissivity and thus a stronger influence on radiative energy imbalance (e.g. Liepert et al., 2009; Andrews et al., 2010; Rotstayn et al., 2013; Samset et al., 2016; Liu et al., 2018). The apparent hydrological sensitivity (percent change in precipitation divided by absolute change in temperature; Fläschner et al., 2016) for anthropogenic aerosol is twice that for GHGs (Kloster et al., 2010; Salzmann, 2016; Samset et al., 2016). This enhanced sensitivity means that anthropogenic aerosol reductions might be expected to play a relatively more important role in future increases in global precipitation for a given temperature change. Several studies using CMIP5 models estimate an increase in global-mean precipitation between 0.09 and $0.16 \mathrm{mmd}^{-1}$ by 2100 from aerosol reductions (e.g. Levy et al., 2013; Rotstayn et al., 2013; Westervelt et al., 2015).

The effects of future aerosol reductions are likely to be felt more strongly at regional rather than global scales due to their heterogeneous forcing distribution and strong influence on circulation patterns. Previous work has identified relatively large temperature increases over Europe (Sillmann et al., 2013), the Arctic (Acosta Navarro et al., 2016), and East Asia (Westervelt et al., 2015), compared to the globalmean response. For precipitation, the regional response is particularly pronounced for the Asian summer monsoon (Levy et al., 2013; Westervelt et al., 2015; Acosta Navarro et al., 2017; Bartlett et al., 2018; Samset et al., 2018). Here, precipitation is sensitive to changes in remote aerosol through its control on the interhemispheric temperature gradient and intertropical convergence zone (ITCZ) location and the atmospheric wave pattern over Eurasia and to local aerosol changes, which further modify the local monsoon circulation (Polson et al., 2014; Dong et al., 2016; Guo et al., 2016; Shawki et al., 2018; Undorf et al., 2018). A number of studies have suggested that historical aerosol increases are a key driver of the observed decrease in Asian summer monsoon precipitation (Lau and Kim, 2010; Bollasina et al., 2011; Song et al., 2014; Li et al., 2015; Liu et al., 2019), and projected increases in precipitation due to aerosol reductions are consistent with this. Importantly, Asia will undergo the largest anticipated future changes in aerosol amounts worldwide (Lund et al., 2019; Scannell et al., 2019) and is thus a region likely to see an anthropogenic aerosol influence on near-future precipitation trends.

Despite evidence that anthropogenic aerosols influence temperature and precipitation, quantification of the associated changes is hindered by several compounding uncertainties. The degree by which anthropogenic aerosol reductions enhance future climate change is model-dependent. Models with weaker historical aerosol forcing generally have weaker positive radiative forcing from future aerosol reductions and therefore predict relatively moderate global-mean warming (Gillett and Von Salzen, 2013; Westervelt et al., 2015) and moderate precipitation increases due to future aerosol reductions (Rotstayn et al., 2015), compared to models with larger aerosol forcing. The uncertainty in aerosol radiative forcing itself is currently the largest source of uncertainty in estimates of the magnitude of the total anthropogenic forcing on climate, with the most recent estimate producing a $68 \%$ confidence interval from -1.60 to $-0.65 \mathrm{~W} \mathrm{~m}^{-2}$ (Bellouin et al., 2019). This is comparable to the range simulated by CMIP5 models: -1.55 to $-0.68 \mathrm{~W} \mathrm{~m}^{-2}$ (Zelinka et al., 2014). The effect of this uncertainty on regional climate projections may be further enhanced by feedbacks from atmospheric circulation changes (Nordling et al., 2019). The compensating effects from the response to different near-term climate forcers also increases the uncertainty in multi-decadal projections, with future changes in methane and nitrate aerosol having the potential to moderate future temperature enhancements from decreases in anthropogenic aerosol (Bellouin et al., 2011; Shindell et al., 2012; Pietikäinen et al., 2015). At regional scales, changes in land use may also play an important role (Singh et al., 2019b).

In opposition to the CMIP5 generation findings summarised above, Shindell and Smith (2019) recently dismissed the possibility that future aerosol reductions might lead to rapid increases in the magnitude or rate of global-mean warming, even in scenarios with aggressive clean air policies, based on simulations with a reduced-complexity impulse response model (Smith et al., 2018). Yet, this conclusion may not hold when using a fully coupled global climate model (GCM) and when investigating changes beyond global mean temperature. Even if the short atmospheric residence time of anthropogenic aerosol potentially makes their effects negligible on centennial timescales, they are likely important for regional and global climate over the next few decades. This is especially the case for Asia where large aerosol emission changes are anticipated and where aerosol has played an important role in historical changes, in particular for precipitation. In this study, we examine state-of-the-art models and scenarios in CMIP6 and make the case for a potential enhancement of increases in global and Asian temperature and precipitation on a 20-30-year time horizon due to removal of anthropogenic aerosol. Such an effect is an important consideration for adaptation and mitigation strategies. 
Table 1. CMIP6 models and the number of ensemble members for each used in this work.

\begin{tabular}{|c|c|c|c|c|c|c|c|c|c|c|c|c|}
\hline \multirow[b]{2}{*}{ Centre } & \multirow[b]{2}{*}{ Model } & \multicolumn{5}{|c|}{ AOD } & \multicolumn{5}{|c|}{$\mathrm{T}, \mathrm{P}, \mathrm{U} 850$, and V850 } & \multirow[t]{2}{*}{ Data reference } \\
\hline & & hist & $1-1.9$ & $2-4.5$ & $3-7.0$ & $5-8.5$ & hist & $1-1.9$ & $2-4.5$ & $3-7.0$ & & \\
\hline $\mathrm{BCC}$ & BCC-CSM2-MR & & & & & & 3 & & 1 & 1 & 1 & $\begin{array}{l}\text { Wu et al. (2018); } \\
\text { Xin et al. (2019) }\end{array}$ \\
\hline CAMS & CAMS-CSM1-0 & & & & & & 1 & 1 & 1 & 1 & 1 & Rong $(2019 a, b)$ \\
\hline CCCma & CanESM5 & 1 & 1 & 1 & 1 & 1 & 10 & 5 & 10 & 10 & 10 & Swart et al. (2019b, c) \\
\hline CNRM-CERFACS & CNRM-CM6-1 & 6 & & 6 & 6 & 6 & 10 & & 5 & 6 & 5 & Voldoire $(2018,2019 b)$ \\
\hline CNRM-CERFACS & CNRM-ESM2-1 & 5 & 5 & 5 & 5 & 5 & 5 & 5 & 5 & 5 & & Seferian $(2018,2019 b)$ \\
\hline EC-Earth-Consortium & EC-Earth3-Veg & & & & & & 1 & & 1 & & 1 & EC-Earth Consortium (2019a, b) \\
\hline IPSL & IPSL-CM6A-LR & 9 & 1 & 2 & 9 & 1 & 10 & 1 & 2 & 10 & 1 & Boucher et al. (2018a, 2019) \\
\hline MIROC & MIROC6 & & & & & & 3 & 1 & 3 & 3 & 3 & Tatebe and Watanabe (2018) \\
\hline $\mathrm{MOHC}$ & HadGEM3-GC31-LL & & & & & & 4 & & & & & Ridley et al. (2019) \\
\hline $\mathrm{MOHC}$ & UKESM1-0-LL & 6 & 5 & 5 & 5 & 5 & 4 & 4 & 5 & 5 & 5 & $\begin{array}{l}\text { Tang et al. (2019); } \\
\text { Good et al. (2019) }\end{array}$ \\
\hline MRI & MRI-ESM2-0 & & & & & & 3 & 1 & 1 & 1 & 1 & Yukimoto et al. (2019a, c) \\
\hline NASA-GISS & GISS-E2-1-G & & & & & & 5 & & & & & NASA/GISS (2018) \\
\hline NCAR & CESM2 & 10 & & & & & 6 & & & & & Danabasoglu (2019a) \\
\hline NOAA-GFDL & GFDL-CM4 & & & & & & 1 & & 1 & & 1 & Guo et al. $(2018 a, b)$ \\
\hline
\end{tabular}

\section{Data and methods}

\subsection{Models and experiments}

We use data from the CMIP6 (Eyring et al., 2016) historical experiment (1850-2014) and four future scenarios following Shared Socioeconomic Pathways (SSPs) 1-1.9, 2-4.5, 3-7.0, and 5-8.5 (O'Neill et al., 2016; Rao et al., 2017; Riahi et al., 2017), which sample a range of aerosol pathways. At the time of writing, data were only available for between 6 and 14 models for the variables and experiments we consider. The data used in this study are summarised in Table 1 . All available data are used for each experiment, and model means are used in multi-model comparisons, except where otherwise stated. Many CMIP6 models include improved representation of aerosol microphysics and aerosol-cloud interactions compared to CMIP5, such as internal mixing and heterogeneous ice nucleation (e.g. Bellouin et al., 2013; Mulcahy et al., 2018; Kirkevåg et al., 2018; Wyser et al., 2020), and all models we consider include at least the first aerosol indirect effect (Twomey et al., 1984).

The SSPs used in CMIP6 sample a far greater range of uncertainty in future aerosol and precursor emissions than the RCPs used in CMIP5 (Lund et al., 2019; Scannell et al., 2019). Partanen et al. (2018) highlighted the importance of uncertainty in aerosol emission pathways for the potential enhancement of global temperature increases from anthropogenic aerosol reductions. The CMIP5 RCPs 2.6-8.5 sampled only a limited range of this emission uncertainty, with an associated difference in global-mean temperature of no more than $0.18 \mathrm{~K}$ throughout the 21 st century. Contrasting aerosol pathways spanning a wider range of emission uncertainty resulted in a difference of up to $0.86 \mathrm{~K}$ (in 2061). The SSPs span most of this wider range of emissions pathways explored by Partanen et al. (2018). They include large, rapid reductions in aerosol and precursor emissions in SSP11.9 , more moderate reductions (comparable to the RCPs) in SSP2-4.5 and SSP5-8.5, and continued increases in the coming decades in SSP3-7.0 (see Fig. 1). Much of the spread in global emission pathways comes from diversity over Asia and North Africa (Lund et al., 2019).

In our analysis, we compare future decadal-mean climate changes to the present day (1980-2014) across SSPs 1-1.9, $2-4.5,3-7.0$, and 5-8.5. We focus on the period up to the 2050s, when aerosol emission uncertainty is largest, but the full range of uncertainty in greenhouse gas (GHG) emissions has yet to emerge (Fig. 1). However, the changes in GHG emissions in this period are not negligible, and the emerging modelled climate responses we show include the effects of changes in both anthropogenic aerosols and greenhouse gases. The SSPs also consider a range of land use scenarios, with extensive and moderate deforestation in SSP3-7.0 and SSP5-8.5, respectively, little change in forest cover in SSP2-4.5 before 2050, and large-scale afforestation in SSP11.9 (O'Neill et al., 2016). Where data are available, we have provided the global-mean annual-mean effective radiative forcings (ERFs) due to historical changes in anthropogenic aerosols, GHGs, and land use changes in Table 2, as an indicator of the relative importance of these changes on centennial timescales. Typically GHG forcing over the historical period is $2-3$ times larger than aerosol forcing, which is 


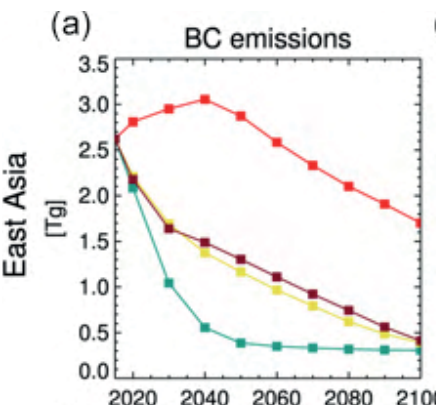

(b)

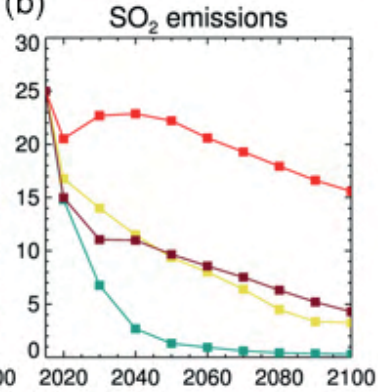

(d)

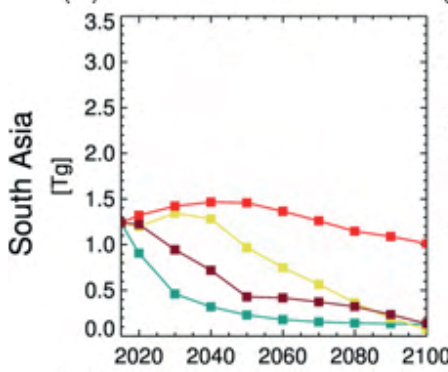

(e)

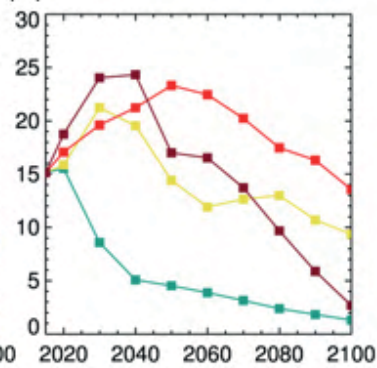

(h)

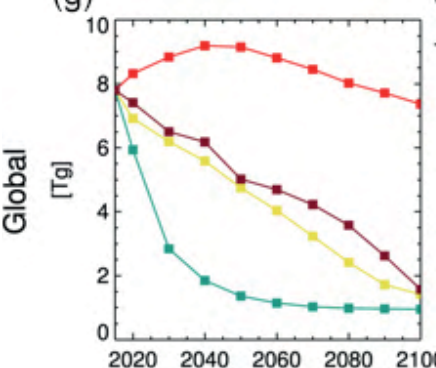

(c) $\mathrm{CO}_{2}$ emissions

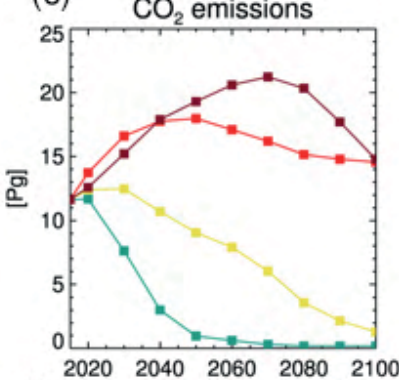

(f)

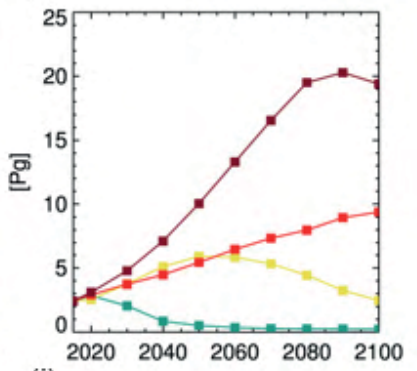

(i)

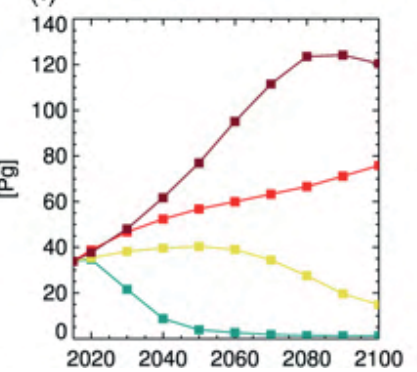

Figure 1. (a) Black carbon ( $\mathrm{Tg}$ ), (b) sulfur dioxide (Tg), and (c) carbon dioxide emissions (Pg) over East Asia for SSPs 1-1.9, 2-4.5, 3-7.0, and 5-8.5. (d-f) Emissions over South Asia. (g-i) Global total emissions. East Asia is the region $20-40^{\circ} \mathrm{N}$ and $100-120^{\circ}$ E. South Asia is the region $5-25^{\circ} \mathrm{N}$ and $55-95^{\circ} \mathrm{E}$.

in turn an order of magnitude greater than land use forcing. When considering the Asian summer monsoon, the regional pattern of forcing is also important (e.g. Dong et al., 2019). The CMIP6 mean ERF over the Asian region is shown in Fig. 2 for anthropogenic aerosols, GHGs, land use and land cover change, and total anthropogenic drivers (ERF from individual models is shown in Figs. S1-S4 in the Supplement for each driver). Anthropogenic aerosols and GHGs are the main contributors to historical anthropogenic forcing over Asia (Fig. 2).

Historical ERF can only be a first-order indicator of the potential relative importance of each driver in future changes, as the distribution and magnitude of future changes may differ, especially for non-GHG forcing. However, comparison of the extreme SSPs for anthropogenic aerosol and land use and land cover changes in 2050 shows that the magnitude of changes between the present day and 2050 is roughly comparable to the changes over Asia between 1850 and 2014 (Fig. S5). This suggests that the historical ERFs are a good indicator of the relative magnitude of these forcings in future and that GHG and anthropogenic aerosol changes are likely to remain the main drivers of Asian summer monsoon trends in the future. Thus, we focus on the effects of anthropogenic aerosol and GHGs in our analysis.

Since multiple forcing agents vary simultaneously in the SSPs, it is not possible to quantify the respective effects of aerosol and GHG changes, although the main driver of an anomaly can still be identified. Consider the global emission changes shown in Fig. 1. SSP1-1.9 has the largest aerosol and GHG emission reduction, while SSP3-7.0 has a moderate increase in aerosol emissions (reverse climate response to SSP1-1.9) and moderate increase in GHG emission (enhanced climate response to SSP1-1.9). If the magnitude of the climate response to these changes decreases monotonically from SSP1-1.9 to SSP3-7.0 (Fig. 3), this indicates that aerosol changes are the main driver of the climate response. Further confirmation of aerosol as the main driver is gained from the comparison of the anomalies in SSP2-4.5 and SSP58.5 , which have similar aerosol pathways but very different greenhouse gas pathways (Figs. 1 and 3). If the climate re- 
(a)

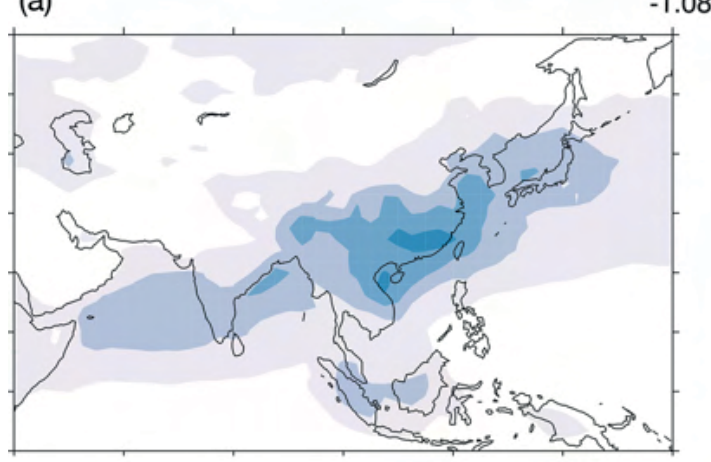

(c)

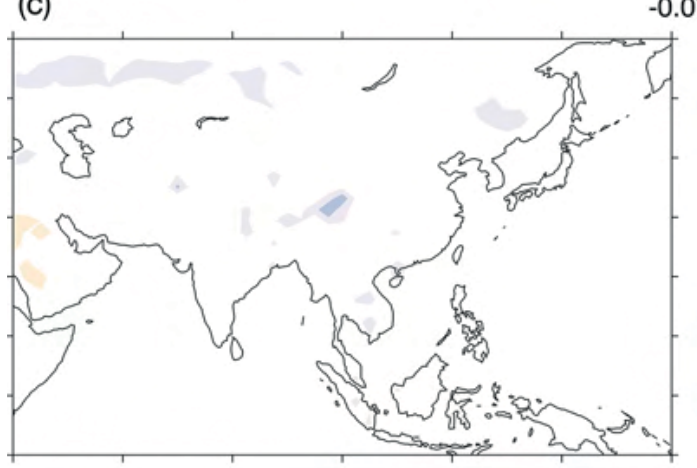

(b)

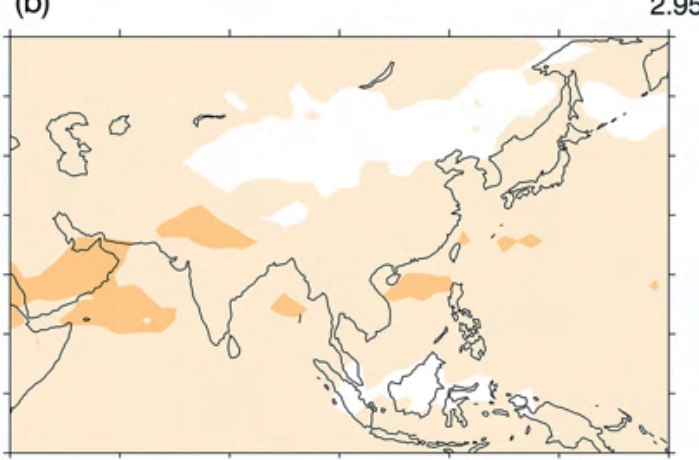

(d)

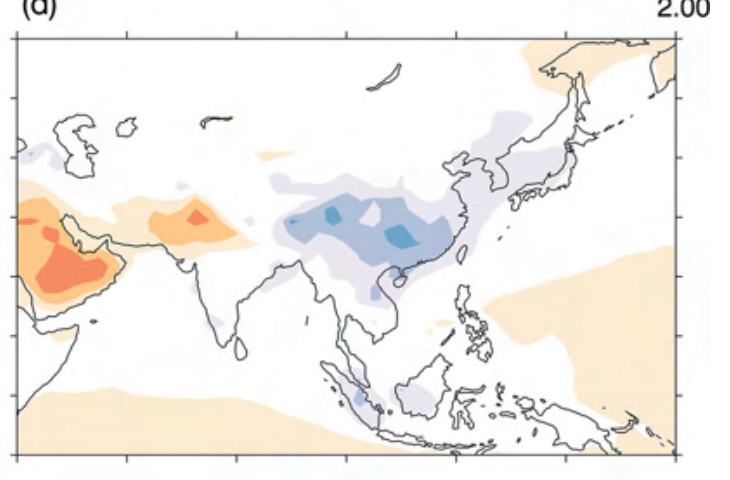

2.95

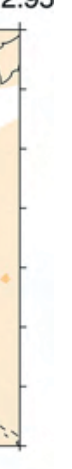

$-\infty$
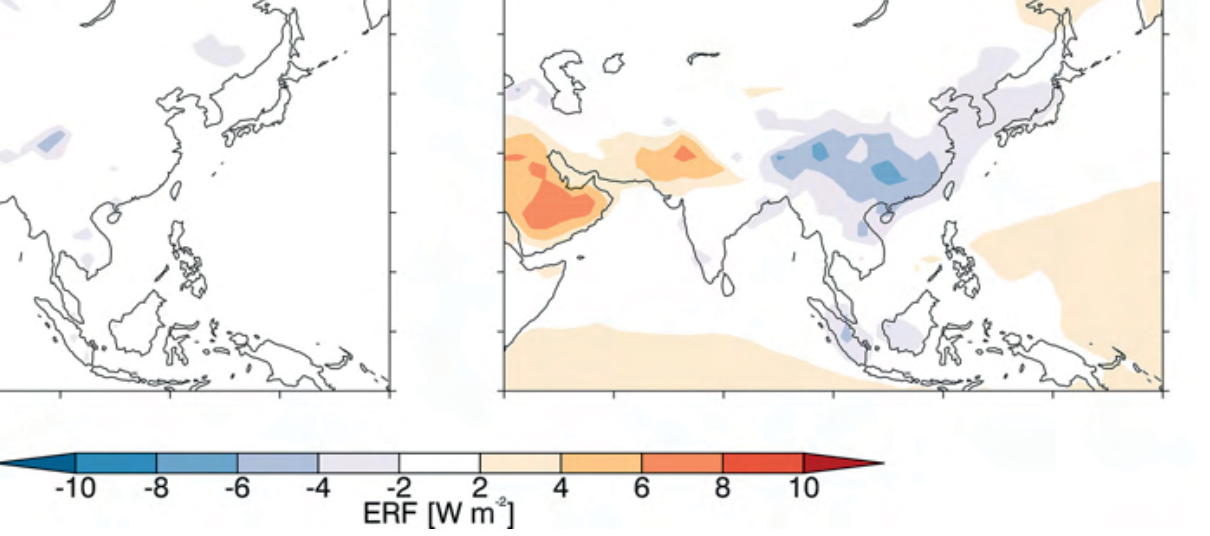

Figure 2. CMIP6 historical (2014 vs. 1850) effective radiative forcing due to (a) anthropogenic aerosols, (b) greenhouse gases, (c) land use and land cover changes, and (d) all anthropogenic drivers, calculated based on the models highlighted in Table 2. The number in the top right of each panel shows the global-mean value $\left(\mathrm{W} \mathrm{m}^{-2}\right)$.

sponse in these two scenarios is similar, then the greenhouse gas influence has yet to emerge over the aerosol signal. As the differences in greenhouse gas emissions between the two scenarios increase, a larger response is expected in SSP58.5, which has large increases in global GHG emissions compared to very moderate increases in SSP2-4.5 (Fig. 1). In cases where GHGs are the main driver of the response, the magnitude will increase monotonically from SSP1-1.9 to SSP5-8.5 (Fig. 3).

In Sect. 4.1, we use an additional DAMIP (Detection and Attribution Model Intercomparison Project; Gillett et al., 2016) experiment, SSP2-4.5-aer. This differs from the companion SSP2-4.5 in that only aerosol emissions are evolving, while all other forcings are held constant at their 1850 levels. This scenario allows the response to anthropogenic aerosols to be seen in isolation from the response to greenhouse gas changes and may thus provide support to any conclusion drawn from the analysis of the SSP2-4.5 experiment. Data for this experiment are so far only available for two models, CanESM5 and MIROC6 (Shiogama, 2019; Swart et al., 2019a). In this analysis, decadal-mean anomalies are again presented relative to the present day (1980-2014). However, in this case, the present day is necessarily defined based on the historical-aer simulation (a historical simulation where only anthropogenic aerosol and precursor emissions are transient, also included in DAMIP).

\subsection{Present-day model evaluation}

Here, we use a number of observation and reanalysis datasets to present a broad evaluation of the performance of CMIP6 models in reproducing present-day (1980-2014) climatologies and linear trends in global temperature and precipitation, the interhemispheric temperature gradient, and the Asian summer monsoon. Global temperature observations are taken from GISTEMP v4 (Hansen et al., 2010; Lenssen et al., 2019), the Goddard Institute for Space Studies gridded dataset, which is based on GHCN v4 over land (Global Historical Climatology Network; Menne et al., 2018) and ERSST v5 over ocean (Extended Reconstructed Sea Surface Temperature; Huang et al., 2017). GISTEMP is provided as anomalies relative to $1951-1980$ on a $2^{\circ} \times 2^{\circ}$ grid. For global precipitation, data from the Global Precipitation 
Table 2. Historical effective radiative forcing (ERF), calculated from RFMIP sstclim experiments, and equilibrium climate sensitivity (ECS) from Zelinka et al. (2020).

\begin{tabular}{|c|c|c|c|c|c|c|}
\hline \multirow[b]{2}{*}{ Centre } & \multirow[b]{2}{*}{ Model } & \multicolumn{3}{|c|}{$\operatorname{ERF}\left(\mathrm{W} \mathrm{m}^{-2}\right)$} & \multirow[t]{2}{*}{ ECS } & \multirow[t]{2}{*}{ RFMIP data reference } \\
\hline & & AA & GHG & LU & & \\
\hline CCCma & CanESM5 & & & & 5.64 & \\
\hline CNRM-CERFACS & CNRM-CM6-1 & -1.15 & 2.64 & & 4.90 & Voldoire (2019a) \\
\hline CNRM-CERFACS & CNRM-ESM2-1 & -0.74 & 2.41 & -0.07 & 4.79 & Seferian (2019a) \\
\hline IPSL* & IPSL-CM6A-LR & -0.59 & 2.84 & -0.02 & 4.56 & Boucher et al. (2018b) \\
\hline MIROC* & MIROC6 & -1.06 & 2.69 & -0.03 & 2.60 & Sekiguchi and Shiogama (2019) \\
\hline MOHC* & HadGEM3-GC31-LL & -1.10 & 3.09 & -0.11 & 5.55 & Andrews (2019) \\
\hline MOHC* & UKESM1-0-LL & -1.11 & 2.97 & -0.18 & 5.36 & O'Connor et al. (2019) \\
\hline MRI* & MRI-ESM2-0 & -1.19 & 3.03 & -0.18 & 3.13 & Yukimoto et al. (2019b) \\
\hline NASA-GISS* & GISS-E2-1-G & -1.32 & 2.92 & -0.00 & 2.71 & NASA/GISS (2019) \\
\hline$N C A R^{*}$ & CESM2 & -1.37 & 3.04 & -0.04 & 5.15 & Danabasoglu (2019b) \\
\hline NOAA-GFDL* & GFDL-CM4 & -0.73 & 3.14 & -0.33 & 3.89 & Paynter et al. (2018) \\
\hline
\end{tabular}

Models shown in italics are only used in historical analysis and do not appear in Figs. 7 to 11. Models with an asterisk (*) are used in the calculation of the ERF shown in Fig. 2.

Aerosol dominated

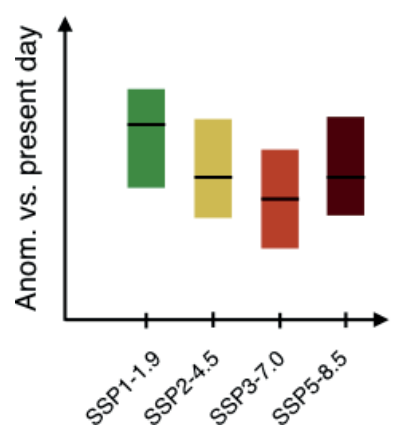

Figure 3. Schematics showing the anticipated pattern of anomalies relative to 1980-2014 across the SSPs in cases where the differences are aerosol-dominated and GHG-dominated, based on the global emission pathways shown in Fig. 1c. Boxes show the interquartile range of CMIP6 models; black lines show the median. Significant differences between the SSPs are seen when the median from one SSP falls outside the interquartile range of another. Significant differences between SSPs are not a condition for identification of the respective patterns but may be observed between the extreme scenarios in each case.

Climatology Project (GPCP; Adler et al., 2003) are used on a $2.5^{\circ} \times 2.5^{\circ}$ grid. GPCP combines gauge- and satellitebased observations over land with satellite observations over ocean. Since there can be large discrepancies between precipitation observations from different sources (Collins et al., 2013; Sperber et al., 2013; Prakash et al., 2015), we use a number of datasets in our evaluation of the Asian summer monsoon. Precipitation observations over land are also taken from APHRODITE (Asian Precipitation - Highly-Resolved Observational Data Integration Towards Evaluation; Yatagai et al., 2012) and the Global Precipitation Climatology Centre (GPCC; Schneider et al., 2014). APHRODITE contains data from a dense network of rain gauges and is used at $0.25^{\circ} \times 0.25^{\circ}$ resolution, within the domain bounded by $60^{\circ} \mathrm{E}, 150^{\circ} \mathrm{E}, 15^{\circ} \mathrm{S}$, and $55^{\circ} \mathrm{N}$. GPCC also provides gaugebased data but at a reduced horizontal resolution $\left(0.5^{\circ} \times 0.5^{\circ}\right)$ compared to APHRODITE. We also show precipitation from CMAP (Climate Prediction Centre Merged Analysis of Precipitation; Xie et al., 1996, 1997), which blends satellite- and gauge-based estimates with NCEP/NCAR reanalysis precipitation. The atmospheric circulation plays an important role in the distribution of Asian summer monsoon precipitation, so we also compare upper and lower tropospheric winds from CMIP6 models to ERA-Interim (Dee et al., 2011).

The global-mean annual-mean temperature anomaly from GISTEMP falls within the range of the CMIP6 ensemble during the historical period (Fig. 4a). However, most models overestimate the rate of recent warming (Fig. 4a, e). The interhemispheric temperature gradient (Northern HemisphereSouthern Hemisphere) anomalies are also consistent in GISTEMP and CMIP6 (Fig. 4b), although the models generally have anomalies that are more positive than seen in the observations. Most models reproduce the negative trend in the interhemispheric temperature gradient in 1950-1974 (Fig. 4e), which is associated with a global increase in anthropogenic aerosol and a weakening of the global monsoon (e.g. Polson et al., 2014). Most models also capture the positive trend 
(a)

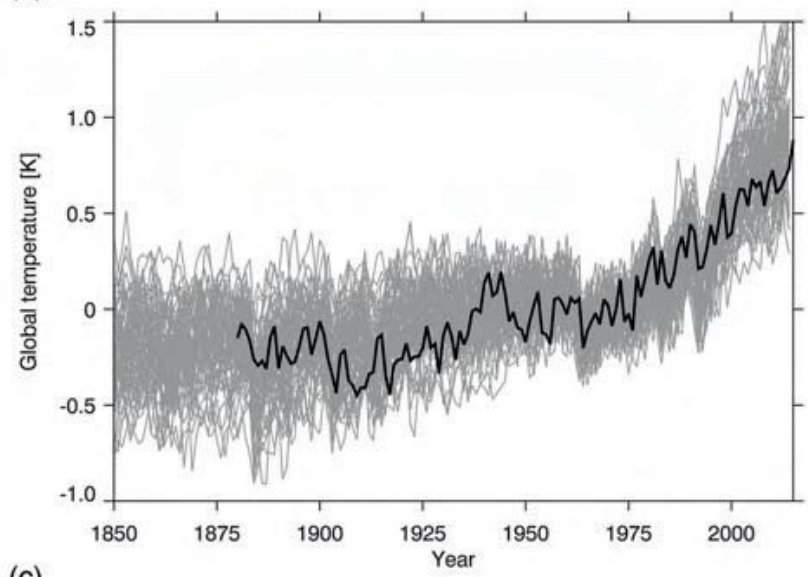

(c)

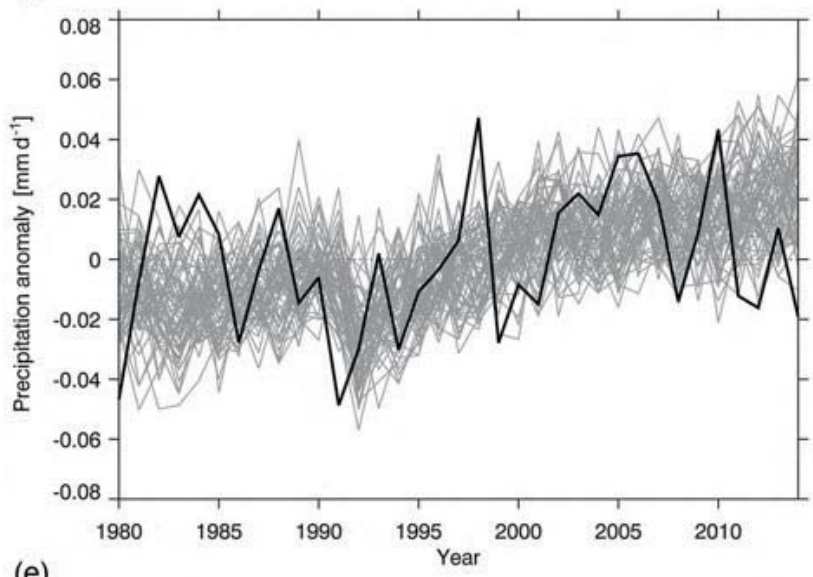

(e)

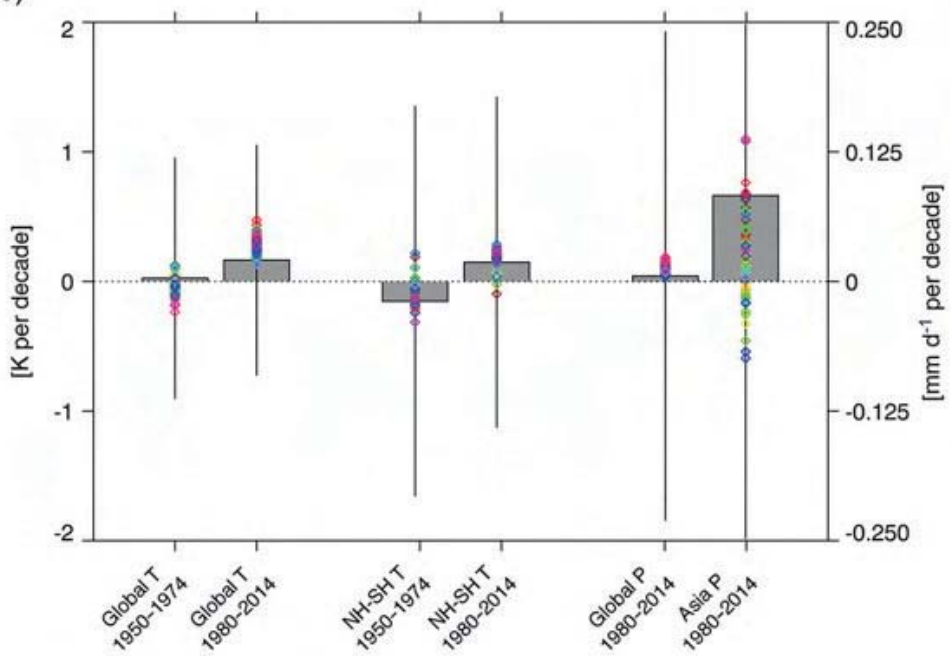

(b)

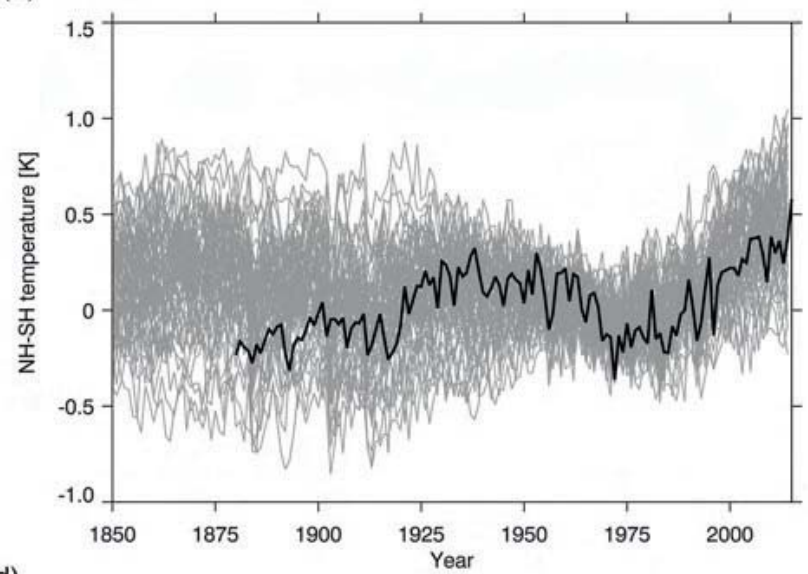

(d)

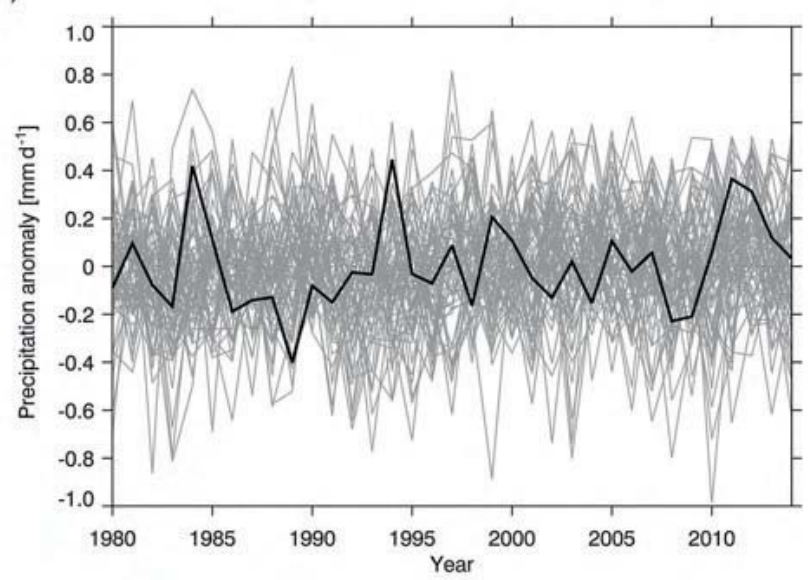

Figure 4. (a) Global-mean annual-mean temperature anomaly relative to 1951-1980 from CMIP6 (grey lines show individual members) and GISTEMP (black). (b) Annual-mean interhemispheric temperature gradient anomaly relative to 1951-1980 from CMIP6 (grey) and GISTEMP. (c) Annual-mean global-mean precipitation anomaly relative to 1980-2014 from CMIP6 (grey) and GPCP (black). (d) JJA-mean Asia-mean precipitation anomaly relative to 1980-2014 from CMIP6 (grey) and GPCP (black). Asia is the region from 5-47.5 $\mathrm{N}$ and $67.5-145^{\circ}$ E. (e) Linear trends in annual-mean global-mean temperature and JJA-mean interhemispheric temperature gradient from CMIP6 (coloured diamonds) and GISTEMP (grey bars) for 1950-1974 and 1980-2014 and linear trends in annual-mean global-mean precipitation and JJA-mean Asia-mean precipitation for 1980-2014 (grey bars are GPCP). Error bars show \pm 1 SE (standard error) on the observed trend. Note that for Asian precipitation this extends beyond the range of the plot and is an order of magnitude larger than the trend. 
in interhemispheric temperature gradient since 1980-2014 when rates of change in the global aerosol burden were relatively small (Fig. 4e).

All models simulate an increase in global-mean annualmean precipitation since 1980, and most model members simulate larger trends than observations (Fig. 4c, e). The observed trend in Asian $\left(67.5-145^{\circ} \mathrm{E}, 5-47.5^{\circ} \mathrm{N}\right)$ summer (June-August, JJA) precipitation is small compared to interannual variability, and this is reflected in large uncertainty in the sign of the modelled trend (Fig. 4d, e).

Compared to APHRODITE, the CMIP6 ensemble mean underestimates summer monsoon precipitation amount over India and overestimates it over the Tibetan Plateau and the Indochina peninsula (Fig. 5a, c, e). The magnitude of the bias between the CMIP6 multi-model mean and APHRODITE is comparable to the magnitude of the difference between observational datasets over north-east China and India, but the model biases over the Tibetan Plateau and the Indochina peninsula are relatively large (Fig. 5d, e). The modelled meridional component of the monsoon circulation at $850 \mathrm{hPa}$ is too strong over the Equatorial Indian Ocean, while the flow over the Bay of Bengal and the extension of the circulation into China are too weak (Fig. 5e). This pattern is seen in almost all models and is highlighted in the comparison of the zonal and meridional components of the $850 \mathrm{hPa}$ wind in CMIP6 and ERA-Interim in Fig. 5f. This weak extension of the summer monsoon into eastern China, with an anomalously strong extension into the subtropical west $\mathrm{Pa}-$ cific (Fig. 5e), is consistent with the pattern of differences between CMIP5 models and observations (Sperber et al., 2013). Nevertheless, the CMIP6 models are more skilful in their representation of the Indian summer monsoon compared to CMIP5 (Gusain et al., 2020).

While aspects of the CMIP6 multi-model mean summer monsoon compare well with observations, and the multimodel mean performs better than the individual models, there is a large inter-model diversity in the monsoon precipitation and atmospheric circulation (summarised in Fig. 5f; maps of present-day means, and anomalies compared to both APHRODITE and GPCP are shown for individual models Figs. S6-S10). Of the models we will consider on an individual basis in Sect. 4.1, CanESM5 has a small regional mean precipitation bias but a weak pattern correlation compared to APHRODITE. It has a particularly large dry bias over India, with less than $3 \mathrm{mmd}^{-1}$ in the seasonal mean and a relatively large excess of precipitation over the Tibetan Plateau and into China. MIROC6 performs relatively well over land but has excessive precipitation west of India (Figs. S6, S7, S9 and S10). Such biases may affect the pattern of the precipitation anomaly in the SSPs relative to the present day (Wilcox et al., 2015).

Aerosol optical depth (AOD) is a measure of the extinction of solar radiation due to scattering and absorption by an aerosol layer. Comparison of $550 \mathrm{~nm}$ AOD from CMIP6 and MODIS (Remer et al., 2008; Platnick, 2015) for the common
2002-2014 period shows that models underestimate AOD over much of the Northern Hemisphere $(\mathrm{NH})$ outside Asia and overestimate it in the Southern Hemisphere ( $\mathrm{SH})$ midlatitudes (Fig. 6a-c). This pattern is common across models, with some exceptions over Asia (Fig. S11 shows the comparison between AOD from individual models and MODIS). CanESM5 overestimates AOD over Eurasia, and northern China in particular, compared to MODIS. UKESM1-0-LL and IPSL-CM6A-LR have more moderate overestimates of AOD over parts of Asia. However, both models underestimate AOD over eastern China, where very high AOD is seen in MODIS.

\subsection{Future anthropogenic aerosol changes}

In all SSPs the largest AOD changes are over Asia (Fig. 6do), consistent with the changes in aerosol and precursor emissions (Fig. 1). Future changes in AOD are characterised by global decreases in SSP1-1.9, with the exception of an initial increase over South Asia, and positive anomalies relative to 1980-2014 over the Tibetan Plateau and southern Africa, which may have a dust component (Fig. 6d-f). AOD changes are characterised by regional contrasts in SSP2-4.5 and SSP5-8.5, with an overall decrease in the NH contrasted with an increase in the SH, and large decreases over East Asia against large increases over South Asia until the 2030s (Fig. 6g-i, m-o). This Asian dipole pattern is persistent in SSP2-4.5 and SSP5-8.5 and strengthens from the present until the 2040s. In these pathways, aerosol and precursor emission are similar, with the large increases in South Asian AOD predominantly driven by increases in $\mathrm{SO}_{2}$ emissions (Fig. 1). Emissions of black carbon in South Asia do follow different trajectories in the two pathways, but black carbon accounts for a smaller proportion of the total emission (Fig. 1) and thus the total AOD. The final scenario we consider, SSP3-7.0, again contrasts widespread decreases in NH AOD against increases in the SH (Fig. 6j-l). However, this scenario also includes large aerosol and precursor emission and AOD increases over East Asia and particularly South Asia. These increases are driven predominantly by $\mathrm{SO}_{2}$ over South Asia but have a BC contribution over East Asia (Fig. 1). As East Asian $\mathrm{SO}_{2}$ is roughly constant between 2014 and 2050 in SSP3-7.0, much of the large positive anomaly there is a reflection of the large positive trend in AOD between 1980 and 2014. The AOD pattern in SSP3-7.0 persists through the three periods shown in Fig. 6, but the East Asian increase starts to weaken by 2050 (Fig. 1).

\section{Global response}

Global-mean annual-mean temperature, precipitation, interhemispheric temperature gradient, and hydrological sensitivity anomalies for 2025-2034, 2035-2044, and 2045-2054 relative to 1980-2014 are shown in Fig. 7. The boxes show 
(a) ${ }_{\text {APHRODITE }}$

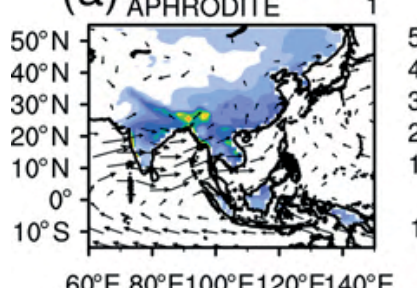

(b)

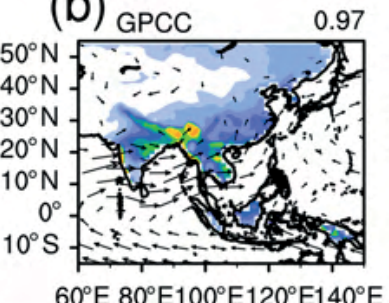

(c)

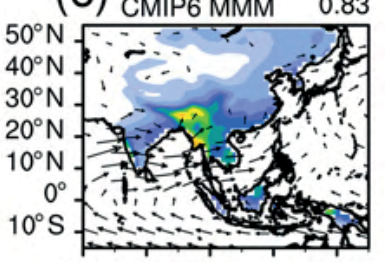

$60^{\circ} \mathrm{E} 80^{\circ} \mathrm{E} 100^{\circ} \mathrm{E} 120^{\circ} \mathrm{E} 140^{\circ} \mathrm{E}$

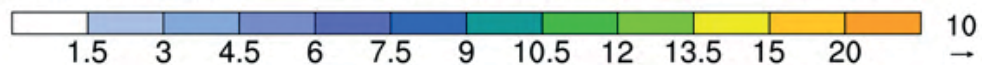

(d) GPCC

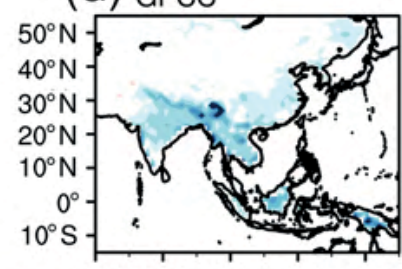

$60^{\circ} \mathrm{E} 80^{\circ} \mathrm{E} 100^{\circ} \mathrm{E} 120^{\circ} \mathrm{E} 140^{\circ} \mathrm{E}$ (e) CMIP6 MMM

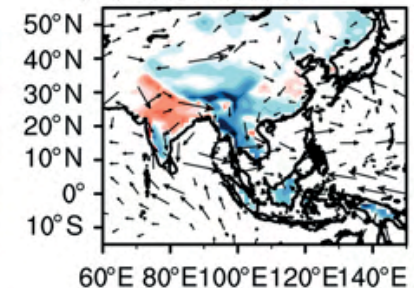

(f)
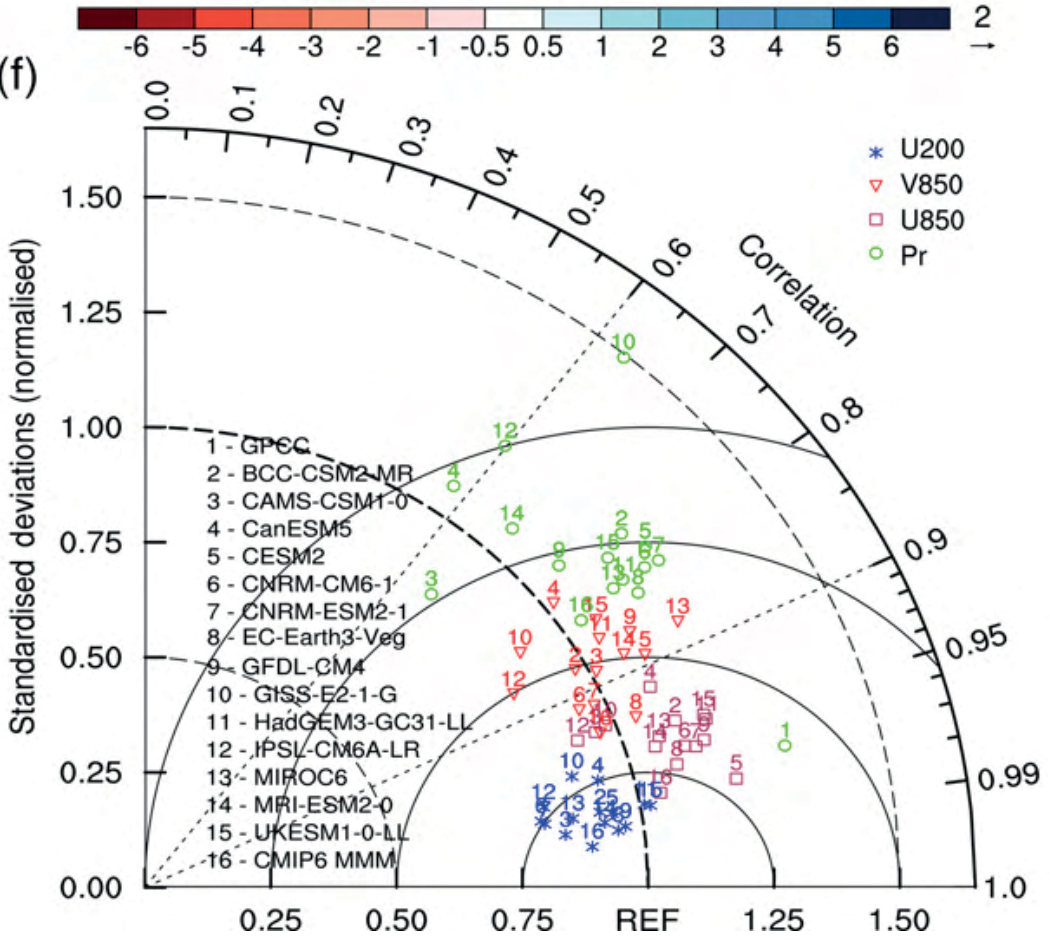

Figure 5. JJA-mean 1980-2014 mean precipitation over land ( $\mathrm{mmd}^{-1}$ ) overlaid with $850 \mathrm{hPa}$ wind ( $\mathrm{ms}^{-1}$ ) from (a) APHRODITE and ERA-Interim, (b) GPCC and ERA-Interim, and (c) CMIP6 (multi-model mean). Values in the top right corner of (a-c) show the pattern correlation with APHRODITE precipitation. (d) Precipitation bias in GPCC relative to APHRODITE. (e) CMIP6 precipitation relative to APHRODITE and CMIP6 $850 \mathrm{hPa}$ winds relative to ERA-Interim. (f) Taylor diagram showing the relationship between individual CMIP6 models, the CMIP6 multi-model mean (point 16), GPCC (point 1), and APHRODITE precipitation and ERA-Interim winds.

the interquartile range, based on the mean response from each individual model. Individual model responses are overlaid as black diamonds, and the horizontal bar shows the multi-model median. The $95 \%$ confidence interval (95\% CI) about a median can be found from the empirical relationship:
$95 \% \mathrm{CI}= \pm \frac{1.57 \times \mathrm{IQR}}{\sqrt{n}}$,

where IQR is the interquartile range, and $n$ is the number of points (McGill et al., 1978). For the sample size used in this work $(n=11), \frac{1.57}{\sqrt{n}} \approx 0.5$, so we use the interquartile 
(a) MODIS (MYD08_M3 AOD)
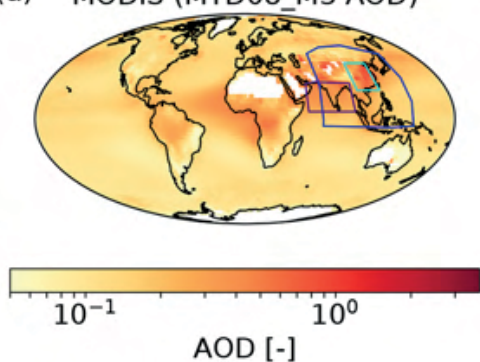

2025-2034

(d)

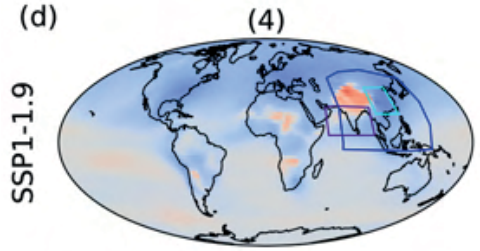

(e)

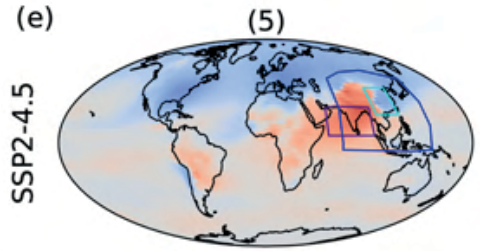

(f)

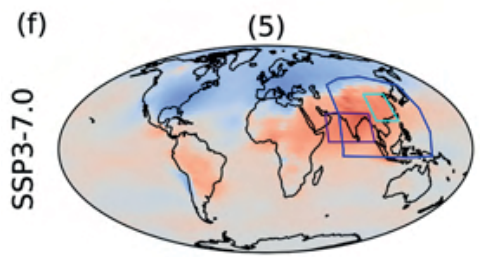

(g)

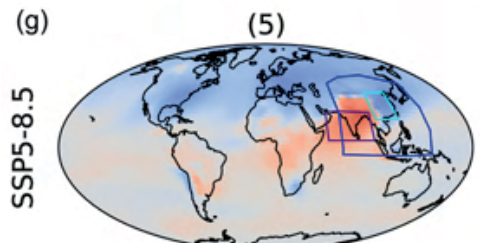

(b)
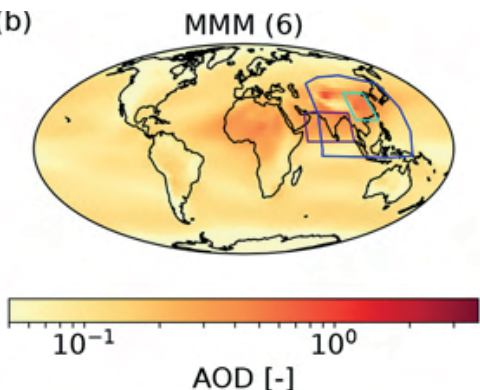

$2035-2044$

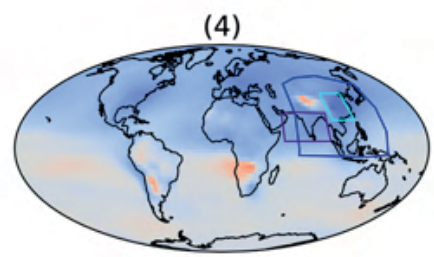

(5)

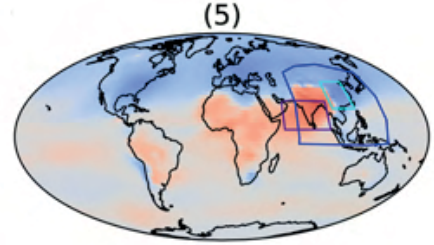

(5)

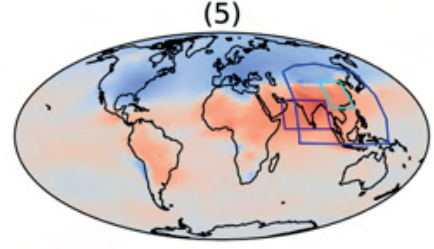

(5)

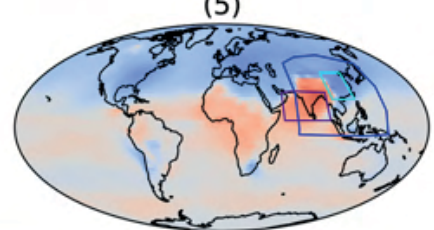

(c)

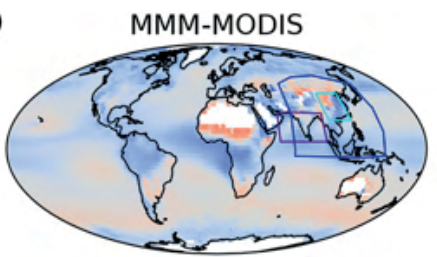

$\triangle \mathrm{AOD}[-]$

2045-2054

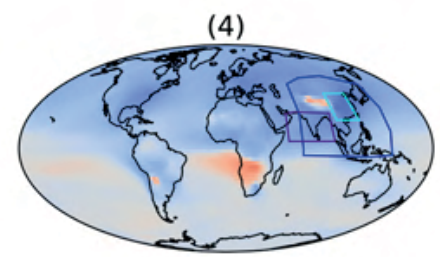

(5)

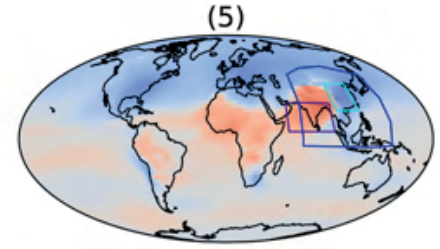

(5)

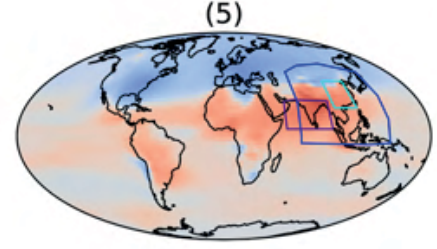

(5)

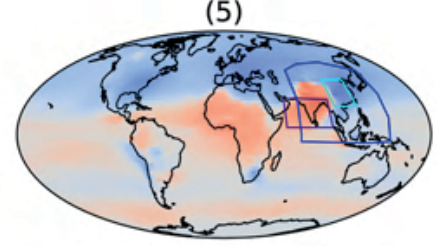

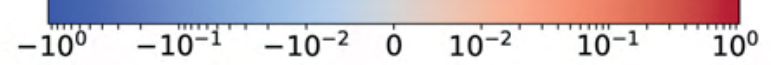

$\triangle \mathrm{AOD}[-]$ wrt to $1980-2014$

Figure 6. (a) 2002-2014 mean aerosol optical depth at 550 nm from MODIS. (b) 2002-2014 mean CMIP6 multi-model mean aerosol optical depth at $550 \mathrm{~nm}$ (based on six models; see Table 1). (c) CMIP6 bias relative to MODIS. CMIP6 AOD anomalies for 2025-2034, 2035-2044, and 2045-2054 vs. 1980-2014 for (d) SSP1-1.9, (e) SSP2-4.5, (f) SSP3-7.0, and (g) SSP5-8.5. For SSP1-1.9 the anomalies are based on four models. For all other panels, five models are used (Table 1). Blue, purple, and turquoise boxes show the "Asia", "South Asia", and "East Asia" regions used in later analysis. Asia is the region bounded by $5-47.5^{\circ} \mathrm{N}, 67.5-145^{\circ} \mathrm{E}$, East Asia is the region bounded by $20-40^{\circ} \mathrm{N}$ and $100-120^{\circ} \mathrm{E}$, and South Asia is the region bounded by $5-25^{\circ} \mathrm{N}$ and $55-95^{\circ} \mathrm{E}$.

range to determine significance, rather than assuming that the confidence interval is symmetric about the median. Significant differences between anomalies from different SSPS are identified when the median anomaly from one SSP lies outside the interquartile range of another and give additional support for the qualitative aerosol- and GHG-driven patterns sketched in Fig. 3.

For each period shown in Fig. 7a, the global-mean temperature anomalies are broadly ordered according to their GHG pathway and diverge with time in a similar fashion to GHG 
(a)

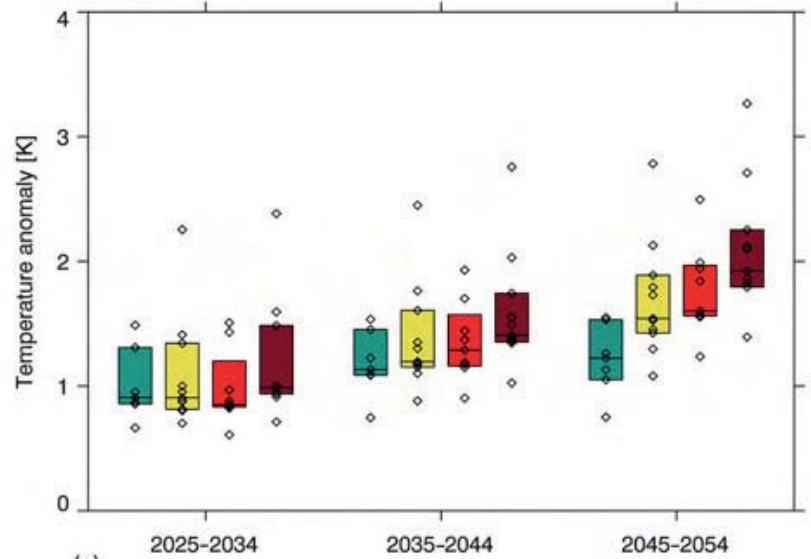

(c)

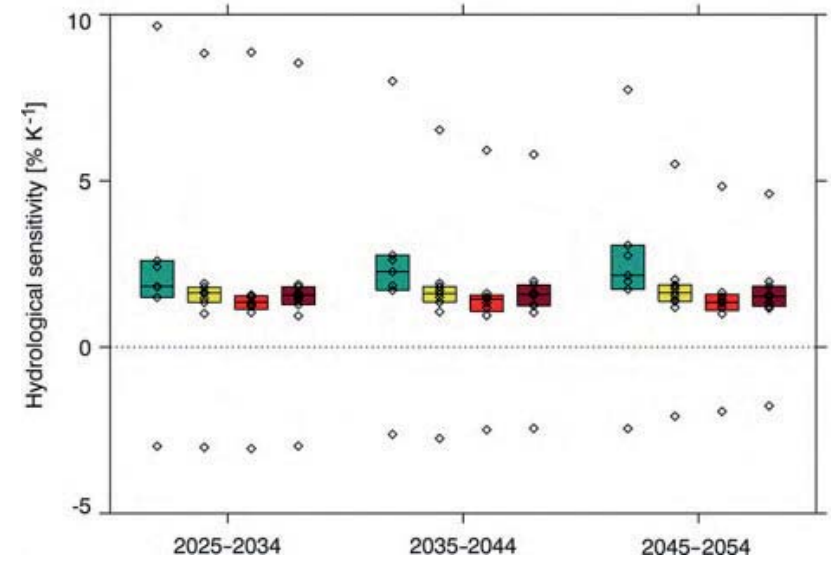

(b)

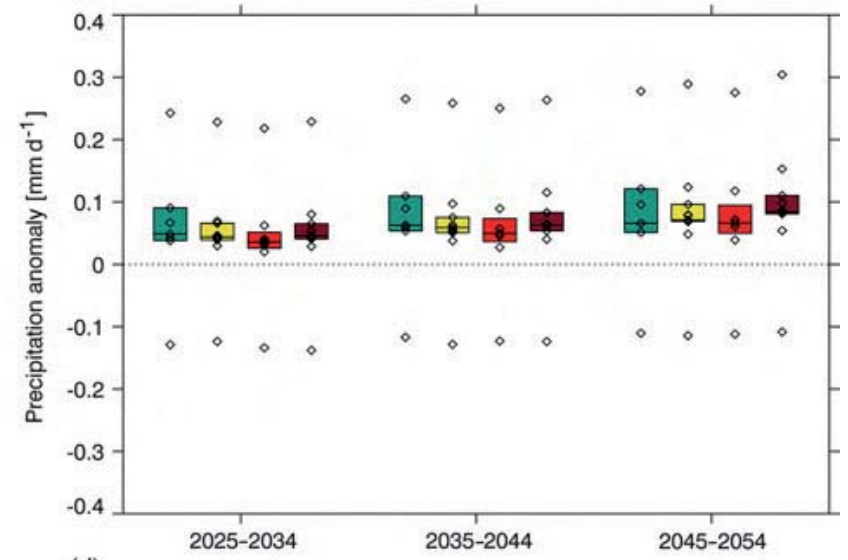

(d)

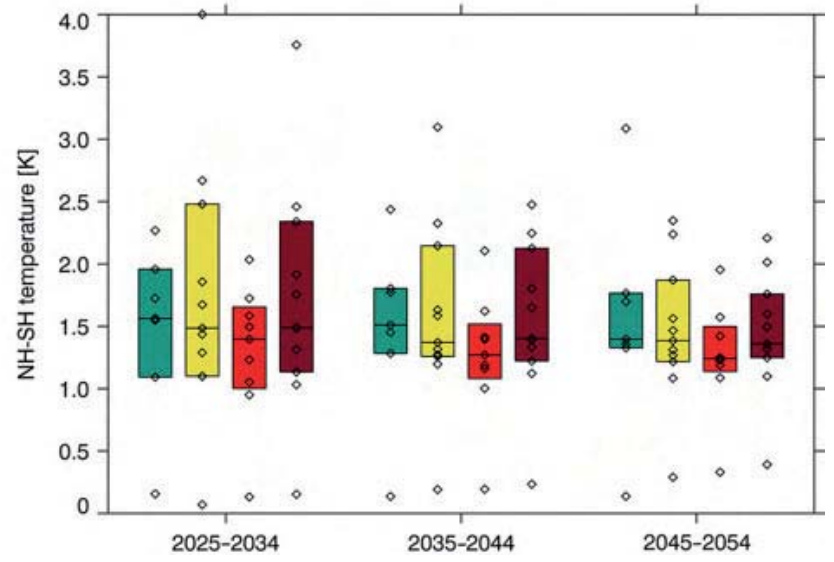

Figure 7. Global-mean annual-mean anomalies in (a) near-surface temperature $(\mathrm{K})$, (b) precipitation $\left(\mathrm{mmd}^{-1}\right)$, and (c) hydrological sensitivity $\left(\% \mathrm{~K}^{-1}\right.$ ) relative to $1980-2014$. (d) Annual-mean anomalies in interhemispheric temperature gradient (K) relative to 1980-2014. Coloured bars show the interquartile range, and the horizontal bar within this shows the median. Diamonds show values from each model listed in Table 1 as having data availability for a given SSP. Where multiple ensemble members are available, the model mean is used.

emissions (Figs. 1c and 3). By 2045-2054, SSP2-4.5, 3-7.0, and 5-8.5 anomalies relative to $1980-2014$ are significantly larger than those for SSP1-1.9. The anomaly from SSP5-8.5 is also significantly larger than that from SSP2-4.5. This suggests that anthropogenic aerosol plays a limited role in the evolution of global mean near-surface temperature on these timescales, supporting the conclusions of Shindell and Smith (2019). However, as will be discussed in Sect. 4, anthropogenic aerosol does play a role in the pattern and magnitude of regional temperature change. Importantly, anthropogenic aerosol is the main driver of trends in the interhemispheric temperature gradient until 2050 (Figs. 3 and 7d), which has a strong control on ITCZ position and the global monsoon and thus regional precipitation. There is a large spread in interhemispheric temperature gradient anomalies across models, consistent with the large uncertainty in historical trends (Fig. 4e), but a monotonic increase in the magnitude of the median anomaly from SSP3-7.0 to SSP1-1.9, consistent with an aerosol-driven response, is present in all three future periods. In 2035-2044 and 2045-2054 the SSP3-7.0 anomaly is significantly smaller than the SSP1-1.9 anomaly. The dominant role of anthropogenic aerosol is further supported by the comparable magnitude of anomalies in SSP2-4.5 and SSP58.5 (Figs. 3 and 7d).

There is a clear aerosol-driven signal in future increases in global mean precipitation and hydrological sensitivity (Figs. 3 and $7 \mathrm{~b}, \mathrm{c}$ ), with a significantly larger median anomaly in SSP1-1.9 compared to SSP3-7.0 in 2025-2034 and 2035-2044. There is the suggestion of the beginning of a shift towards GHGs as the dominant driver of precipitation increases in 2050, where the median SSP1-1.9 anomaly is marginally smaller than in SSP2-4.5, and the median anomaly in SSP5-8.5 is marginally larger than that in SSP24.5. GHGs are the main driver of global precipitation change by the end of the 21st century (not shown). The aerosol signal in hydrological sensitivity is larger and more persistent. SSP1-1.9 has significantly larger median hydrological sensitivity anomalies relative to 1980-2014 than SSP37.0 in 2025-2034 and significantly larger median anomalies than all other SSPs in 2035-2044 and 2045-2054. SSP1- 
Asia
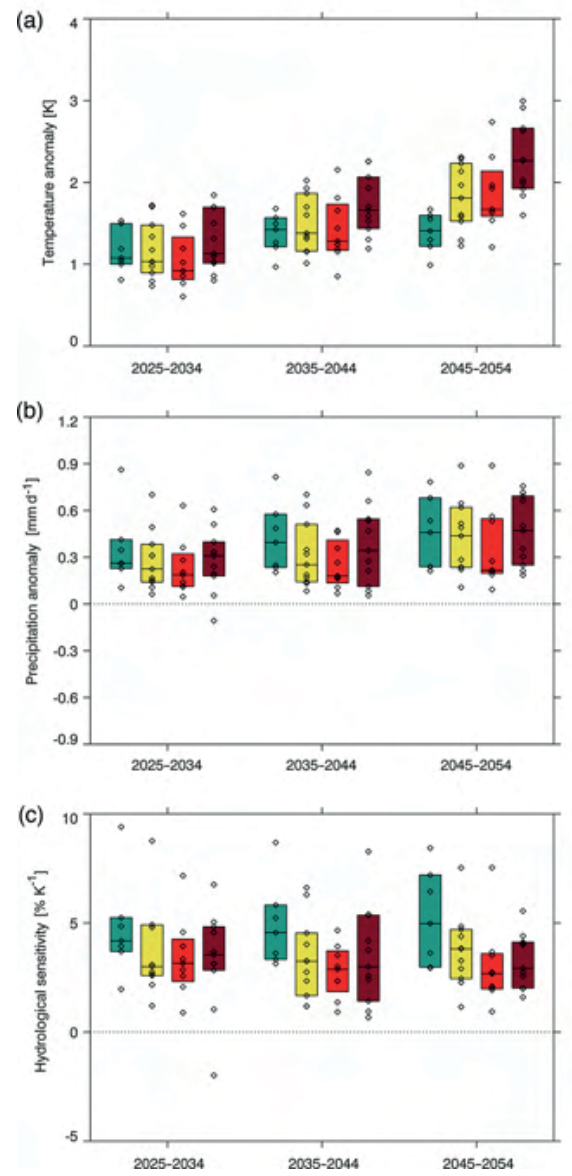

East Asia
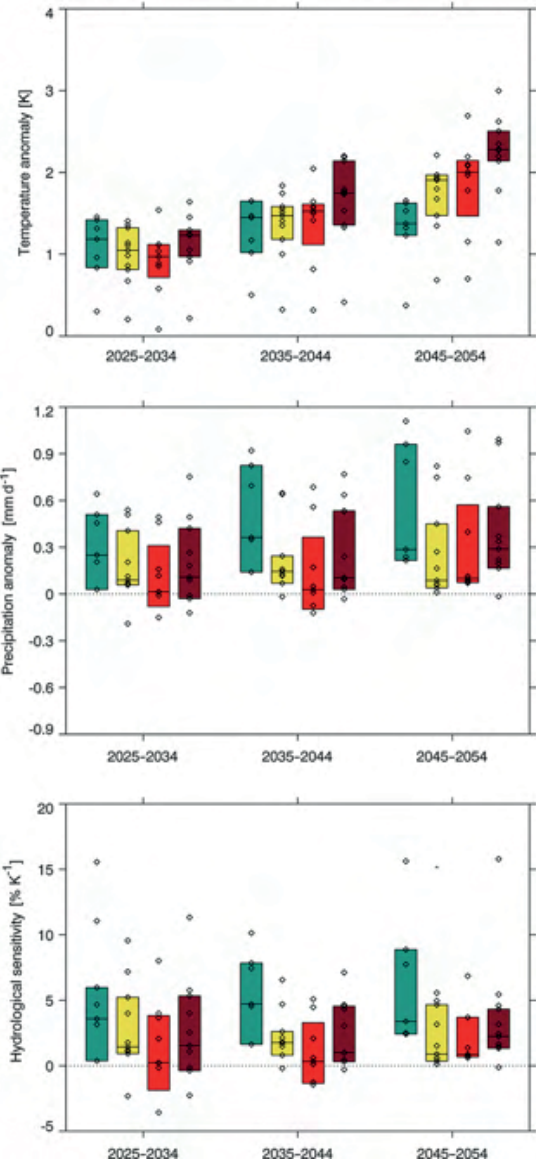

South Asia
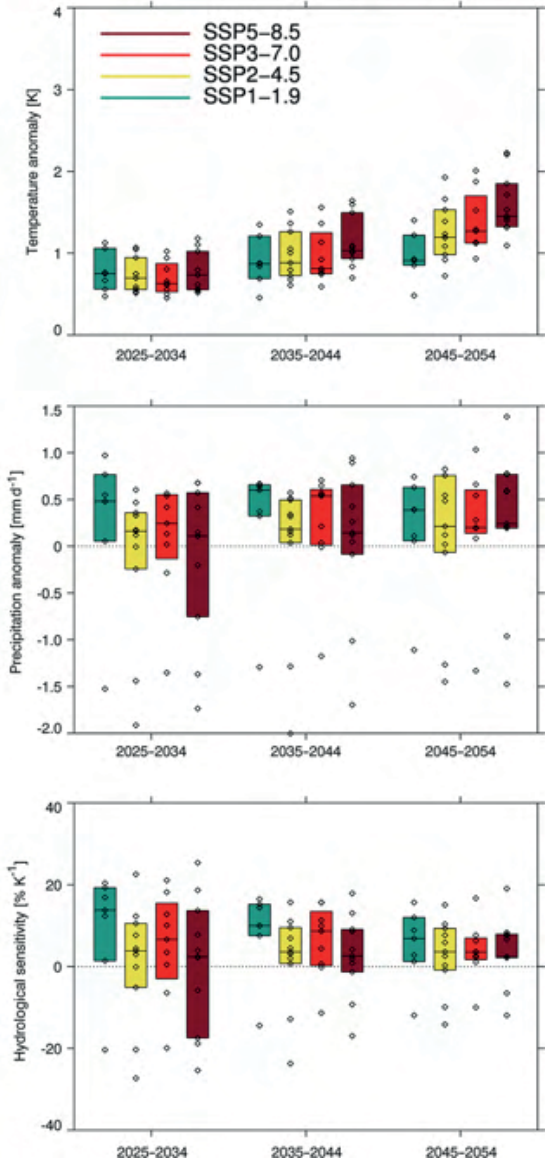

Figure 8. Regional-mean JJA-mean (a) temperature (K), (b) precipitation $\left(\mathrm{mm} \mathrm{d}^{-1}\right)$, and (c) hydrological sensitivity $\left(\% \mathrm{~K}^{-1}\right)$ anomalies relative to 1980-2014 for Asia, East Asia, and South Asia. The three regions are indicated by the boxes in Fig. 6. Coloured bars show the interquartile range, and the horizontal bar within this shows the median. Diamonds show values from each model listed in Table 1 as having data availability for a given SSP. Where multiple ensemble members are available, the model mean is used. Note that different $y$ ranges are used for each region in (b) and (c).

1.9 anomalies remain larger throughout the 21 st century (not shown).

A number of prominent outliers can be seen in Fig. 7. These points are not indicators of uncertainty in the response to anthropogenic aerosol emissions in the SSPs or in the relative differences in the anomalies compared to 1980-2014 from each SSP: for each variable the outlying model is the same for each period; and for precipitation and hydrological sensitivity the high outliers can be seen to show the same aerosol-driven pattern across the periods as the multi-model median response. The outliers are likely reflections of differing climate sensitivities in the models (Table 2). As shown in Fig. 4e, there are large positive trends in both globalmean temperature and precipitation between 1980 and 2014, which contribute to the magnitude of the anomalies shown in Fig. 7. Models in Fig. 7 with large temperature anomalies are CanESM5 and UKESM1-0-LL. MIROC6 has the smallest anomalies. These models are also those with the highest and lowest equilibrium climate sensitivities in our ensemble (Table 2). For precipitation, the large outlier is UKESM1-0LL, and the small outlier is CAMS-CSM1-0. The precipitation climatologies and patterns of future changes for these models are not unusual compared to other models, as can be seen in Figs. S6-S10 and S16.

\section{Asian summer monsoon response}

The decrease in Asian monsoon precipitation observed in the second half of the 20th century has been largely attributed to the global increase in anthropogenic aerosols (Bollasina et al., 2011; Song et al., 2014; Polson et al., 2014). The hemispheric asymmetry in aerosol forcing leads to an energy imbalance between the hemispheres, which in turn causes a slowdown of the meridional overturning circulation, and a weakening of the monsoon circulation (Bollasina et al., 2011; 

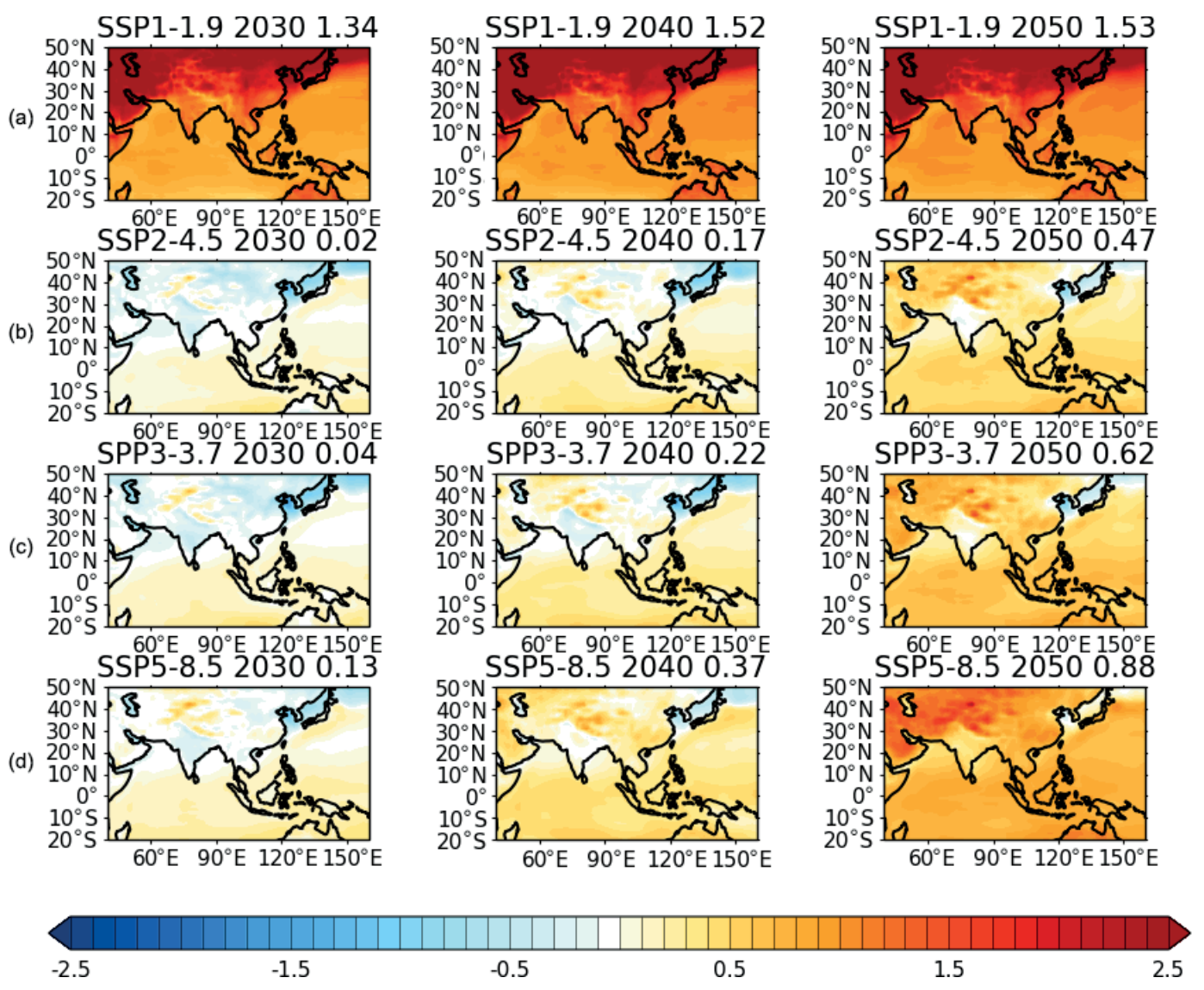

Figure 9. (a) CMIP6-mean JJA-mean near-surface temperature anomaly (K) for 2025-2034, 2035-2044, and 2045-2054 vs. 1980-2014 from SSP1-1.9. Relative anomalies for (b) SSP2-4.5, (c) SSP3-7.0, and (d) SSP5-8.5 vs. SSP1-1.9. The numbers shown at the top right of each panel are the Asian mean, where Asia is the region bounded by $5-47.5^{\circ} \mathrm{N}, 67.5-145^{\circ} \mathrm{E}$.

Song et al., 2014; Lau et al., 2017; Undorf et al., 2018). Local aerosol emissions further modify monsoon circulation and precipitation (Cowan and Cai, 2011; Guo et al., 2015; Undorf et al., 2018). In contrast to anthropogenic aerosols, where circulation changes are an important component of the response to forcing, GHGs mainly affect (increase) monsoon precipitation by enhancing tropospheric water vapour and thus increasing moisture transport toward India (Li et al., 2015).

Global aerosol reductions in SSP1-1.9 briefly cause faster warming over all Asian regions than the other scenarios considered, with SSP1-1.9 warming significantly more than SSP3-7.0, but this effect does not persist beyond the 2040s (Fig. 8a). However, anthropogenic aerosol does affect the regional pattern of warming (Fig. 9), with slower increases in land temperature in many areas, and India in particular, in SSP2-4.5, 3-7.0, and 5-8.5 compared to SSP1-1.9. This pattern is robust across models (Fig. S12). The growing influence of GHGs with time can also be seen in Figs. $8 \mathrm{a}$ and 9 as greater warming in SSP5-8.5 compared to SSP2-4.5 in the 2040s. The GHG-driven pattern is established by $2045-$ 2054, when all SSPs warm significantly more than SSP11.9. Continued increases in anthropogenic aerosol emissions in SSP3-7.0 appear to moderate land warming compared to other SSPs, despite large GHG increases (Figs. 8a and 9).

The influence of aerosol is more clearly seen, and more persistent in time, in regional mean precipitation than regional mean temperature (Figs. 3 and 8a, b), as for the global-mean case (Fig. 7b). Over Asia, the largest modelmedian precipitation increase relative to 1980-2014 occurs in SSP1-1.9 for 2025-2034 and 2035-2044 (significantly larger than SSP2-4.5 in 2025-2034 and significantly larger than SSP3-7.0 in all periods shown). The smallest precipitation increases are seen in SSP3-7.0 during these periods. Increases in SSP2-4.5 lie between those in SSP3-7.0 and SSP11.9. The same pattern is seen over East Asia. There is some indication that precipitation anomalies relative to 1980-2014 are slightly larger in SSP5-8.5 compared to SSP2-4.5, but the growing difference between the two scenarios that was seen for temperature is not seen here. By 2100, GHGs are the dominant influence on the relative magnitude of the future increases in Asian summer monsoon precipitation across the SSPs, but the timing of the transition is model-dependent, as illustrated in Fig. 10. 


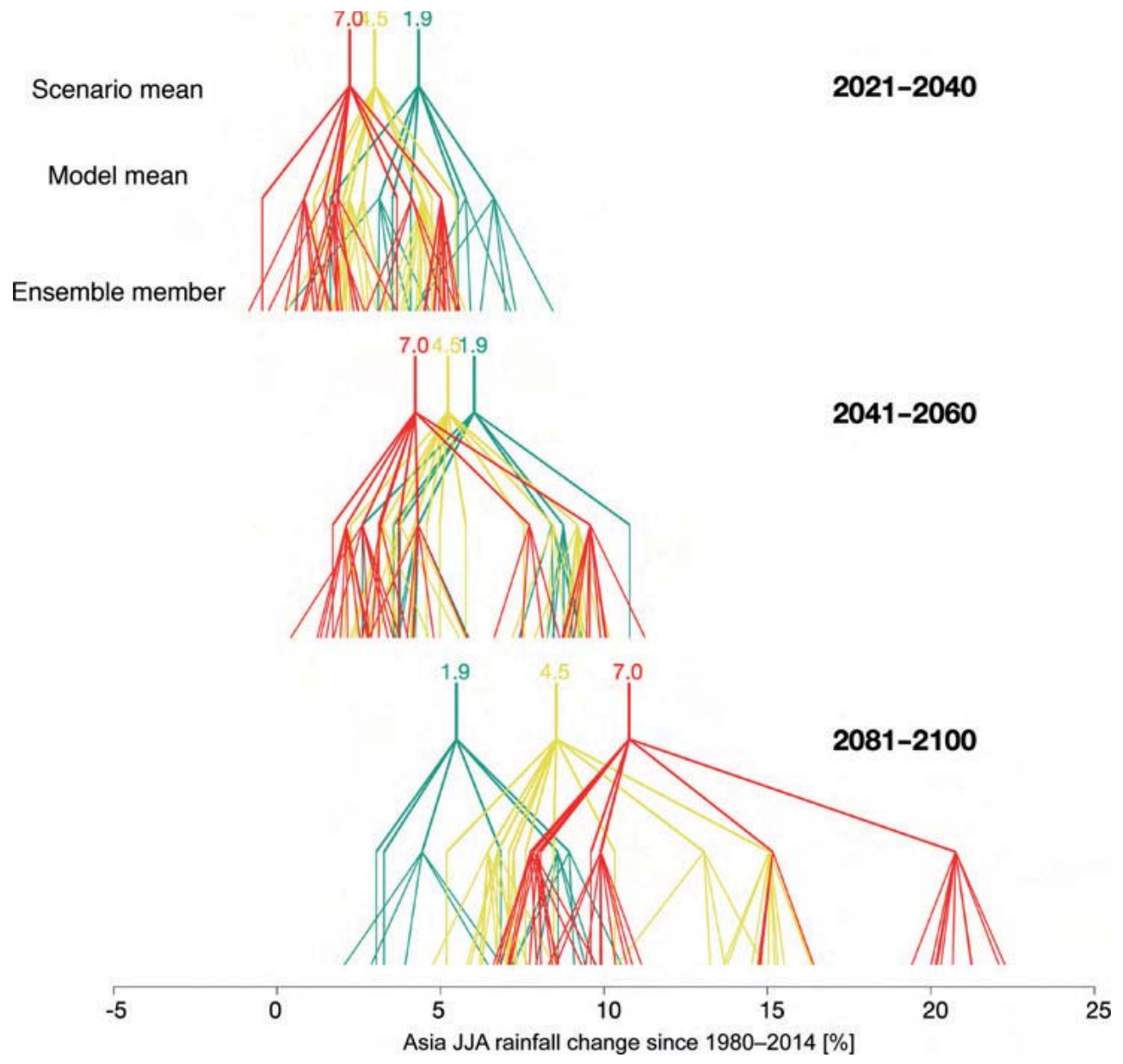

Figure 10. Asia-mean JJA-mean precipitation anomaly (\%) relative to 1980-2014 in scenario and model means and individual ensemble members for 2021-2040, 2041-2060, and 2081-2100 from SSP1-1.9, SSP2-4.5, and SSP3-7.0.

Over Asia and East Asia, precipitation increases relative to 1980-2014 are significantly smaller in SSP3-7.0 compared to SSP1-1.9 until the mid-21st century (Fig. 8b). Over East Asia, JJA mean precipitation is not significantly larger than in 1980-2014 in SSP3-7.0 until 2045-2054. A similar pattern of aerosol-dominated differences between the SSPs is seen in hydrological sensitivity over Asia and East Asia (Figs. 3 and $8 \mathrm{c}$ ). The beginnings of the GHG influence are seen in hydrological sensitivity over East Asia in 2045-2054, when the SSP5-8.5 anomaly is slightly larger than that from SSP2-4.5. However, the clear GHG-dominated pattern seen for temperature (Fig. 8a) is not seen here.

Figures 11 and 12 show that the pattern of Asian precipitation changes is similar, regardless of the emission pathway that is followed, but that the magnitude of the changes is pathway-dependent, as summarised in Fig. 8. Figure 11 shows the absolute anomaly compared to 1980-2014, while Fig. 12 shows the anomaly relative to the SSP1-1.9 response. In Fig. 12, the influence of GHGs can be seen, with greater GHG emissions driving greater drying over the Equatorial Indian Ocean and further increases in precipitation over India (particularly in the comparison between SSP2-4.5 and SSP58.5 and in SSP3-7.0 in the 2050s), as for temperature (Fig. 9). Precipitation increases are smaller in SSP2-4.5, SSP3-7.0, and SSP5-8.5 compared to SSP1-1.9 (Figs. 8 and 11), mainly due to differences over northern India, Bangladesh, and the Bay of Bengal (Fig. 12). The pattern seen in the model-mean anomaly (Fig. 12) is robust across models (Fig. S13).

The pattern of precipitation anomalies relative to 1980 2014 across the SSPs is different over South Asia compared to East Asia and Asia (Figs. 3 and 8). This suggests that the continued increases in local aerosol emissions may be relatively more important here than the remote decreases. All precipitation anomalies are positive, although many are not significantly different to zero. In 2025-2034 and 20352044 precipitation and hydrological sensitivity anomalies in SSP2-4.5 and SSP5-8.5 are smaller than those in SSP1-1.9 and SSP3-7.0, following neither the pattern expected from global and East Asian aerosol pathways, nor the GHG pathways (Fig. 3). This similarity between SSP2-4.5 and SSP58.5, which is seen in all three periods for South Asia, suggests that the dipole in aerosol and precursor emissions and AOD 
(a)

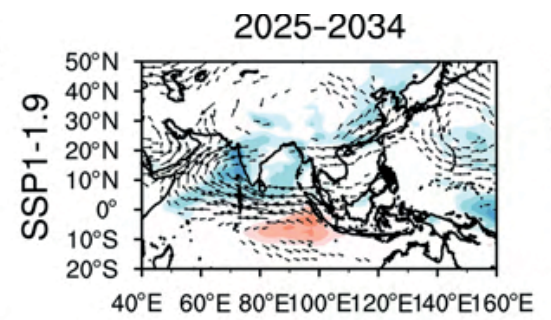

(b)

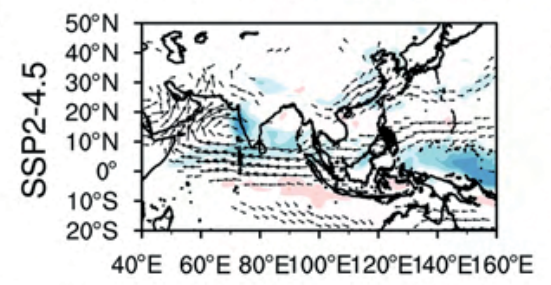

(c)

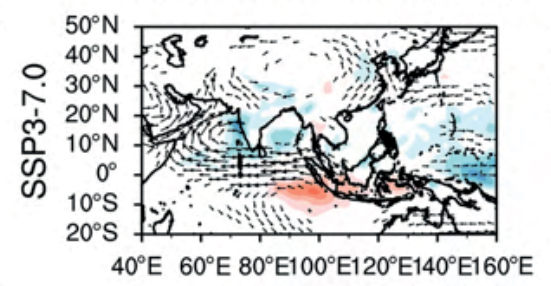

(d)

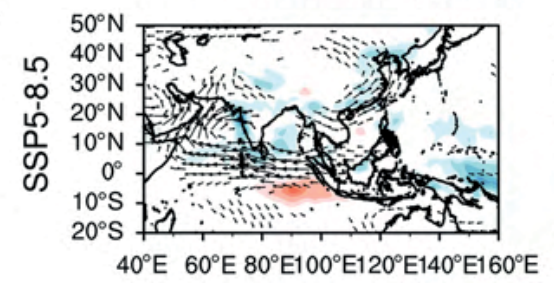

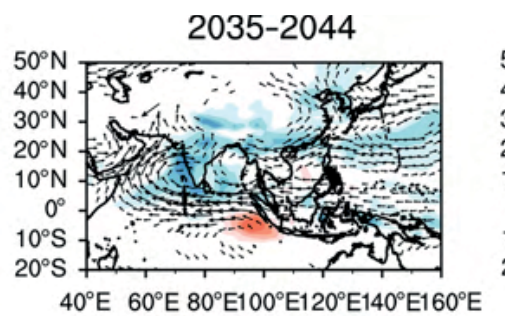
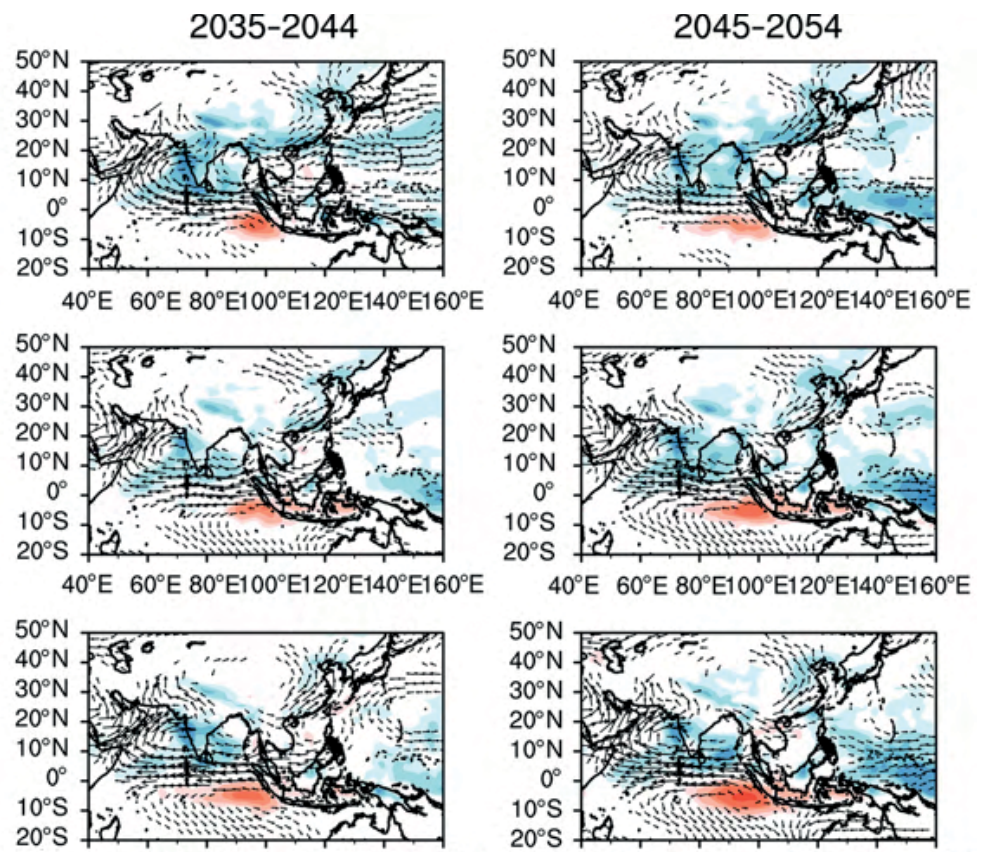

$40^{\circ} \mathrm{E} 60^{\circ} \mathrm{E} 80^{\circ} \mathrm{E} 100^{\circ} \mathrm{E} 120^{\circ} \mathrm{E} 140^{\circ} \mathrm{E} 160^{\circ} \mathrm{E}$
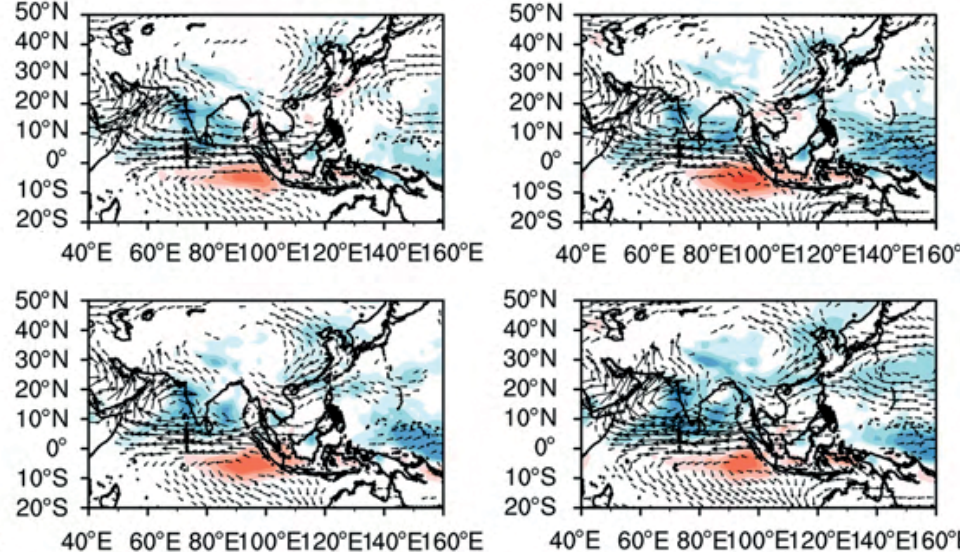

$40^{\circ} \mathrm{E} 60^{\circ} \mathrm{E} 80^{\circ} \mathrm{E} 100^{\circ} \mathrm{E} 120^{\circ} \mathrm{E} 140^{\circ} \mathrm{E} 160^{\circ} \mathrm{E}$

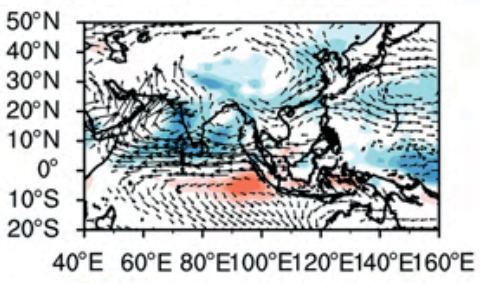

$40^{\circ} \mathrm{E} 60^{\circ} \mathrm{E} 80^{\circ} \mathrm{E} 100^{\circ} \mathrm{E} 120^{\circ} \mathrm{E} 140^{\circ} \mathrm{E} 160^{\circ} \mathrm{E}$

Figure 11. CMIP6-mean JJA-mean precipitation $\left(\mathrm{mm} \mathrm{d}^{-1}\right)$ and $850 \mathrm{hPa}$ wind anomalies $\left(\mathrm{m} \mathrm{s}^{-1}\right)$ for 2025-2034, 2035-2044, and 2045-2054 vs. 1980-2014 from (a) SSP1-1.9, (b) SSP2-4.5, (c) SSP3-7.0, and (d) SSP5-8.5.

anomalies between East Asia and South Asia in these scenarios (Figs. 1 and 6) may be further suppressing future increases in precipitation over South Asia due to feedback between the East and South Asian monsoon system responses to forcing (Ha et al., 2018; Singh et al., 2019a). Overall, there is much more uncertainty in the South Asian precipitation changes compared to East Asia, as evidenced by the larger inter-model spread (Fig. 8). Land use changes may also contribute to scenario uncertainty in South Asian precipitation changes (Singh et al., 2019b), although they are likely to be very model-dependent and influence smaller spatial scales than those we consider here (Figs. 2 and S3).

\subsection{Aerosol only SSP2-4.5}

The deviation of the South Asian precipitation response from the GHG- and aerosol-driven patterns sketched in Fig. 3 suggests that the response to local aerosol changes, which have a different time evolution to those over East Asia and in the global mean (Fig. 1), may be competing with the response to remote aerosols emission changes. Such behaviour is con- sistent with the findings in earlier investigations of precipitation changes over South Asia, which have shown that both regional and local changes in anthropogenic aerosol are required to reproduce historical trends (e.g. Guo et al., 2016; Undorf et al., 2018). The suppressed precipitation increase in SSP2-4.5 and SSP5-8.5 relative to SSP1-1.9 and SSP37.0 is a fingerprint of the Asian dipole in AOD trends seen in these scenarios until the mid-21st century and in current observations (Fig. 6; Samset et al., 2019).

Analysis of SSP2-4.5-aer, in which only anthropogenic aerosol emissions are varying with time following the SSP24.5 pathway, allows the response to aerosol changes in this pathway to be isolated from that due to GHG increases. In this case, a dipole in temperature anomalies, with cooling over India and warming over East Asia, and in sea-level pressure, with a positive anomaly over India, the Bay of Bengal, and the Indochina peninsula, and a negative anomaly over the rest of Asia, can clearly be seen in both MIROC6 (Fig. 13) and CanESM5 (Fig. S14). This feature matches the dipole pattern in AOD changes (Fig. 6) and is apparent 
(a) $50 \%$
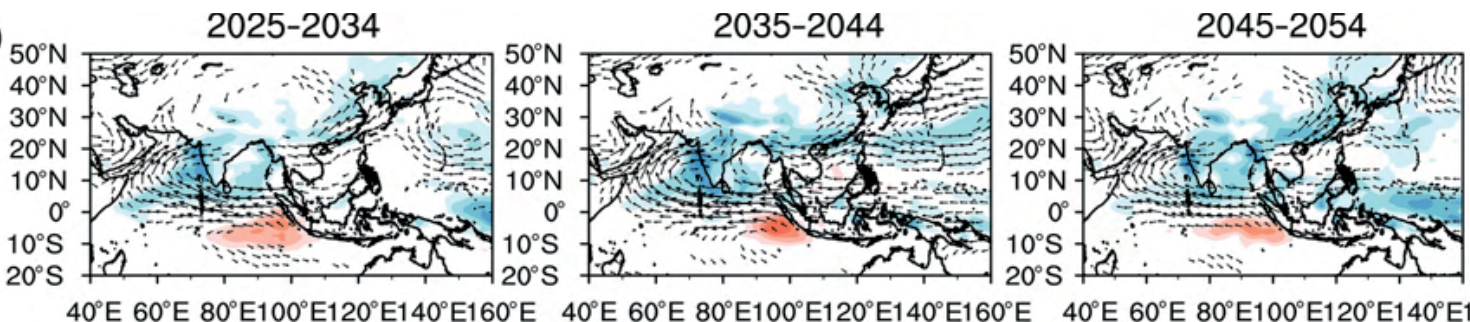

$40^{\circ} \mathrm{E} 60^{\circ} \mathrm{E} 80^{\circ} \mathrm{E} 100^{\circ} \mathrm{E} 120^{\circ} \mathrm{E} 140^{\circ} \mathrm{E} 160^{\circ} \mathrm{E} \quad 40^{\circ} \mathrm{E} 60^{\circ} \mathrm{E} 80^{\circ} \mathrm{E} 100^{\circ} \mathrm{E} 120^{\circ} \mathrm{E} 140^{\circ} \mathrm{E} 160^{\circ} \mathrm{E} \quad 40^{\circ} \mathrm{E} 60^{\circ} \mathrm{E} 80^{\circ} \mathrm{E} 100^{\circ} \mathrm{E} 120^{\circ} \mathrm{E} 140^{\circ} \mathrm{E} 160^{\circ} \mathrm{E}$

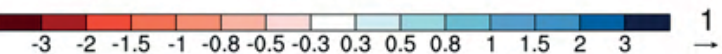

(b) $50^{\circ} \mathrm{N}$ SSP2-4.5
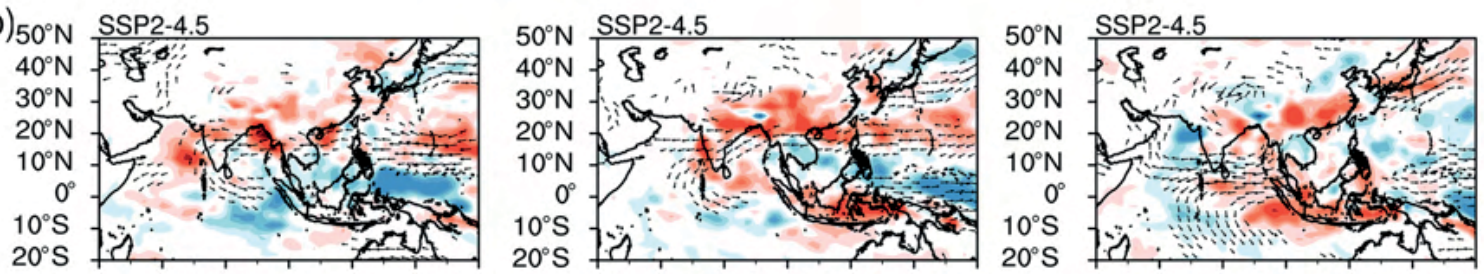

$40^{\circ} \mathrm{E} 60^{\circ} \mathrm{E} 80^{\circ} \mathrm{E} 100^{\circ} \mathrm{E} 120^{\circ} \mathrm{E} 140^{\circ} \mathrm{E} 160^{\circ} \mathrm{E} \quad 40^{\circ} \mathrm{E} 60^{\circ} \mathrm{E} 80^{\circ} \mathrm{E} 100^{\circ} \mathrm{E} 120^{\circ} \mathrm{E} 140^{\circ} \mathrm{E} 160^{\circ} \mathrm{E} 40^{\circ} \mathrm{E} 60^{\circ} \mathrm{E} 80^{\circ} \mathrm{E} 100^{\circ} \mathrm{E} 120^{\circ} \mathrm{E} 140^{\circ} \mathrm{E} 160^{\circ} \mathrm{E}$

(c) $50^{\circ} \mathrm{N}$ SSP3-7.0
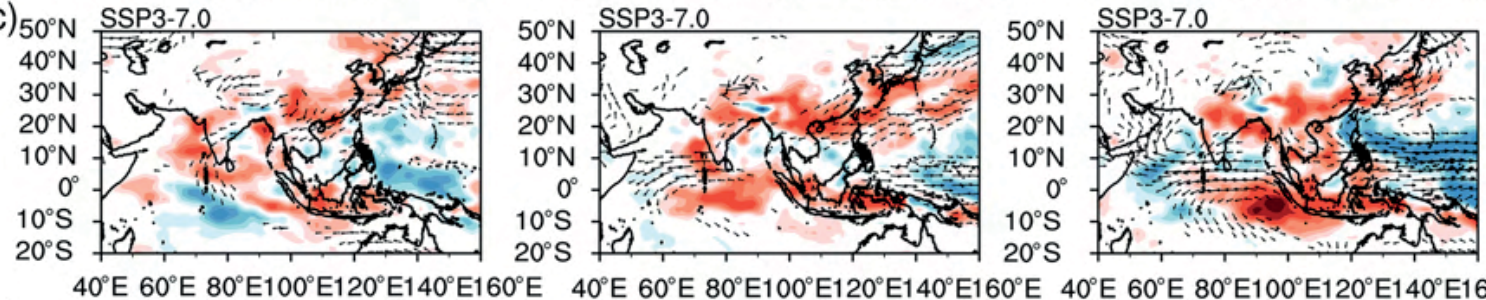

(d) $50^{\circ} \mathrm{N}$ SSP5-8.5
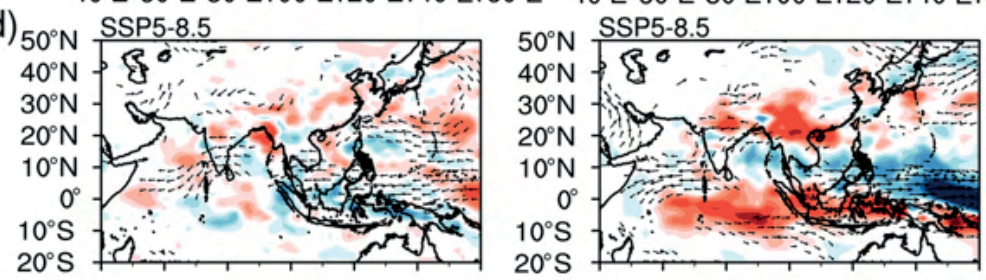

年 $40^{\circ} \mathrm{E} 60^{\circ} \mathrm{E} 80^{\circ} \mathrm{E} 100^{\circ} \mathrm{E} 120^{\circ} \mathrm{E} 140^{\circ} \mathrm{E} 160^{\circ} \mathrm{E}$

$40^{\circ} \mathrm{E} 60^{\circ} \mathrm{E} 80^{\circ} \mathrm{E} 100^{\circ} \mathrm{E} 120^{\circ} \mathrm{E} 140^{\circ} \mathrm{E} 160^{\circ} \mathrm{E} \quad 40^{\circ} \mathrm{E} 60^{\circ} \mathrm{E} 80^{\circ} \mathrm{E} 100^{\circ} \mathrm{E} 120^{\circ} \mathrm{E} 140^{\circ} \mathrm{E} 160^{\circ} \mathrm{E} \quad 40^{\circ} \mathrm{E} 60^{\circ} \mathrm{E} 80^{\circ} \mathrm{E} 100^{\circ} \mathrm{E} 120^{\circ} \mathrm{E} 140^{\circ} \mathrm{E} 160^{\circ} \mathrm{E}$

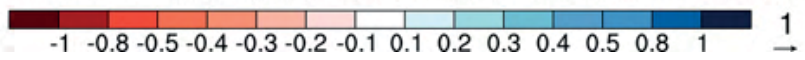

Figure 12. (a) JJA-mean precipitation $\left(\mathrm{mm} \mathrm{d}^{-1}\right)$ and $850 \mathrm{hPa}$ wind anomalies $\left(\mathrm{m} \mathrm{s}^{-1}\right)$ for 2025-2034, 2035-2044, and 2045-2054 vs. 19802014 from SSP1-1.9. Anomalies from (b) SSP2-4.5, (c) SSP3-7.0, and (d) SSP5-8.5 relative to the anomalies from SSP1-1.9. To enable a fair comparison of the precipitation patterns, only models with data availability for all scenarios are used (see Table 1).

in the SSP2-4.5 response up to 2050 as a moderated GHGinduced warming over South Asian relative to East Asia (Figs. 9 and 14). Comparing the SSP2-4.5-aer and SSP2-4.5 responses (Figs. 13 vs. 14 for MIROC6; Figs. S14 vs. S15 for CanESM5) shows that aerosol largely acts to offset the GHGdriven response, rather than determining the overall pattern of the response.

Differences in the character of the precipitation anomaly can be seen when comparing the anomalies pre- and post2050. In the earlier period, when South Asian aerosol emissions continue to increase, precipitation anomalies are either weakly positive or negative over India, the Bay of Bengal, and the Indochina peninsula. Post-2050, when anthropogenic aerosols are decreasing throughout Asia, precipitation increases are larger relative to $1980-2014$. There are also suggestions of this structure in the CMIP6 mean SSP2-4.5 re- sponse, where increases in precipitation are weak over India and the Bay of Bengal compared to the SSP1-1.9 response (Figs. 11 and 12), but it is not as clear. This is likely partly due to the influence of GHG increases and partly due to the effects of taking the mean response over models with large differences in their mean precipitation field (Fig. 5). However, a number of the individual models do simulate a similar tripolar pattern in precipitation change in SSP2-4. 5 to those in MIROC6 (Figs. 11, 12 and S9). Further study into the precipitation responses to the Asian aerosol dipole is needed to understand the mechanisms underlying this response. 

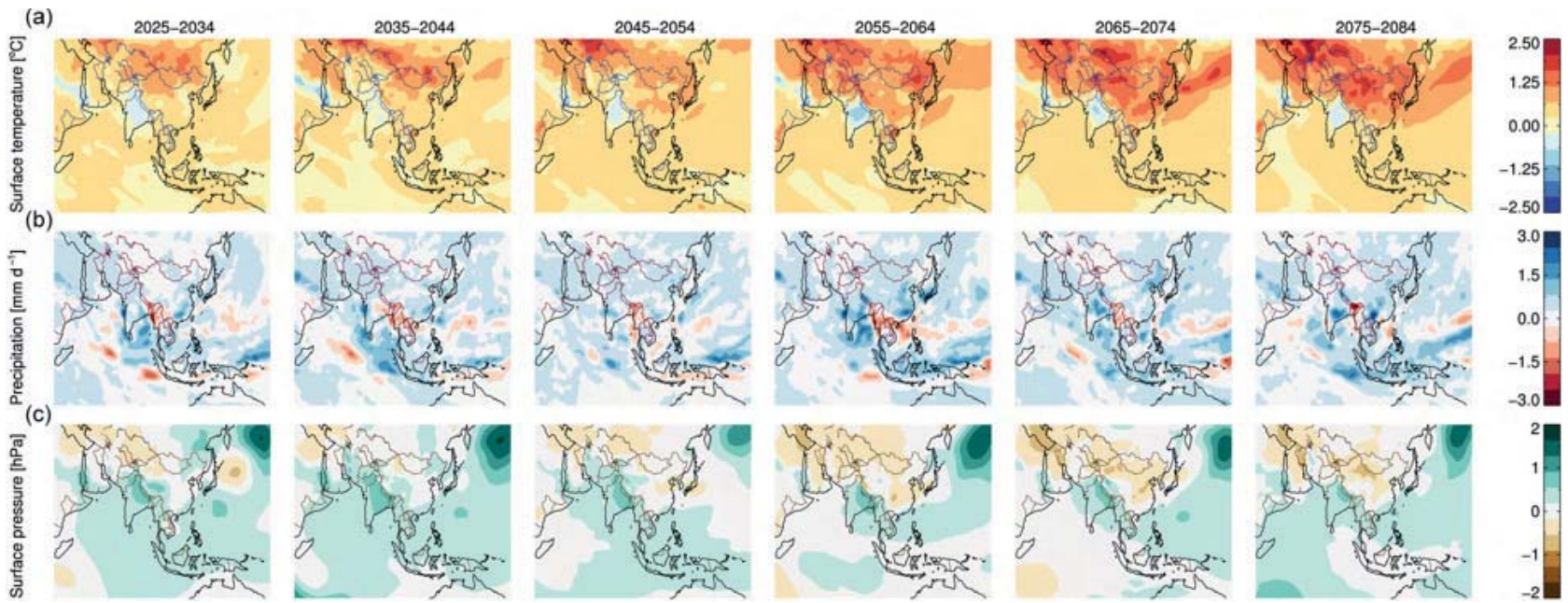

Figure 13. JJA-mean (a) near-surface temperature (K), (b) precipitation $\left(\mathrm{mmd}^{-1}\right)$, and (c) sea level pressure (hPa) anomalies for 10-year periods vs. 1980-2014 from an anthropogenic aerosol only version of SSP2-4.5 (SSP2-4.5-aer) with MIROC6.

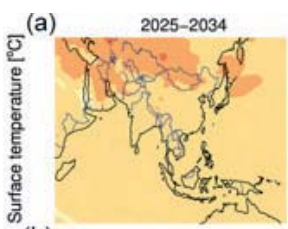

(b)
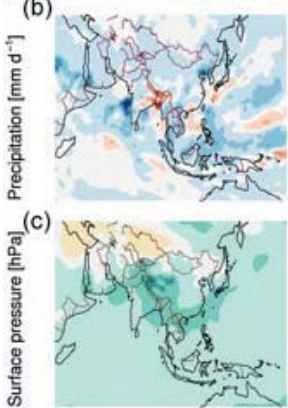
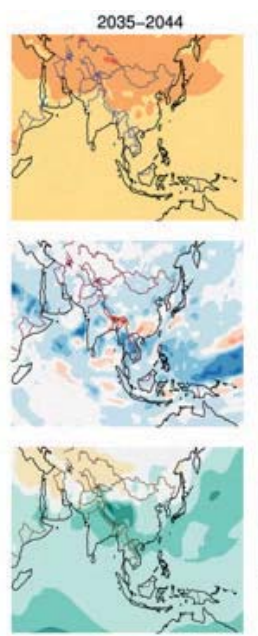
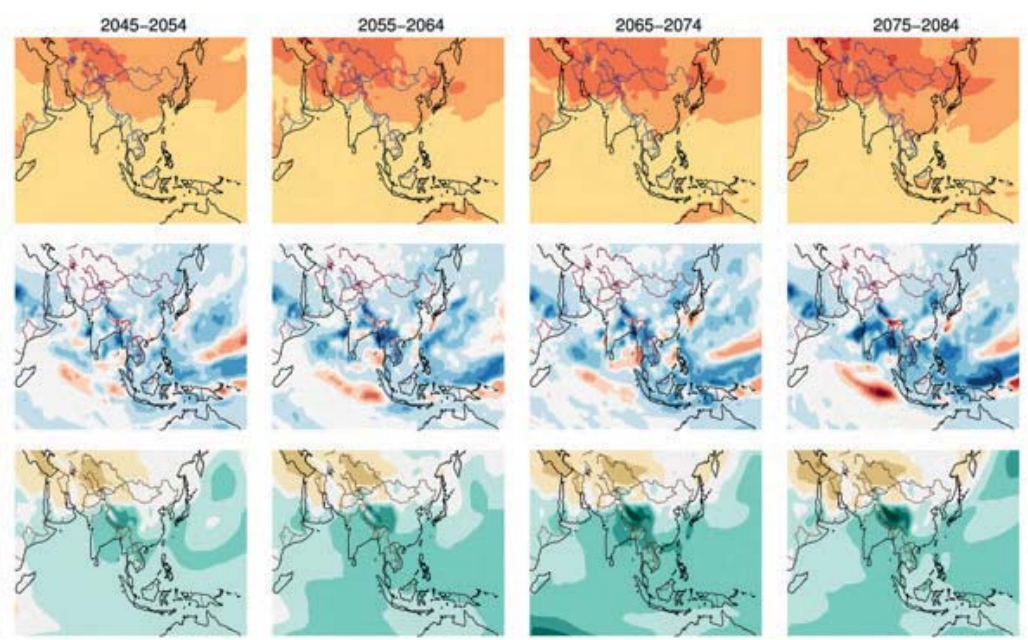
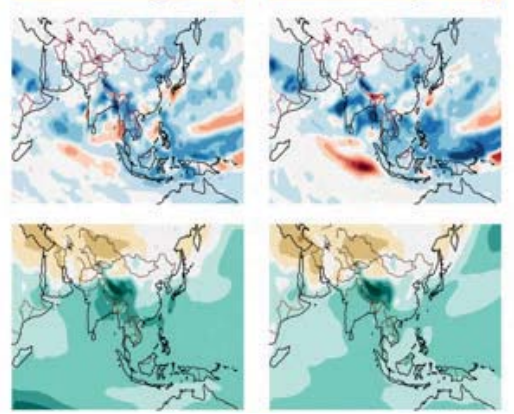
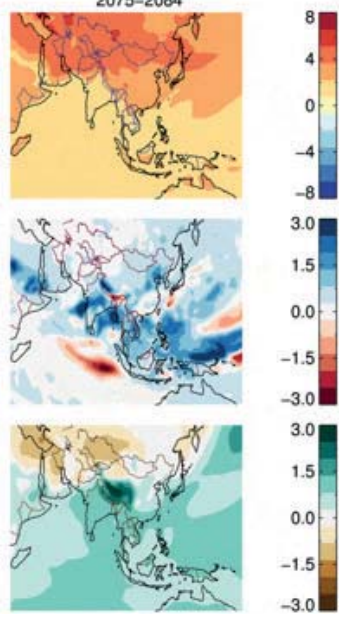

Figure 14. JJA-mean (a) near-surface temperature $(\mathrm{K})$, (b) precipitation $\left(\mathrm{mmd}^{-1}\right)$, and (c) sea level pressure (hPa) anomalies for 10-year periods vs. 1980-2014 from SSP2-4.5 in MIROC6.

\section{Conclusions}

There is large uncertainty in future anthropogenic aerosol emission pathways. This is likely to be of limited importance for global-mean temperature, but anthropogenic aerosol does play an important role in changes in regional temperature and global and regional precipitation until 2050 under the Shared Socioeconomic Pathways. Rapid reductions in anthropogenic aerosol and precursor emissions in SSP1-1.9 lead to larger increases in global and Asian summer monsoon precipitation compared to SSP2-4.5, 3-7.0, and 5-8.5 over East Asia and South Asia, despite the large decrease in greenhouse gases in SSP1-1.9.

In SSP2-4.5, 3.-7.0, and 5-8.5, anthropogenic aerosol emissions continue to increase until the mid-21st century over South Asia. This leads to weaker future increases in regional precipitation until 2050, compared to SSP1-1.9, particularly over northern India. In SSP2-4.5 and 5-8.5 continued increases in South Asian aerosol optical depth occur, while it decreases over East Asia. This may further suppress the precipitation increases in northern India compared to SSP1-1.9. However, there is large inter-model uncertainty in the South Asian precipitation changes.

A dipole in aerosol optical depth trends over Asia has been observed since 2010 (Samset et al., 2019), suggesting that SSP2-4.5, SSP5-8.5 (where the current AOD dipole pattern persists), or SSP1-1.9 (where anthropogenic aerosol is reduced in both regions) is more likely to be followed in the real world than SSP3-7.0 (where anthropogenic aerosol increases in both regions). This presents the possibility of 
large uncertainty in South Asian summer monsoon precipitation on a 30-50-year time horizon due to uncertainty in local aerosol emission pathways.

Data availability. All data used in this work are freely available for research purposes.

Supplement. The supplement related to this article is available online at: https://doi.org/10.5194/acp-20-11955-2020-supplement.

Author contributions. All authors designed the analysis and wrote the paper. LJW, ZL, BHS, EH, MTL, KN, and SU performed the analysis.

Competing interests. The authors declare that they have no conflict of interest.

Special issue statement. This article is part of the special issue "The Aerosol Chemistry Model Intercomparison Project (AerChemMIP)". It is not associated with a conference.

Acknowledgements. This work and its contributors Laura Wilcox, Zhen Liu, and Massimo Bollasina were supported by the UKChina Research and Innovation Partnership Fund through the Met Office Climate Science for Service Partnership (CSSP) China as part of the Newton Fund. Laura Wilcox received additional support from the Natural Environment Research Council (NERC; grant NE/S004890/1, EMERGENCE) and the International Meteorological Institute (IMI) visiting scientist program. Marianne T. Lund and Bjørn H. Samset acknowledge funding by the Research Council of Norway through grant no. 248834 (QUISARC). Kalle Nordling and Joonas Merikanto acknowledge support from the Academy of Finland project RECIA (grant no. 287440) and European Research Council project ECLAIR (grant no. 646857).

We acknowledge the World Climate Research Programme, which, through its Working Group on Coupled Modelling, coordinated and promoted CMIP6. We thank the climate modelling groups for producing and making available their model output, the Earth System Grid Federation (ESGF) for archiving the data and providing access, and the multiple funding agencies who support CMIP6 and ESGF. APHRODITE precipitation data are available from http://www.chikyu.ac.jp/precip. GISTEMP temperature data and CMAP, GPCC, and GPCP precipitation data were provided by the NOAA/OAR/ESRL PSD, Boulder, Colorado, USA, from their website at https://www.esrl.noaa.gov/psd/. We also acknowledge the use of ERA-Interim data produced by ECMWF and provided by the British Atmospheric Data Centre and the National Centre for Atmospheric Science. The analysis in this work was performed on the JASMIN super-data-cluster (Lawrence et al., 2012). JASMIN is managed and delivered by the UK Science and Technology Facilities Council (STFC) Centre for Environmental Data Archival (CEDA)
Financial support. This research has been supported by the Newton Fund (CSSP China), the Natural Environment Research Council (grant no. NE/S004890/1), the Research Council of Norway (grant no. 248834), the Academy of Finland (grant no. 287440), and the European Research Council (grant no. 646857).

Review statement. This paper was edited by Hailong Wang and reviewed by Fengfei Song and one anonymous referee.

\section{References}

Acosta Navarro, J. C., Varma, V., Riipinen, I., Seland, Ø. Kirkevåg, A., Struthers, H., Iversen, T., Hansson, H. C., and Ekman, A. M. L.: Amplification of Arctic warming by past air pollution reductions in Europe, Nat. Geosci., 9, 277-281, https://doi.org/10.1038/ngeo2673, 2016.

Acosta Navarro, J. C., Ekman, A. M. L., Pausata, F. S. R., Lewinschal, A., Varma, V., Seland, Ø., Gauss, M., Iversen, T., Kirkevåg, A., Riipinen, I., and Hansson, H. C.: Future Response of Temperature and Precipitation to Reduced Aerosol Emissions as Compared with Increased Greenhouse Gas Concentrations, J. Climate, 30, 939-954, https://doi.org/10.1175/JCLI-D16-0466.1, 2017.

Adler, R. F., Huffman, G. J., Chang, A., Ferraro, R., Xie, P.-P., Janowiak, J., Rudolf, B., Schneider, U., Curtis, S., Bolvin, D., Gruber, A., Susskind, J., Arkin, P., Nelkin, E., Adler, R. F., Huffman, G. J., Chang, A., Ferraro, R., Xie, P.-P., Janowiak, J., Rudolf, B., Schneider, U., Curtis, S., Bolvin, D., Gruber, A., Susskind, J., Arkin, P., and Nelkin, E.: The Version-2 Global Precipitation Climatology Project (GPCP) Monthly Precipitation Analysis (1979-Present), J. Hydrometeorol., 4, 1147-1167, https://doi.org/10.1175/15257541(2003)004<1147:TVGPCP>2.0.CO;2, 2003.

Andrews, T.: MOHC HadGEM3-GC31-LL model output prepared for CMIP6 RFMIP, Earth System Grid Federation, https://doi.org/10.22033/ESGF/CMIP6.475, 2019.

Andrews, T., Forster, P. M., Boucher, O., Bellouin, N., and Jones, A.: Precipitation, radiative forcing and global temperature change, Geophys. Res. Lett., 37, L14701, https://doi.org/10.1029/2010GL043991, 2010.

Bartlett, R. E., Bollasina, M. A., Booth, B. B. B., Dunstone, N. J., Marenco, F., Messori, G., and Bernie, D. J.: Do differences in future sulfate emission pathways matter for near-term climate? A case study for the Asian monsoon, Clim. Dynam., 50, 18631880, https://doi.org/10.1007/s00382-017-3726-6, 2018.

Bellouin, N., Rae, J., Jones, A., Johnson, C., Haywood, J., and Boucher, O.: Aerosol forcing in the Climate Model Intercomparison Project (CMIP5) simulations by HadGEM2-ES and the role of ammonium nitrate, J. Geophys. Res., 116, D20206, https://doi.org/10.1029/2011JD016074, 2011.

Bellouin, N., Mann, G. W., Woodhouse, M. T., Johnson, C., Carslaw, K. S., and Dalvi, M.: Impact of the modal aerosol scheme GLOMAP-mode on aerosol forcing in the Hadley Centre Global Environmental Model, Atmos. Chem. Phys., 13, 3027 3044, https://doi.org/10.5194/acp-13-3027-2013, 2013.

Bellouin, N., Quaas, J., Gryspeerdt, E., Kinne, S., Stier, P., Watson Parris, D., Boucher, O., Carslaw, K., Christensen, M., 
Daniau, A., Dufresne, J., Feingold, G., Fiedler, S., Forster, P., Gettelman, A., Haywood, J., Lohmann, U., Malavelle, F., Mauritsen, T., McCoy, D., Myhre, G., Mülmenstädt, J., Neubauer, D., Possner, A., Rugenstein, M., Sato, Y., Schulz, M., Schwartz, S., Sourdeval, O., Storelvmo, T., Toll, V., Winker, D., and Stevens, B.: Bounding global aerosol radiative forcing of climate change, Rev. Geophys., 58, 2019RG000660, https://doi.org/10.1029/2019RG000660, 2019.

Bollasina, M. A., Ming, Y., and Ramaswamy, V.: Anthropogenic aerosols and the weakening of the South Asian summer monsoon, Science, 334, 502-505, https://doi.org/10.1126/science.1204994, 2011.

Boucher, O., Randall, D., Artaxo, P., Bretherton, C., Feingold, G., Forster, P., Kerminen, V.-M., Kondo, Y., Liao, H., Lohmann, U., Rasch, P., Satheesh, S., Sherwood, S., Stevens, B., and Zhang, X.-Y.: Clouds and Aerosols, in: Climate Change 2013: The Physical Science Basis. Contribution of Working Group I to the Fifth Assessment Report of the Intergovernmental Panel on Climate Change, edited by: Stocker, T. F., Qin, D., Plattner, G.-K., Tignor, M., Allen, S. K., Boschung, J., Nauels, A., Xia, Y., Bex, V., and Midgley, P. M., Cambridge University Press, Cambridge, UK and New York, NY, USA, 571-657, 2013.

Boucher, O., Denvil, S., Caubel, A., and Foujols, M. A.: IPSL IPSLCM6A-LR model output prepared for CMIP6 CMIP historical, https://doi.org/10.22033/ESGF/CMIP6.5195, Earth System Grid Federation, 2018a.

Boucher, O., Denvil, S., Caubel, A., and Foujols, M. A.: IPSL IPSL-CM6A-LR model output prepared for CMIP6 RFMIP, Earth System Grid Federation, https://doi.org/10.22033/ESGF/CMIP6.1531, 2018b.

Boucher, O., Denvil, S., Caubel, A., and Foujols, M. A.: IPSL IPSL-CM6A-LR model output prepared for CMIP6 ScenarioMIP, Earth System Grid Federation, https://doi.org/10.22033/ESGF/CMIP6.1532, 2019.

Chalmers, N., Highwood, E. J., Hawkins, E., Sutton, R., and Wilcox, L. J.: Aerosol contribution to the rapid warming of nearterm climate under RCP 2.6, Geophys. Res. Lett., 39, L18709, https://doi.org/10.1029/2012GL052848, 2012.

Collins, M., AchutaRao, K., Ashok, K., Bhandari, S., Mitra, A. K., Prakash, S., Srivastava, R., and Turner, A.: Observational challenges in evaluating climate models, Nat. Clim. Change, 3, 940941, https://doi.org/10.1038/nclimate2012, 2013.

Cowan, T. and Cai, W.: The impact of Asian and nonAsian anthropogenic aerosols on 20th century Asian summer monsoon, Geophys. Res. Lett., 38, L11703, https://doi.org/10.1029/2011GL047268, 2011.

Danabasoglu, G.: NCAR CESM2 model output prepared for CMIP6 CMIP historical, Earth System Grid Federation, https://doi.org/10.22033/ESGF/CMIP6.7627, 2019a.

Danabasoglu, G.: NCAR CESM2 model output prepared for CMIP6 RFMIP, Earth System Grid Federation, https://doi.org/10.22033/ESGF/CMIP6.2199, 2019b.

Dee, D. P., Uppala, S. M., Simmons, A. J., Berrisford, P., Poli, P., Kobayashi, S., Andrae, U., Balmaseda, M. A., Balsamo, G., Bauer, P., Bechtold, P., Beljaars, A. C. M., van de Berg, L., Bidlot, J., Bormann, N., Delsol, C., Dragani, R., Fuentes, M., Geer, A. J., Haimberger, L., Healy, S. B., Hersbach, H., Hólm, E. V., Isaksen, L., Kållberg, P., Köhler, M., Matricardi, M., McNally, A. P., Monge-Sanz, B. M., Morcrette, J.-J., Park, B.-K., Peubey,
C., de Rosnay, P., Tavolato, C., Thépaut, J.-N., and Vitart, F.: The ERA-Interim reanalysis: configuration and performance of the data assimilation system, Q. J. Roy. Meteorol. Soc., 137, 553597, https://doi.org/10.1002/qj.828, 2011.

Dong, B., Sutton, R., Highwood, E., and Wilcox, L.: Preferred response of the East Asian summer monsoon to local and non-local anthropogenic sulphur dioxide emissions, Clim. Dynam., 46, 1733-1751, https://doi.org/10.1007/s00382-015-2671-5, 2016.

Dong, B., Wilcox, L. J., Highwood, E. J., and Sutton, R. T.: Impacts of recent decadal changes in Asian aerosols on the East Asian summer monsoon: roles of aerosol-radiation and aerosol-cloud interactions, Clim. Dynam., 53, 3235-3256, https://doi.org/10.1007/s00382-019-04698-0, 2019.

EC-Earth Consortium (EC-Earth): EC-Earth-Consortium EC-Earth3-Veg model output prepared for CMIP6 CMIP historical, Earth System Grid Federation, https://doi.org/10.22033/ESGF/CMIP6.4706, 2019a.

EC-Earth Consortium (EC-Earth): EC-Earth-Consortium EC-Earth3-Veg model output prepared for CMIP6 ScenarioMIP, Earth System Grid Federation, https://doi.org/10.22033/ESGF/CMIP6.727, 2019b.

Eyring, V., Bony, S., Meehl, G. A., Senior, C. A., Stevens, B., Stouffer, R. J., and Taylor, K. E.: Overview of the Coupled Model Intercomparison Project Phase 6 (CMIP6) experimental design and organization, Geosci. Model Dev., 9, 1937-1958, https://doi.org/10.5194/gmd-9-1937-2016, 2016.

Fläschner, D., Mauritsen, T., Stevens, B., Fläschner, D., Mauritsen, T., and Stevens, B.: Understanding the Intermodel Spread in Global-Mean Hydrological Sensitivity, J. Climate, 29, 801-817, https://doi.org/10.1175/JCLI-D-15-0351.1, 2016.

Gillett, N. P. and Von Salzen, K.: The role of reduced aerosol precursor emissions in driving near-term warming, Environ. Res. Lett., 8, 034008, https://doi.org/10.1088/1748-9326/8/3/034008, 2013.

Gillett, N. P., Shiogama, H., Funke, B., Hegerl, G., Knutti, R., Matthes, K., Santer, B. D., Stone, D., and Tebaldi, C.: The Detection and Attribution Model Intercomparison Project (DAMIP v1.0) contribution to CMIP6, Geosci. Model Dev., 9, 3685-3697, https://doi.org/10.5194/gmd-9-3685-2016, 2016.

Good, P., Sellar, A., Tang, Y., Rumbold, S., Ellis, R., Kelley, D., Kuhlbrodt, T., and Walton, J.: MOHC UKESM1.0-LL model output prepared for CMIP6 ScenarioMIP, Earth System Grid Federation, https://doi.org/10.22033/ESGF/CMIP6.1567, 2019.

Guo, H., John, J. G., Blanton, C., McHugh, C., Nikonov, S., Radhakrishnan, A., Zadeh, N. T., Balaji, V., Durachta, J., Dupuis, C., Menzel, R., Robinson, T., Underwood, S., Vahlenkamp, H., Dunne, K. A., Gauthier, P. P. G., Ginoux, P., Griffies, S. M., Hallberg, R., Harrison, M., Hurlin, W., Malyshev, S., Naik, V., Paulot, F., Paynter, D. J., Ploshay, J., Schwarzkopf, D. M., Seman, C. J., Shao, A., Silvers, L., Wyman, B., Zeng, Y., Adcroft, A., Dunne, J. P., Held, I. M., Krasting, J. P., Horowitz, L. W., Milly, P. C. D., Shevliakova, E., Winton, M., and Zhao, M.: NOAA-GFDL GFDL-CM4 model output prepared for CMIP6 CMIP historical, Earth System Grid Federation, https://doi.org/10.22033/ESGF/CMIP6.8594, 2018a.

Guo, H., John, J. G., Blanton, C., McHugh, C., Nikonov, S., Radhakrishnan, A., Zadeh, N. T., Balaji, V., Durachta, J., Dupuis, C., Menzel, R., Robinson, T., Underwood, S., Vahlenkamp, H., Dunne, K. A., Gauthier, P. P. G., Ginoux, P., Griffies, S. M., 
Hallberg, R., Harrison, M., Hurlin, W., Lin, P., Malyshev, S., Naik, V., Paulot, F., Paynter, D. J., Ploshay, J., Schwarzkopf, D. M., Seman, C. J., Shao, A., Silvers, L., Wyman, B., Yan, X., Zeng, Y., Adcroft, A., Dunne, J. P., Held, I. M., Krasting, J. P., Horowitz, L. W., Milly, C., Shevliakova, E., Winton, M., Zhao, M., and Zhang, R.: NOAA-GFDL GFDL-CM4 model output prepared for CMIP6 ScenarioMIP, Earth System Grid Federation, https://doi.org/10.22033/ESGF/CMIP6.9242, 2018 b.

Guo, L., Turner, A. G., and Highwood, E. J.: Impacts of 20th century aerosol emissions on the South Asian monsoon in the CMIP5 models, Atmos. Chem. Phys., 15, 6367-6378, https://doi.org/10.5194/acp-15-6367-2015, 2015.

Guo, L., Turner, A. G., and Highwood, E. J.: Local and remote impacts of aerosol species on indian summer monsoon rainfall in a GCM, J. Climate, 29, 6937-6955, https://doi.org/10.1175/JCLID-15-0728.1, 2016.

Gusain, A., Ghosh, S., and Karmakar, S.: Added value of CMIP6 over CMIP5 models in simulating Indian summer monsoon rainfall, Atmos. Res., 232, 104680, https://doi.org/10.1016/J.ATMOSRES.2019.104680, 2020.

Ha, K.-J., Seo, Y.-W., Lee, J.-Y., Kripalani, R. H., and Yun, K.S.: Linkages between the South and East Asian summer monsoons: a review and revisit, Clim. Dynam., 51, 4207-4227, https://doi.org/10.1007/s00382-017-3773-z, 2018.

Hansen, J., Ruedy, R., Sato, M., and Lo, K.: Global surface temperature change, Rev. Geophys., 48, RG4004, https://doi.org/10.1029/2010RG000345, 2010.

Hegerl, G. C., Brönnimann, S., Cowan, T., Friedman, A. R., Hawkins, E., Iles, C., Müller, W., Schurer, A., and Undorf, S.: Causes of climate change over the historical record, Environ. Res. Lett., 14, 123006, https://doi.org/10.1088/17489326/ab4557, 2019.

Hienola, A., Partanen, A.-I., Pietikäinen, J.-P., O’Donnell, D., Korhonen, H., Matthews, H. D., and Laaksonen, A.: The impact of aerosol emissions on the $1.5^{\circ} \mathrm{C}$ pathways, Environ. Res. Lett., 13, 044011, https://doi.org/10.1088/1748-9326/aab1b2, 2018.

Huang, B., Thorne, P. W., Banzon, V. F., Boyer, T., Chepurin, G., Lawrimore, J. H., Menne, M. J., Smith, T. M., Vose, R. S., and Zhang, H.-M.: Extended Reconstructed Sea Surface Temperature, Version 5 (ERSSTv5): Upgrades, Validations, and Intercomparisons, J. Climate, 30, 8179-8205, https://doi.org/10.1175/JCLI-D-16-0836.1, 2017.

Jones, G. S., Stott, P. A., and Christidis, N.: Attribution of observed historical near-surface temperature variations to anthropogenic and natural causes using CMIP5 simulations, J. Geophys. Res.Atmos., 118, 4001-4024, https://doi.org/10.1002/jgrd.50239, 2013.

Kirkevåg, A., Grini, A., Olivié, D., Seland, Ø., Alterskjær, K., Hummel, M., Karset, I. H. H., Lewinschal, A., Liu, X., Makkonen, R., Bethke, I., Griesfeller, J., Schulz, M., and Iversen, T.: A production-tagged aerosol module for Earth system models, OsloAero5.3 - extensions and updates for CAM5.3-Oslo, Geosci. Model Dev., 11, 3945-3982, https://doi.org/10.5194/gmd-11-3945-2018, 2018.

Klimont, Z., Kupiainen, K., Heyes, C., Purohit, P., Cofala, J., Rafaj, P., Borken-Kleefeld, J., and Schöpp, W.: Global anthropogenic emissions of particulate matter including black carbon, Atmos. Chem. Phys., 17, 8681-8723, https://doi.org/10.5194/acp-178681-2017, 2017.
Kloster, S., Dentener, F., Feichter, J., Raes, F., Lohmann, U., Roeckner, E., and Fischer-Bruns, I.: A GCM study of future climate response to aerosol pollution reductions, Clim. Dynam., 34, 11771194, https://doi.org/10.1007/s00382-009-0573-0, 2010.

Lau, W. K., Kim, K. M., and Ruby Leung, L.: Changing circulation structure and precipitation characteristics in Asian monsoon regions: greenhouse warming vs. aerosol effects, Geosci. Lett., 4, 28, https://doi.org/10.1186/s40562-017-0094-3, 2017.

Lau, W. K. M. and Kim, K.-M.: Fingerprinting the impacts of aerosols on long-term trends of the Indian summer monsoon regional rainfall, Geophys. Res. Lett., 37, L16705, https://doi.org/10.1029/2010GL043255, 2010.

Lawrence, B., Bennett, V. L., Churchill, J., Juckes, M., Kershaw, P., Oliver, P., Pritchard, M., and Stephens, A.: The JASMIN super-data-cluster, arXiv preprint arXiv:1204.3553, available at: https://www.academia.edu/2871931/The_JASMIN_ super-data-cluster (last access: 16 October 2020), 2012.

Lenssen, N. J. L., Schmidt, G. A., Hansen, J. E., Menne, M. J., Persin, A., Ruedy, R., and Zyss, D.: Improvements in the GISTEMP Uncertainty Model, J. Geophys. Res.-Atmos., 124, 6307 6326, https://doi.org/10.1029/2018JD029522, 2019.

Levy, H., Horowitz, L. W., Schwarzkopf, M. D., Ming, Y., Golaz, J.-C., Naik, V., and Ramaswamy, V.: The roles of aerosol direct and indirect effects in past and future climate change, J. Geophys. Res.-Atmos., 118, 4521-4532, https://doi.org/10.1002/jgrd.50192, 2013.

Li, X., Ting, M., Li, C., and Henderson, N.: Mechanisms of Asian Summer Monsoon Changes in Response to Anthropogenic Forcing in CMIP5 Models, J. Climate, 28, 4107-4125, https://doi.org/10.1175/jcli-d-14-00559.1, 2015.

Liepert, B. G., Feichter, J., Lohmann, U., and Roeckner, E.: Can aerosols spin down the water cycle in a warmer and moister world?, Geophys. Res. Lett., 31, L06207, https://doi.org/10.1029/2003GL019060, 2004.

Liepert, B. G., Previdi, M., Liepert, B. G., and Previdi, M.: Do Models and Observations Disagree on the Rainfall Response to Global Warming?, J. Climate, 22, 3156-3166, https://doi.org/10.1175/2008JCLI2472.1, 2009.

Liu, L., Shawki, D., Voulgarakis, A., Kasoar, M., Samset, B. H., Myhre, G., Forster, P. M., Hodnebrog, Ø., Sillmann, J., Aalbergsjø, S. G., Boucher, O., Faluvegi, G., Iversen, T., Kirkevåg, A., Lamarque, J.-F., Olivié, D., Richardson, T., Shindell, D., Takemura, T., Liu, L., Shawki, D., Voulgarakis, A., Kasoar, M., Samset, B. H., Myhre, G., Forster, P. M., Hodnebrog, Ø., Sillmann, J., Aalbergsjø, S. G., Boucher, O., Faluvegi, G., Iversen, T., Kirkevåg, A., Lamarque, J.-F., Olivié, D., Richardson, T., Shindell, D., and Takemura, T.: A PDRMIP Multimodel Study on the Impacts of Regional Aerosol Forcings on Global and Regional Precipitation, J. Climate, 31, 4429-4447, https://doi.org/10.1175/JCLI-D-17-0439.1, 2018.

Liu, Y., Cai, W., Sun, C., Song, H., Cobb, K. M., Li, J., Leavitt, S. W., Wu, L., Cai, Q., Liu, R., Ng, B., Cherubini, P., Büntgen, U., Song, Y., Wang, G., Lei, Y., Yan, L., Li, Q., Ma, Y., Fang, C., Sun, J., Li, X., Chen, D., and Linderholm, H. W.: Anthropogenic Aerosols Cause Recent Pronounced Weakening of Asian Summer Monsoon Relative to Last Four Centuries, Geophys. Res. Lett., 46, 5469-5479, https://doi.org/10.1029/2019GL082497, 2019. 
Lund, M. T., Myhre, G., and Samset, B. H.: Anthropogenic aerosol forcing under the Shared Socioeconomic Pathways, Atmos. Chem. Phys., 19, 13827-13839, https://doi.org/10.5194/acp-1913827-2019, 2019.

McGill, R., Tukey, J. W., and Larsen, W. A.: Variations of box plots, Am. Stat., 32, 12-16, https://doi.org/10.1080/00031305.1978.10479236, 1978.

Menne, M. J., Williams, C. N., Gleason, B. E., Rennie, J. J., and Lawrimore, J. H.: The Global Historical Climatology Network Monthly Temperature Dataset, Version 4, J. Climate, 31, 98359854, https://doi.org/10.1175/JCLI-D-18-0094.1, 2018.

Moss, R. H., Edmonds, J. A., Hibbard, K. A., Manning, M. R., Rose, S. K., van Vuuren, D. P., Carter, T. R., Emori, S., Kainuma, M., Kram, T., Meehl, G. A., Mitchell, J. F. B., Nakicenovic, N., Riahi, K., Smith, S. J., Stouffer, R. J., Thomson, A. M., Weyant, J. P., and Wilbanks, T. J.: The next generation of scenarios for climate change research and assessment, Nature, 463, 747-756, https://doi.org/10.1038/nature08823, 2010.

Mulcahy, J. P., Jones, C., Sellar, A., Johnson, B., Boutle, I. A., Jones, A., Andrews, T., Rumbold, S. T., Mollard, J., Bellouin, N., Johnson, C. E., Williams, K. D., Grosvenor, D. P., and McCoy, D. T.: Improved Aerosol Processes and Effective Radiative Forcing in HadGEM3 and UKESM1, J. Adv. Model. Earth Syst., 10, 2786-2805, https://doi.org/10.1029/2018MS001464, 2018.

NASA/GISS - NASA Goddard Institute for Space Studies : NASA-GISS GISS-E2.1G model output prepared for CMIP6 CMIP historical, Earth System Grid Federation, https://doi.org/10.22033/ESGF/CMIP6.7127, 2018.

NASA/GISS - NASA Goddard Institute for Space Studies (NASA/GISS): NASA-GISS GISS-E2.1G model output prepared for CMIP6 RFMIP, Earth System Grid Federation, https://doi.org/10.22033/ESGF/CMIP6.2072, 2019.

Nordling, K., Korhonen, H., Räisänen, P., Alper, M. E., Uotila, P., O'Donnell, D., and Merikanto, J.: Role of climate model dynamics in estimated climate responses to anthropogenic aerosols, Atmos. Chem. Phys., 19, 9969-9987, https://doi.org/10.5194/acp19-9969-2019, 2019.

O'Connor, F., Dalvi, M., Kahana, R., Johnson, B., Mulcahy, J., Robertson, E., Shim, S., and Wiltshire, A.: MOHC UKESM1.0LL model output prepared for CMIP6 RFMIP, Earth System Grid Federation, https://doi.org/10.22033/ESGF/CMIP6.11061, 2019.

O’Neill, B. C., Tebaldi, C., van Vuuren, D. P., Eyring, V., Friedlingstein, P., Hurtt, G., Knutti, R., Kriegler, E., Lamarque, J.-F., Lowe, J., Meehl, G. A., Moss, R., Riahi, K., and Sanderson, B. M.: The Scenario Model Intercomparison Project (ScenarioMIP) for CMIP6, Geosci. Model Dev., 9, 3461-3482, https://doi.org/10.5194/gmd-9-3461-2016, 2016.

Partanen, A.-I., Landry, J.-S., and Matthews, H. D.: Climate and health implications of future aerosol emission scenarios, Environ. Res. Lett., 13, 024028, https://doi.org/10.1088/17489326/aaa511, 2018.

Paynter, D. J., Menzel, R., Jones, A., Schwarzkopf, D. M., Freidenreich, S., Wyman, B., Blanton, C., McHugh, C., Radhakrishnan, A., Vahlenkamp, H., Rand, K., Silvers, L., Guo, H., John, J. G., Ploshay, J., Balaji, V., and Wilson, C.: NOAA-GFDL GFDLCM4 model output prepared for CMIP6 RFMIP, Earth System Grid Federation, https://doi.org/10.22033/ESGF/CMIP6.1643, 2018
Pietikäinen, J.-P., Kupiainen, K., Klimont, Z., Makkonen, R., Korhonen, H., Karinkanta, R., Hyvärinen, A.-P., Karvosenoja, N., Laaksonen, A., Lihavainen, H., and Kerminen, V.-M.: Impacts of emission reductions on aerosol radiative effects, Atmos. Chem. Phys., 15, 5501-5519, https://doi.org/10.5194/acp15-5501-2015, 2015.

Platnick, S.: MODIS Atmosphere L3 Monthly Product, NASA MODIS Adaptive Processing System, Earth System Grid Federation, https://doi.org/10.5067/MODIS/MYD08_M3.006, 2015.

Polson, D., Bollasina, M., Hegerl, G. C., and Wilcox, L. J.: Decreased monsoon precipitation in the Northern Hemisphere due to anthropogenic aerosols, Geophys. Res. Lett., 41, 6023-6029, https://doi.org/10.1002/2014GL060811, 2014.

Prakash, S., Mitra, A. K., Momin, I. M., Rajagopal, E. N., Basu, S., Collins, M., Turner, A. G., Achuta Rao, K., and Ashok, K.: Seasonal intercomparison of observational rainfall datasets over India during the southwest monsoon season, Int. J. Climatol., 35, 2326-2338, https://doi.org/10.1002/joc.4129, 2015.

Rao, S., Klimont, Z., Smith, S. J., Van Dingenen, R., Dentener, F., Bouwman, L., Riahi, K., Amann, M., Bodirsky, B. L., van Vuuren, D. P., Aleluia Reis, L., Calvin, K., Drouet, L., Fricko, O., Fujimori, S., Gernaat, D., Havlik, P., Harmsen, M., Hasegawa, T., Heyes, C., Hilaire, J., Luderer, G., Masui, T., Stehfest, E., Strefler, J., van der Sluis, S., and Tavoni, M.: Future air pollution in the Shared Socioeconomic Pathways, Global Environ. Change, 42, 346-358, https://doi.org/10.1016/J.GLOENVCHA.2016.05.012, 2017.

Remer, L. A., Kleidman, R. G., Levy, R. C., Kaufman, Y. J., Tanré, D., Mattoo, S., Martins, J. V., Ichoku, C., Koren, I., Yu, H., and Holben, B. N.: Global aerosol climatology from the MODIS satellite sensors, J. Geophys. Res., 113, D14S07, https://doi.org/10.1029/2007JD009661, 2008.

Riahi, K., van Vuuren, D. P., Kriegler, E., Edmonds, J., O’Neill, B. C., Fujimori, S., Bauer, N., Calvin, K., Dellink, R., Fricko, O., Lutz, W., Popp, A., Cuaresma, J. C., KC, S., Leimbach, M., Jiang, L., Kram, T., Rao, S., Emmerling, J., Ebi, K., Hasegawa, T., Havlik, P., Humpenöder, F., Da Silva, L. A., Smith, S., Stehfest, E., Bosetti, V., Eom, J., Gernaat, D., Masui, T., Rogelj, J., Strefler, J., Drouet, L., Krey, V., Luderer, G., Harmsen, M., Takahashi, K., Baumstark, L., Doelman, J. C., Kainuma, M., Klimont, Z., Marangoni, G., Lotze-Campen, H., Obersteiner, M., Tabeau, A., and Tavoni, M.: The Shared Socioeconomic Pathways and their energy, land use, and greenhouse gas emissions implications: An overview, Global Environ. Change, 42, 153-168, https://doi.org/10.1016/J.GLOENVCHA.2016.05.009, 2017.

Ridley, J., Menary, M., Kuhlbrodt, T., Andrews, M., and Andrews, T.: MOHC HadGEM3-GC31-LL model output prepared for CMIP6 CMIP historical, Earth System Grid Federation, https://doi.org/10.22033/ESGF/CMIP6.6109, 2019.

Rong, X.: CAMS CAMS CSM1.0 model output prepared for CMIP6 CMIP historical, Earth System Grid Federation, https://doi.org/10.22033/ESGF/CMIP6.9754, 2019a.

Rong, X.: CAMS CAMS-CSM1.0 model output prepared for CMIP6 ScenarioMIP, Earth System Grid Federation, https://doi.org/10.22033/ESGF/CMIP6.11004, 2019b.

Rotstayn, L. D., Collier, M. A., Chrastansky, A., Jeffrey, S. J., and Luo, J.-J.: Projected effects of declining aerosols in RCP4.5: unmasking global warming?, Atmos. Chem. Phys., 13, 1088310905, https://doi.org/10.5194/acp-13-10883-2013, 2013. 
Rotstayn, L. D., Collier, M. A., and Luo, J.-J.: Effects of declining aerosols on projections of zonally averaged tropical precipitation, Environ. Res. Lett., 10, 044018, https://doi.org/10.1088/1748-9326/10/4/044018, 2015.

Salzmann, M.: Global warming without global mean precipitation increase?, Sci. Adv., 2, e1501572, https://doi.org/10.1126/sciadv.1501572, 2016.

Samset, B. H., Myhre, G., Forster, P. M., Hodnebrog, Ø., Andrews, T., Faluvegi, G., Fläschner, D., Kasoar, M., Kharin, V., Kirkevåg, A., Lamarque, J., Olivié, D., Richardson, T., Shindell, D., Shine, K. P., Takemura, T., and Voulgarakis, A.: Fast and slow precipitation responses to individual climate forcers: A PDRMIP multimodel study, Geophys. Res. Lett., 43, 2782-2791, https://doi.org/10.1002/2016GL068064, 2016.

Samset, B. H., Sand, M., Smith, C. J., Bauer, S. E., Forster, P. M., Fuglestvedt, J. S., Osprey, S., and Schleussner, C.F.: Climate Impacts From a Removal of Anthropogenic Aerosol Emissions, Geophys. Res. Lett., 45, 1020-1029, https://doi.org/10.1002/2017GL076079, 2018.

Samset, B. H., Lund, M. T., Bollasina, M., Myhre, G., and Wilcox, L.: Emerging Asian aerosol patterns, Nat. Geosci., 12, 582-584, https://doi.org/10.1038/s41561-019-0424-5, 2019.

Scannell, C., Booth, B. B. B., Dunstone, N. J., Rowell, D. P., Bernie, D. J., Kasoar, M., Voulgarakis, A., Wilcox, L. J., Acosta Navarro, J. C., Seland, Ø., and Paynter, D. J.: The Influence of Remote Aerosol Forcing from Industrialized Economies on the Future Evolution of East and West African Rainfall, J. Climate, 32, 8335-8354, https://doi.org/10.1175/JCLI-D-18-0716.1, 2019.

Schneider, U., Becker, A., Finger, P., Meyer-Christoffer, A., Ziese, M., and Rudolf, B.: GPCC's new land surface precipitation climatology based on quality-controlled in situ data and its role in quantifying the global water cycle, Theor. Appl. Climatol., 115, 15-40, https://doi.org/10.1007/s00704-013-0860-x, 2014.

Seferian, R.: CNRM-CERFACS CNRM-ESM2-1 model output prepared for CMIP6 CMIP historical, Earth System Grid Federation, https://doi.org/10.22033/ESGF/CMIP6.4068, 2018.

Seferian, R.: CNRM-CERFACS CNRM-ESM2-1 model output prepared for CMIP6 RFMIP, Earth System Grid Federation, https://doi.org/10.22033/ESGF/CMIP6.9565, 2019a.

Seferian, R.: CNRM-CERFACS CNRM-ESM2-1 model output prepared for CMIP6 ScenarioMIP, Earth System Grid Federation, https://doi.org/10.22033/ESGF/CMIP6.1395, 2019 b.

Sekiguchi, M. and Shiogama, H.: MIROC MIROC6 model output prepared for CMIP6 RFMIP, Earth System Grid Federation, https://doi.org/10.22033/ESGF/CMIP6.895, 2019.

Shawki, D., Voulgarakis, A., Chakraborty, A., Kasoar, M., and Srinivasan, J.: The South Asian Monsoon Response to Remote Aerosols: Global and Regional Mechanisms, J. Geophys. Res.-Atmos., 123, 11585-11601, https://doi.org/10.1029/2018JD028623, 2018.

Shindell, D. and Smith, C. J.: Climate and air-quality benefits of a realistic phase-out of fossil fuels, Nature, 573, 408-411, https://doi.org/10.1038/s41586-019-1554-z, 2019.

Shindell, D., Kuylenstierna, J. C. I., Vignati, E., van Dingenen, R., Amann, M., Klimont, Z., Anenberg, S. C., Muller, N., Janssens-Maenhout, G., Raes, F., Schwartz, J., Faluvegi, G., Pozzoli, L., Kupiainen, K., Höglund-Isaksson, L., Emberson, L., Streets, D., Ramanathan, V., Hicks, K., Oanh, N. T. K., Milly, G., Williams, M., Demkine, V., and Fowler, D.: Si- multaneously mitigating near-term climate change and improving human health and food security, Science, 335, 183-189, https://doi.org/10.1126/science.1210026, 2012.

Shiogama, H.: MIROC MIROC6 model output prepared for CMIP6 DAMIP, Earth System Grid Federation, https://doi.org/10.22033/ESGF/CMIP6.894, 2019.

Sillmann, J., Pozzoli, L., Vignati, E., Kloster, S., and Feichter, J.: Aerosol effect on climate extremes in Europe under different future scenarios, Geophys. Res. Lett., 40, 2290-2295, https://doi.org/10.1002/grl.50459, 2013.

Singh, D., Bollasina, M., Ting, M., and Diffenbaugh, N. S.: Disentangling the influence of local and remote anthropogenic aerosols on South Asian monsoon daily rainfall characteristics, Clim. Dynam., 52, 6301-6320, https://doi.org/10.1007/s00382-018-45129, 2019a.

Singh, D., Ghosh, S., Roxy, M. K., and McDermid, S.: Indian summer monsoon: Extreme events, historical changes, and role of anthropogenic forcings, Wires Clim. Change, 10, e571, https://doi.org/10.1002/wcc.571, 2019b.

Smith, C. J., Forster, P. M., Allen, M., Leach, N., Millar, R. J., Passerello, G. A., and Regayre, L. A.: FAIR v1.3: a simple emissions-based impulse response and carbon cycle model, Geosci. Model Dev., 11, 2273-2297, https://doi.org/10.5194/gmd-11-2273-2018, 2018.

Song, F., Zhou, T., and Qian, Y.: Responses of East Asian summer monsoon to natural and anthropogenic forcings in the 17 latest CMIP5 models, Geophys. Res. Lett., 41, 596-603, https://doi.org/10.1002/2013GL058705, 2014.

Sperber, K. R., Annamalai, H., Kang, I.-S., Kitoh, A., Moise, A., Turner, A., Wang, B., and Zhou, T.: The Asian summer monsoon: an intercomparison of CMIP5 vs. CMIP3 simulations of the late 20th century, Clim. Dynam., 41, 2711-2744, https://doi.org/10.1007/s00382-012-1607-6, 2013.

Swart, N. C., Cole, J. N. S., Kharin, V. V., Lazare, M., Scinocca, J. F., Gillett, N. P., Anstey, J., Arora, V., Christian, J. R., Jiao, Y., Lee, W. G., Majaess, F., Saenko, O. A., Seiler, C., Seinen, C., Shao, A., Solheim, L., von Salzen, K., Yang, D., Winter, B., and Sigmond, M.: CCCma CanESM5 model output prepared for CMIP6 DAMIP, Earth System Grid Federation, https://doi.org/10.22033/ESGF/CMIP6.1305, 2019a.

Swart, N. C., Cole, J. N. S., Kharin, V. V., Lazare, M., Scinocca, J. F., Gillett, N. P., Anstey, J., Arora, V., Christian, J. R., Jiao, Y., Lee, W. G., Majaess, F., Saenko, O. A., Seiler, C., Seinen, C., Shao, A., Solheim, L., von Salzen, K., Yang, D., Winter, B., and Sigmond, M.: CCCma CanESM5 model output prepared for CMIP6 CMIP historical, Earth System Grid Federation, https://doi.org/10.22033/ESGF/CMIP6.3610, 2019b.

Swart, N. C., Cole, J. N. S., Kharin, V. V., Lazare, M., Scinocca, J. F., Gillett, N. P., Anstey, J., Arora, V., Christian, J. R., Jiao, Y., Lee, W. G., Majaess, F., Saenko, O. A., Seiler, C., Seinen, C., Shao, A., Solheim, L., von Salzen, K., Yang, D., Winter, B., and Sigmond, M.: CCCma CanESM5 model output prepared for CMIP6 ScenarioMIP, Earth System Grid Federation, https://doi.org/10.22033/ESGF/CMIP6.1317, 2019c.

Tang, Y., Rumbold, S., Ellis, R., Kelley, D., Mulcahy, J., Sellar, A., Walton, J., and Jones, C.: MOHC UKESM1.0-LL model output prepared for CMIP6 CMIP historical, Earth System Grid Federation, https://doi.org/10.22033/ESGF/CMIP6.6113, 2019. 
Tatebe, H. and Watanabe, M.: MIROC MIROC6 model output prepared for CMIP6 CMIP historical, Earth System Grid Federation, https://doi.org/10.22033/ESGF/CMIP6.5603, 2018.

Taylor, K. E., Stouffer, R. J., and Meehl, G. A.: An Overview of CMIP5 and the Experiment Design, B. Am. Meteorol. Soc., 93, 485-498, https://doi.org/10.1175/BAMS-D-1100094.1, https://doi.org/10.1175/BAMS-D-11-00094.1, 2012.

Twomey, S. A., Piepgrass, M., and Wolfe, T. L.: An assessment of the impact of pollution on global cloud albedo, Tellus B, 36, 356366, https://doi.org/10.1111/j.1600-0889.1984.tb00254.x, 1984.

Undorf, S., Polson, D., Bollasina, M. A., Ming, Y., Schurer, A., and Hegerl, G. C.: Detectable Impact of Local and Remote Anthropogenic Aerosols on the 20th Century Changes of West African and South Asian Monsoon Precipitation, J. Geophys. Res.-Atmos., 123, 4871-4889, https://doi.org/10.1029/2017JD027711, 2018.

van Vuuren, D. P., Edmonds, J., Kainuma, M., Riahi, K., Thomson, A., Hibbard, K., Hurtt, G. C., Kram, T., Krey, V., Lamarque, J. F., Masui, T., Meinshausen, M., Nakicenovic, N., Smith, S. J., and Rose, S. K.: The representative concentration pathways: An overview, Climatic Change, 109, 5-31, 2011.

Voldoire, A.: CMIP6 simulations of the CNRM-CERFACS based on CNRM-CM6-1 model for CMIP experiment historical, Earth System Grid Federation, https://doi.org/10.22033/ESGF/CMIP6.4066, 2018.

Voldoire, A.: CNRM-CERFACS CNRM-CM6-1 model output prepared for CMIP6 RFMIP, Earth System Grid Federation, https://doi.org/10.22033/ESGF/CMIP6.1383, 2019a.

Voldoire, A.: CNRM-CERFACS CNRM-CM6-1 model output prepared for CMIP6 ScenarioMIP, Earth System Grid Federation, https://doi.org/10.22033/ESGF/CMIP6.1384, 2019b.

Westervelt, D. M., Horowitz, L. W., Naik, V., Golaz, J.-C., and Mauzerall, D. L.: Radiative forcing and climate response to projected 21 st century aerosol decreases, Atmos. Chem. Phys., 15, 12681-12703, https://doi.org/10.5194/acp-15-12681-2015, 2015.

Wilcox, L. J., Highwood, E. J., and Dunstone, N. J.: The influence of anthropogenic aerosol on multi-decadal variations of historical global climate, Environ. Res. Lett., 8, 24033, https://doi.org/10.1088/1748-9326/8/2/024033, 2013.

Wilcox, L., Dong, B., Sutton, R., and Highwood, E.: The 2014 hot, dry summer in Northeast Asia, B. Am. Meteorol. Soc., 96, S105S110, https://doi.org/10.1175/BAMS-D-15-00123.1, 2015.

Wu, P., Christidis, N., and Stott, P.: Anthropogenic impact on Earth's hydrological cycle, Nat. Clim. Change, 3, 807-810, https://doi.org/10.1038/nclimate1932, 2013.

Wu, T., Chu, M., Dong, M., Fang, Y., Jie, W., Li, J., Li, W., Liu, Q., Shi, X., Xin, X., Yan, J., Zhang, F., Zhang, J., Zhang, L., and Zhang, Y.: BCC BCC-CSM2MR model output prepared for CMIP6 CMIP historical, Earth System Grid Federation, https://doi.org/10.22033/ESGF/CMIP6.2948, 2018.

Wyser, K., van Noije, T., Yang, S., von Hardenberg, J., O'Donnell, D., and Döscher, R.: On the increased climate sensitivity in the EC-Earth model from CMIP5 to CMIP6, Geosci. Model Dev., 13, 3465-3474, https://doi.org/10.5194/gmd-133465-2020, 2020.
Xie, P., Arkin, P. A., Xie, P., and Arkin, P. A.: Analyses of Global Monthly Precipitation Using Gauge Observations, Satellite Estimates, and Numerical Model Predictions, J. Climate, 9, 840-858, https://doi.org/10.1175/15200442(1996)009<0840:AOGMPU>2.0.CO;2, 1996.

Xie, P., Arkin, P. A., Xie, P., and Arkin, P. A.: Global Precipitation: A 17-Year Monthly Analysis Based on Gauge Observations, Satellite Estimates, and Numerical Model Outputs, B. Am. Meteorol. Soc., 78, 2539-2558, https://doi.org/10.1175/15200477(1997)078<2539:GPAYMA>2.0.CO;2, 1997.

Xin, X., Wu, T., Shi, X., Zhang, F., Li, J., Chu, M., Liu, Q., Yan, J., Ma, Q., and Wei, M.: BCC BCC-CSM2MR model output prepared for CMIP6 ScenarioMIP, Earth System Grid Federation, https://doi.org/10.22033/ESGF/CMIP6.1732, 2019.

Yatagai, A., Kamiguchi, K., Arakawa, O., Hamada, A., Yasutomi, N., Kitoh, A., Yatagai, A., Kamiguchi, K., Arakawa, O., Hamada, A., Yasutomi, N., and Kitoh, A.: APHRODITE: Constructing a Long-Term Daily Gridded Precipitation Dataset for Asia Based on a Dense Network of Rain Gauges, B. Am. Meteorol. Soc., 93, 1401-1415, https://doi.org/10.1175/BAMS-D-1100122.1, 2012.

Yukimoto, S., Koshiro, T., Kawai, H., Oshima, N., Yoshida, K., Urakawa, S., Tsujino, H., Deushi, M., Tanaka, T., Hosaka, M., Yoshimura, H., Shindo, E., Mizuta, R., Ishii, M., Obata, A., and Adachi, Y.: MRI MRI-ESM2.0 model output prepared for CMIP6 CMIP historical, Earth System Grid Federation, https://doi.org/10.22033/ESGF/CMIP6.6842, 2019a.

Yukimoto, S., Koshiro, T., Kawai, H., Oshima, N., Yoshida, K., Urakawa, S., Tsujino, H., Deushi, M., Tanaka, T., Hosaka, M., Yoshimura, H., Shindo, E., Mizuta, R., Ishii, M., Obata, A., and Adachi, Y.: MRI MRI-ESM2.0 model output prepared for CMIP6 RFMIP, Earth System Grid Federation, https://doi.org/10.22033/ESGF/CMIP6.635, 2019b.

Yukimoto, S., Koshiro, T., Kawai, H., Oshima, N., Yoshida, K., Urakawa, S., Tsujino, H., Deushi, M., Tanaka, T., Hosaka, M., Yoshimura, H., Shindo, E., Mizuta, R., Ishii, M., Obata, A., and Adachi, Y.: MRI MRI-ESM2.0 model output prepared for CMIP6 ScenarioMIP, Earth System Grid Federation, https://doi.org/10.22033/ESGF/CMIP6.638, 2019c.

Zelinka, M. D., Andrews, T., Forster, P. M., and Taylor, K. E.: Quantifying Components of Aerosol-Cloud-Radiation Interactions in Climate Models, J. Geophys. Res.-Atmos., 119, 7599 7615, https://doi.org/10.1002/2014JD021710, 2014.

Zelinka, M. D., Myers, T. A., McCoy, D. T., Po-Chedley, S., Caldwell, P. M., Ceppi, P., Klein, S. A., and Taylor, K. E.: Causes of Higher Climate Sensitivity in CMIP6 Models, Geophys. Res. Lett., 47, e2019GL085782, https://doi.org/10.1029/2019GL085782, 2020. 

(C) 2021 Atmos. Chem. Phys

Reprinted, with permission, from ACP, 21, 5865-5881, doi:10.5194/acp-21-5865-202 



\title{
How Asian aerosols impact regional surface temperatures across the globe
}

\author{
Joonas Merikanto ${ }^{1}$, Kalle Nordling ${ }^{1}$, Petri Räisänen ${ }^{1}$, Jouni Räisänen ${ }^{2}$, Declan O'Donnell ${ }^{1}$, Antti-Ilari Partanen ${ }^{1}$, and \\ Hannele Korhonen ${ }^{1}$ \\ ${ }^{1}$ Finnish Meteorological Institute, Helsinki, Finland \\ ${ }^{2}$ INAR Physics, University of Helsinki, Helsinki, Finland
}

Correspondence: Joonas Merikanto (joonas.merikanto@fmi.fi)

Received: 7 October 2020 - Discussion started: 10 December 2020

Revised: 3 March 2021 - Accepted: 4 March 2021 - Published: 19 April 2021

\begin{abstract}
South and East Asian anthropogenic aerosols mostly reside in an air mass extending from the Indian Ocean to the North Pacific. Yet the surface temperature effects of Asian aerosols spread across the whole globe. Here, we remove Asian anthropogenic aerosols from two independent climate models (ECHAM6.1 and NorESM1) using the same representation of aerosols via MACv2-SP (a simple plume implementation of the second version of the Max Planck Institute Aerosol Climatology). We then robustly decompose the global distribution of surface temperature responses into contributions from atmospheric energy flux changes. We find that the horizontal atmospheric energy transport strongly moderates the surface temperature response over the regions where Asian aerosols reside. Atmospheric energy transport and changes in clear-sky longwave radiation redistribute the temperature effects efficiently across the Northern Hemisphere and to a lesser extent also over the Southern Hemisphere. The model-mean global surface temperature response to Asian anthropogenic aerosol removal is $0.26 \pm 0.04{ }^{\circ} \mathrm{C}(0.22 \pm 0.03$ for ECHAM6. 1 and $0.30 \pm 0.03{ }^{\circ} \mathrm{C}$ for NorESM1) of warming. Model-to-model differences in global surface temperature response mainly arise from differences in longwave cloud $(0.01 \pm 0.01$ for ECHAM6.1 and $0.05 \pm 0.01^{\circ} \mathrm{C}$ for NorESM1) and shortwave cloud $\left(0.03 \pm 0.03\right.$ for ECHAM6. 1 and $0.07 \pm 0.02^{\circ} \mathrm{C}$ for NorESM1) responses. The differences in cloud responses between the models also dominate the differences in regional temperature responses. In both models, the northernhemispheric surface warming amplifies towards the Arctic, where the total temperature response is highly seasonal and weakest during the Arctic summer. We estimate that under a
\end{abstract}

strong Asian aerosol mitigation policy tied with strong climate mitigation (Shared Socioeconomic Pathway 1-1.9) the Asian aerosol reductions can add around 8 years' worth of current-day global warming during the next few decades.

\section{Introduction}

Understanding how regional climates respond to different climate forcers is crucial for assessing how climate change impacts societies. Samset et al. (2018) showed that anthropogenic aerosols cool the global-mean surface temperature in four latest-generation climate models by between $0.5-1.1 \mathrm{~K}$. However, the regional impacts of anthropogenic aerosols on surface temperatures remain particularly complicated to unravel (Persad and Caldeira, 2018; Nordling et al., 2019).

Due to the short lifetime of aerosols, their distribution in the atmosphere is highly heterogeneous and dependent on the location of their emissions and on various dynamical and microphysical processes influencing also their properties and climate effects. Aerosols give rise to both local and remote temperature responses, so that the geographic distributions of aerosol radiative forcing and temperature effects are largely dislocated (Shindell et al., 2010; Nordling at al., 2019). Furthermore, the same aerosol emissions originating from different regions vary in their climate forcing efficacies, with their global surface temperature response per unit global radiative forcing differing by factors of between 2 and 14, depending on aerosols species and the models used (Kasoar et al., 2018; Westervelt, et al., 2020; Persad and Caldeira, 2018). 
During the past decades air pollution levels in Europe and North America have decreased considerably, while they have grown in South and East Asia. These opposing changes in air pollution have kept the overall global anthropogenic aerosol radiative forcing close to constant since the mid-1970s (Murphy 2013; Fiedler et al., 2019). South and East Asia have become the dominant sources of anthropogenic aerosol emissions (Lamarque et al., 2010). Consequently, air pollution has become a major health problem in Asia. Ambient aerosol pollution reduces the life expectancy by 1.24 years in East Asia and by 1.56 years in South Asia (Apte et al., 2018) and is attributable to 0.67 million deaths per year in India alone (Balakrishnan et al., 2019). Shared Socioeconomic Pathways (SSPs) predict that strong air pollution mitigation policies (SSP1-1.9) could reduce the Asian anthropogenic aerosol emissions from their 2015 levels by $55 \%$ already by 2030 and by $90 \%$ by 2100 (Lund et al., 2019, see also their Fig. S2).

Large past changes and potentially at least equally significant future changes in Asian aerosols have prompted recent studies on their global and regional surface temperature effects. Kasoar et al. (2016) used three climate models (HadGEM3-GA4, CESM1, and GISS-E2) to study regional surface temperature responses to the removal of $\mathrm{SO}_{2}$ emissions from China. Two of the three models showed northernhemispheric warming due to aerosol removal but of significantly different magnitude, while the third model showed no significant surface temperature responses. The authors pinpointed the mixed results from the models to their different treatments of aerosol microphysical processes and aerosolcloud interactions. Westervelt et al. (2020) also used three climate models (GFDL, CESM1, and GISS-E2) to investigate the surface temperature responses to the removals (or significant reductions) of aerosol sources from several different regions, including China and India. Overall, the models varied in aerosol radiative forcings and regional temperature response patterns associated with Asian aerosol reductions but suggested that the reductions mostly result in a significant surface temperature increase across the Northern Hemisphere and particularly over the Arctic. Persad and Caldeira (2018) used the CAM5 model to place an equivalent to China's total annual year 2000 anthropogenic aerosol emissions at different locations around the globe. They found that emissions placed in China cooled the whole Northern Hemisphere, while the same emissions placed in India resulted in a mixed regional response of warming and cooling.

Recent studies have also investigated the combined impacts of Asian anthropogenic aerosols on precipitation and surface temperatures. Liu et al. (2018) showed that the temperature effects of idealized Asian aerosol perturbations spread across the Northern Hemisphere in a multi-model Precipitation Driver and Response Model Intercomparison Project (PDRMIP) study. They also showed that increases in Asian sulfate aerosols strongly suppressed Asian monsoon precipitation by enhancing horizontal atmospheric heat transport to the region and raising surface pressure. Wilcox et al. (2020) showed that future reductions in global aerosol emissions, dominated by changes in Asian aerosol emissions, lead to accelerated increases in Asian monsoon precipitation in CMIP6 experiments but had a limited impact on projected future changes in surface temperatures.

Here, we explore the global and regional surface temperature responses to a complete removal of South and East Asian anthropogenic aerosols using two different climate models, ECHAM6.1 and NorESM1. As in Nordling et al. (2019), we use an identical description of anthropogenic aerosols in both models. The use of identical aerosols across the models allows us to study the similarities and differences in model dynamical responses to aerosols and exclude the model response perturbations that result from differences in modeled aerosols. Further, we aim to understand the robustness of changes in the climate system that lead to the local and remote changes in surface temperatures.

It is complicated to resolve the pathway from a climate forcing to a regional surface temperature response in climate models even for globally homogeneous greenhouse gases, let alone for aerosols. A significant climate perturbation results in a complex set of responses in general circulation patterns, cloud properties, surface albedo, atmospheric water vapor concentrations, et cetera. Surface temperature responses result from a combination of all these different climate feedbacks. Therefore, even a seemingly robust regional surface temperature signal in different climate models may result from a different combination of feedbacks that sums up to a similar temperature response.

Räisänen (2017) presented a new method built around the concept of effective planetary emissivity for a robust decomposition of the energetic components that sum up to the geographic distribution of surface temperature responses. Here, we extend the method to better resolve the longwave cloud feedback using radiative kernels and apply it for the analysis of the model results. The method allows separating the contributions from atmospheric heat transport, changes in shortwave and longwave radiation related to clear sky and clouds, surface energy fluxes, and surface albedo to a local surface temperature response.

\section{Method}

\subsection{Model experiments and analysis}

We use ECHAM6.1 (Stevens et al., 2013) and NorESM1 (Bentsen et al., 2013; Iversen et al., 2013; Kirkevåg et al., 2013) general circulation models to carry out 100-year slab ocean equilibrium runs for the present-day (year 2005) atmosphere without South and East Asian anthropogenic aerosols, but leaving all other aerosol sources intact. The last 60 years of equilibrated climate data from each simulation are used for the analysis. These runs are compared to 
otherwise identical baseline climate runs of same length but having all aerosol sources on. For the baseline, we use the same ECHAM6.1 and NorESM1 model runs as presented in Nordling et al. (2019).

The background pre-industrial aerosols (mainly consisting of natural organics and sulfate, sea salt, and dust) for ECHAM6.1 are prescribed using the climatology of Kinne et al. (2013), while for NorESM1, they are simulated by the model's bottom-up aerosol microphysics scheme (Kirkevåg et al., 2013) (see also Fig. 2 and Appendix A in Fiedler et al., 2019, describing the pre-industrial aerosols for both of the applied models and the related discussion within). In both cases, the impact of modern-day (year 2005) anthropogenic aerosols is represented via the MACv2-SP climatology (Stevens et al., 2017). MACv2-SP uses in situ observations of aerosol optical depth (AOD) for the top-tobottom representation of aerosol-radiation effects and calculates the aerosol direct and first indirect effects through changes in fixed three-dimensional AOD fields with monthly time resolution. The anthropogenic impact on AOD is represented through nine different aerosol plumes, which together represent the sources and transport of anthropogenic aerosols, including biomass burning. In the runs without Asian anthropogenic aerosols we have turned off plume numbers 3 and 4 . The direct and indirect instantaneous aerosol radiative forcings are calculated online in the models using double radiation calls. The global instantaneous forcing can be modeled nearly identically with MACv2-SP in ECHAM6.1 and NorESM1, albeit there are some modelto-model differences related to model-specific representations of clouds, surface albedo, and natural aerosol (Nordling et al., 2019). The effective radiative forcing (analyzed by Fiedler et al., 2019, for multi-decadal fixed-sea-surfacetemperature runs for ECHAM6.3 and NorESM1 models using the same pre-industrial aerosol representations as here) shows somewhat larger model-to-model variations, but the geographic patterns of the effective radiative forcings with MACv2-SP are close to those of instantaneous radiative forcings. The differences in global anthropogenic aerosol radiative forcings between the ECHAM6.1 and NorESM1 models with MACv2-SP aerosols are small enough to be insignificant for the obtained temperature responses, as discussed in Nordling et al. (2019). However, different representations of natural background aerosol in the models can lead to differences in obtained indirect aerosol forcing (Carslaw et al., 2013; Fiedler et al., 2019), and this is the case also for Asian anthropogenic aerosols when using the model-intrinsic pre-industrial aerosol representations in NorESM1 and ECHAM6.1, as we will discuss later. Here, both models were coupled to their intrinsic mixedlayer (slab) ocean model representations (for ECHAM6.1 see Roeckner et al., 2003; for NorESM1 see Bitz et al., 2012), and hence changes in ocean currents are not accounted for in our analysis. The reported equilibrium climate sensitivity is
3.5 K for NorESM1 (Räisänen et al., 2017) and also 3.5 K for ECHAM6.1 (Mauritsen and Roeckner, 2020).

The analysis of results is based on monthly-mean values of data, calculated separately for each month in the 60-year time series. The response uncertainties in global-mean values are calculated as standard error of means using a $95 \%$ confidence interval for individual models and as a pooled standard error of the mean with a $95 \%$ confidence interval for responses averaged over the two models. The statistical significance of regional responses is evaluated using a Student's $t$ test with an autocorrelation correction according to Zwiers and von Storch (1995).

\subsection{Temperature response decomposition}

We decompose the distribution of local surface temperature responses to local changes in atmospheric energetic components using a method presented in Räisänen (2017). The method only requires standardly archived climate model output for the decomposition.

The rate of change of total energy in an atmospheric column is

$\frac{\delta E}{\delta t}=\mathrm{SW}_{\mathrm{TOA}}^{\downarrow}-\mathrm{LW}_{\mathrm{TOA}}^{\uparrow}-F_{\mathrm{SURF}}^{\downarrow}+C^{\rightarrow}$,

where $\mathrm{SW}_{\text {TOA }}^{\downarrow}$ is the net incoming shortwave radiation and $\mathrm{LW}_{\mathrm{TOA}}^{\uparrow}$ is the outgoing longwave radiation at the top of the atmosphere, $C \rightarrow$ is the net horizontal heat transport into the column, and the net downward heat flux into the surface is given by

$F_{\text {SURF }}^{\downarrow}=\mathrm{SW}_{\mathrm{SURF}}^{\downarrow}+\mathrm{LW}_{\mathrm{SURF}}^{\downarrow}-\mathrm{SH}^{\uparrow}-\mathrm{LH}^{\uparrow}$,

where $\mathrm{SW}_{\mathrm{SURF}}^{\downarrow}$ and $\mathrm{LW}_{\mathrm{SURF}}^{\downarrow}$ are the net shortwave and longwave radiation fluxes into the surface, and $\mathrm{SH}^{\uparrow}$ and $\mathrm{LH}^{\uparrow}$ are the upwards sensible and latent heat fluxes, respectively. To relate Eq. (1) with the surface air temperature $T$ one defines (Räisänen and Ylhäisi, 2015; Räisänen, 2017)

$\mathrm{LW}_{\mathrm{TOA}}^{\uparrow}=\varepsilon_{\mathrm{eff}} \sigma T^{4}$,

where the effective planetary emissivity $\varepsilon_{\text {eff }}$ is essentially a measure of the local atmospheric greenhouse effect. Substituting Eq. (3) into Eq. (1) gives

$\varepsilon_{\mathrm{eff}} \sigma T^{4}=\mathrm{SW}_{\mathrm{TOA}}^{\downarrow}-F_{\mathrm{SURF}}^{\downarrow}+C^{\rightarrow}-\frac{\delta E}{\delta t}$.

Then, letting [] mark the mean state between baseline and perturbed climates, the change in Eq. (4) between the two climate states can be written as

$$
\begin{aligned}
\sigma\left[\varepsilon_{\mathrm{eff}}\right] \Delta\left(T^{4}\right)= & -\sigma \Delta \varepsilon_{\mathrm{eff}}\left[T^{4}\right] \\
& +\Delta \mathrm{SW}_{\mathrm{TOA}}^{\downarrow}-\Delta F_{\mathrm{SURF}}^{\downarrow}+\Delta\left(C^{\rightarrow}-\frac{\delta E}{\delta t}\right) .
\end{aligned}
$$

Linearizing the left-hand side of Eq. (5) as

$\sigma\left[\varepsilon_{\mathrm{eff}}\right] \Delta\left(T^{4}\right) \approx 4 \sigma\left[\varepsilon_{\mathrm{eff}}\right]\left[T^{3}\right] \Delta T=D \Delta T$ 
allows the decomposition of surface temperature response into changes in energy flux components in the atmospheric column,

$\Delta T=\Delta T_{\mathrm{LW}}+\Delta T_{\mathrm{SW}}+\Delta T_{\mathrm{SURF}}+\Delta T_{\mathrm{CONV}}$,

where

$\Delta T_{\mathrm{LW}}=-\frac{\sigma \Delta \varepsilon_{\mathrm{eff}}\left[T^{4}\right]}{D}$

$\Delta T_{\mathrm{SW}}=\frac{\Delta \mathrm{SW}_{\mathrm{TOA}}^{\downarrow}}{D}$,

$\Delta T_{\mathrm{SURF}}=-\frac{\Delta F_{\mathrm{SURF}}^{\downarrow}}{D}$,

$\Delta T_{\mathrm{CONV}}=\frac{\Delta\left(C^{\rightarrow}-\frac{\delta E}{\delta t}\right)}{D}$.

We mark the surface temperature change due to horizontal heat transport and the change in the energy storage (Eq. 8d) collectively as CONV, as together they represent the convergence of energy. Annually, the change in the energy storage of an atmospheric column averages to zero in an equilibrium climate (Porter et al., 2010; Räisänen, 2017), and Eq. (8d) corresponds to the difference in horizontal heat transport between two equilibrium climates. However, on monthly and seasonal timescales the changes in atmospheric energy storage can be significant.

The terms on the right-hand side of Eq. (8a) and (8b) can be further expanded to separate the surface temperature responses due to clear-sky and cloud radiative effects. The standard climate model output contains radiative fluxes both for all-sky and clear-sky (CS) conditions, so that the temperature response to longwave cloud radiative effect can be obtained as

$$
\begin{aligned}
\Delta T_{\mathrm{LW}} \mathrm{CRE} & =\Delta T_{\mathrm{LW}}-\Delta T_{\mathrm{LW}_{\mathrm{CS}}} \\
& =-\frac{\sigma \Delta \varepsilon_{\mathrm{eff}}\left[T^{4}\right]}{D}+\frac{\sigma \Delta \varepsilon_{\mathrm{eff}, \mathrm{cs}}\left[T^{4}\right]}{D} .
\end{aligned}
$$

Räisänen (2017) calculated the surface temperature response due to changes in longwave cloud emissivity as $\Delta T_{\mathrm{LW}}$ CRE but noted that it is a negatively biased approximation of the actual cloud longwave feedback, as also discussed by Soden et al. (2004). Here, we extend the calculation to allow for a more precise separation of thermal radiation to its clear-sky and cloud contributions with the help of radiative kernels. Radiative kernels are climate-model-derived radiative responses to small changes in climate state, such as to changes in atmospheric temperature, surface temperature, or water vapor under clear-sky and all-sky conditions. We use the radiative kernels of Block and Mauritsen (2013) and their Eq. (4) to calculate a corrected longwave cloud feedback

$$
\begin{aligned}
\Delta \mathrm{LW}_{\mathrm{cld}}^{\downarrow} \approx & \Delta \mathrm{LW}_{\mathrm{CRE}}^{\downarrow}-\Delta \mathrm{LW}_{\mathrm{cor}}^{\downarrow}, \text { namely } \\
\Delta \mathrm{LW}_{\mathrm{cor}}^{\downarrow}= & \left(K_{T}-K_{T}^{\mathrm{clr}}\right) \Delta T+\sum_{i}\left(K_{T_{i}}-K_{T_{i}}^{\mathrm{clr}}\right) \Delta T_{i} \\
& +\sum_{i}\left(K_{w_{i}}-K_{w_{i}}^{\mathrm{clr}}\right) \Delta(\ln q)_{i},
\end{aligned}
$$

where $K_{\mathrm{T}}$ and $K_{\mathrm{w}}$ are different model level mass-weighted radiative kernels, $q$ is the specific humidity, and the summations are carried over the model levels $i$. Block and Mauritsen (2013) generated their radiative kernels with the ECHAM6 climate model, and here we apply the kernels both to the ECHAM6.1 and NorESM1 models. This should bring no major bias for the NorESM1 calculations, as Myhre et al. (2018) showed that radiative kernels do not significantly depend on the specific model used for their construction. The calculated correction is used to redistribute the effect of $\Delta \varepsilon_{\text {eff }}$ between the cloud and clear-sky terms as

$$
\begin{aligned}
& \Delta T_{\mathrm{LW}_{\mathrm{cld}}}=\Delta T_{\mathrm{LW}_{\mathrm{CRE}}}-\frac{\Delta \mathrm{LW}_{\mathrm{cor}}^{\downarrow}}{D}, \\
& \Delta T_{\mathrm{LW}_{\mathrm{clr}}}=\Delta T_{\mathrm{LW}_{\mathrm{CS}}}+\frac{\Delta \mathrm{LW}_{\mathrm{cor}}^{\downarrow}}{D},
\end{aligned}
$$

where $\Delta T_{\mathrm{LW}_{\text {cld }}}$ and $\Delta T_{\mathrm{LW}_{\mathrm{clr}}}$ are the corrected longwave cloud and clear-sky temperature responses.

As discussed in Räisänen (2017), the top-of-atmosphere shortwave radiative responses for clear-sky and all-sky conditions can also be further separated to physically more meaningful terms using the approximative partial radiative perturbation (APRP) method of Taylor et al. (2007).

$$
\begin{aligned}
\Delta T_{\mathrm{SW}}= & \Delta T_{\mathrm{SW}_{\mathrm{IN}}}+\Delta T_{\mathrm{SW}_{\mathrm{clr}}}+\Delta T_{\mathrm{SW}_{\mathrm{cld}}} \\
& +\Delta T_{\mathrm{SW}_{\text {Albedo }}}+\Delta T_{\mathrm{SW}_{\mathrm{NL}}}
\end{aligned}
$$

where $\Delta T_{\mathrm{SW}_{\text {IN }}}$ corresponds to changes in incoming solar radiation (zero in our model experiments), $\Delta T_{\mathrm{SW}_{\mathrm{clr}}}$ is the corrected clear-sky shortwave temperature response, $\Delta T_{\mathrm{SW}_{\text {cld }}}$ is the shortwave cloud response, $\Delta T_{\mathrm{SW}_{\text {Albedo }}}$ is the temperature response due to changes in surface albedo, and $\Delta T_{\mathrm{SW}_{\mathrm{NL}}}$ is a non-linear correction term, small enough to be insignificant for the analysis.

Hereafter, we use the subscripts in $\Delta T$ terms as shorthand notations when discussing the various temperature responses (so that $\Delta T_{\mathrm{SW}_{\mathrm{clr}}}$ is discussed as $\mathrm{SW}_{\text {clr }}$ etc.).

\section{Results}

\subsection{Radiative forcing}

Figure 1 shows the net change in instantaneous top-ofatmosphere aerosol radiative forcing, $\triangle \mathrm{IRF}$, due to removal of South and East Asian anthropogenic aerosols, calculated as an average over the full 60-year equilibrated climate data 
sets over both models as

$$
\begin{aligned}
& \Delta \mathrm{IRF} \text { (removed S\&E Asian anthropogenic aerosols) } \\
& =\operatorname{IRF} \text { (no S\&E Asian anthropogenic aerosols) } \\
& \quad-\operatorname{IRF} \text { (all aerosols). }
\end{aligned}
$$

Note that since we here remove the Asian anthropogenic aerosols from the models, $\triangle \mathrm{IRF}$ is positive in sign, i.e., that of warming. $\triangle \mathrm{IRF}$ further breaks into $\triangle \mathrm{IRF}=\Delta \mathrm{IRF}_{\mathrm{d}}+$ $\Delta I R F_{i d}$, where $\Delta I F_{d}$ describes the change in aerosol direct radiative forcing due to the net change in direct radiation attenuation of aerosols through their scattering and absorption of solar radiation. $\Delta I R F_{i d}$ is the change in indirect radiative forcing (the Twomey effect) between the runs without and with South and East Asian anthropogenic aerosols. The geographical pattern of $\triangle I R F$ is nearly identical for ECHAM6.1 and NorESM1, with the model-to-model correlation coefficient of 0.99 . However, the modeled globally averaged $\triangle I R F$ differs slightly between the models, being $0.38 \pm 0.00 \mathrm{~W} \mathrm{~m}^{-2}$ for ECHAM6. 1 and $0.41 \pm 0.00 \mathrm{~W} \mathrm{~m}^{-2}$ for NorESM1, with a model mean of $0.40 \pm 0.00 \mathrm{~W} \mathrm{~m}^{-2}$. Results for individual models are shown in the Appendix Fig. A1.

In the models, $\triangle \mathrm{IRF}$ due to removal of Asian anthropogenic aerosols is concentrated on a distinctive patch over the region surrounding the aerosol sources. The change in local radiative forcing reaches up to $8.3 \mathrm{~W} \mathrm{~m}^{-2}$ over SE China. The change in direct radiative forcing $\triangle \mathrm{IRF}_{\mathrm{d}}$ in the models is responsible for slightly over a half $(0.22 \pm 0.00$; $0.23 \pm 0.00 \mathrm{~W} \mathrm{~m}^{-2}$ for ECHAM6.1 and $0.20 \pm 0.00 \mathrm{~W} \mathrm{~m}^{-2}$ for NorESM1 with a model-to-model correlation coefficient 0.96) of the total globally averaged $\triangle I R F$ and more focused on the polluted regions than the change in indirect forcing $\Delta$ IRF $_{\text {id }}\left(0.18 \pm 0.00 ; 0.15 \pm 0.00 \mathrm{~W} \mathrm{~m}^{-2}\right.$ for ECHAM6.1 and $0.21 \pm 0.00 \mathrm{~W} \mathrm{~m}^{-2}$ for NorESM1 with a model-to-model correlation coefficient 0.94 ), which spreads more evenly over a larger area. The higher model-to-model correlation coefficient for $\triangle I R F$ than for $\Delta I_{R F}$ and $\triangle I R F_{i d}$ separately indicates a cancellation of regional model-to-model differences when changes in direct and indirect radiative forcings are summed up. This cancellation of differences in $\triangle I R F$ suggests that differences in modeled cloud fields mainly distribute $\triangle I R F$ differently to its $\triangle I_{R F}$ and $\triangle I R F_{i d}$ components in the models. While the aerosols enhance the cloud albedo, clouds also diminish the direct reflection of sunlight by aerosols with compensating effects on the total radiative response. However, differences in modeled pre-industrial background aerosols likely also play a role in model-tomodel difference in $\triangle \mathrm{IRF}_{\mathrm{id}}$.

\subsection{Annually averaged temperature response decomposition}

We first describe the commonalities in modeled surface temperature responses to the omission of South and East Asian aerosols in the two models, before discussing their differences. The average global equilibrium temperature response

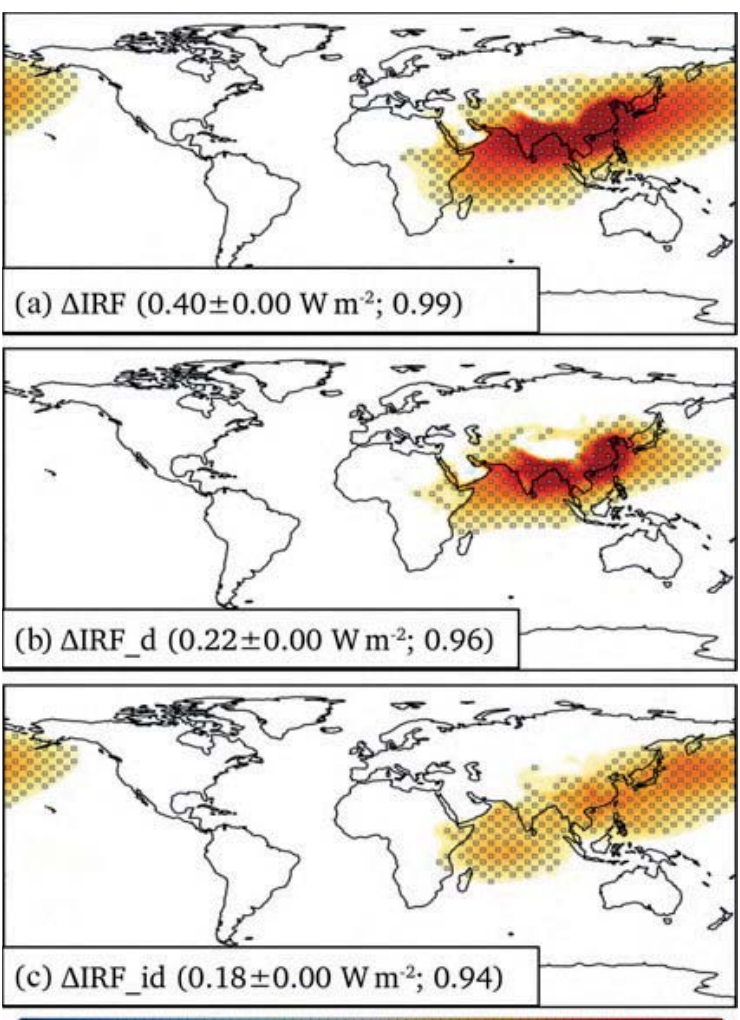

\begin{tabular}{lllllllllllllllllllllll}
\hline .0 & -3.6 & -3.2 & -2.8 & -2.4 & -2.0 & -1.6 & -1.2 & 0.8 & 0.4 & 0.0 & 0.4 & 0.8 & 1.2 & 1.6 & 2.0 & 2.4 & 2.8 & 3.2 & 3.6 & 4.0
\end{tabular}

$\triangle \mathrm{IRF}\left(\mathrm{W} \mathrm{m}^{-2}\right)$

Figure 1. The change in the mean instantaneous radiative forcing between runs without and with South and East Asian aerosols using the MACv2-SP aerosol scheme, averaged over the two climate models (individual models shown in Fig. A1). Parentheses show the average global-mean value and the model-to-model correlation coefficient, respectively. (a) Change in the total aerosol radiative forcing, (b) change in the direct aerosol radiative forcing, and (c) change in the indirect aerosol radiative forcing. Stippling shows regions where the results are statistically significant at the $p<0.05$ level for both models, and models also agree on the sign.

$\Delta T$ to the removal of aerosols across the two models is shown in Fig. 2A (individual models are shown in Figs. A2a and A3a, and global-level results are collected on Table A1). The regional distribution of surface temperature response is strikingly different from the distribution of South and East Asian anthropogenic aerosol forcing, with surface warming spreading over the entire Northern Hemisphere and to a lesser extent also to the Southern Hemisphere. Indeed, significant warming extends to regions where no change in aerosols is modeled, such as over to the North American continent $(0.5 \mathrm{~K})$, and to Arctic regions with warming exceeding $1 \mathrm{~K}$. The warming over the region with the strongest change in local aerosol forcing (SE China) is $1.5 \mathrm{~K}$ with a local climate sensitivity of $0.18 \mathrm{~K} \mathrm{~W}^{-1} \mathrm{~m}^{2}$ (i.e., $1.5 \mathrm{~K} / 8.3 \mathrm{~W} \mathrm{~m}^{-2}$ ), while the globally averaged warming is $0.26 \pm 0.04 \mathrm{~K}$ with a climate sensitivity of $0.65 \pm 0.11 \mathrm{KW}^{-1} \mathrm{~m}^{2}$ ). A similar global 
climate sensitivity of $0.58 \pm 0.23 \mathrm{KW}^{-1} \mathrm{~m}^{2}$ ) for a 10 -fold increase in Asian sulfate aerosols was found in models that participated to the multi-model intercomparison project PDRMIP (Liu et al., 2018).

As described in the Method section (Sect. 2), the total local temperature response can be represented as a sum of responses in clear and cloudy-sky shortwave $\left(\mathrm{SW}_{\mathrm{clr}}\right.$ and $\mathrm{SW}_{\text {cld }}$ ) and longwave $\left(\mathrm{LW}_{\mathrm{clr}}\right.$ and $\left.\mathrm{LW}_{\text {cld }}\right)$ radiation, surface albedo (ALBEDO), surface energy fluxes (SURF), and an energy convergence term (CONV) representing the horizontal transport of heat for annually averaged results. The annually averaged temperature responses for each of the energetic terms, averaged over the 60-year sets of equilibrated climate runs with both models, are shown in Fig. $2 \mathrm{~b}-\mathrm{h}$. The sum of surface temperature responses to individual energetic terms (sum over Fig. 2b-h) reproduces the total surface temperature response in Fig. 2a with a spatial correlation coefficient $\mathrm{cc}=0.998$ and an identical global mean.

First it can be noted that the geographical distribution of temperature responses due to changes in clear-sky shortwave radiation, $\mathrm{SW}_{\mathrm{clr}}$ (Fig. 2b), resembles closely the distribution of shortwave direct radiative forcing, $\Delta \mathrm{IRF}_{\mathrm{d}}$ (Fig. 1b), with a correlation coefficient $\mathrm{cc}=0.96 . \mathrm{SW}_{\mathrm{clr}}$ is also one of the major energetic terms of the total globally averaged temperature response, responsible for $0.08 \pm 0.01 \mathrm{~K}$ of the total globally averaged temperature response of $0.26 \pm 0.04 \mathrm{~K}$.

Over the whole region of positive radiative forcing $(\triangle \mathrm{IRF}$ in Fig. 1a) the warming is moderated by the cooling caused by the transport of energy away from the region, CONV (Fig. 2c). CONV also efficiently redistributes the temperature effects across the globe. Since CONV only acts by horizontally redistributing atmospheric energy, its effect on the global surface temperature response is effectively zero $(-0.01 \pm 0.02 \mathrm{~K})$.

Unlike for the connection between $\mathrm{SW}_{\mathrm{clr}}$ and $\Delta \mathrm{IRF}_{\mathrm{d}}$, the geographical distribution of temperature responses due to changes in cloudy-sky shortwave radiation, $\mathrm{SW}_{\text {cld }}$ (Fig. 2d) corresponds only weakly to the geographical distribution of the change in shortwave cloud radiative forcing $\Delta \mathrm{IRF}_{\mathrm{id}}$ (Fig. 1c) $(\mathrm{cc}=0.23)$. Indeed, while there is a pronounced positive $\triangle \mathrm{IRF}_{\mathrm{id}}$ in South Asia and the western subtropical North Pacific in Fig. 1c, much of the warming response in this region appears actually in the $\mathrm{LW}_{\text {cld }}$ term (Fig. 2e). This is because of feedbacks that lead to changes in cloud cover and other cloud properties. Clouds both reflect SW radiation and reduce outgoing longwave radiation (e.g., Loeb et al., 2018), and changes in cloud amount tend to have opposing effects on $\mathrm{SW}_{\text {cld }}$ and $\mathrm{LW}_{\text {cld }}$. The average total cloud cover change in the models is shown in Fig. 3a. The global distribution of cloud cover changes correlates strongly with $\mathrm{LW}_{\text {cld }}(\mathrm{cc}=0.77)$ and anti-correlates with $\mathrm{SW}_{\text {cld }}(\mathrm{cc}=$ -0.74 ). Only by summing $\mathrm{SW}_{\text {cld }}$ and $\mathrm{LW}_{\text {cld }}$ (Fig. $2 \mathrm{i}$ ) one can again recognize the warming response to $\Delta \mathrm{IRF}_{\text {id }}$ (Fig. 1c) $(\mathrm{cc}=0.70)$. There is a marked and statistically significant increase in cloud cover over India, Mainland Southeast Asia, and the western subtropical North Pacific, accompanied by a strong decrease in $\mathrm{SW}_{\text {cld }}$ and increase in $\mathrm{LW}_{\text {cld }}$. The strong increase in cloud cover over India and Mainland Southeast Asia leads to a weaker overall surface temperature response (Fig. 2a) in these regions. In contrast, the decrease in cloud cover over East Asia amplifies the temperature response over the region. Further, the changes in clouds also contribute to remote temperature responses, such as to a weakening of the cloud cover over the Mediterranean and central Asia with compensating surface temperature effects from the $\mathrm{SW}_{\text {cld }}$ and $\mathrm{LW}_{\text {cld }}$ pathways. Overall, the combined effect of clouds $\left(\mathrm{SW}_{\mathrm{cld}}+\mathrm{LW}_{\mathrm{cld}}\right)$ on the globally averaged temperature response is $0.08 \pm 0.04 \mathrm{~K}$.

Together with the horizontal energy transport CONV, also the clear-sky longwave response $\mathrm{LW}_{\mathrm{clr}}$ acts as a strong redistributor of the surface temperature changes across the globe. Similarly to $\mathrm{CO}_{2}$ forcing (Räisänen, 2017), $\mathrm{LW}_{\mathrm{clr}}$ $(0.08 \pm 0.03 \mathrm{~K})$ is one of the major terms in the overall global temperature response also for aerosols. This is somewhat counterintuitive, as the modeled aerosols only impact the shortwave radiation in clear and cloudy skies. The geographical distribution of $\mathrm{LW}_{\mathrm{clr}}$ mainly results from a combination of atmospheric water vapor and lapse rate feedbacks (Pithan and Mauritsen, 2014; Räisänen, 2017), but the separation of these feedbacks is not pursued in this study.

Figure $2 \mathrm{f}$ shows the annual average change across both models in ALBEDO, that is, the surface temperature response to the change in surface albedo. The change in surface albedo is related to changes in snow and sea ice cover, but interestingly the surface albedo (ratio between reflected and incoming surface shortwave radiation) also changes over India in both models, likely due to changes in the ratio of direct vs. diffuse solar radiation. The surface albedo change further pushes the geographical distribution of warming towards northern latitudes. The globally averaged temperature effect of the surface albedo change is nevertheless small $(0.02 \pm 0.01 \mathrm{~K})$.

The annually averaged temperature response due to changes in surface energy flux, SURF (Fig. 2g), is zero over the continents as there is no net annual exchange of heat between continental surface and the atmosphere regardless of climate state and nonzero mainly over ocean regions where there are changes in sea ice cover. In climate runs with fully coupled ocean models, instead of slab ocean models used here, the annually averaged oceanic surface terms could be larger due to changes in oceanic circulation and heat transport. Since we have run the modeled climates to an equilibrium, the yearly averaged global SURF is zero $(0.00 \pm 0.04 \mathrm{~K})$; yet, it introduces a significant noise term in the results. However, the oceanic SURF term plays an important role in the seasonal cycle of regional temperature responses, as we will discuss further when describing the seasonality of modeled temperature responses. 

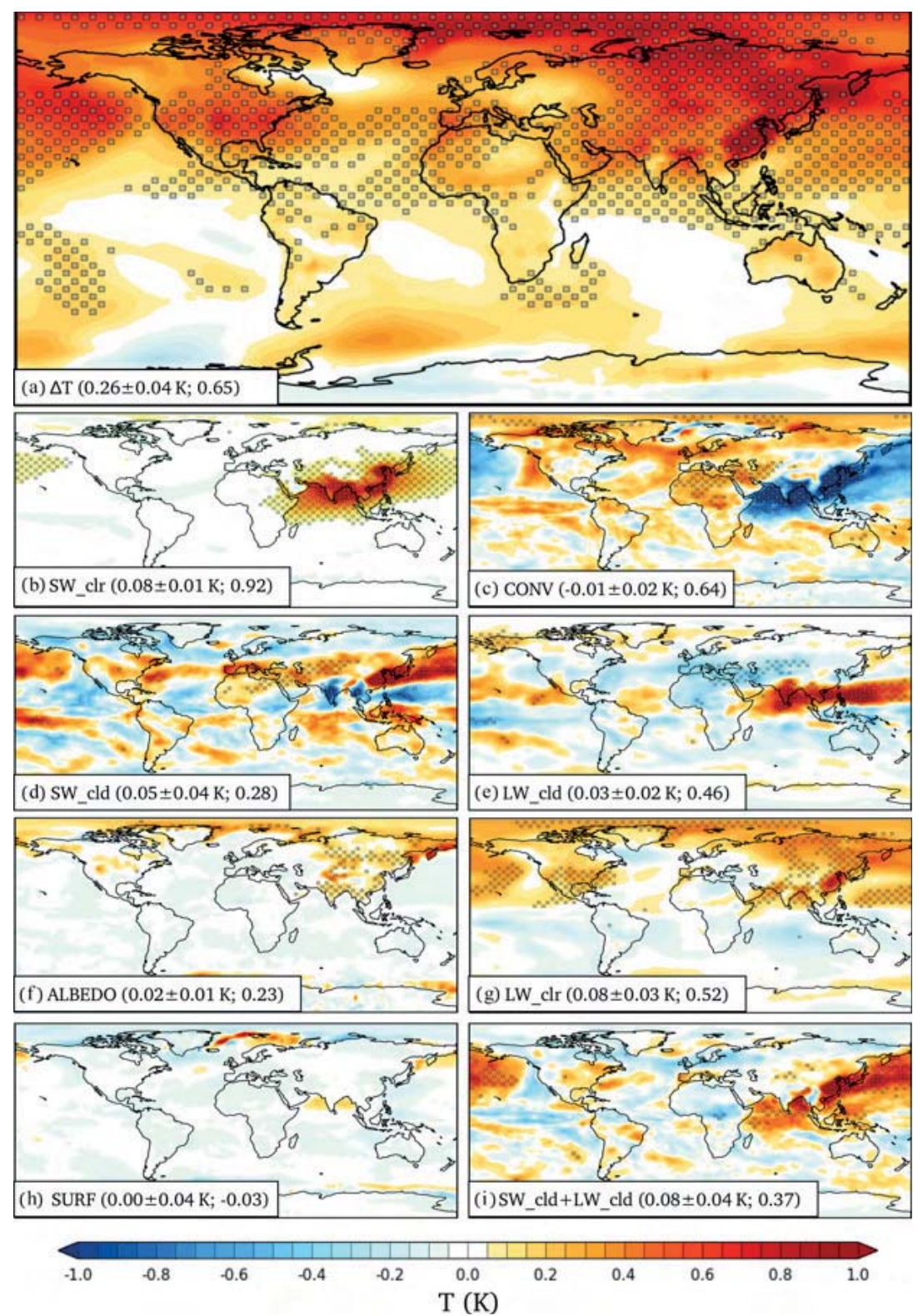

Figure 2. The geographical distributions of annually averaged surface air $(2 \mathrm{~m})$ temperature responses due to the removal of South and East Asian aerosols (mean over ECHAM6.1 and NorESM1 climate models). Brackets show global average responses in kelvins and the model-tomodel correlation coefficient, respectively. (a) The total surface temperature response. (b-h) Contributions to the total surface temperature response from shortwave clear-sky response (b), horizontal atmospheric heat transport (c), shortwave cloud response (d), longwave cloud response (e), surface albedo change (f), longwave clear-sky response (g), and surface energy flux change (h). (b-h) Sum up to the response seen in panel (a). Panel (i) shows the combined shortwave and longwave cloud response. Stippling shows regions where the results are statistically significant at the $p<0.05$ level for both models, and models also agree on the sign.

\subsection{Model-to-model differences in regional temperature responses}

The parentheses in Figs. 1, 2, and 3 show the model-to-model correlation coefficients for the geographical distributions of changes in radiative forcings, temperature response terms, and cloud cover due to the removal of South and East Asian anthropogenic aerosols. The coefficients describe the geo- graphical uniformity of responses for the ECHAM6.1 and NorESM1 climate models using the same representation of anthropogenic aerosols via the MACv2-SP aerosol scheme.

The strong correlation between modeled change in aerosol direct radiative forcing $\Delta \mathrm{IRF}_{\mathrm{d}}(\mathrm{cc}=0.96)$ translates into a strong correlation between the modeled surface temperature response due to $\mathrm{SW}_{\mathrm{clr}}(\mathrm{cc}=0.91)$. However, the strong cor- 

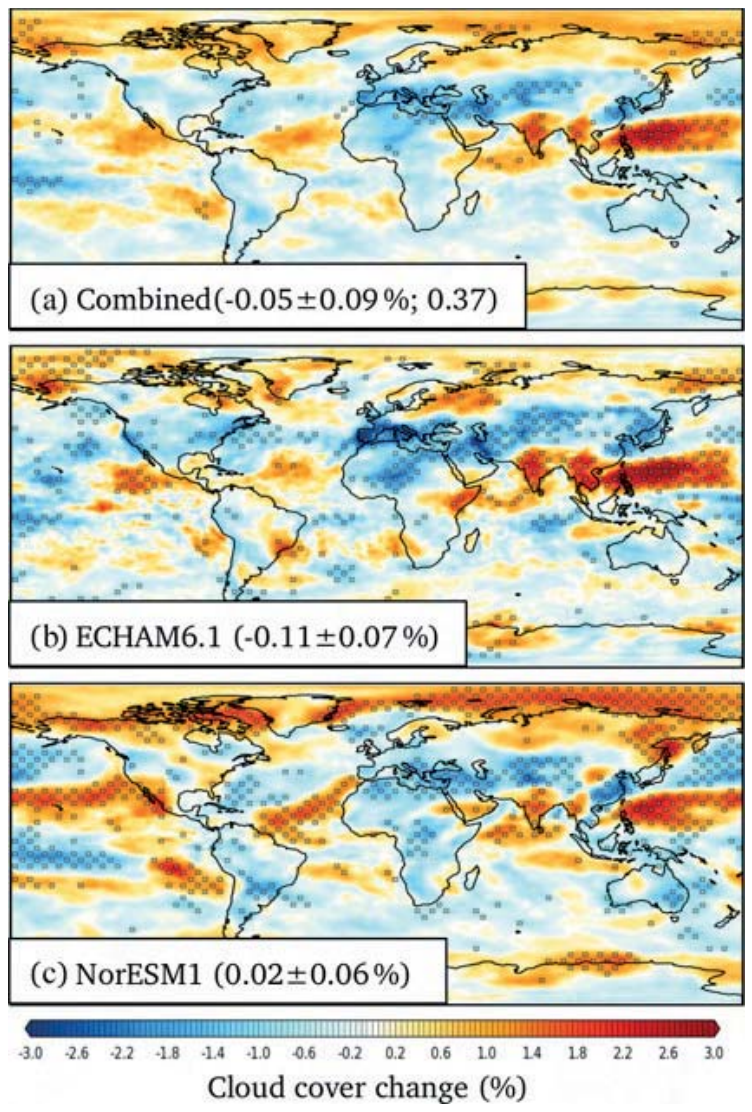

Figure 3. The geographical distributions of annually averaged changes in total cloud cover due to the removal of South and East Asian aerosols. (a) Cloud cover change averaged over both ECHAM6.1 and NorESM1 climate models. Brackets show global average responses in percentages and the model-to-model correlation coefficient, respectively. Stippling shows regions where the results are statistically significant at the $p<0.05$ level for both models, and models also agree on the sign. (b, c) Cloud cover change in ECHAM6.1 and NorESM1, respectively. Brackets give global average responses in percentages. Stippling shows regions where the results are statistically significant at the $p<0.05$ level

relation for the change in aerosol indirect radiative forcing $\Delta \operatorname{IRF}_{\mathrm{id}}(\mathrm{cc}=0.96)$ does not result in a strong correlation between the modeled $\mathrm{SW}_{\mathrm{cld}}(\mathrm{cc}=0.28)$. This is due to different changes in modeled cloud fields and the high sensitivity of $\mathrm{SW}_{\text {cld }}$ to such changes. As discussed in the previous section, the changes in cloud fields also lead to changes in $\mathrm{LW}_{\text {cld }}$. In both models the change in $\mathrm{LW}_{\mathrm{cld}}(\mathrm{cc}=0.46)$ is particularly pronounced over the Asian monsoon region, where the cloud cover increases due to the omission of South and East Asian anthropogenic aerosols. The total surface temperature response due to clouds in the two models, $\mathrm{SW}_{\text {cld }}+\mathrm{LW}_{\text {cld }}$ $(\mathrm{cc}=0.37)$, has a similarly low correlation as the change in total cloud cover $(\mathrm{cc}=0.37)$ between the two models. The distribution of annual average surface temperature responses due to changes in atmospheric energy transport,
CONV $(\mathrm{cc}=0.64)$, is modeled relatively robustly across the models, given that CONV extends over both hemispheres. The correlation between annual $\mathrm{LW}_{\mathrm{clr}}$ terms $(\mathrm{cc}=0.52)$ is modest, and differences in $\mathrm{LW}_{\text {clr }}$ contribute to model differences in the total temperature response particularly over North Asia. The surface temperature responses to albedo changes in the models, ALBEDO $(\mathrm{cc}=0.23)$, have a rather weak correlation, but much of the deviation in ALBEDO responses results from sporadic differences in modeled Southern Ocean sea ice.

The total surface temperature response $\Delta T(\mathrm{cc}=0.65)$ due to removal of South and East Asian anthropogenic aerosols using the MACv2-SP aerosol scheme has a weaker correlation than the temperature response due to removal of all anthropogenic MACv2-SP aerosols in the same models $(\mathrm{cc}=0.78)$ (Nordling et al., 2019). The total globally and annually averaged surface temperature responses in the models due to the removal of South and East Asian anthropogenic aerosols $(0.22 \pm 0.03 \mathrm{~K}$ for ECHAM6. 1 and $0.30 \pm 0.03 \mathrm{~K}$ for NorESM1) also differ more than the corresponding values for the complete removal of anthropogenic aerosols $(0.48 \pm$ $0.04 \mathrm{~K}$ for ECHAM6.1 and $0.50 \pm 0.06 \mathrm{~K}$ for NorESM1, with error given here using a $95 \%$ confidence interval). For the removal of South and East Asian anthropogenic aerosols modeled here, the largest contributors to the differences in modeled globally and annually averaged surface temperature responses between the two models are the cloud terms $\mathrm{SW}_{\text {cld }}(0.03 \pm 0.03 \mathrm{~K}$ for ECHAM6.1 and $0.07 \pm 0.02 \mathrm{~K}$ for NorESM1) and $\mathrm{LW}_{\text {cld }}(0.01 \pm 0.01 \mathrm{~K}$ for ECHAM6.1 and $0.05 \pm 0.01 \mathrm{~K}$ for NorESM1).

\subsection{Seasonal cycle of temperature responses across Northern Hemisphere latitudes}

The seasonal cycle of latitudinal temperature responses is shown in Fig. 4a for ECHAM6.1 and in Fig. 4b for NorESM1. The figures also highlight the latitudinal dislocation of the change in aerosol radiative forcing and the resulting temperature response. In both models the change in radiative forcing peaks between $20-30^{\circ} \mathrm{N}$, but the temperature responses are strongest over the high north.

The seasonality of the latitudinal surface temperature responses (star symbols in Fig. 4) is modest in both models from low to mid-latitudes, with opposing changes in energetic terms contributing to balancing cooling and warming seasonal responses. Throughout the Northern Hemisphere both shortwave and longwave clear-sky terms $\left(\mathrm{SW}_{\mathrm{clr}}\right.$ and $\mathrm{LW}_{\text {clr }}$ shown with color bars) remain positive during all seasons. Surface temperature changes due to cloud shortwave responses $\left(\mathrm{SW}_{\mathrm{cld}}\right)$ are strongest during the summer, being positive in the mid-latitudes but mostly negative elsewhere. The cloud longwave term $\left(\mathrm{LW}_{\text {cld }}\right)$ typically opposes the $\mathrm{SW}_{\text {cld }}$ responses, and particularly strongly over the 10 $20^{\circ} \mathrm{N}$ band due to opposing responses to changes in cloudiness in the region. The change in the net oceanic surface 


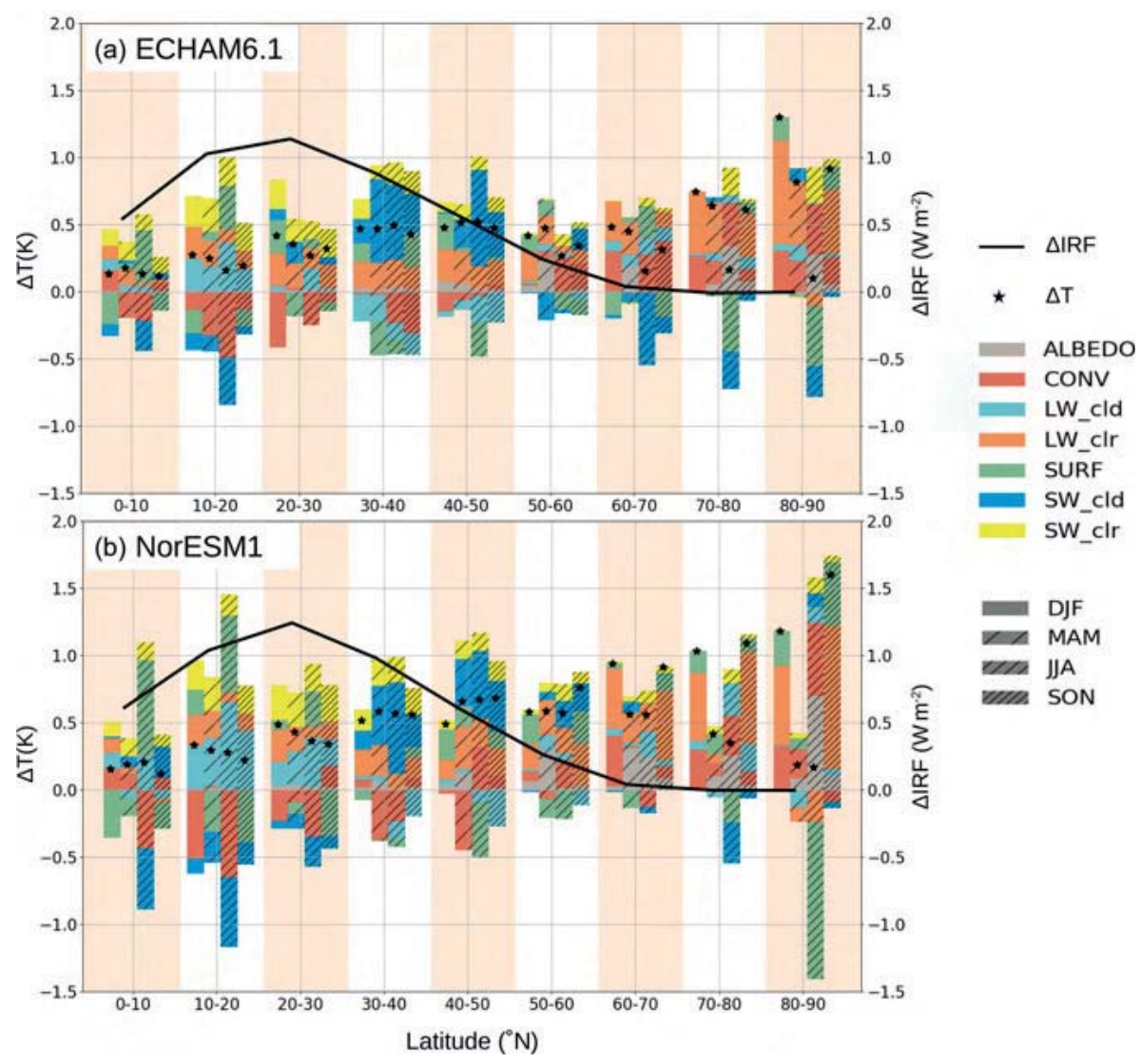

Figure 4. Seasonal cycles of surface temperature responses averaged over the northern-hemispheric latitude bands for the ECHAM6.1 (a) and NorESM1 (b) models. Color bars show the different contributions to seasonal mean temperature responses shown with the star symbols. Different seasons are indicated with different hatchings over the color bars. The solid lines indicate the change in the annual average Asian aerosol instantaneous radiative forcing $(\Delta \mathrm{IRF})$ for each model. The modest seasonality in radiative forcing is not shown for the sake of clarity.

energy flux (SURF) amplifies the summer warming in 0$20^{\circ} \mathrm{N}$ during the Asian monsoon, and overall the changes in oceanic surface fluxes tend to regulate the modest seasonality of temperature responses from low to mid-latitudes and amplify the seasonality of the response in the Arctic. Atmospheric energy transport and storage (CONV) also regulates the modest seasonality of responses from low to midlatitudes together with SURF, although these terms tend to oppose each other. The seasonal CONV terms grow from mostly negative at low northern latitudes towards mostly positive at high northern latitudes, reflecting the increase in atmospheric energy transport towards the high north.

The differences in modeled latitudinal temperature responses become larger from $50^{\circ} \mathrm{N}$ northwards, where the direct influence from the change in aerosol radiative forcing diminishes. Between $50-70^{\circ} \mathrm{N}$ warming from the longwave clear-sky term is stronger in NorESM1 than in ECHAM6.1, and the negative shortwave cloud term also contributes to lesser warming in ECHAM6.1.
In the Arctic, the surface temperature warming is large in both models in the northern-hemispheric autumn and winter and characterized by a near lack of negative energetic terms and strong $\mathrm{LW}_{\mathrm{clr}}$ terms in both models. The models produce mixed results for the Arctic spring, but both models show a steep summer minimum in the overall surface temperature response. The Arctic summer response is characterized by the positive surface albedo (ALBEDO) and energy transport effects (CONV) opposed by a strongly negative surface energy term (SURF) corresponding to oceanic heat uptake. In Arctic summer, the shortwave cloud effects $\mathrm{SW}_{\text {cld }}$ are more negative in ECHAM6.1 than in NorESM1, with very modest effects for the rest of the year. During other seasons, the surface energy (SURF) term becomes positive as the ocean releases the energy stored. Thus, in the Arctic, SURF amplifies the seasonality of the temperature response. 


\section{Conclusions and discussion}

In this work, we have represented the modern-day anthropogenic aerosols identically in two climate models with independent development histories and studied the equilibrium climate responses to the removal of East and South Asian anthropogenic aerosols. This forcing gives rise to a positive surface temperature response, the global mean of which is somewhat larger in NorESM1 $(0.30 \pm 0.03 \mathrm{~K})$ than in ECHAM6.1 $(0.22 \pm 0.03 \mathrm{~K})$. Both models robustly show that the warming response spreads across both hemispheres and is particularly strong in the Arctic.

The temperature decomposition method by Räisänen (2017) provides a valuable tool for analyzing how the surface temperature response to a regional forcing spreads to remote regions. Over the polluted regions in South and East Asia, the removal of anthropogenic aerosols leads to a strong surface warming contribution from additional solar radiation reaching the surface under clear-sky conditions. The local temperature effects due to changes in clouds are however more complex. While the removal of modeled aerosols in the applied MACv2-SP aerosol scheme (Stevens et al., 2017) only affects the cloud shortwave properties via the first indirect aerosol effect, the cloud responses manifest themselves both in shortwave and longwave channels, with changes in cloud amount having opposite shortwave and longwave effects on surface temperatures.

The driver of the wide geographical spreading of the temperature response appears to be the strong tendency of atmospheric heat transport to regulate surface warming over the region of diminished aerosol forcing while simultaneously enhancing the warming in remote locations. Also, changes in the clear-sky longwave responses associated at least in part with increased water vapor further amplify the surface temperature warming over the Northern Hemisphere. In both models the seasonality of the latitudinal surface temperature responses is modest in northern low and mid-latitudes but strong over the Arctic.

The mechanisms driving the strongly seasonal Arctic response resemble those for the CMIP5 ensemble for $\mathrm{CO}_{2}$ doubling (Räisänen, 2017) and historical transient simulations (Pithan and Mauritsen, 2014). They involve the ice-albedo feedback, where additional sea ice melt during spring and summer leads to increased absorption of solar radiation by the larger open water area in the Arctic Ocean during summer and autumn. During the summer the Arctic Ocean is thermalized close to the freezing temperature and the trapped solar radiation is stored as heat within the ocean (e.g., Holland and Bitz, 2003; Screen and Simmonds, 2010). This heat is then released during autumn and winter, elevating the atmospheric sub-zero temperatures. However, it is the longwave clear-sky response that contributes most to the seasonality and the overall Arctic warming, supporting the strong role of temperature feedbacks in the Arctic warming (Pithan and Mauritsen, 2014) also in cases of South and East Asian anthropogenic aerosol removal. Further, it is notable that in this study a strong Arctic surface temperature response takes place despite the lack of modeled changes in oceanic heat transport, which have been previously shown to dominate the increase in heat transport towards the Arctic due to reductions in European anthropogenic aerosol emissions (AcostaNavarro et al., 2016).

The temperature decomposition method also allows an analysis of the similarities and differences between the response in ECHAM6.1 and NorESM1. It was found that the larger global annual mean warming in NorESM1 than in ECHAM6. $1(0.30 \pm 0.03 \mathrm{~K}$ vs. $0.22 \pm 0.03 \mathrm{~K})$ is primarily associated with the shortwave cloud response $(0.07 \pm 0.02 \mathrm{~K}$ for NorESM1 and $0.03 \pm 0.03 \mathrm{~K}$ for ECHAM6.1) and the longwave cloud response $(0.05 \pm 0.01 \mathrm{~K}$ for NorESM1 and $0.01 \pm 0.01 \mathrm{~K}$ for ECHAM6.1). Furthermore, there are significant differences in the geographic patterns of cloud cover responses, which lead to equally significant local/regional differences in the combined shortwave and longwave cloud surface temperature responses. Overall, these differences notwithstanding, it is however encouraging that the geographical distribution of remote surface temperature response is robust in the two independent climate models, when run with identical anthropogenic aerosol descriptions. Not just the distribution of total surface temperature response is similar in the models but also the distributions of different energy flux drivers, which together constitute the obtained temperature responses, are mostly similar.

The effective radiative forcing (ERF) due to adding MACv2-SP aerosols was shown to be $-0.50 \mathrm{~W} \mathrm{~m}^{-2}$ for ECHAM6.3 and $-0.65 \mathrm{~W} \mathrm{~m}^{-2}$ for NorESM1 by Fiedler et al. (2019). As such, the total ERF for all anthropogenic aerosols computed using the MACv2-SP scheme is in the low-end range of typical ERFs (between -0.29 and $-1.44 \mathrm{~W} \mathrm{~m}^{-2}$ ) obtained for CMIP5 models with modelintrinsic aerosol schemes (Shindell et al., 2015) and closely matches the recent estimate of $-0.55 \mathrm{~W} \mathrm{~m}^{-2}$ for the 1750 2015 change in global aerosol ERF by Lund et al. (2019). The global annual temperature response for adding MACv2SP aerosols was shown to be $-0.48 \mathrm{~K}$ for ECHAM6.1 and $-0.50 \mathrm{~K}$ for NorESM1, being in the low end of equilibrium temperature responses $(-0.5$ to $-1.1 \mathrm{~K})$ for adding modelintrinsic anthropogenic aerosols in four contemporary climate models (Samset et al., 2018). Therefore, the annual average temperature response of $0.26 \pm 0.04 \mathrm{~K}$ obtained here can be considered to be a conservative estimate for the removal of South and East Asian anthropogenic aerosols.

To contextualize the effects of strong Asian aerosol pollution mitigation scenarios on the changes in global surface temperatures, we note that global temperatures have increased by an average of $0.18^{\circ} \mathrm{C}$ per decade during 1980 2019 (NOAA global climate report 2019). Lund et al. (2019) showed that under the Socioeconomic Shared Pathway 11.9 , the strong air pollution mitigation scenarios tied with $\mathrm{CO}_{2}$ mitigation policies lead to a $55 \%$ drop in combined an- 
thropogenic aerosol emissions from South and East Asian regions already by 2030 . Our models predict an annually averaged global warming of $0.26 \pm 0.04^{\circ} \mathrm{C}$ if the South and East Asian anthropogenic aerosols are removed totally. Assuming a linear relationship between aerosol emission reductions and temperature effects and a relatively fast transient climate response for the aerosols, the Asian emissions reductions can add another 7.9 (6.7-9.2) years' worth of current-day global warming on top of greenhouse-gas-related warming during the next few decades, thus significantly pushing back the near-decadal effects of strong $\mathrm{CO}_{2}$ mitigation policies under Socioeconomic Shared Pathway 1-1.9. 


\section{Appendix A}

\section{ECHAM6.1}
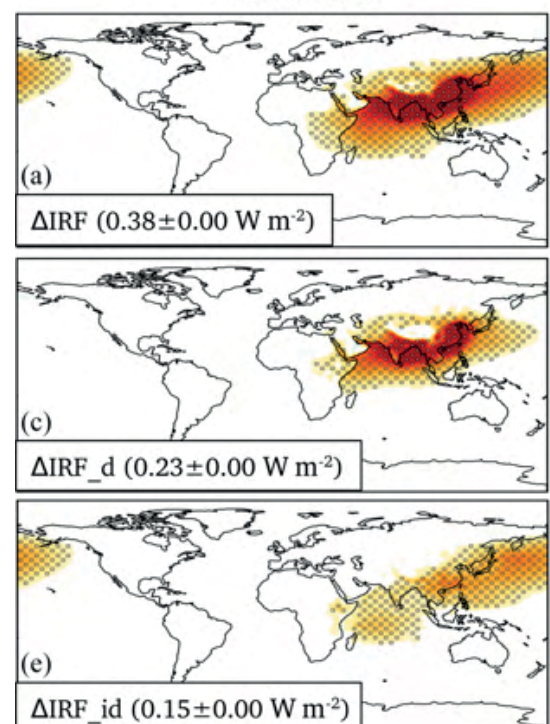

NorESM1
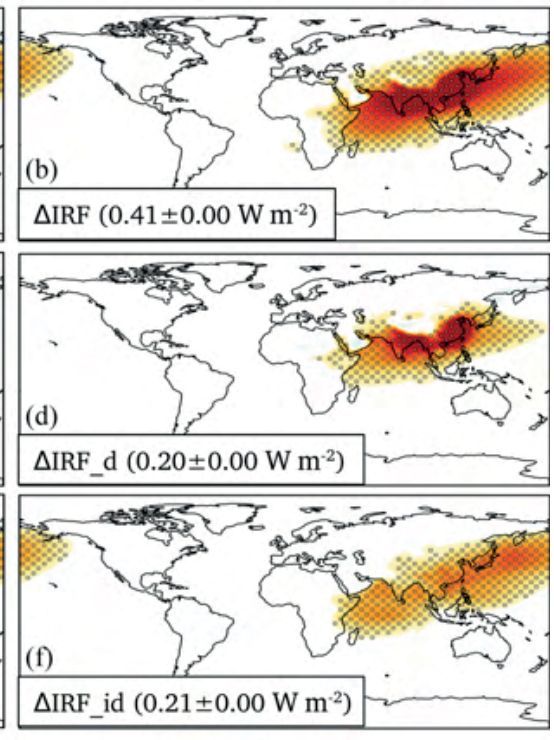

$\begin{array}{llllllllllllllllllllllllllllllll}4.0 & -3.6 & -3.2 & -2.8 & -2.4 & -2.0 & -1.6 & -1.2 & -0.8 & -0.4 & 0.0 & 0.4 & 0.8 & 1.2 & 1.6 & 20 & 2.4 & 2.8 & 3.2 & 3.6 & 4.0\end{array}$

$\triangle \mathrm{IRF}\left(\mathrm{Wm}^{-2}\right)$

Figure A1. The change in the mean instantaneous radiative forcings for runs without and with SE Asian aerosols shown for the individual models (a, c, e, ECHAM6.1; b, d, f, NorESM1).

Table A1. Upper rows for each model and model mean: yearly global-mean values in kelvins, with errors on the means given with a $95 \%$ confidence interval. Error on the model mean is given as a pooled sample standard error on the mean. Values in brackets show the standard deviations in yearly mean values (pooled standard deviations for model mean). The bottom row: spatial correlation between NorESM1 and ECHAM6.1.

\begin{tabular}{lrrrrrrrrr}
\hline & $\Delta T$ & $\mathrm{LW}_{\text {clr }}$ & $\mathrm{SW}_{\text {clr }}$ & $\mathrm{LW}_{\text {cld }}$ & $\mathrm{SW}_{\text {cld }}$ & ALBEDO & CONV & SURF LW $_{\text {cld }}+\mathrm{SW}_{\text {cld }}$ \\
\hline ECHAM6.1 & $0.22 \pm 0.03$ & $0.09 \pm 0.01$ & $0.08 \pm 0.00$ & $0.01 \pm 0.01$ & $0.03 \pm 0.03$ & $0.01 \pm 0.01$ & $\begin{array}{r}0.00 \pm 0.01 \\
0.01 \pm 0.03\end{array}$ & $0.04 \pm 0.03$ \\
& $(0.12876)$ & $(0.05751)$ & $(0.01674)$ & $(0.03961)$ & $(0.12634)$ & $(0.03652)$ & $(0.03005)$ & $(0.09962)$ & $(0.01169)$ \\
\hline \multirow{2}{*}{ NorESM1 } & $0.30 \pm 0.03$ & $0.08 \pm 0.02$ & $0.09 \pm 0.00$ & $0.05 \pm 0.01$ & $0.07 \pm 0.02$ & $0.03 \pm 0.01$ & $-0.01 \pm 0.01$ & $0.00 \pm 0.03$ & $0.12 \pm 0.02$ \\
& $(0.11558)$ & $(0.08762)$ & $(0.01489)$ & $(0.04337)$ & $(0.09526)$ & $(0.02346)$ & $(0.05439)$ & $(0.09717)$ & $(0.07647)$ \\
\hline Model mean & $0.26 \pm 0.04$ & $0.08 \pm 0.03$ & $0.08 \pm 0.01$ & $0.03 \pm 0.02$ & $0.05 \pm 0.04$ & $0.02 \pm 0.01$ & $-0.01 \pm 0.02$ & $0.00 \pm 0.04$ & $0.08 \pm 0.04$ \\
& $(0.12235)$ & $(0.07411)$ & $(0.01584)$ & $(0.04153)$ & $(0.11188)$ & $(0.03069)$ & $(0.04394)$ & $(0.09840)$ & $(0.09879)$ \\
\hline Correlation & 0.651 & 0.519 & 0.918 & 0.461 & 0.279 & 0.226 & 0.642 & -0.031 & 0.372 \\
\hline
\end{tabular}




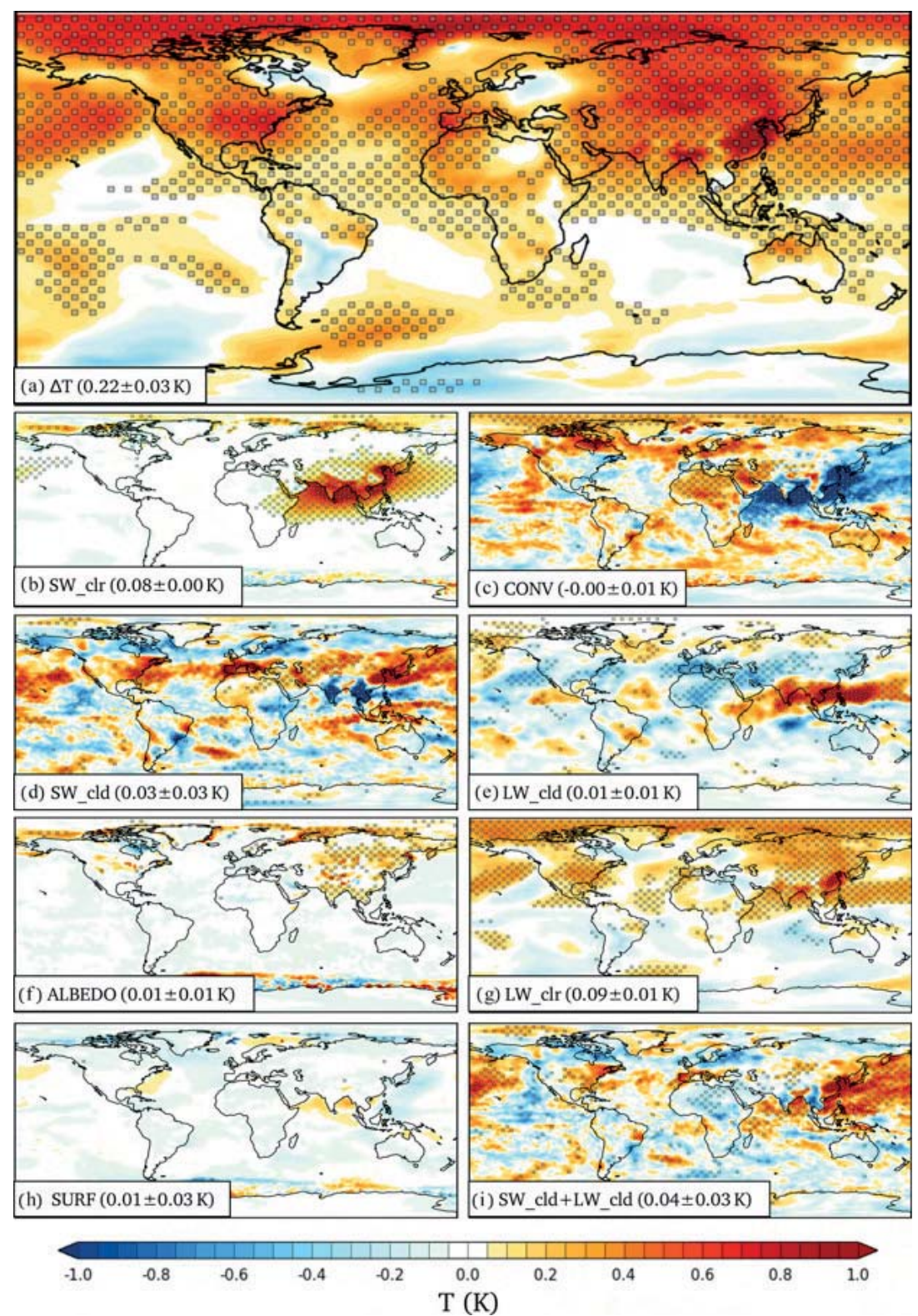

Figure A2. The geographical distributions of annually averaged surface air $(2 \mathrm{~m})$ temperature responses due to the removal of South and East Asian aerosols for ECHAM6.1. Brackets show global averages. (a) The total surface response. (b-h) Contributions to the total surface temperature response from shortwave clear-sky response (b), horizontal atmospheric heat transport (c), shortwave cloud response (d), longwave cloud response (e), surface albedo change (f), longwave clear-sky response (g), and surface energy flux change (h). (b-h) Sum up to the response seen in panel (a). Panel (i) shows the combined shortwave and longwave cloud response. 


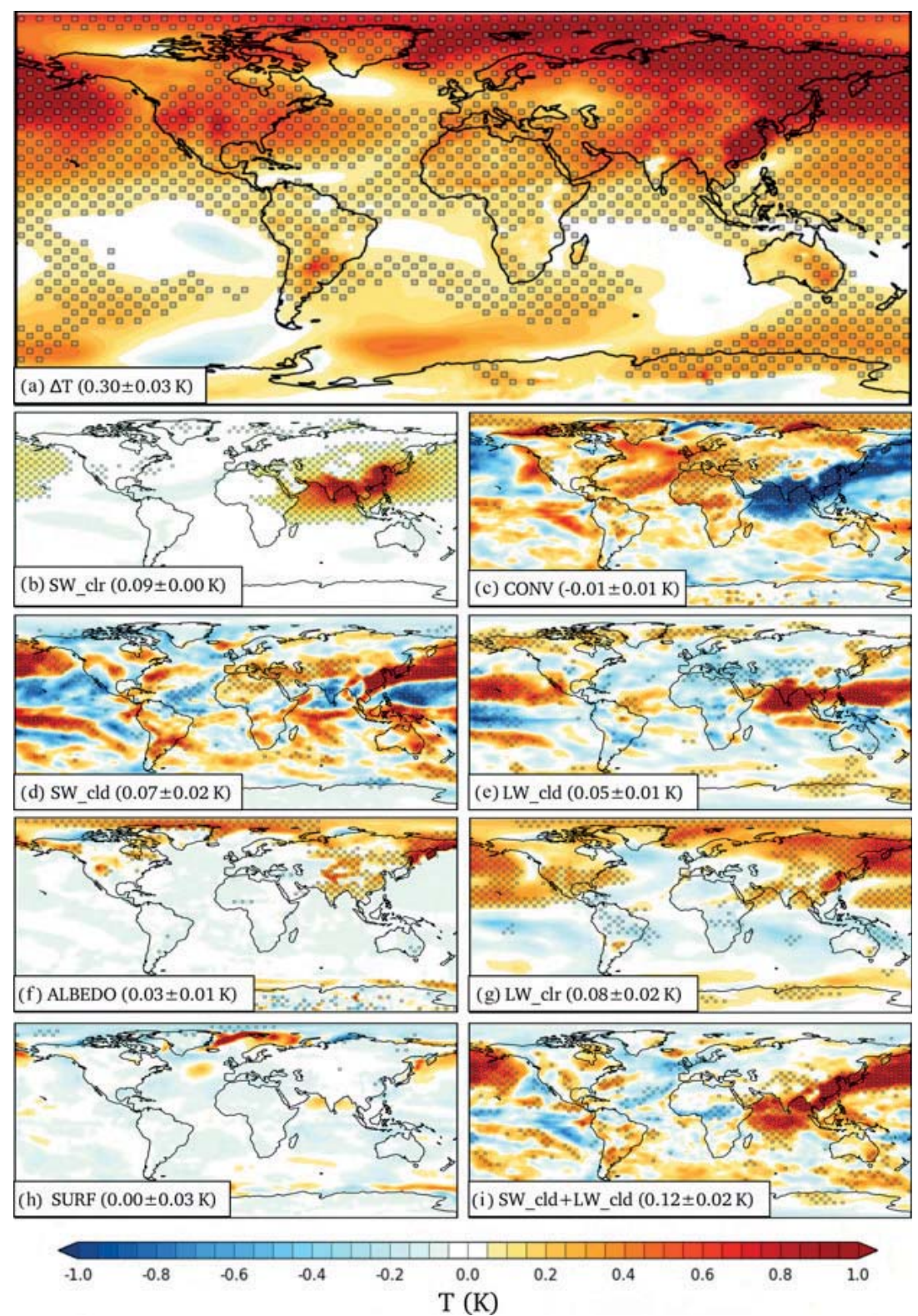

Figure A3. As Fig. A2 but for the NorESM1 model. 
Data availability. Data and scripts are available at https://doi. org/10.23728/fmi-b2share.aa3085799bff4be798342e4c0d66caa3 (Merikanto et al., 2020).

Author contributions. The manuscript was written by JM with contributions from all authors. KN performed ECHAM6.1 simulations with help from JM, PR, and DO'D. PR performed all NorESM1 simulations. The data analysis was carried out by JM and KN and guided by JR. HK came up with the initial research idea, and AIP assisted with project coordination.

Competing interests. The authors declare that they have no conflict of interest.

Acknowledgements. We wish to thank the editor and the two anonymous reviewers for the constructive comments on the manuscript. The authors would also like to thank Stephanie Fiedler for providing the MACv2-SP code for ECHAM6.1.

Financial support. This research has been supported by the European Research Council (ECLAIR, grant no. 646857) and the Academy of Finland (grant nos. 287440 and 308365).

Review statement. This paper was edited by Kostas Tsigaridis and reviewed by two anonymous referees.

\section{References}

Acosta Navarro, J. C., Varma, V., Riipinen, I., Seland, Ø., Kirkevåg, A., Struthers, H., Iversen, T., Hansson, H. C., and Ekman, A. M. L.: Amplification of Arctic warming by past air pollution reductions in Europe, Nat. Geosci., 9, 277-281, https://doi.org/10.1038/ngeo2673, 2016.

Apte, J. S., Brauer, M., Cohen, A. J., Ezzati, M., and Pope, C. A.: Ambient PM2.5 reduces global and regional life expectancy, Environ. Sci. Technol. Lett., 5, 546-551, https://doi.org/10.1021/acs.estlett.8b00360, 2018.

Balakrishnan, K., Dey, S., Gupta, T., Dhaliwal, R. S., Brauer, M., Cohen, A. J., Stanaway, J. D., Beig, G., Joshi, T. K., Aggarwal, A. N., Sabde, Y., Sadhu, H., Frostad, J., Causey, K., Godwin, W., Shukla, D. K., Kumar, G. A., Varghese, C. M., Muraleedharan, P., Agrawal, A., Anjana, R. M., Bhansali, A., Bhardwaj, D., Burkart, K., Cercy, K., Chakma, J. K., Chowdhury, S., Christopher, D. J., Dutta, E., Furtado, M., Ghosh, S., Ghoshal, A. G., Glenn, S. D., Guleria, R., Gupta, R., Jeemon, P., Kant, R., Kant, S., Kaur, T., Koul, P. A., Krish, V., Krishna, B., Larson, S. L., Madhipatla, K., Mahesh, P. A., Mohan, V., Mukhopadhyay, S., Mutreja, P., Naik, N., Nair, S., Nguyen, G., Odell, C. M., Pandian, J. D., Prabhakaran, D., Prabhakaran, P., Roy, A., Salvi, S., Sambandam, S., Saraf, D., Sharma, M., Shrivastava, A., Singh, V., Tandon, N., Thomas, N. J., Torre, A., Xavier, D., Yadav, G., Singh, S., Shekhar, C., Vos, T., Dandona, R., Reddy,
K. S., Lim, S. S., Murray, C. J. L., Venkatesh, S., and Dan-dona, L.: The impact of air pollution on deaths, disease burden, and life expectancy across the states of India: the Global Bur-den of Disease Study 2017, Lancet Planetary Health, 3, e26-e39, https://doi.org/10.1016/S2542-5196(18)30261-4, 2019.

Bitz, C., Shell, K., Gent, P., Bailey, D., Danabasoglu, G., Armour, K., Holland, M., and Kiehl, J.: Climate Sensitivity of the Community Climate System Model, Version 4, J. Clim., 25, 3053 3070, https://doi.org/10.1175/JCLI-D-11-00290.1, 2012.

Block, K. and Mauritsen, T.: Forcing and feedback in the MPIESM-LR coupled model under abruptly quadrupled $\mathrm{CO}_{2}, \mathrm{~J}$. Adv. Model. Earth Sy., 5, 676-691, 2013.

Carslaw, K., Lee, L., Reddington, C., Pringle, K., Rap, A., Forster, P., Mann, G., Spracklen, D., Woodhouse, M., Regayre, L., and Pierce, J. R.: Large contribution of natural aerosols to uncertainty in indirect forcing, Nature, 503, 67-71, 2013.

Fiedler, S., Kinne, S., Huang, W. T. K., Räisänen, P., O’Donnell, D., Bellouin, N., Stier, P., Merikanto, J., van Noije, T., Makkonen, R., and Lohmann, U.: Anthropogenic aerosol forcing insights from multiple estimates from aerosol-climate models with reduced complexity, Atmos. Chem. Phys., 19, 6821-6841, https://doi.org/10.5194/acp-19-6821-2019, 2019.

Holland, M. and Bitz, C.: Polar amplification of climate change in coupled models, Clim. Dyn., 21, 221-232, https://doi.org/10.1007/s00382-003-0332-6, 2003.

Iversen, T., Bentsen, M., Bethke, I., Debernard, J. B., Kirkevåg, A., Seland, Ø., Drange, H., Kristjansson, J. E., Medhaug, I., Sand, M., and Seierstad, I. A.: The Norwegian Earth System Model, NorESM1-M - Part 2: Climate response and scenario projections, Geosci. Model Dev., 6, 389-415, https://doi.org/10.5194/gmd-6-389-2013, 2013.

Kasoar, M., Voulgarakis, A., Lamarque, J.-F., Shindell, D. T., Bellouin, N., Collins, W. J., Faluvegi, G., and Tsigaridis, K.: Regional and global temperature response to anthropogenic $\mathrm{SO}_{2}$ emissions from China in three climate models, Atmos. Chem. Phys., 16, 9785-9804, https://doi.org/10.5194/acp-169785-2016, 2016.

Kasoar, M., Shawki, D., and Voulgarakis, A.: Similar spatial patterns of global climate response to aerosols from different regions, Clim. Atmos. Sci., 1, 12, https://doi.org/10.1038/s41612018-0022-z, 2018

Kinne, S., O’Donnell, D., Stier, P., Kloster, S., Zhang, K., Schmidt, H., Rast, S., Giorgetta, M., Eck, T. F., and Stevens, B.: MAC-v1: A new global aerosol climatology for climate studies, J. Adv. Model. Earth Sy., 5, 704-740, https://doi.org/10.1002/jame.20035, 2013.

Kirkevåg, A., Iversen, T., Seland, Ø., Hoose, C., Kristjánsson, J. E., Struthers, H., Ekman, A. M. L., Ghan, S., Griesfeller, J., Nilsson, E. D., and Schulz, M.: Aerosol-climate interactions in the Norwegian Earth System Model - NorESM1-M, Geosci. Model Dev., 6, 207-244, https://doi.org/10.5194/gmd-6207-2013, 2013.

Lamarque, J.-F., Bond, T. C., Eyring, V., Granier, C., Heil, A., Klimont, Z., Lee, D., Liousse, C., Mieville, A., Owen, B., Schultz, M. G., Shindell, D., Smith, S. J., Stehfest, E., Van Aardenne, J., Cooper, O. R., Kainuma, M., Mahowald, N., McConnell, J. R., Naik, V., Riahi, K., and van Vuuren, D. P.: Historical (1850-2000) gridded anthropogenic and biomass burning emissions of reactive gases and aerosols: methodol- 
ogy and application, Atmos. Chem. Phys., 10, 7017-7039, https://doi.org/10.5194/acp-10-7017-2010, 2010.

Liu, L., Shawki, D., Voulgarakis, A., Kasoar, M., Samset, B. H., Myhre, G., Forster, P. M., Hodnebrog, Ø., Sillmann, J., Aalbergsjø, S. G., Boucher, O., Faluvegi, G., Iversen, T., Kirkevåg, A., Lamarque, J.-F., Olivié, D., Richardson, T., Shindell, D., Takemura, T., Liu, L., Shawki, D., Voulgarakis, A., Kasoar, M., Samset, B. H., Myhre, G., Forster, P. M., Hodnebrog, Ø., Sillmann, J., Aalbergsjø, S. G., Boucher, O., Faluvegi, G., Iversen, T., Kirkevåg, A., Lamarque, J.-F., Olivié, D., Richardson, T., Shindell, D., and Takemura, T.: A PDRMIP Multimodel Study on the Impacts of Regional Aerosol Forcings on Global and Regional Precipitation, J. Clim., 31, 4429-4447, https://doi.org/10.1175/JCLI-D-17-0439.1, 2018.

Loeb, N. G., Doelling, D. R., Wang, H. L., Su, W. Y., Nguyen, C., Corbett, J. G., Liang, L. S., Mitrescu, C., Rose, F. G., and Kato, S.: Clouds and the Earth's Radiant Energy System (CERES)Energy Balanced and Filled (EBAF) Top-ofAtmosphere (TOA)Edition-4.0 Data Product, J. Clim., 31, 895918, 2018.

Lund, M. T., Myhre, G., and Samset, B. H.: Anthropogenic aerosol forcing under the Shared Socioeconomic Pathways, Atmos. Chem. Phys., 19, 13827-13839, https://doi.org/10.5194/acp-1913827-2019, 2019.

Mauritsen, T. and Roeckner, E.: Tuning the MPI-ESM1.2 global climate model to improve the match with instrumental record warming by lowering its climate sensitivity, J. Adv. Model. Earth Sy., 12, e2019MS002037, https://doi.org/10.1029/2019MS002037, 2020.

Merikanto, J., Nordling, K., and Räisänen, P.: How Asian aerosols impact regional surface temperatures across the globe; NorESM1 and ECHAM6.1 data, Finnish Meteorological Institute, https://doi.org/10.23728/fmib2share.aa3085799bff4be798342e4c0d66caa3, 2020.

Murphy, D. M.: Little net clear-sky radiative forcing from recent regional redistribution of aerosols, Nat. Geosci., 6, 258-262, 2013.

Myhre, G., Kramer, R. J., Smith, C. J., Hodnebrog, Ø., Forster, P., Soden, B. J., Samset, B. H., Stjern, C. W., Andrews, T., Boucher, O., Faluvegi, G., Fläschner, D., Kasoar, M., Kirkevåg, A., Lamarque, J. F., Olivié, D., Richardson, T., Shindell, D., Stier, P., Takemura, T., Voulgarakis, A., and Watson-Parris, D.: Quantifying the Importance of Rapid Adjustments for Global Precipitation Changes, Geophys. Res. Lett., 45, 11399-11405, https://doi.org/10.1029/2018GL079474, 2018.

NOAA National Centers for Environmental Information, State of the Climate: Global Climate Report for Annual 2019, https: //www.ncdc.noaa.gov/sotc/global/201913 (last access: 24 June 2020), 2020.

Nordling, K., Korhonen, H., Räisänen, P., Alper, M. E., Uotila, P., O'Donnell, D., and Merikanto, J.: Role of climate model dynamics in estimated climate responses to anthropogenic aerosols, Atmos. Chem. Phys., 19, 9969-9987, https://doi.org/10.5194/acp19-9969-2019, 2019.

Persad, G. G. and Caldeira, K.: Divergent global-scale temperature effects from identical aerosols emitted in different regions, Nat. Commun., 9, 3289, https://doi.org/10.1038/s41467-018-058386, 2018
Pithan, F. and Mauritsen, T.: Arctic amplification dominated by temperature feedbacks in contemporary climate models, Nat Geosci., 7, 181-184, https://doi.org/10.1038/ngeo2071, 2014.

Porter, D. F., Cassano, J. J., Serreze, M. C., and Kindig, D. N.: New estimates of the large-scale Arctic atmospheric energy budget, J. Geophys. Res., 115, D08108, https://doi.org/10.1029/2009JD012653, 2010.

Roeckner, E., Bäuml, G., Bonaventura, L., Brokopf, R., Esch, M., Giorgetta, M., Hagemann, S., Kirchner, I., Kornblueh, L., Manzini, E., Rhodin, A., Schlese, U., Schulzweida, U., and Tompkins, A.: The atmospheric general circulation model ECHAM5. PART I: Model description, Tech. Rep. 349, MaxPlanck-Inst. fur Meteorol., Hamburg, Germany, 2003.

Räisänen, J.: An energy balance perspective on regional CO2induced temperature changes in CMIP5 models, Clim. Dynam., 48, 3441-3454, 2017.

Räisänen, J. and Ylhäisi, J. S.: $\mathrm{CO}_{2}$-induced climate change in northern Europe: CMIP2 versus CMIP3 versus CMIP5, Clim. Dynam., 45, 1877-1897, 2015.

Räisänen, P., Makkonen, R., Kirkevåg, A., and Debernard, J. B.: Effects of snow grain shape on climate simulations: sensitivity tests with the Norwegian Earth System Model, The Cryosphere, 11, 2919-2942, https://doi.org/10.5194/tc-11-2919-2017, 2017.

Samset, B. H., Sand, M., Smith, C. J., Bauer, S. E., Forster, P. M., Fuglestvedt, J. S., Osprey, S., and Schleussner, C.F.: Climate Impacts From a Removal of Anthropogenic Aerosol Emissions, Geophys. Res. Lett., 45, 1020-1029, https://doi.org/10.1002/2017GL076079, 2018

Screen, J. A. and Simmonds, I.: The central role of diminishing sea ice in recent Arctic temperature amplification, Nature, 464 1334-1337, 2010.

Shindell, D., Faluvegi, G., Rotstayn, L., and Milly, G.: Spatial patterns of radiative forcing and surface temperature change, J. Geophys. Res., 120, 5385-5403, https://doi.org/10.1002/2014JD022752, 2015.

Soden, B. J., Broccoli, A. J., and Hemler, R. S.: On the use of cloud forcing to estimate cloud feedback, J. Clim., 17, 36613665, 2004.

Stevens, B., Giorgetta, M., Esch, M., Mauritsen, T., Crueger, T., Rast, S., Salzmann, M., Schmidt, H., Bader, J., Block, K., Brokopf, R., Fast, I., Kinne, S., Kornblueh, L., Lohmann, U., Pin-cus, R., Reichler, T., and Roeckner, E.: Atmospheric component of the MPI-M Earth System Model: ECHAM6, J. Adv. Model. Earth Sy., 5, 146-172, 2013.

Stevens, B., Fiedler, S., Kinne, S., Peters, K., Rast, S., Müsse, J., Smith, S. J., and Mauritsen, T.: MACv2-SP: a parameterization of anthropogenic aerosol optical properties and an associated Twomey effect for use in CMIP6, Geosci. Model Dev., 10, 433 452, https://doi.org/10.5194/gmd-10-433-2017, 2017.

Shindell, D. T., Schulz, M., Ming, Y., Takemura, T., Faluvegi, G., and Ramaswamy, V.: Spatial scales of climate response to inhomogeneous radiative forcing, J. Geophys. Res., 115, D19110, https://doi.org/10.1029/2010JD014108, 2010.

Taylor, K. E., Crucifix, M., Braconnot, P., Hewitt, C. D., Doutriaux, C., Broccoli, A. J., Mitchell, J. F. B., and Webb, M. J.: Estimating Shortwave Radiative Forcing and Response in Climate Models, J. Clim., 20, 2530-2543, https://doi.org/10.1175/JCLI4143.1, 2007. 
Westervelt, D. M., Mascioli, N. R., Fiore, A. M., Conley, A. J., Lamarque, J.-F., Shindell, D. T., Faluvegi, G., Previdi, M., Correa, G., and Horowitz, L. W.: Local and remote mean and extreme temperature response to regional aerosol emissions reductions, Atmos. Chem. Phys., 20, 3009-3027, https://doi.org/10.5194/acp-20-3009-2020, 2020.

Wilcox, L. J., Liu, Z., Samset, B. H., Hawkins, E., Lund, M. T., Nordling, K., Undorf, S., Bollasina, M., Ekman, A. M. L., Krishnan, S., Merikanto, J., and Turner, A. G.: Accelerated increases in global and Asian summer monsoon precipitation from future aerosol reductions, Atmos. Chem. Phys., 20, 11955-11977, https://doi.org/10.5194/acp-20-11955-2020, 2020
Zwiers, F. W. and von Storch, H.: Taking Serial Correlation into Account in Tests of the Mean, J. Clim., 8, 336-351, 1995. 

(C) Atmos. Chem. Phys.

Reprinted, with permission, from Atmos. Chem. Phys., doi: 10.5194/acp-2021-401 



\section{Understanding the surface temperature response and its uncertainty to $\mathrm{CO}_{2}, \mathrm{CH}_{4}$, black carbon and sulfate}

Kalle Nordling ${ }^{1}$, Hannele Korhonen ${ }^{1}$, Jouni Räisänen ${ }^{2}$, Antti-Ilari Partanen ${ }^{1}$, Bjørn H. Samset ${ }^{3}$ and Joonas Merikanto ${ }^{1}$

${ }^{1}$ Finnish Meteorological Institute, Helsinki, Finland.

$5 \quad{ }^{2}$ INAR/Physics, University of Helsinki, Helsinki, Finland.

${ }^{3}$ CICERO Center of International Climate Research, Oslo, Norway.

Correspondence to: Kalle Nordling(kalle.nordling@fmi.fi)

Abstract. Understanding the regional surface temperature responses to different anthropogenic climate forcing agents, such as greenhouse gases and aerosols, is crucial for understanding past and future regional climate changes. In modern climate models, the regional temperature responses vary greatly for all major forcing agents, but the causes of this variability are poorly understood. Here, we analyse how changes in atmospheric and oceanic energy fluxes due to perturbations in different anthropogenic climate forcing agents lead to changes in global and regional surface temperatures. We use climate model data on idealized perturbations in four major anthropogenic climate forcing agents $\left(\mathrm{CO}_{2}, \mathrm{CH}_{4}\right.$, and sulfate and black carbon aerosols) from PDRMIP climate experiments for six climate models (CanESM2, HadGEM2-ES, NCAR-CESM1-CAM4, NorESM1, MIROC-SPRINTARS, GISS-E2). Particularly, we decompose the regional energy budget contributions to the surface temperature responses due to changes in longwave and shortwave fluxes under clear-sky and cloudy conditions, surface albedo changes, and oceanic and atmospheric energy transport. We also analyse the regional model-to-model temperature response spread due to each of these components. The global surface temperature response stems from changes in longwave emissivity for greenhouse gases $\left(\mathrm{CO}_{2}\right.$ and $\left.\mathrm{CH}_{4}\right)$ and mainly from changes in shortwave clear-sky fluxes for aerosols (sulfate and black carbon). The global surface temperature response normalized by effective radiative forcing is nearly the same for all forcing agents $\left(0.63,0.54,0.57,0.61 \mathrm{KW}^{-1} \mathrm{~m}^{2}\right)$. While the main physical processes driving global temperature responses vary between forcing agents, for all forcing agents the model-to-model spread in temperature responses is dominated by differences in modelled changes in longwave clear-sky emissivity. Furthermore, in polar regions for all forcing agents the differences in surface albedo change is a key contributor to temperature responses and its spread. For black carbon the modelled differences in temperature response due to shortwave clear-sky radiation are also important in the Arctic. Regional model-tomodel differences due to changes in shortwave and longwave cloud radiative effect strongly modulate each other. For aerosols clouds play a major role in the model spread of regional surface temperature responses. In regions with strong aerosol forcing the model-to-model differences arise from shortwave clear-sky responses and are strongly modulated by combined temperature responses to oceanic and atmospheric heat transport in the models. 


\section{Introduction}

Climate change projections depend highly on future scenarios of climate mitigation actions. But in addition to uncertainty arising from different possible futures particularly in timescales of decades the climate projection uncertainties are dominated by the climate model response uncertainty (Hawkins \& Sutton, 2009; Lehner et al., 2020). This arises from structural differences between different climate models. Climate models differ on how they represent the radiative forcing of anthropogenic greenhouse gases and aerosols. But perhaps more importantly, they respond differently to the same external radiative forcing (Nordling et al., 2019). As stated in Lehner (2020) the model spread in the estimated temperature responses is affected by inter-model differences in both the forcing and in how the models respond to the forcing.

40 Smith et al. (2020) quantified the effective radiative forcings (ERFs) for modern-day greenhouse gas and aerosol concentrations for a range of climate models participating to CMIP6 multi-model climate experiments. They showed that since CMIP5, the spread in modelled radiative forcing has narrowed down. Despite this, the response uncertainty in CMIP6 models appears to have grown from CMIP5 models (Lehner et al., 2020; Zelinka et al., 2020). Uncertainty in the climate response hampers efforts to robustly define carbon emission targets to maintain global warming below specified limits, such as below $1.5^{\circ} \mathrm{C}$ (Matthews et al., 2021; Rogelj et al., 2019). Furthermore, the carbon emission targets depend on the climate response to radiative forcers besides carbon dioxide, such as aerosols and methane (Tokarska et al., 2018). Modern day anthropogenic aerosols cool the global surface temperatures between 0.5-1.1 ${ }^{\circ} \mathrm{C}$ (Samset et al., 2018, Nordling et al., 2019), and their future reductions can accelerate global warming and enhance global precipitation (e.g. Merikanto et al., 2021; Wilcox et al., 2020).

50 Besides the need to better understand the impacts of different climate forcing agents on the global climate, there is an urgent need to better understand how they impact climate on regional scale. The spatial distribution of aerosols is highly heterogenous, and much of the modern-day effective aerosol radiative forcing is concentrated over the South and East Asian region (Fiedler et al., 2019), while the radiative forcing of long-lived greenhouse gases is much more uniform (Shindell et al., 2015). Aerosols have both local and remote climate effects which depend on the emission region and type of aerosol (Merikanto et al., 2021; Nordling et al., 2019; Persad \& Caldeira, 2018). Furthermore, the differences in regional distributions of aerosol surface temperature responses are not dominated by the aerosol description in modern climate models (Nordling et al., 2019). Therefore, differences in modelled regional temperature responses for both greenhouse gases and aerosols appear to mainly depend on differences in dynamic responses of the atmosphere-ocean-sea ice system in the models. The main focus of this paper are these differences in modelled responses to aerosol and greenhouse gas perturbations in different climate models.

The Precipitation Driver Response Model Intercomparison Project (PDRMIP) (Myhre et al., 2017) provides a data set that allows us to investigate how different climate forcing agents affect the Earth's climate in global and regional scale. PDRMIP 
comprised idealized single-forcer scenarios for several independent climate models. Previously, the PDRMIP data set has been used to study e.g. how different forcing agents affect the Arctic amplification (Stjern et al., 2019) and how they produce rapid adjustments and ERF (Smith et al., 2018). Estimating ERF is not straightforward, and different methods provide a variety of different results. For example, Tang et al. (2019) used PRDMIP data to estimate ERF for different climate forcing agents with several different methods. The model-mean estimated ERF for the doubling of carbon dioxide concentrations varied from 3.65 to $4.70 \mathrm{Wm}^{-2}$ depending on the method and on how rapid adjustments were included in the estimate. Richardson et al. (2019) showed that ERF calculated from fixed-sea-surface experiments is a good predictor for the global temperature change for different forcing agents, and particularly so if the adjustments due to land temperature change are included.

The model differences in climate response are often investigated through radiative feedback analysis (e.g. Zelinka et al., 2020). While the feedback analysis is particularly suitable for analyzing the root causes of model-to-model differences in the equilibrium climate sensitivity (the equilibrium temperature response to doubled atmospheric carbon dioxide concentrations),

75 it is less suitable for exploring regional temperature response variance between the models due to the nonlinearity of regional feedbacks (Andrews et al., 2012). Räisänen \& Ylhäisi (2015) formulated an energy balance framework to explore the impact of the top-of-the atmosphere (TOA) radiative fluxes, atmospheric energy transport and the net surface energy flux on regional surface temperatures. The method relies on the local conservation of energy and it is therefore mathematically an almost exact solution for the decomposition of energetic components of the temperature response. Its also takes into account both the

80 horizontal energy transport and surface energy fluxes on the local energy balance. Räisänen (2017) included a more detailed shortwave radiative flux treatment according to Taylor et al. (2007), and Merikanto et al. (2021) included a cloud radiative kernel treatment for a more physical separation of longwave cloud and clear-sky radiative fluxes. In this paper, we use this energy balance framework with climate model data from PDRMIP experiments to study the origins of regional temperature response and its standard deviation in six different climate models to four different climate forcing agents (carbon dioxide, methane, sulfate and black carbon). Evaluation of the mechanisms responsible for the model spread is key for understanding why models still exhibit a substantial spread in temperature response even when forced identically.

\section{Materials and Methods}

\subsection{Decomposition of the surface temperature response}




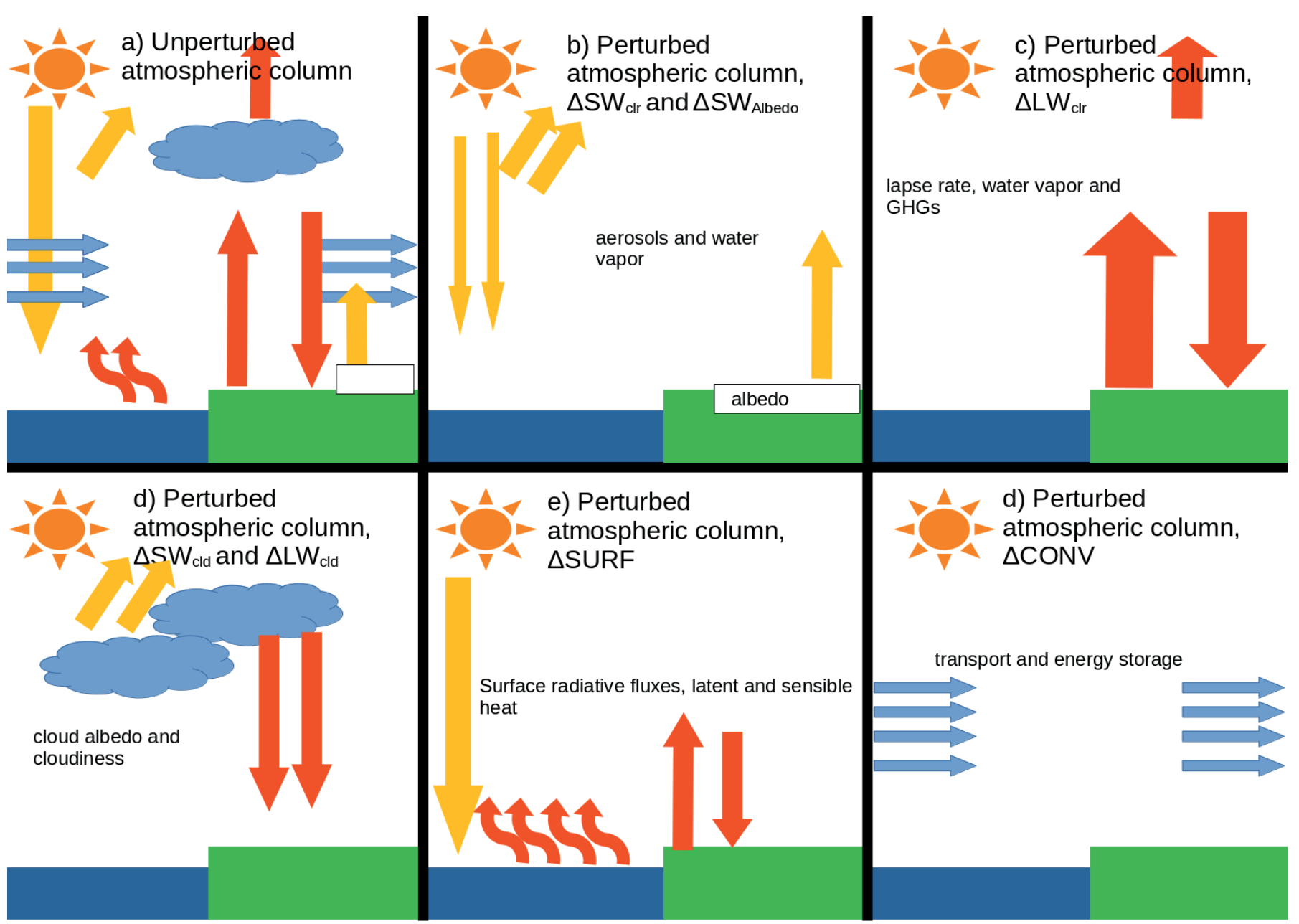

Figure 1. Illustration of the local atmospheric energy budget in a single atmospheric column from the surface to the top-of model atmosphere (TOA). We attribute the change in local surface temperature to changes in different terms of the local energy budget. (a) Unperturbed conditions, where red arrows indicate longwave (thermal) radiation, yellow arrows indicate shortwave (solar) radiation, blue arrows indicate horizontal incoming and outgoing energy, and curvy red arrows indicate latent and sensible heat. Under perturbed conditions, we decompose the change in the energy budget to (b) the change in TOA solar radiation due to changes in surface albedo, and to the change in shortwave clearsky flux (separately). The change in shortwave clear-sky flux is mainly caused by changes in aerosol concentrations or changes in atmospheric water vapor; (c) the change in longwave TOA flux, which is mainly caused by changes in atmospheric water vapor concentrations, atmospheric thermal structure (lapse rate) or greenhouse gas concentrations; (d) changes in longwave and shortwave TOA fluxes, separately, due to changes in cloudiness and cloud microphysics, (e) the combined change in surface energy balance, including the change in the net shortwave and longwave energy 
flux into the surface and changes in latent and sensible heat fluxes; (f) the combined change in horizontal energy transport and internal energy of the atmospheric column, calculated from the convergence of energy.

105 We attribute local surface air temperature response to different energetic components, namely to changes in local longwave clear-sky and cloud fluxes associated with change in emissivity $\left(\Delta \boldsymbol{L} \boldsymbol{W}_{\boldsymbol{T} \boldsymbol{O} \boldsymbol{A}, \boldsymbol{c l r}, \boldsymbol{e}}^{\uparrow}\right.$ and $\Delta \boldsymbol{L} \boldsymbol{W}_{\boldsymbol{T} \boldsymbol{O} \boldsymbol{A}, \boldsymbol{c l d}, \boldsymbol{e}}^{\uparrow}$, respectively, with the arrow indicating the vector direction towards space) at TOA, shortwave clear-sky and cloud radiative fluxes $\left(\Delta \boldsymbol{S} \boldsymbol{W}_{T \mathbf{T}}^{\downarrow} \boldsymbol{A}, \boldsymbol{c l r}\right.$ and $\left.\Delta \boldsymbol{S} \boldsymbol{W}_{\text {TOA,cld }}^{\downarrow}\right)$, changes in surface energy fluxes $\left(\Delta \boldsymbol{F}_{S U R F}^{\downarrow}\right.$, essentially representing changes in atmosphere-to-ocean net heat flux), and convergence of atmospheric energy ( $\triangle \boldsymbol{C O N V}$, representing horizontal atmospheric heat transport). These changes

110 are illustrated in Fig. 1.We use the method presented in Räisänen and Ylhäisi (2015), Räisänen (2017), and Merikanto et al. (2021). The method is based on a concept of planetary emissivity(Harshvardhan and Cess, 1976), which links the local surface air temperature $(\boldsymbol{T})$ to the outgoing long wave radiation at the top of the atmospheric column $\left(\boldsymbol{L} \boldsymbol{W}_{\boldsymbol{T} \boldsymbol{}}^{\uparrow} \boldsymbol{A}\right)$,

$$
\varepsilon_{e f f}=\frac{L W_{T O A}^{\uparrow}}{\sigma T^{4}}
$$

where $\varepsilon_{e f f}$ is an effective local planetary emissivity and $\sigma$ is the Boltzmann constant. Then, letting [ ] to mark the mean state

115 between baseline and perturbed climates, the change in outgoing longwave radiation between the two climate states can be written as

$$
\Delta L W_{T O A}^{\uparrow}=4 \sigma\left[\varepsilon_{e f f}\right]\left[T^{3}\right] \Delta T+\sigma \Delta \varepsilon_{e f f}\left[T^{4}\right]=D \Delta T+\Delta L W_{T O A, \varepsilon}^{\uparrow}
$$

where $\boldsymbol{D} \Delta \boldsymbol{T}$ is the local change in outgoing thermal radiation at constant emissivity (i.e at fixed thermal atmospheric structure and water vapor concentration), and hence $\boldsymbol{D}$ represents the local Planck feedback parameter. $\Delta \boldsymbol{L} \boldsymbol{W}_{\boldsymbol{T} \boldsymbol{O}}^{\uparrow} \boldsymbol{A}, \boldsymbol{\varepsilon}$ is the change in the outgoing thermal radiation associated with the change in the local emissivity of the atmosphere.

The rate of energy change within an atmospheric column is given by the energy balance equation

$$
\frac{\delta E}{\delta t}=S W_{T O A}^{\downarrow}-L W_{T O A}^{\uparrow}-F_{S U R F}^{\downarrow}+C^{\rightarrow}
$$

where $\frac{\delta E}{\delta t}$ is the change of internal energy within the column with respect to time, $S W_{T O A}^{\downarrow}$ is the net incoming flux of solar 125 radiation, and $C^{\rightarrow}$ is the horizontal transport of energy to the column, and the net downward heat flux $F_{S U R F}^{\downarrow}$ into the surface is given by 
$F_{S U R F}^{\downarrow}=S W_{S U R F}^{\downarrow}+L W_{S U R F}^{\downarrow}-S H^{\uparrow}-L H^{\uparrow}$.

130 The change in $L W_{T O A}^{\uparrow}$ between two climate states can thus be written as

$$
\Delta L W_{T O A}^{\uparrow}=\Delta S W_{T O A}^{\downarrow}-\Delta F_{S U R F}^{\downarrow}+\Delta\left(C^{\rightarrow}-\frac{\delta E}{\delta t}\right)
$$

Using Eq. (2) with Eq. (5), the local change in surface temperature can be decomposed to different energetic components as

$$
\Delta T=-\frac{\Delta L W_{T O A, \varepsilon}^{\uparrow}}{D}+\frac{\Delta S W_{T O A}^{\downarrow}}{D}-\frac{\Delta F_{S U R F}^{\downarrow}}{D}+\frac{\Delta\left(C^{\rightarrow}-\frac{\delta E}{\delta t}\right)}{D}=\Delta T_{L W}+\Delta T_{S W}+\Delta T_{S U R F}+\Delta T_{C O N V}
$$

$\Delta \boldsymbol{T}_{\boldsymbol{L W}}, \Delta \boldsymbol{T}_{\boldsymbol{S W}}$ and $\Delta \boldsymbol{T}_{\boldsymbol{S U R F}}$ can be calculated directly from the standard energy flux output of the models, and $\Delta \boldsymbol{T}_{\boldsymbol{C O N V}}$ as a residual term. $\Delta \boldsymbol{T}_{\boldsymbol{C O N V}}$ includes both horizontal energy transport and change in local atmospheric energy storage which is insignificant at annual time scales. Furthermore, $\Delta \boldsymbol{T}_{\boldsymbol{S W}}$ can be decomposed into clear-sky, cloud, albedo and non-linear terms using the Approximate Partial Radiative Perturbation (APRP) method (Taylor et al., 2007),

$$
\Delta S W_{T O A}^{\downarrow}=\Delta S W_{T O A, i n}^{\downarrow}+\Delta S W_{T O A, c l r}^{\downarrow}+\Delta S W_{T O A, c l d}^{\downarrow}+\Delta S W_{T O A, \text { albedo }}^{\downarrow}+\Delta S W_{T O A, n l}^{\downarrow}
$$

where $\triangle S W_{T O A, i n}^{\downarrow}$ is the change in incoming solar radiation, $\Delta S W_{T O A, c l r}^{\downarrow}$ is the change in net TOA solar radiation due to changes

140 in clear-sky radiative properties of the atmosphere, $\triangle S W_{T O A, c l d}^{\downarrow}$ the change in net TOA solar radiation due to changes in clouds, $\triangle S W_{T O A, a l b e d o}^{\downarrow}$ the change in net TOA solar radiation due to change in surface albedo, and $\Delta S W_{T O A, n l}^{\downarrow}$ is a non-linear correction term arising from the APRP method. $\triangle S W_{T O A, i n}^{\downarrow}$ is constant if the incoming solar flux is constant. $\triangle S W_{T O A, n l}^{\downarrow}$ is typically negligibly small, and can be ignored (Räisänen, 2017; Merikanto et al., 2021).

Also $\boldsymbol{\Delta} \boldsymbol{L} \boldsymbol{W}_{\mathbf{T O A}, \boldsymbol{\varepsilon}}^{\uparrow}$ can be decomposed into clear-sky $(\mathrm{CS})$ and cloud radiative effect (CRE) components,

$$
\Delta L W_{T O A, \varepsilon}^{\uparrow}=\Delta L W_{T O A, C S, \varepsilon}^{\uparrow}+\Delta L W_{T O A, C R E, \varepsilon}^{\uparrow}
$$

However, $\Delta \boldsymbol{L} \boldsymbol{W}_{\mathbf{T O A}, \boldsymbol{C R E , \varepsilon}}^{\uparrow}$ is affected by changes in non-cloud feedbacks (water vapor, surface albedo and air temperature), making it a negatively biased approximation of the actual cloud longwave feedback. To obtain a more accurate estimation of 
the actual cloud contribution to longwave emissivity change, we applied the radiative kernel method of (Soden et al., 2008). With this method, a correction factor can be calculated,

150

$$
\Delta L W_{c o r r}^{\uparrow}=\left(K_{T}-K_{T}^{c l r}\right) \Delta T+\sum_{i}\left(K_{T_{i}}-K_{T_{i}}^{c l r}\right) \Delta T_{i}+\sum_{i}\left(K_{w_{i}}-K_{w_{i}}^{c l r}\right) \Delta(\ln q)_{i}
$$

where $K_{T}, K_{T_{i}}$ and $K_{w_{i}}$ represent radiative kernels where each state variable (surface temperature, temperature profile and water vapor respectively) is perturbed by unit change. The corrected clear-sky and cloud longwave emissivity changes then become

$$
\Delta L W_{T O A, c l r, \varepsilon}^{\uparrow}=\Delta L W_{T O A, C S, \varepsilon}^{\uparrow}+\Delta L W_{c o r r}^{\uparrow}
$$

$$
\Delta L W_{T O A, c l d, \varepsilon}^{\uparrow}=\Delta L W_{T O A, C R E, \varepsilon}^{\uparrow}-\Delta L W_{c o r r}^{\uparrow}
$$

All results have been calculated using three different kernels (ECHAM (Block \& Mauritsen, 2013), GFDL (Pendergrass et al., 2018) and HadGEM2 (Smith, 2018) to obtain a better estimate of the overall cloud effect. The correction factor of Eq. (9) has been calculated as an average of the three kernels.

Finally, the local surface temperature responses are decomposed as

160

$$
\begin{gathered}
\Delta T=-\frac{\Delta L W_{T O A, c l r, \varepsilon}^{\uparrow}}{D}-\frac{\Delta L W_{T O A, c l d, \varepsilon}^{\uparrow}}{D}+\frac{\Delta S W_{T O A, c l r}^{\downarrow}}{D}+\frac{\Delta S W_{T O A, c l d}^{\downarrow}}{D}+\frac{\Delta S W_{T O A, A l b e d o}^{\downarrow}}{D}-\frac{\Delta F_{S U R F}^{\downarrow}}{D} \\
+\frac{\Delta\left(C^{\rightarrow}-\frac{\delta E}{\delta t}\right)}{D} \\
=-\Delta L W_{c l r, \varepsilon}-\Delta L W_{c l d, \varepsilon}+\Delta S W_{c l r}+\Delta S W_{c l d}+\Delta S W_{\text {Albedo }}+\Delta \mathrm{SURF}+\Delta \mathrm{CONV}
\end{gathered}
$$

In the above equation, the temperature responses related to the first five components build up from a sum of the instant radiative forcing (if any), rapid adjustments associated with the component, and a temperature dependent feedback which adjusts its magnitude as the surface temperature changes, normalized by $\boldsymbol{D}$ (the Planck feedback). Therefore, temperature responses related to these terms are functions of a constant term (forcing and adjustments) and a time dependent term (the impact of

165 feedback due to surface temperature changes). For example, the LW flux response to a change in clear-sky longwave emissivity is $\Delta L W_{T O A, c l r, \varepsilon}^{\uparrow} \approx \boldsymbol{F}_{T O A, L W, c l r, \varepsilon}^{\uparrow}-\lambda_{L R+L W W V} \Delta \boldsymbol{T}$ in a linearized a forcing-feedback framework, where $\boldsymbol{F}_{T O A, L W, c l r}^{\uparrow}$ is the 
longwave component of the effective radiative forcing and $\lambda_{L R+L W W V}$ is the combined longwave lapse-rate and water vapor

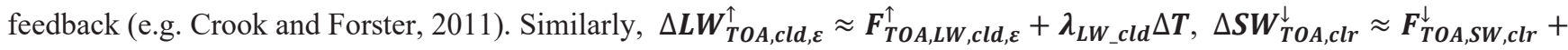
$\lambda_{S W W V} \Delta T, \quad \Delta S W_{T O A, c l d}^{\downarrow} \approx F_{T O A, S W, c l d}^{\downarrow}+\lambda_{S W, c l d} \Delta T$, and $\Delta S W_{T O A, A l b e d o}^{\downarrow} \approx F_{T O A, S W, A l b e d o}^{\downarrow}+\lambda_{S W, A l b e d o} \Delta T . \Delta F_{S U R F}^{\downarrow}$ and

$170 \Delta\left(C^{\rightarrow}-\frac{\delta E}{\delta \boldsymbol{t}}\right)$ do not have direct counterparts in the linear forcing-feedback analysis, and they have been incorporated as part of the energy budget in regional forcing-feedback analysis in various ways in the literature (Crook et al., 2011; Feldl \& Roe, 2013; Lu \& Cai, 2009).

\subsection{Decomposition of the standard deviation in surface temperature response}

Decomposing the temperature responses $\Delta \boldsymbol{T}_{\boldsymbol{i}}$ also allows us to to decompose their contributions $\boldsymbol{C S} \boldsymbol{D}_{\boldsymbol{i}}$ to the model-to-model standard deviations $\sigma_{\Delta T}$ of the total temperature responses by,

$$
C S D_{i}=\frac{\operatorname{cov}\left(\Delta T_{i}, \Delta T\right)}{\sigma_{\Delta T}}=r_{i} \sigma_{\Delta T_{i}}
$$

where $\operatorname{cov}\left(\Delta T_{i}, \Delta T\right)$ is the model-to-model covariance between $i$ :th time-averaged local temperature response component and

180 the total local temperature response of a model experiment, $\boldsymbol{r}_{\boldsymbol{i}}$ and $\boldsymbol{\sigma}_{\boldsymbol{\Delta} \boldsymbol{T}_{\boldsymbol{i}}}$ are their model-to-model correlation and the standard deviation, respectively, and $\boldsymbol{\sigma}_{\boldsymbol{\Delta} \boldsymbol{T}}$ is the standard deviation of time-averaged temperature responses in different models. $\boldsymbol{C S} \boldsymbol{D}_{\boldsymbol{i}}$ 's sum up to the inter-model standard deviations of the temperature responses,

$$
\sum_{i} C S D_{i}=\sigma_{\Delta T}
$$

\subsection{Models and Simulations}

We use climate model data from (PDRMIP) (Myhre et al., 2017). In PDRMIP, several independent climate models were used 185 to simulate various idealized climate perturbations. The models used in this study are listed in Table 1. According to Knutti (2013) all these models belong to different model families, and hence are independent from each other. Our study uses data from experiments of instant doubling of $\mathrm{CO}_{2}$ concentrations (co2x2), tripling of $\mathrm{CH}_{4}$ concentrations (ch4x3), five folding sulfate emission (sulx5) and ten folding black carbon emissions (bcx10) (see Table 2). Perturbations were relative to the 
https://doi.org/10.5194/acp-2021-401

Preprint. Discussion started: 22 June 2021

(c) Author(s) 2021. CC BY 4.0 License.

(c) (7)
Atmospheric

Chemistry

and Physics

Discussions

baseline which had the present day (models except HadGEM2-ES) or the pre-industrial (HadGEM2-ES) levels of

190 anthropogenic forcing agents.

Table 1. PDRMIP models used in this study, ocean and aerosol configuration of the model and which aerosol-cloud interactions are included.

\begin{tabular}{|c|c|c|c|c|}
\hline Model & Ocean Setup & Aerosol setup & Interactive so4/bc & Key refenreces \\
\hline CanESM2 & Coupled & Emissions & yes/no & Arora et al., 2011 \\
\hline NCAR-CESM1- & Slab ocean & Fixed & no/no & Gent et al., 2011 \\
\hline CAM4 & & concentrations & & Neale et al., 2010 \\
\hline GISS-E2-R & Coupled & Fixed concentration & no/no & Schmidt et al., 2014 \\
\hline \multirow[t]{2}{*}{ HadGEM2-ES } & Coupled & Emissions & yes/no & Collins et al., 2011 \\
\hline & & & & Martin et al., 2011 \\
\hline \multirow[t]{4}{*}{ NorESM1 } & Coupled & Fixed & yes/yes & Bentsen et al., 2013; \\
\hline & & concentrations & & Iversen et al., 2013; \\
\hline & & & & Kirkevåg et al., \\
\hline & & & & 2013 \\
\hline \multirow{6}{*}{$\begin{array}{l}\text { MIROC- } \\
\text { SPRINTARS }\end{array}$} & Coupled & HTAP2 Emissions & yes/yes & Watanabe et al., \\
\hline & & & & 2010; \\
\hline & & & & Takemura et al., \\
\hline & & & & 2005 \\
\hline & & & & Takemura et al., \\
\hline & & & & 2009 \\
\hline
\end{tabular}

195 Table 2: Description of PDRMIP experiments 
Experiment name

baseline

$\operatorname{co} 2 \times 2$

$\operatorname{ch} 4 \times 3$

sulx 5

bex10

\section{Description}

Anthropogenic forcing agents are at present day levels or at preindustrial

levels

Instantaneous doubling of the $\mathrm{CO}_{2}$ concentration relative to the base case

Instantaneous tripling of the $\mathrm{CH}_{4}$ concentration relative to the base case

Five-folding the sulfate concentration or emissions relative to the base case
Ten-folding black carbon concentration or emissions relative to the base case

All simulations consisted of 100-year baseline and perturbed runs, and the last 50 years of these runs are used for the temperature response analysis carried out here. The PRDMIP experiments also included additional fixed sea-surface temperature runs, which we use for the calculation of the effective radiative forcing $\left(\mathrm{ERF}_{\mathrm{fsst}}\right)$ associated with each climate

200 perturbation. We also calculated the effective radiative forcing by regressing the top-of-atmosphere radiative imbalance against surface temperature change $\left(\mathrm{ERF}_{\text {reg }}\right)$ by using the full 100-year timeseries of experiments, as further discussed below. Aerosol emissions were either defined explicitly or by multiplying pre-defined concentrations derived from AeroCom Phase II (Myhre et al., 2012) (see Table 1). Only NorESM1 and MIROC-SPRINTARS include the aerosol indirect effect (the Twomey effect) for black carbon; however, the semi-indirect effect is included in all models. The aerosol cloud effects from sulfate are included 
205 in all models except NCAR-ESM1-CAM4 and GISS-E2-R. We include the six PDRMIP models which had reported all necessary fields for this analysis.

\subsection{Global TOA radiative forcing and surface temperature responses of analyzed experiments}

210 In this paper, we focus on decomposed local and global temperature responses normalized by the global effective radiative forcing $\left(\mathrm{ERF}_{\mathrm{fsst}}\right)$ obtained from fixed-sea-surface-temperature experiments for each modelled perturbation. The normalization by $\mathrm{ERF}_{\text {fsst }}$ enables us to compare the temperature responses of different modelled perturbations with each other on a level ground, as $\mathrm{ERF}_{\text {fsst }}$ varies in sign and magnitude between different perturbations. Also, particularly in aerosol and methane experiments the modelled $\mathrm{ERF}_{\text {fsst }}$ values vary between different models, likely due to differences in model aerosol setups and

215 baseline methane concentrations.

Figure 2 shows the calculated effective radiative forcings and the global mean temperature responses (the difference in perturbed climate for the years 50-100 and the corresponding years from the base case) in the analyzed PDRMIP experiments. The effective radiative forcing is calculated from both fixed-sea-surface-temperature simulations $\left(\mathrm{ERF}_{\text {fsst }}\right.$, no land-warming 220 corrections included) and by regressing the top-of-atmosphere radiative imbalance with respect to surface temperature change by using the full 100-year timeseries of experiments (ERF ${ }_{\text {reg, }}$, Gregory et al., 2004). 


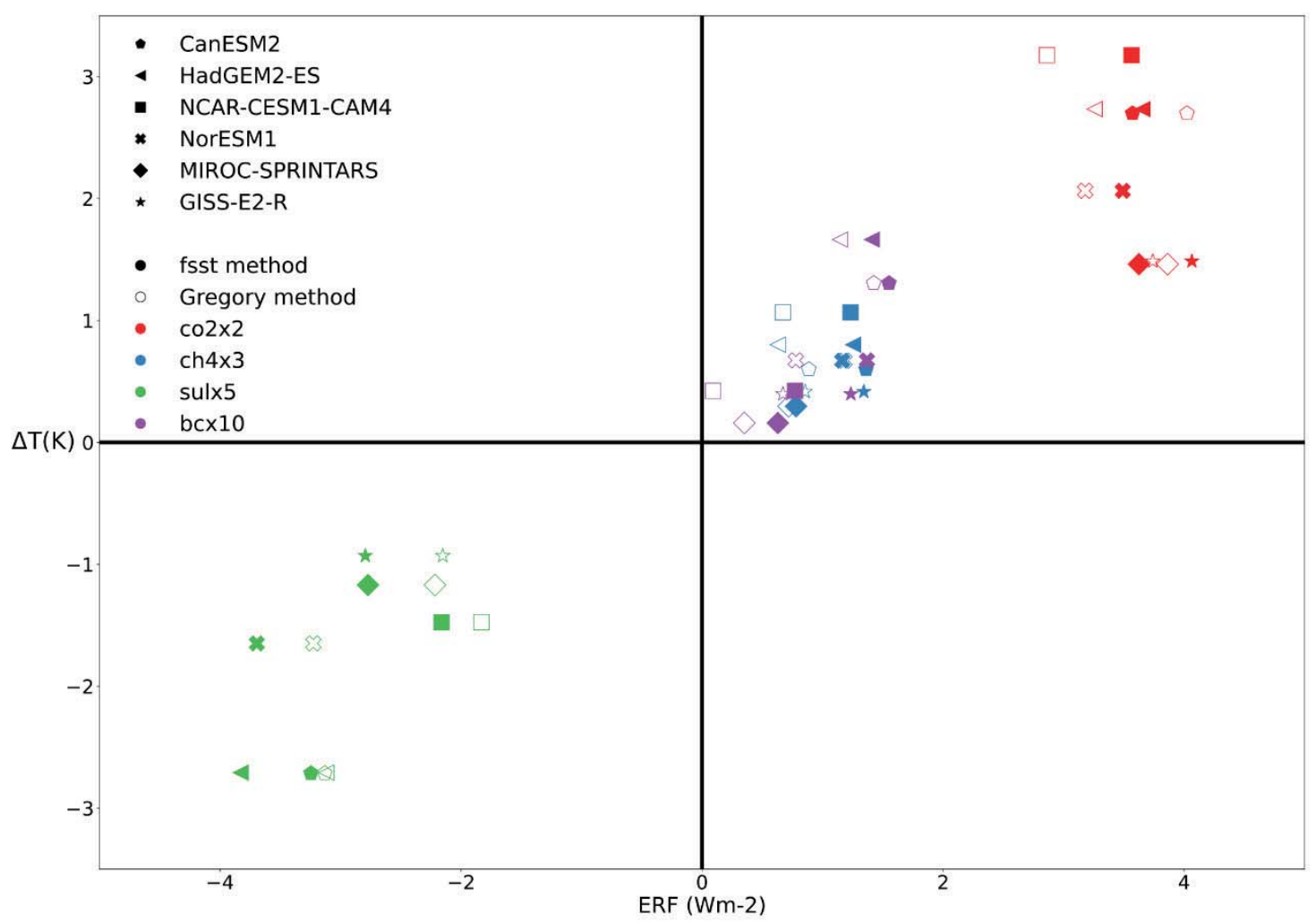

Figure 2: The global average temperature responses for each experiment and each model (y-axis) averaged over years 50-100 after the sudden introduction of climate perturbations. The calculated ERFs for each experiment and model are shown on the $x$-axis, with non-filled marks indicating the ERF reg obtained using the Gregory method, and the filled markers indicating $\mathrm{ERF}_{\text {fsst }}$ obtained from fixed-sea-surface-temperature simulations.

One of the models (NCAR-CESM1-CAM) was ran using a slab ocean configuration, while the rest of the models contained fully interactive ocean configurations. Since the equilibrium is reached in a few decades with slab ocean configurations while 230 with fully interactive ocean configuration it takes centuries, the perturbed experiments with models besides NCAR-CESM1CAM are still in a transient state. As a multi-model mean over the years 50-100 of the perturbed runs, the doubling of $\mathrm{CO}_{2}$ concentration (red marks) leads to a $2.27 \mathrm{~K}$ rise in global surface temperatures with a model-to-model standard deviation (std) of $0.65 \mathrm{~K}$. The corresponding values are for tripling of $\mathrm{CH}_{4}$ (blue marks) $0.64 \mathrm{~K}$ ( $\operatorname{std} 0.25 \mathrm{~K}$ ), five folding sulfate aerosols (green marks) $-1.77 \mathrm{~K}$ (std $0.70 \mathrm{~K}$ ) and ten folding black carbon (purple) aerosols $0.77 \mathrm{~K}$ (std $0.54 \mathrm{~K})$. The exact numbers for each 
235 forcer and model are shown in the supplementary (Tables S1-S4), and the estimated equilibrium temperature responses for each of the experiments is shown in Table S5.

The multi-model-mean $\mathrm{ERF}_{\text {fsst }}$ values for co2x2, ch4x3, sulx5 and bcx10 experiments are, respectively, $3.66 \mathrm{Wm}^{-2}$ (std 0.19 $\left.\mathrm{Wm}^{-2}\right), 1.19 \mathrm{Wm}^{-2}\left(\operatorname{std} 0.19 \mathrm{Wm}^{-2}\right),-3.08 \mathrm{Wm}^{-2}\left(\operatorname{std} 0.58 \mathrm{Wm}^{-2}\right)$, and $1.16 \mathrm{Wm}^{-2}\left(\operatorname{std} 0.34 \mathrm{Wm}^{-2}\right)$. When the effective forcings are calculated from regressions using the full 100-year timeseries, the corresponding ERF reg values are $3.49 \mathrm{Wm}^{-2}$, $\left(\mathrm{std}_{0.41}\right.$ $\left.\mathrm{Wm}^{-2}\right), 0.82 \mathrm{Wm}^{-2}\left(\operatorname{std} 0.19 \mathrm{Wm}^{-2}\right),-2.61 \mathrm{Wm}^{-2}\left(\operatorname{std} 0.56 \mathrm{Wm}^{-2}\right)$, and $0.74 \mathrm{Wm}^{-2}\left(\operatorname{std} 0.45 \mathrm{Wm}^{-2}\right)$. Tang (2019) has carried out complete analysis of $\mathrm{ERF}_{\text {fsst }}$ and $\mathrm{ERF}_{\text {reg }}$ for the PDRMIP data, and our values are consistent with the values presented there. We also refer the readers to Tang (2019) for the $\mathrm{ERF}_{\text {fsst }}$ values obtained with the land warming correction accounted for, and for $\mathrm{ERF}_{\text {reg }}$ calculated from the first 30 years of perturbed experiments.

Figure 2 show that only weak relationship between the model-to-model values in $\mathrm{ERF}_{\text {fsst }}$ (or $\mathrm{ERF}_{\text {reg }}$ ) and the model-to-model spread in temperature response can be seen for co $2 x 2$ and ch $4 x 3$ experiments, while some relationship exists for the $5 \times x u l f$ and 10xbc experiments. Correlations between the models' temperature response and their $\mathrm{ERF}_{\mathrm{fsst}}$ are for co2x 2 and ch4x3, 0.52 and 0.43 while with sulx 5 and bcx 10 correlations are 0.61 and 0.78 . As also visible in Fig. 1 for individual models, the

250 application of the regression method for the full 100-year timeseries of experiments provides consistently lower values for ERF compared to values obtained from fixed sea surface temperature calculations. Overall, ERF fsst appears to be a more suitable choice for the surface temperature response normalization of different experiments due to very small values of $\mathrm{ERF}_{\text {reg }}$ associated with some bcx10 experiments.

\section{Results}

In the following sections, we present decomposed effective temperature responses for each analyzed experiment and modelto-model spread of these decompositions. The effective surface temperature responses and their decompositions are calculated for each atmospheric column separately from the average differences in perturbed climates for the years 50-100 after a sudden

260 perturbation and the corresponding years from the baseline simulations without perturbations. The local temperature responses are normalized by the globally averaged $\mathrm{ERF}_{\text {fsst }}$ for each experiment (hence the term effective). Scaling with $\mathrm{ERF}_{\text {fsst }}$ allows a simpler comparison of responses between different forcing agents, but it also changes the sign of responses in case of sulx 5 experiments. This is because in contrast to the other three forcing agents, the radiative forcing is negative for increasing sulfate concentrations

The local temperature responses related to longwave and shortwave TOA components build up from a combination of the local instant top-of-atmosphere radiative forcing and rapid adjustments associated with each term, and a temperature dependent 
feedback which adjusts its magnitude as the surface temperature changes, as described in the end of Section 2.1. Therefore, temperature responses related to these components are functions of a constant term - forcing (if any) and rapid adjustments and a time dependent term - the impact of feedback as surface temperature changes.

The temperature response decomposition applied here relies on a local conservation of energy in each atmospheric column, and hence the sums of individual temperature response components generate the local total surface temperature responses with high accuracy. Below, Section 3.1 presents the globally averaged results. Section 3.2 then presents the regional distributions 275 of the decomposed surface temperature responses and their zonal averages. Section 3.3 presents the regional and latitudinal distributions of the model-to-model standard deviations of the effective temperature components, and the contributions of each of the decomposed surface temperature response components to the total standard deviations of the responses.

\subsection{Decomposed global effective surface temperature responses for different forcers}

Figure 3 shows the globally averaged effective surface temperature responses and their decomposed components for each model and perturbation experiment, calculated by using the temperature decomposition method described in Section 2.1. The components of the effective surface temperature responses describe the combined global contributions of the TOA forcing (in case of clear-sky $\Delta \mathrm{LW}_{\text {clr }}, \Delta \mathrm{SW}_{\text {clr }}$ components and $\Delta \mathrm{LW}_{\text {cld }}$ and $\Delta \mathrm{SW}_{\text {cld }}$ cloud components) and the effects of rapid adjustments

285 and feedbacks associated with each component. Of the components not associated with the TOA radiative forcing, $\Delta \mathrm{SW}_{\text {Albedo }}$ is directly related to the response due to surface albedo feedback, $\triangle \mathrm{SURF}$ is a measure of the surface energy flux imbalance on global surface temperatures due to oceanic heat uptake in the models, and $\triangle \mathrm{CONV}$ describes the impact of horizontal surface energy transport and change in atmospheric heat uptake. The models which have a fully coupled ocean have not fully reached equilibrium, and therefore there is still some heat flux from the atmosphere to the ocean. Thus, the effective 290 temperature response from this heat flux is always negative. Globally, $\triangle \mathrm{CONV}$ averages effectively to zero in each experiment since the energy transport only redistributes regional surface temperature effects, and the change in atmospheric heat uptake is negligible on annual or longer timescales (Räisänen, 2017). 


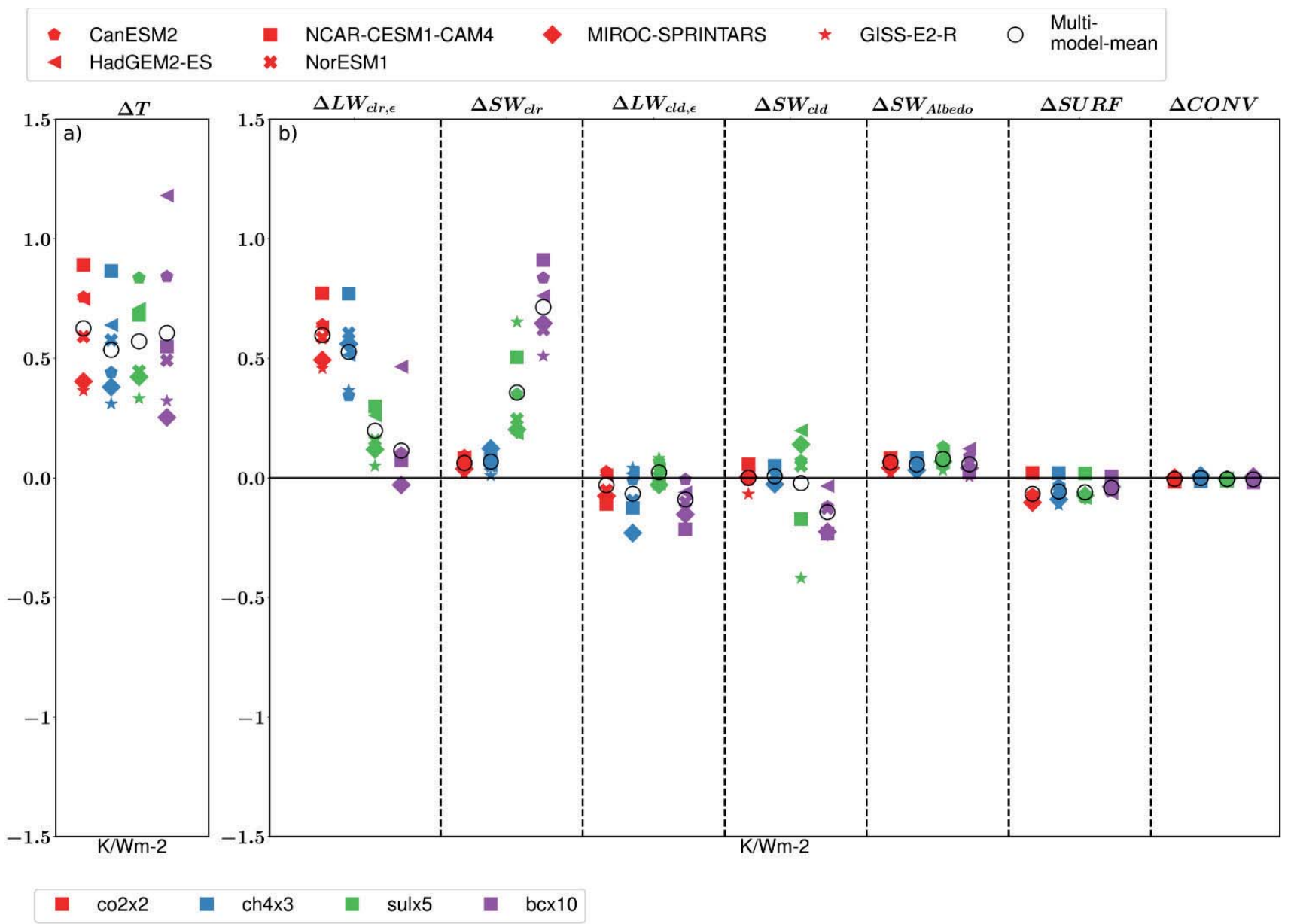

Figure 3. The global mean effective temperature response and its decomposition, calculated as the difference between means over the last 50 years of the perturbed and the baseline experiments. (a) The effective temperature response (absolute temperature response divided by $\mathbf{E R F}_{\text {fsst }}$ ) for the six models shown with different symbols, and four different radiative forcers shown with different colors. (b) The decomposition of the effective temperature response to different energetic components. Individual panels in (b) describe (from the left) the contributions to total effective temperature response due to the change in longwave clear-sky emissivity $\left(\Delta L W_{\mathrm{clr}, \varepsilon}\right)$, change in TOA shortwave radiation $\left(\Delta S W_{\mathrm{clr}}\right)$, change in longwave cloud emissivity $\left(\Delta L W_{\mathrm{cld}, \varepsilon}\right)$, net ocean surface heat flux ( $\triangle \mathrm{SURF})$, and change in atmospheric energy transport ( $\triangle \mathrm{CONV})$.

The total effective temperature responses (temperature response divided by the $\mathrm{ERF}_{\mathrm{sst}}$ ) for $\operatorname{co} 2 \times 2$, ch4x3, sulx 5 , and bcx 10 experiments are $0.63 \mathrm{KW}^{-1} \mathrm{~m}^{2}(\operatorname{std} 0.19), 0.54 \mathrm{KW}^{-1} \mathrm{~m}^{2}(\operatorname{std} 0.18), 0.57 \mathrm{KW}^{-1} \mathrm{~m}^{2}$ (std 0.18$)$ and $0.61 \mathrm{KW}^{-1} \mathrm{~m}^{2}(\mathrm{std} 0.32)$, respectively. Hence, the mean value and the model-to-model spread in total effective temperature response is similar for 
different forcers, as shown in previous PDRMIP studies (Richardson et al., 2018; Samset et al., 2018; Stjern et al., 2017). The change in TOA longwave clear-sky emissivity is the key driver of the effective temperature response for the greenhouse gas experiments (co2x2 and ch4x3), with the multi-model-mean effective surface temperature responses to $\Delta \mathrm{LW}_{\mathrm{clr}}$ matching nearly exactly the overall responses $\left(0.60 \mathrm{KW}^{-1} \mathrm{~m}^{2} \pm 0.10\right.$ and $0.53 \mathrm{KW}^{-1} \mathrm{~m}^{2} \pm 0.18$ respectively). $\Delta \mathrm{LW}_{\text {clr }}$ results from the change in clear-sky planetary emissivity, i.e. from the combination of the longwave clear-sky radiative forcing and its adjustments, and the change in the thermal structure of the atmosphere and water vapor concentrations which evolve with the surface temperature response (lapse rate and water vapor feedbacks). For the aerosol experiments (sulx 5 and bcx10) the effective temperature response associated with $\Delta \mathrm{LW}$ clr is only a small contribution to the total temperature response. This is because for aerosols the instantaneous radiative forcing associated with the longwave clear-sky radiation is small.

The differences in effective temperature responses associated with the $\Delta \mathrm{SW}_{\mathrm{clr}}$ between the greenhouse gas and aerosol forcers can be understood via a similar narrative as in case of $\Delta \mathrm{LW}_{\mathrm{clr}}$ responses. The total effective temperature response for aerosol experiments (sulx5 and bcx10) is largely dominated by the temperature response to $\Delta \mathrm{SW}_{\mathrm{clr}}$, since much of instantaneous aerosol radiative forcing takes place via this channel. For the greenhouse gas experiments the temperature response to $\Delta \mathrm{SW}_{\mathrm{clr}}$ originates from the shortwave water vapor feedback and direct GHG's shortwave forcing (Etminan et al., 2016), and its modelmean contribution to total effective temperature response is comparable to that from the albedo response $(\sim 10 \%)$.

The multi-model-mean effective temperature responses related to $\Delta \mathrm{LW}_{\text {cld }}$ and $\Delta \mathrm{SW}_{\text {cld }}$ are close to zero for all experiments besides for bcx10, for which the cloud temperature responses modestly oppose the total effective temperature response. For the sulx 5 experiment, the model-mean $\Delta \mathrm{SW}_{\text {cld }}$ is near zero and its spread is high between the models. A significant part of the spread is related to the lack of cloud-aerosol interaction in NCAR-CESM1-CAM4 and GISS-E2-R. In these models, $\Delta$ SWcld reduces the sulfate-induced global mean cooling, whereas it amplifies the cooling in the other models.

330 The global effective temperature response from the changes in surface albedo is similar across each experiment. The mean effective temperature response due to albedo change varies from $\sim 10 \%$ (co2x2, chx3 and bcx 10$)$ to $14 \%$ (sulx5) of the total effective temperature response. In the aerosol experiments the aerosol setup has a significant effect on the temperature contribution of the surface albedo change. Emission-driven models tend to produce a higher albedo effective temperature response than the concentration-driven models.

\subsection{Origins of regional temperature responses for different climate forcers}

The model-mean spatial distributions of effective temperature responses and their decomposed components are shown in Fig. 4. The zonal means of different components are shown in Fig. 5, where we have summed up the contributions of surface and atmospheric energy transport components ( $\triangle \mathrm{SURF}$ and $\triangle \mathrm{CONV}$ ) due to their strong tendency to balance each other regionally. 
Furthermore, the total response due to clouds ( $\Delta \mathrm{LW}_{\text {cld }}$ and $\Delta \mathrm{SW}_{\text {cld }}$ ) is shown in Figure 5 together with individual cloud components. Again, we remind the reader that scaling all results with $\mathrm{ERF}_{\text {fsst }}$ changes the sign of responses in sulx 5 experiments.

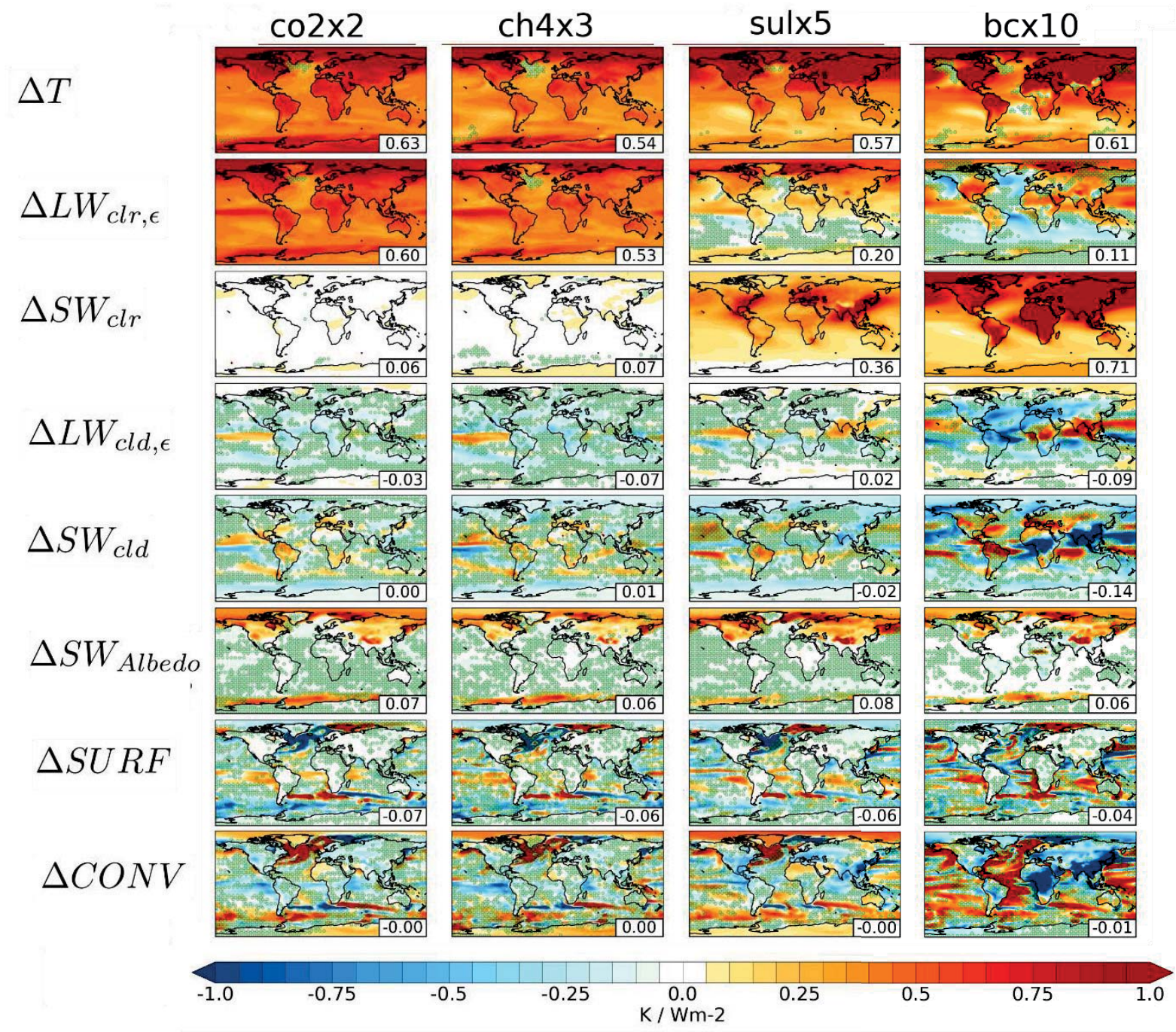

345 Figure 4. The multi-model mean effective temperature response (row 1) for four different climate forcers, i.e. carbon dioxide (column 1), methane (column 2), sulfate (column 3) and black carbon (column 4), and its decomposition to different energy balance terms. (Long- and shortwave clear-sky ( $\Delta L W_{\text {clr, }} \Delta S W_{\text {crr }}$ ), clouds, surface energy exchange ( $\left.\Delta S U R F\right)$ and horizontal energy transport $(\triangle \mathrm{CONV}))$. Dotted areas show regions where only 3-4 out of the 6 models agree on the sign of the response. 

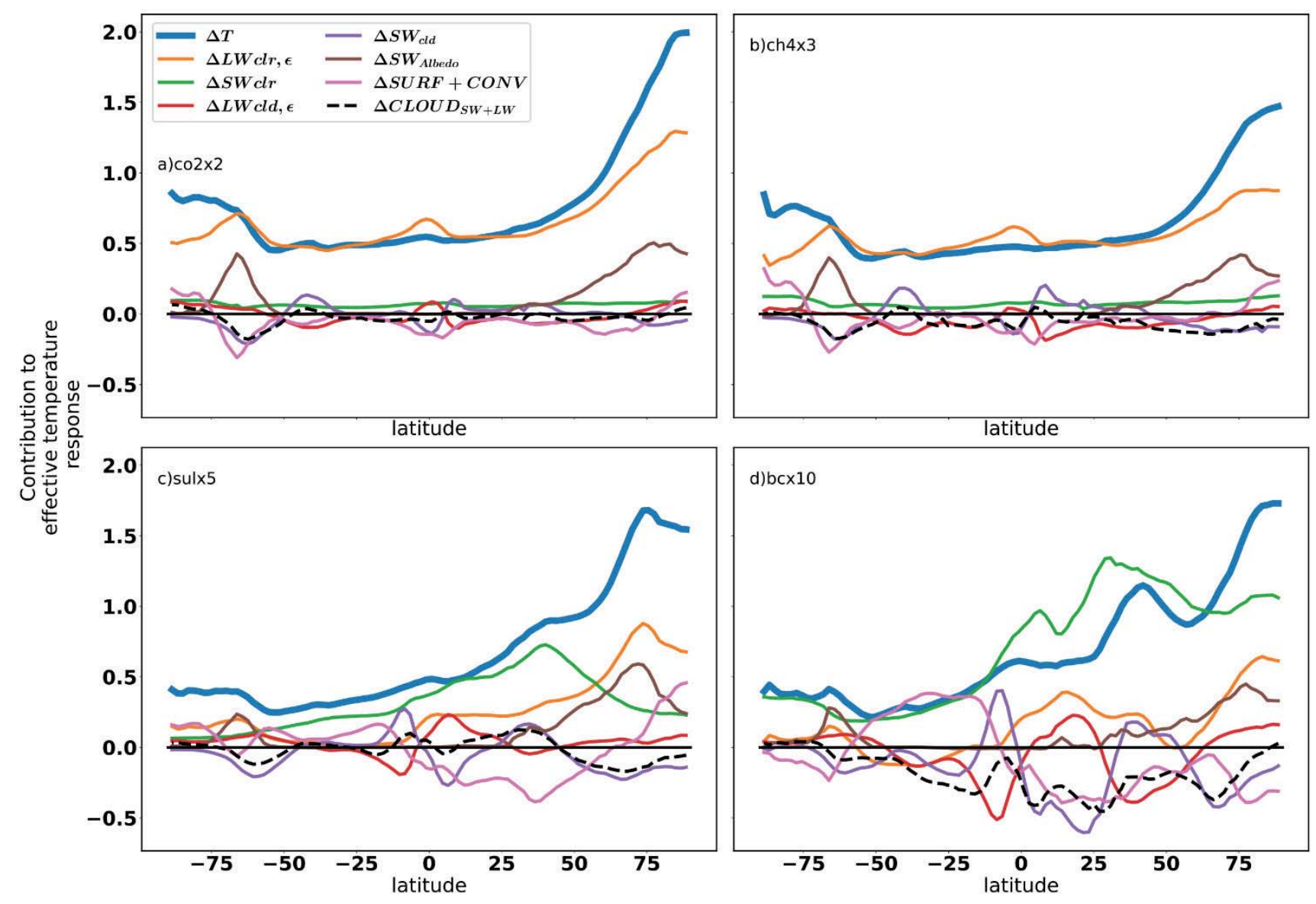

350 Figure 5: Zonal average multi-model mean effective temperature response (thick blue lines) and its decomposition into different energetic terms (thin coloured lines) for different climate forcers. Panel (a) shows co2x2, panel (b) ch4x3, panel (c) sulx5 and panel (d) bcx10 experiment.

The spatial distribution of the total effective temperature response is largely similar for each forcer, although the total response to aerosols is stronger over the continental Northern midlatitudes, compared to total responses to greenhouse gases, and weaker over the Southern hemisphere oceans. Regionally, local maximum effective temperature responses are found in the Barents Sea for all forcers, with maximum values of 2.38, 2.04, 2.96 and $2.53 \mathrm{KW}^{-1} \mathrm{~m}^{2}$ for $\operatorname{co} 2 \mathrm{x} 2$, ch4 4 , sulx 5 and bcx 10 , respectively. Stejrn et al. (2019) showed that the largest local temperature responses in PRDMIP experiments are in regions with the largest 360 sea ice changes. Differences between forcers can be seen for example over the Antarctic region where both greenhouse gas experiments $(\operatorname{ch} 2 \times 2, \operatorname{ch} 4 \times 3)$ produce Antarctic amplification which is not seen in the aerosol experiments. The effective 
temperature responses in the bcx10 experiment show higher contrasts between land and sea regions than in the other experiments.

365 For greenhouse gases, the regional effective temperature responses are mostly associated with the response to $\Delta \mathrm{LW}_{\text {clr. }}$. However, with all forcers the spatial distribution of the $\Delta \mathrm{LW}_{\mathrm{clr}}$ contribution resembles the overall effective temperature response. The spatial correlation coefficients between the effective total and $\Delta \mathrm{LW}_{\mathrm{clr}}$-induced temperature responses for the $\operatorname{co} 2 \times 2, \operatorname{ch} 4 \times 3$, sulx 5 and bcx 10 experiments are $0.90,0.81,0,94$ and 0.74 , respectively. The difference between the greenhouse gas and aerosol experiments is that for greenhouse gases the $\Delta \mathrm{LW}_{\mathrm{clr}}$ response includes the combined effects of forcing, its rapid adjustments and lapse rate and water vapor feedbacks, while for aerosols the response results only from the rapid adjustments and lapse rate and water vapor feedbacks. For the $\operatorname{co} 2 \times 2$ and $\operatorname{ch} 4 \times 3$ experiments, the total effective temperature response and $\Delta \mathrm{L} \mathrm{W}_{\mathrm{clr}}$ temperature response differ most in the equatorial Pacific Ocean, where the $\Delta \mathrm{LW}$ clr response exceeds the total response. The high $\Delta \mathrm{LW}_{\text {clr }}$ temperature response in this region is compensated by contributions from $\Delta \mathrm{SW}_{\text {cld }}, \Delta \mathrm{LW}_{\text {cld }}$ and atmospheric energy transport $\triangle \mathrm{CONV}$ (see Fig, 4).

For aerosols, most of the effective temperature response is due to $\Delta \mathrm{SW}_{\mathrm{clr}}$. Besides the modest water vapor contributions to $\Delta \mathrm{SW}_{\mathrm{clr}}$, this response is directly related to excess scattering and absorption of solar radiation (direct aerosol radiative forcing) due to changes in aerosol concentrations, as was shown in Merikanto et al. (2021). Most of the sulfate emissions originate from Asia, Europe and North America, while most of the black carbon emissions originate from Asia, Europe and North America and African, South American and boreal wildfires (Myhre et al., 2012), This makes the forcing in both cases stronger in the Northern than in the Southern hemisphere. The $\Delta \mathrm{SW}_{\mathrm{clr}}$ temperature response to these emissions can be clearly seen both for the bcx 10 and sulx 5 experiments (see Fig. 5). For the bcx 5 experiments, the local effective temperature response due to $\Delta \mathrm{SW}_{\text {clr }}$ exceeds the total effective temperature response from the tropics to the Northern midlatitudes (Fig. 5). These local excess warming responses by $\Delta \mathrm{SW}_{\mathrm{clr}}$ in bcx 5 experiments are counteracted by temperature responses to changes in atmospheric energy transport and clouds. In case of aerosols, $\Delta \mathrm{LW}_{\text {clr }}$ contributes to the effective temperature response mainly in the Northern hemisphere continents and Arctic sea-ice regions. In the bcx10 experiments, $\Delta \mathrm{LW}_{\mathrm{clr}}$ induces a clear negative contribution over ocean regions related to changes in the vertical temperature distribution of the atmosphere (see Fig. S2).

There is significant variation in the regional effective temperature contributions due to clouds between regions and forcing agents. In the greenhouse gas experiments ( $\mathrm{co} 2 \times 2$ and $\mathrm{ch} 4 \times 3)$ the regional effective temperature responses due to $\Delta \mathrm{LW}$ cld and $\Delta \mathrm{SW}_{\text {cld }}$ tend to cancel each other, except over the Southern Ocean where the total cloud contribution is dominated by a negative $\Delta \mathrm{SW}_{\text {cld }}$ (see Fig. 5). This relates to a strong increase in cloud cover in the same regions (see Figures $\mathrm{S} 4$ and $\mathrm{S} 5$ ).

With aerosols, the net effect of clouds is more complicated. Both the sulx 5 and bcx10 experiments show a similar negative effective temperature response due to $\Delta \mathrm{SW}_{\text {cld }}$ over the Southern Ocean as the greenhouse gases. However, Northern 
hemispheric cloud responses are larger in magnitude for aerosols than for greenhouse gases, and for the bcx10 experiment in particular. Throughout the latitudes bcx10 causes a strong net cloud cooling, except for the polar regions where the net cloud responses are small. The sign of the regional $\Delta \mathrm{SW}_{\text {cld }}$ effective temperature response in the bcx 10 experiments depends strongly on the region. There is a negative temperature response due to $\Delta \mathrm{SW}_{\mathrm{cld}}$ in Asia and Africa, but positive over the Amazon region. This is related to the cloud cover change, as black carbon increases the cloud cover over Asia and Africa, but decreases it over the Amazon (see Fig, S5) due to the semi-direct aerosol effect of black carbon. Contrary to bcx10, sulx5 shows a mild positive contribution from clouds over Northern hemispheric midlatitudes and a mild cooling response in the Arctic regions. However, the strength of the $\Delta \mathrm{SW}_{\text {cld }}$ responses in the sulx 5 experiments depends on the inclusion or lack of aerosol-cloud indirect effect in the models.

The effective temperature response to surface albedo change originates from the change in sea-ice and snow cover and is always positive. Changes in surface albedo have a modest effect on the global effective temperature response with all forcers $\left(0.07,0.06,0.08,0.06 \mathrm{KW}^{-1} \mathrm{~m}^{2}\right.$ for the co $2 \times 2, \operatorname{ch} 4 \times 3$, sulx 5 , bcx 10 experiments, respectively). However, in some regions, the effective temperature response to albedo change exceeds $1 \mathrm{KW}^{-1} \mathrm{~m}^{2}$ for all forcers. Over the Arctic, the regions of local maximum values are the same where the overall effective temperature responses are highest, highlighting the role of sea-ice changes causing locally high temperature responses. The local maximum values of the effective temperature response to albedo change also match with the regions with a positive temperature response to ocean heat exchange ( $\triangle \mathrm{SURF}$ ). The change in surface albedo also enhances the temperature response over the Southern Ocean, but there the temperature response to oceanic heat exchange is slightly negative. However, over the Southern Ocean the temperature response signal to surface albedo change

415 is mainly visible in the co2x 2 and ch $4 \times 3$ experiments, and appears to be driven by the longwave clear-sky forcing and feedbacks, and ocean heat transport.

Over the oceans, $\triangle \mathrm{SURF}$ has a large impact on the effective temperature response, with the $\operatorname{co} 2 \times 2$, ch $4 \times 3$ and sulx 5 experiments all showing negative effective temperature contributions due to $\triangle \mathrm{SURF}$ south of Greenland and positive contributions over the Barents Sea. With black carbon a robust negative signal over the northern North Atlantic is missing, however, but similarly to other forcers there is a robust positive signal over the Barents Sea. As earlier found for increased $\mathrm{CO}_{2}$ by Räisänen (2017), the effects of oceanic heat transport and storage ( $\triangle \mathrm{SURF}$ ) and atmospheric heat transport $(\Delta \mathrm{CONV})$ strongly oppose each other over the oceans in the co2x2, ch4x3 and sulx 5 experiments. In the sulx 5 and bcx 10 experiments, $\triangle \mathrm{CONV}$ also significantly compensates for the surface temperature effects due to changes in $\Delta \mathrm{SW}_{\text {clr }}$, which reflects changes in the direct aerosol forcing.

\subsection{Model-to-model spread in regional effective temperature responses for different forcers}


Similarly, to the effective temperature response itself, also its model-to-model spread (standard deviation) can be decomposed

430 to components that sum up to the total spread in the effective surface temperature response (Sect. 2.2). Figure 6 shows the decomposed model-to-model standard deviations of the total effective temperature responses (first row) for each perturbation experiment, and the decomposed contributions of each component to the spread in total responses. The latitudinal distributions of the different components are shown in Fig. 7.

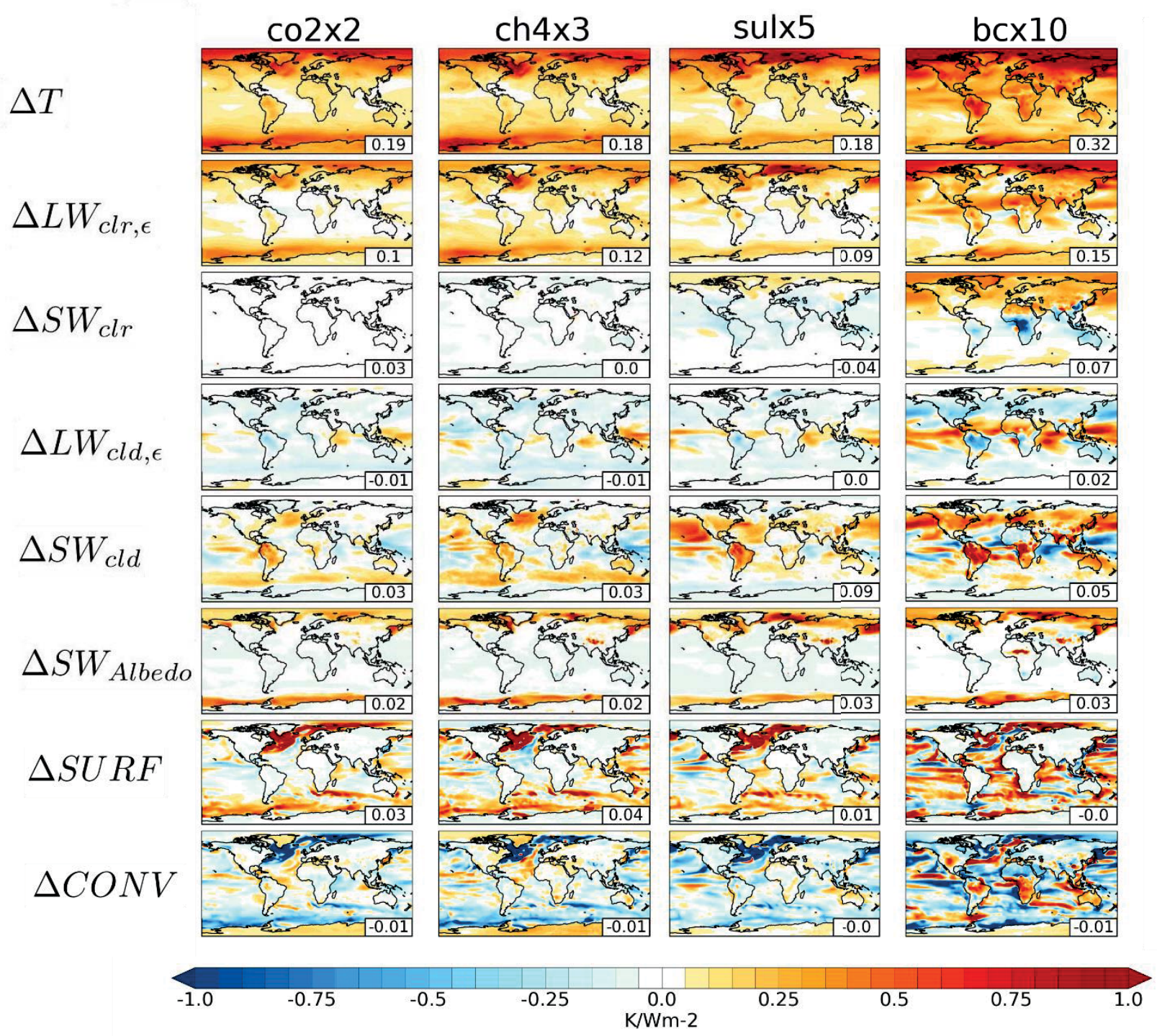

435 Figure 6. The model-to-model standard deviation of the effective temperature response to different climate perturbations (row 1) and its decomposed different energetic components (rows 2-8). Each column shows results for four different climate forcers, i.e. carbon dioxide (column 1), methane (column 2), sulfate (column 3) and black carbon (column 4). The global mean values are shown at the bottom-right corner of each panel. 

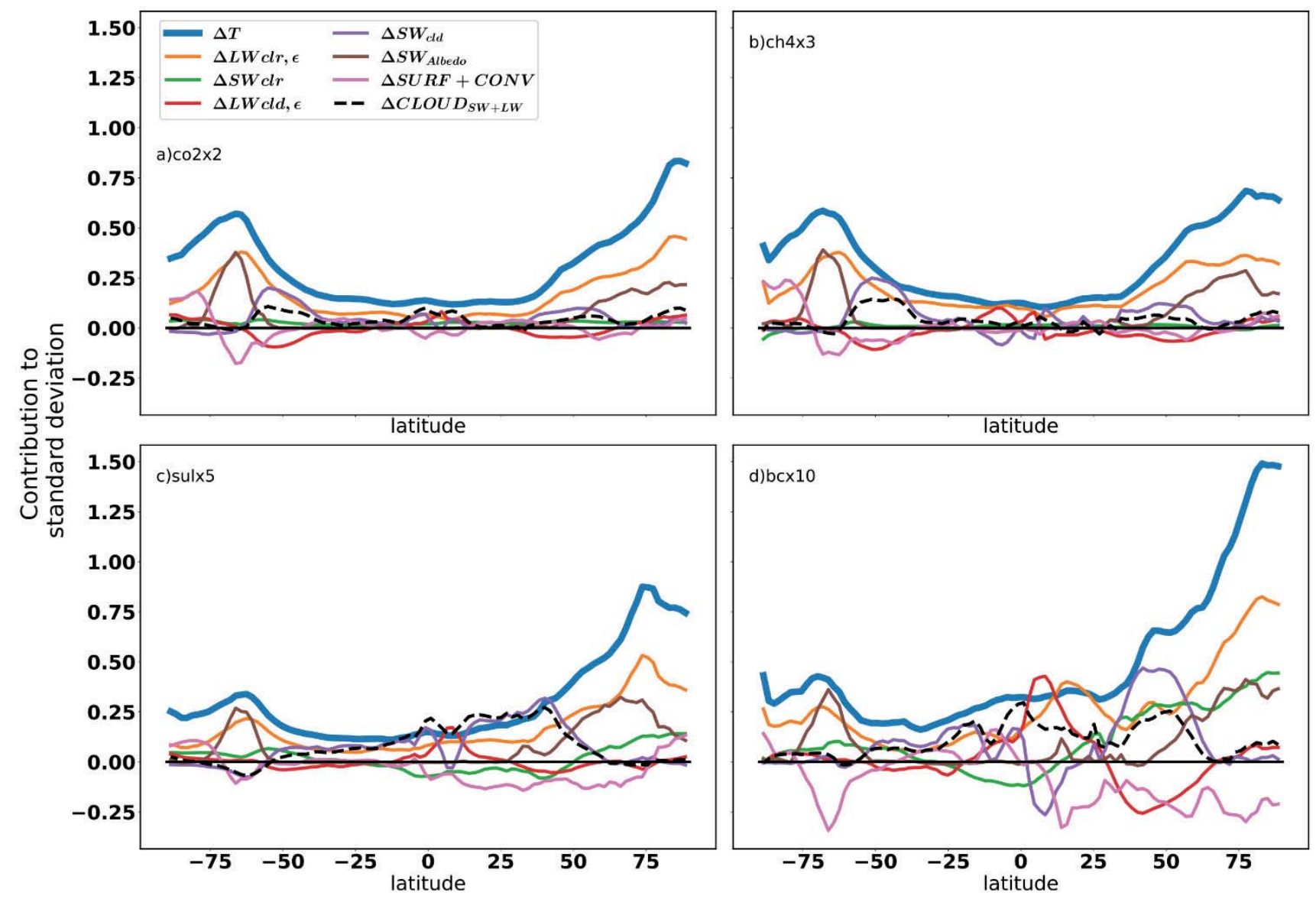

Figure 7. Zonal mean of the total standard deviation of the effective temperature response (thick blue line), and the contributions of the different energy balance terms to it (thin lines, see the legend in (a)). Panel (a) shows co2x2, panel (b) ch4x3, panel (c) sulx5 and panel (d) bcx10 experiment.

The globally averaged magnitude of the model-to-model spread is similar between co2x 2 , ch4x 3 and sulx 5 experiments $(0.19$, 0.18 , and $0.18 \mathrm{KW}^{-1} \mathrm{~m}^{2}$, respectively). Black carbon induces a much larger variability between the models $\left(0.32 \mathrm{KW}^{-1} \mathrm{~m}^{2}\right)$. The spatial structure of the model-to-model spread resembles the spatial structure of the effective temperature response. Furthermore, the spread in the temperature response amplifies towards polar regions, but the polar amplification of the spread 450 is even stronger than the amplification of the responses. Indeed, the majority of the model spread comes from the sea ice regions in the high latitudes, but the location of the maximum model-to-model spread varies between forcers. With co2x 2 and ch4x3, the regions with highest model spread are in the Arctic Ocean region north of Siberia $\left(1.10 \mathrm{KW}^{-1} \mathrm{~m}^{2}\right.$ with co2x2 and $1.30 \mathrm{KW}^{-1} \mathrm{~m}^{2}$ with $\left.\mathrm{ch} 4 \mathrm{x} 3\right)$ and in the Labrador Sea $\left(0.90 \mathrm{KW}^{-1} \mathrm{~m}^{2}\right.$ with $\operatorname{co} 2 \times 2$, and $1.60 \mathrm{KW}^{-1} \mathrm{~m}^{2}$ with ch4x3). With sulfate, the 
spread is the largest in the ocean region between Iceland and Svalbard $\left(2.47 \mathrm{KW}^{-1} \mathrm{~m}^{2}\right)$, and for black carbon east of Svalbard $\left(2.23 \mathrm{KW}^{-1} \mathrm{~m}^{2}\right)$. In the co2x2 and ch $4 \times 3$ experiments, the strongest component in model-to-model spread is $\Delta \mathrm{LW}$ clr (see Fig. 7), but the partial contributions of other components are also significant. The amplification of the spread in the effective temperature response towards high latitudes (Fig. 7) is strongly related to additional spread arising from differences in the surface albedo response ( $\Delta \mathrm{SW}_{\text {Albedo }}$ ), reflecting differences in sea ice and snow cover responses. The total contributions of cloud responses to the model spread are significant over Southern and Northern midlatitudes and to a lesser extent over the equatorial region. In the Southern Ocean sea-ice regions, the model spread originates from differences in the $\Delta \mathrm{LW}_{\text {clr }}$ and $\triangle \mathrm{SW}_{\text {Albedo }}$ responses in the models, as well as from differences in the oceanic heat exchange ( $\triangle \mathrm{SURF}$ ) compensated by differences in the atmospheric heat transport ( $\triangle \mathrm{CONV}$ ) (see Fig. 6). Between $30-45^{\circ} \mathrm{S}$, the model spread due to the combined effect of clouds ( $\left.\Delta \mathrm{SW}_{\text {cld }}+\Delta \mathrm{LW}_{\text {cld }}\right)$ is also evident. However, in the co2x2 and ch4x3 experiments the $\Delta \mathrm{SW}_{\text {cld }}$ and $\Delta \mathrm{LW}_{\text {cld }}$ terms often oppose each other, thus making the combined contribution of clouds to the total model spreads small in these experiments.

In the aerosol experiments (sulx5 and bcx10) the build-up of the model-to-model spread is more complicated than for the greenhouse gas experiments, despite similarities in the latitudinal distribution of the total spread of the effective temperature response. The contributions of $\Delta \mathrm{SW}_{\mathrm{clr}}$ (the pathway of aerosol direct radiative forcing) and the combined cloud response $\left(\Delta \mathrm{SW}_{\text {cld }}+\Delta \mathrm{LW}_{\text {cld }}\right.$ ) to the total model spread are much more significant in the aerosol experiments than in the greenhouse gas experiments. In the aerosol experiments, $\Delta \mathrm{SW}_{\text {clr }}$ adds to the model spread over the Southern Ocean in both the sulx 5 and bcx 10 experiments, suppresses the model spread over midlatitude and equatorial oceans in sulx 5 and over Southern hemisphere and equatorial continents in bcx 10, and adds model spread over Northern hemispheric continents (bcx5) and over the Arctic Ocean (both sulx5 and bcx10). Clouds have a large impact on the regional model-to-model spread in the aerosol experiments, and dominate the zonal means of the model spread in the sulx 5 experiments outside of the polar regions. Much of the model spread related to the combined cloud contributions $\left(\Delta \mathrm{SW}_{\text {cld }}+\Delta \mathrm{LW}_{\text {cld }}\right)$ results from differences in the aerosol setups in the models. With aerosol experiments (sulx5 and bcx10) most of the cloud-induced model-to-model spread is related to emissions sources, and is highly affected by which aerosol-cloud effects are included in the models. Also for aerosols, the contributions to model spread due to $\Delta \mathrm{SW}_{\text {cld }}$ and $\Delta \mathrm{LW}_{\text {cld }}$ often oppose each other, but the stronger model spread related to the $\Delta \mathrm{SW}_{\text {cld }}$ response dominates the overall cloud contribution in midlatitudes, while model spread due to $\Delta \mathrm{LW}_{\text {cld }}$ dominates the model spread over the equatorial regions.

On the other hand, in the aerosol experiments (sulx5 and bcx10) the atmospheric heat transport ( $\triangle \mathrm{CONV}$ ) tends to compensate the regional differences in model responses more efficiently than in the greenhouse gas experiments. In addition, the total heat transport ( $\triangle \mathrm{SURF}+\triangle \mathrm{SURF})$ reduces the zonally averaged model spread (see Fig. 7), particularly in the case of the bex 10 experiments. Similarly to the greenhouse gas experiments, $\Delta \mathrm{LW}$ clr is still a major driver of model-to-model spread also in the aerosol experiments, and particularly in the high latitude regions (Fig. 6). Compared to the greenhouse gas experiments, the 
aerosol experiments exhibit much greater contributions from $\Delta \mathrm{SW}_{\text {Albedo }}$ to the overall model-to-model spread in the Arctic region. In the co2x 2 and ch4x3 experiments, the maximum contributions to the model spread in the Arctic due to $\Delta \mathrm{SW}_{\mathrm{Albedo}}$ are 0.23 and $0.29 \mathrm{KW}^{-1} \mathrm{~m}^{2}$, respectively, while for sulx 5 and bcx10 the corresponding values are 0.32 and $0.41 \mathrm{KW}^{-1} \mathrm{~m}^{2}$, respectively. In the Southern hemisphere high latitudes aerosols and greenhouse gases have a similar structure in model-tomodel variability, however the aerosol experiments do not show a clear signal from $\Delta \mathrm{SW}_{\text {cld }}$ in the Southern Ocean.

Previously, the model-to-model spread in global climate sensitivity (equilibrium response to doubled $\mathrm{CO}_{2}$ concentration) has been largely attributed to differences in cloud feedback strength (Colman, 2003; Zelinka et al., 2020; Zhao et al., 2016). Our results point to somewhat divergent conclusions. Similarly to $\mathrm{Hu}$ et al. (2020), our results point to the water vapor feedback as the main mechanism leading to model spread. If the model spread is only attributed using feedback analysis, model differences in the forcing and adjustments may counteract some of the differences. However, it should be noted that our results are based on only six different models, and hence might be biased. For example, Zelinka et al. (2020) show that the contribution of clouds to the equilibrium climate sensitivity response exhibits notably large variation from approximately $-0.2 \mathrm{~K}$ to $3 \mathrm{~K}$ for

500 CMIP6 models and $-0.18 \mathrm{~K}$ to $2.6 \mathrm{~K}$ for CMIP5. In our results $\Delta \mathrm{SW}_{\text {cld }}$ and $\Delta \mathrm{LW}_{\text {cld }}$ largely cancel each other out in the co2x2 experiments, leading to a smaller combined cloud contribution to the model spread and contributes only $12 \%$ (see table S1) to the global model spread. For comparison, for a sample of 16 CMIP5 models with a transient response to doubling of $\mathrm{CO}_{2}$, Räisänen (2017) found the clear-sky LW response to be the largest contributor to the model spread in 34\% of the global area, whereas the combined cloud response had this position in $29 \%$ of the world.

\section{Discussion and Conclusions}

In this work, we have conducted an energy balance decomposition of the near-surface temperature response resulting from doubling $\mathrm{CO}_{2}$, tripling $\mathrm{CH}_{4}$, five folding sulfate concentrations, and ten folding black carbon concentrations for six independent climate models. The regional temperature response was then decomposed to contributions from different energy balance terms, namely changes in LW and SW clear-sky and cloud radiative fluxes (SW and LW), the net surface energy flux (SURF), and horizontal energy transport (CONV). All forcers produce a similar global response per unit ERF $(0.63,0.54,0.57$ and 0.61 $\mathrm{KW}^{-1} \mathrm{~m}^{2}$ for increasing $\mathrm{CO}_{2}, \mathrm{CH}_{4}$, sulfates and black carbon, respectively). The majority of the globally averaged temperature change for doubling the $\mathrm{CO}_{2}$ and tripling the $\mathrm{CH}_{4}$ concentration, originates from changes in clear-sky planetary emissivity ( 0.60 and $0.53 \mathrm{KW}^{-1} \mathrm{~m}^{2}$ respectively), i.e. from the combination of the longwave clear-sky radiative forcing with the change in the thermal structure of the atmosphere and water vapor concentrations. In the aerosol experiments (sulfate and black carbon)

515 the key driver of surface temperature response is the change in the clear-sky shortwave radiative flux $\left(0.36\right.$ and $0.71 \mathrm{KW}^{-1} \mathrm{~m}^{2}$ respectively) related to excess scattering and absorption of solar radiation (direct aerosol radiative forcing) due to changes in aerosol concentrations. We note that if only models including sulfate aerosol-cloud interactions are included, the SW cloud terms are in the same magnitude $\left(\Delta \mathrm{SW}_{\mathrm{clr}}=0.25\right.$ and $\left.\Delta \mathrm{SW}_{\mathrm{cld}}=0.12 \mathrm{KW}^{-1} \mathrm{~m}^{2}\right)$. See below for a more detailed discussion on different aerosol setups. The overall temperature response to the forcers is largest in high latitudes, where the response is driven 
by changes in LW clear-sky fluxes and changes in surface albedo, except for black carbon for which the majority of the total response comes from the clear-sky SW term in the high latitudes.

The temperature decomposition method provides a tool for understanding regional and global temperature changes. However, the original method is somewhat simplistic in its treatment of LW cloud processes (Räisänen, 2017). In Merikanto et al. (2021) we implemented a radiative kernel correction to make the LW treatment of clouds more realistic. However, despite this correction we still have a negative effective LW temperature response from clouds when the $\mathrm{CO}_{2}$ concentration is doubled, whereas literature suggests a positive LW cloud feedback (Tomassini et al., 2013; Vial et al., 2013). This is due to neglecting the positive masking effect of increasing $\mathrm{CO}_{2}$ on the LW cloud forcing, since the corresponding effects can not be calculated for the other forcing agents with existing kernels. The applied radiative kernels for the temperature and $\mathrm{H}_{2} \mathrm{O}$ have a relatively minor effect on global averages of the LW cloud and clear-sky terms (see Fig, S6). Similarly to previous studies (Smith et al., 2018), we found that the relative importance of the kernel correction does not depend on the radiative kernel used.

In our study, clouds play a minor role in the global mean temperature response, as the LW cloud and SW cloud terms tend to cancel each other out. However, regionally the temperature response originating from the clouds is a significant contributor.

535 For all forcers, the temperature response in the Antarctic sea-ice region and in the Southern Ocean is dampened by clouds. With BC clouds dampen the regional temperature response in Asia, North America, Africa, and Europe, and enhance the warming in Amazon. In contrast to clouds, with all forcing agents surface albedo changes enhance the temperature responses in high latitudes. For greenhouse gases, the mild polar amplification in south is associated with a negative contribution from the ocean heat exchange over the Southern Ocean, negative total cloud contribution and a mild LW clear-sky component.

We also decompose the model-to-model spread to the contributions of energy balance terms. The model-to-model spread is the largest in the same regions as the average temperature response, i.e. at high latitudes, where the spread is driven by differences in the lapse-rate and water vapor feedbacks $\left(\Delta \mathrm{LW}_{\text {clr }}\right)$ and differences in surface albedo $(\Delta \mathrm{SW}$ Albedo $)$ changes. For the aerosol-induced temperature responses, also differences in the direct aerosol forcing $\left(\Delta \mathrm{SW}_{\mathrm{clr}}\right)$ generate a significant contribution to the model spread, especially for black carbon. This partly arises from different aerosol configuration between models.

The aerosol configuration is important in the generation of the effective temperature response and its model-to-model spread. In the aerosol experiments, part of the model-to-model spread originates from the difference between aerosol setups, with the emission-driven models generating a higher effective temperature response than the concentration-driven models. For sulx5, the concentration-driven models' mean effective temperature response is $0.49 \mathrm{KW}^{-1} \mathrm{~m}^{2}$ while for the emission-driven models it is $0.66 \mathrm{KW}^{-1} \mathrm{~m}^{2}$. The corresponding numbers for the bcx 10 experiments are $0.45 \mathrm{KW}^{-1} \mathrm{~m}^{2}$ and $0.76 \mathrm{KW}^{-1} \mathrm{~m}^{2}$. For the sulx 5 experiments, the sign and the regional distribution of $\Delta \mathrm{SW}_{\text {cld }}$ is strongly related to the aerosol setup; however, it should be 
noted that two out of the three concentration-driven models do not include aerosol-cloud interactions. In the bcx 10 experiment, the aerosol setup modifies the $\Delta \mathrm{SW}_{\mathrm{clr}}$ and $\Delta \mathrm{LW}_{\mathrm{clr}}$ temperature responses (see $\mathrm{S} 1$, showing the decomposed temperature responses separately for the concentration and emission-driven models for the sulx 5 and bcx 10 experiments). The aerosol configuration also plays a crucial role in the SW-albedo response. For both the sulx 5 and bcx 10 aerosol experiments, only the emission-driven models show a significant temperature contribution from the $\Delta \mathrm{SW}_{\text {Albedo }}$ term $\left(0.1\right.$ and $0.08 \mathrm{KW}^{-1} \mathrm{~m}^{2}$ respectively) whereas the corresponding mean values for the concentration driven models are only 0.06 and $0.03 \mathrm{KW}^{-1} \mathrm{~m}^{2}$.

We have demonstrated that the mechanisms behind model uncertainty vary between different regions and forcing agents. Understanding the atmosphere's dynamical response to different forcers is key to understand future climate changes at the regional level. This is especially important in the case of aerosols, which are predicted to decline in the near future due to climate change and air pollution mitigation actions.

\section{Data and code availability}

Data and scripts used for data analysis can be obtained by contacting corresponding author

\section{Author contributions}

570 The manuscript was written by KN and JM, with contributions from all authors. KN and JM performed the analysis with help of JR. BS provided the PDRMIP data.

\section{Competing interests:}

The authors declare that they have no conflict of interest

\section{Acknowledgements}

We gratefully acknowledge the efforts of the PDRMIP community, and the modelers who have kindly made their simulation results publicly available. Storage and availability of PDRMIP data was provided by UNINETT Sigma2 - the National Infrastructure for High Performance Computing and Data Storage in Norway. BHS acknowledges funding by the Research 580 Council of Norway, project nr. 244141 (NetBC). JR acknowledges funding by Academy of Finland Flagship funding (grant. nr 337549). KN acknowledges funding by Academy of Finland grant nr. 340791. 


\section{References}

Andrews, T., Gregory, J. M., Webb, M. J., and Taylor, K. E.: Forcing, feedbacks and climate sensitivity in CMIP5 coupled atmosphere-ocean climate models. Geophysical Research Letters, 39(9), 2012

Arora, V. K., Scinocca, J. F., Boer, G. J., Christian, J. R., Denman, K. L., Flato, G. M., Kharin, V., Lee, W. and Merryfield, W. J.: Carbon emission limits required to satisfy future representative concentration pathways of greenhouse gases. Geophysical Research Letters, 38(5),2011

Bentsen, M., Bethke, I., Debernard, J. B., Iversen, T., Kirkevåg, A., Seland, ø., Drange, H., Roelandt, C., Seierstad, I. A., Hoose, C., and5Kristjánsson, J. E.: The Norwegian Earth System Model, NorESM1-M - Part 1: Description and basic evaluation of the physical climate,Geosci. Model Dev, 6, 687-720, https://doi.org/10.5194/gmd-6-687-2013, www.geosci-model-dev.net/6/687/2013/, 2013.

Block, K. and Mauritsen, T.: Forcing and feedback in the MPI-ESM-LR coupled model under abruptly quadrupled CO2, J. Adv. Model. Earth Syst., 5, 676-691, 2013.

Collins, W. J., Bellouin, N., Doutriaux-Boucher, M., Gedney, N., Halloran, P., Hinton, T., Hughes, J., Jones, C. D., Joshi, M., Liddicoat, S., Martin, G., O'Connor, F., Rae, J., Senior, C., Sitch, S., Totterdell, I., Wiltshire, A and Woodward, S.. Development and evaluation of an Earth-Syst,em model-HadGEM2. Geoscientific Model Development, 4(4), 10511075. doi:10.5194/Gmd-4-1051-2011, 2011

600 Colman, R.: A comparison of climate feedbacks in general circulation models. Climate Dynamics, 20 (7-8), 865-873.

Crook, J. A., Forster, P. M., and Stuber, N.: Spatial patterns of modeled climate feedback and contributions to temperature response and polar amplification. Journal of Climate, 24(14), 3575-3592., 2011

Etminan, M., Myhre, G., Highwood, E. J., and Shine, K. P.: Radiative forcing of carbon dioxide, methane, and nitrous oxide: A significant revision of the methane radiative forcing. Geophysical Research Letters, 43(24), 12,614-12,623. doi:10.1002/2016GL071930, 2016

Feldl, N., and Roe, G. H.: The nonlinear and nonlocal nature of climate feedbacks. Journal of Climate, 26(21), 8289-8304, 2013

Fiedler, S., Kinne, S., Huang, W. T. K., Räisänen, P., O'Donnell, D., Bellouin, N., Stier, P., Merikanto, J., Noije, T., and Makkonen, R. Anthropogenic aerosol forcing-insights from multiple estimates from aerosol-climate models with reduced complexity. Atmospheric Chemistry and Physics, 19(10), 6821-6841., 2019

Gent, P. R., Danabasoglu, G., Donner, L. J., Holland, M. M., Hunke, E. C., Jayne, S. R., Lawrence, D, Neale, R, Rasch, P, and Vertenstein, M. (2011). The community climate system model version 4. Journal of Climate, 24(19), 4973-4991. 2011

Gregory, J. M., Ingram, W. J., Palmer, M. A., Jones, G. S., Stott, P. A., Thorpe, R. B., Lowe, J., Johns, T., and Williams, K. D. (2004). A new method for diagnosing radiative forcing and climate sensitivity. Geophysical Research Letters, 31(3) 
Harshvardhan and Cess: Stratospheric aerosols: Effect upon atmospheric temperature and global climate, Tellus,124,2019

Hawkins, E., and Sutton, R., The potential to narrow uncertainty in regional climate predictions. Bulletin of the American Meteorological Society, 90(8), 1095-1108., 2009

Hu, X., Fan, H., Cai, M., Sejas, S. A., Taylor, P., and Yang, S., A less cloudy picture of the inter-model spread in future global warming projections. Nature Communications, 11(1), 1-11.,2020

Iversen, T., Bentsen, M., Bethke, I., Debernard, J. B., Kirkevåg, A., Seland, Ø., Drange, H., Kristjansson, J. E., Medhaug, I., Sand, M., and Seierstad, I. A.: The Norwegian Earth System Model, NorESM1-M -Part 2: Climate response and scenario projections, Geosci. Model Dev., 6, 389-415, https://doi.org/10.5194/gmd-6-389-2013, 2013.

Kirkevåg, A., Iversen, T., Seland, Ø., Hoose, C., Kristjánsson, J. E.,Struthers, H., Ekman, A. M. L., Ghan, S., Griesfeller, J., Nilsson, E. D., and Schulz, M.:Aerosol-climate interactions in the Norwegian Earth System Model -NorESM1-M, Geosci.ModelDev.,6,207-244,https://doi.org/10.5194/gmd-6207-2013, 2013.

Knutti, R., Masson, D., and Gettelman, A., Climate model genealogy: Generation CMIP5 and how we got there. Geophysical Research Letters, 40(6), 1194-1199., 2013

Lehner, F., Deser, C., Maher, N., Marotzke, J., Fischer, E. M., Brunner, L., Knutti, R., and Hawkins, E., Partitioning climate projection uncertainty with multiple large ensembles and CMIP5/6. Earth System Dynamics, 11(2), 491-508.. 2020.

Lu, J., amd Cai, M., A new framework for isolating individual feedback processes in coupled general circulation climate models. Part I: Formulation. Climate Dynamics, 32(6), 873-885., 2019.

Martin, G. M., Bellouin, N., Collins, W. J., Culverwell, I. D., Halloran, P. R., Hardiman, S. C., Hinton, T. J., Jones, C. D., McDonald, R. E.. and McLaren, A. J., The HadGEM2 family of Met Office Unified Model climate configurations, Geosci. Model Dev., 4, 723-757, doi: 10.5194., 2011

Matthews, H. D., Tokarska, K. B., Rogelj, J., Smith, C. J., MacDougall, A. H., Haustein, K., Mengis, N., Sippel, S., Forster, P., and Knutti, R., An integrated approach to quantifying uncertainties in the remaining carbon budget. Communications Earth \& Environment, 2(1), 1-11., 2021

Merikanto, J., Nordling, K., Räisänen, P., Räisänen, J., O'Donnell, D., Partanen, A., and Korhonen, H., How Asian aerosols impact regional surface temperatures across the globe. Atmospheric Chemistry and Physics, 1-27. 2021.

Myhre, G., Forster, P. M., Samset, B. H., Hodnebrog, O., Sillmann, J., Aalbergsjo, S. G., Andrews, T., Boucher, O., Faluvegi, G., Flaschner, D., Iversen, T., Kasoar, M., Kharin, V., Kirkevag, A., Lamarque, J. -F., Olivie, D., Richardson, T. B., Shindell, D., Shine, K. P., Stjern, C. W., Takemura, T., Voulgarakis, A., and Zwiers, F., PDRMIP: a Precipitation Driver and Response Model Intercomparison Project--protocol and preliminary results: PDRMIP investigates the role of various drivers of climate change for mean and extreme precipitation changes based on multiple climate model output and energy budget analyses. Bulletin of the American Meteorological Society, 98(6), 1185. doi:10.1175/BAMS-D-16-0019.1, 2017.

Myhre, G., Samset, B. H., Schulz, M., Balkanski, Y., Bauer, S., Berntsen, T. K., Bian, H., Bellouin, N., Chin, M., Diehl, T., Easter, R. C., Feichter, J., Ghan, S. J., Hauglustaine, D., Iversen, T., Kinne, S., Kirkevåg, A., Lamarque, J.-F., Lin, G., Liu, X., Luo, G., Ma, X., Penner, J. E., Rasch, P. J., Seland, ØSkeie, R. B., Stier, P., Takemura, T., Tsigaridis, K., Wang, Z., Xu, L., Yu, H., Yu, F., Yoon, J.-H.,Zhang, K., Zhang, H., and Zhou, C., Radiative forcing of the direct 
aerosol effect from AeroCom Phase II simulations. Atmospheric Chemistry and Physics Discussions, 12(8), 2235522413. doi:10.5194/acpd-12-22355-2012, 2012

Neale, R. B., Richter, J. H., Conley, A. J., Park, S., Lauritzen, P. H., Gettelman, A., Williamson, D. L., Rasch, P. J., Vavrus, S. J., and Taylor, M. A. (2010). Description of the NCAR Community Atmosphere Model (CAM 4.0), NCAR Tech. Note, TN-485, , 212., 2010

Nordling, K., Korhonen, H., R ais anen, P., Alper, M. E., Uotila, P., O'Donnell, D., and Merikanto, J., Role of climate model dynamics in estimated climate responses to anthropogenic aerosols. Atmospheric Chemistry and Physics, 19(15), 99699987., 2019

Pendergrass, A. G., Conley, A., and Vitt, F. M., Surface and top-of-atmosphere radiative feedback kernels for CESMCAM5. Earth System Science Data, 10(1), 317-324., 2018.

Persad, G. G., and Caldeira, K., Divergent global-scale temperature effects from identical aerosols emitted in different regions. Nature Communications, 9(1), 1-9., 2018.

Räisänen, J, An energy balance perspective on regional CO 2-induced temperature changes in CMIP5 models. Climate Dynamics, 48(9-10), 3441-3454., 2017.

Räisänen, J., and Ylhäisi, J. S, CO 2-induced climate change in northern Europe: CMIP2 versus CMIP3 versus CMIP5. Climate Dynamics, 45(7), 1877-1897., 2015.

Richardson, T. B., Forster, P. M., Andrews, T., Boucher, O., Faluvegi, G., Flaeschner, D., Hodnebrog, O., Kasoar, M., Kirkevag, A., Lamarque, J-F., Myhre, G., Olivie, D., Samset, B. H., Shawki, D., Shindell, D., Takemura, T., and Voulgarakis, A., Drivers of Precipitation Change: An Energetic Understanding. Journal of climate,31(23), 9641-9657, 2018

Richardson, T. B., Forster, P. M., Smith, C. J., Maycock, A. C., Wood, T., Andrews, T., Boucher, O., Faluvegi, G., Fläschner, D., Hodnebrog, Ø., Kasoar, M., Kirkevåg, A., Lamarque, J.-F., Mülmenstädt, J., Myhre, G., Olivié, D., Portmann, R. W., Samset, B. H., Shawki, D., Shindell, D., Stier, P., Takemura, T., Voulgarakis, A and Watson-Parris, D, Efficacy of Climate Forcings in PDRMIP Models. Journal of Geophysical Research. Atmospheres, 124(23), 1282412844. doi:10.1029/2019JD030581., 2019

Rogelj, J., Forster, P. M., Kriegler, E., Smith, C. J., and Séférian, R., Estimating and tracking the remaining carbon budget for stringent climate targets. Nature, 571(7765), 335-342., 2019

Samset, B. H., Sand, M., Smith, C. J., Bauer, S. E., Forster, P. M., Fuglestvedt, J. S., Osprey, S., and Schleussner, C.-F., Climate Impacts From a Removal of Anthropogenic Aerosol Emissions, Geophys. Res. Lett., 45, 1020-1029, https://doi.org/10.1002/2017GL076079-.., 2015

Schmidt, G. A., Kelley, M., Nazarenko, L., Ruedy, R., Russell, G. L., Aleinov, I., Bauer, M., Bauer, S. E., Bhat, M. K., Bleck, R., Canuto,V., Chen, Y.-H., Cheng, Y., Clune, T. L., Genio, A. D., de Fainchtein, R., Faluvegi, G., Hansen, J. E., Healy, R. J., Kiang, N. Y., Koch, D.,Lacis, A. A., LeGrande, A. N., Lerner, J., Lo, K. K., Matthews, E. E., Menon, S., Miller, R. L., Oinas, V., Oloso, A. O., Perlwitz, J. P.,Puma, M. J., Putman, W. M., Rind, D., Romanou, A., Sato, M., Shindell, D. T., Sun, S., Syed, R. A., Tausnev, N., Tsigaridis, K., Under,N., Volugarakis, A., Yao, M.-S., and Zhang, J.: Configuration and assessment of the GISS ModelE2 contributions to the CMIP5 archive,445J. Adv. Modell. Earth Syst., 6, 141-184, https://doi.org/10.1002/2013MS000265, 2014. 
https://doi.org/10.5194/acp-2021-401

Preprint. Discussion started: 22 June 2021

(c) Author(s) 2021. CC BY 4.0 License.

Shindell, D. T., Faluvegi, G., Rotstayn, L., and Milly, G., Spatial patterns of radiative forcing and surface temperature response. Journal of Geophysical Research: Atmospheres, 120(11), 5385-5403., 2015

Smith, C., Kramer, R. J., Myhre, G., Forster, P. M., Soden, B. J., Andrews, T., Boucher, O., Faluvegi, G. Fläschner, D., and Hodnebrog, Ø, Understanding rapid adjustments to diverse forcing agents. Geophysical Research Letters, 45(21), 12,023-12,031., 2018

Smith, C., HadGEM2 radiative kernels University of Leeds., 2018.

Smith, C. J., Kramer, R. J., Myhre, G., Alterskjær, K., Collins, W., Sima, A., Boucher, O., Dufresne, J.-L., Nabat, P., Michou, M., Yukimoto, S., Cole, J., Paynter, D., Shiogama, H., O'Connor, F. M., Robertson, E., Wiltshire, A., Andrews, T., Hannay, C., Miller, R., Nazarenko, L., Kirkevåg, A., Olivié, D., Fiedler, S., Lewinschal, A., Mackallah, C., Dix, M., Pincus, R., and Forster, P. M.: Effective radiative forcing and adjustments in CMIP6 models, Atmos. Chem. Phys., 20, 9591-9618, https://doi.org/10.5194/acp-20-9591-2020, 2020.

700 Soden, B. J., Held, I. M., Colman, R., Shell, K. M., Kiehl, J. T., and Shields, C. A., Quantifying climate feedbacks using radiative kernels. Journal of Climate, 21(14), 3504-3520., 2008

Stjern, C. W., Lund, M. T., Samset, B. H., Myhre, G., Forster, P. M., Andrews, T., Boucher, O., Faluvegi,G., Fläschner, D., Iversen, T., Kasoar, M., Kharin, V., Kirkevåg, A., Lamarque, J. F., Olivié, D., Richardson, T., Sand, M., Shawki, D., Shindell, 10D., Smith, C. J., Takemura, T. and Voulgarakis, A.: Arctic Amplification Response to Individual Climate Drivers, J. Geophys. Res. Atmos., doi:10.1029/2018JD029726, 2019

Stjern, C. W., Samset, B. H., Myhre, G., Forster, P. M., Hodnebrog, Ø., Andrews, T., Boucher, O., Faluvegi, G., 738Iversen, T., Kasoar, M., Kharin, V., Kirkevåg, A., Lamarque, J.-F., Olivié, D., Richardson, T., Shawki, D., 739Shindell, D., Smith, C. J., Takemura, T., and Voulgarakis, A.: Rapid Adjustments Cause Weak Surface 740Temperature Response to Increased Black Carbon Concentrations, Journal of Geophysical Research: 741Atmospheres, 122, 11,462-411,481, 10.1002/2017jd027326, 2017.

Takemura, T., Egashira, M., Matsuzawa, K., Ichijo, H., O'ishi, R., and Abe-Ouchi, A., A simulation of the global distribution and radiative forcing of soil dust aerosols at the Last Glacial Maximum. Atmospheric Chemistry $\backslash \&$ Physics, 9(9), 2009

Takemura, T., Nozawa, T., Emori, S., Nakajima, T. Y., and Nakajima, T., Simulation of climate response to aerosol direct and indirect effects with aerosol transport-radiation model. Journal of Geophysical Research: Atmospheres, 110(D2), 2005

Tang, T., Shindell, D., Faluvegi, G., Myhre, G., Olivié, D., Voulgarakis, A., Kasoar, M., Andrews, T., Boucher, O., Forster, P., Hodne-brog, O., Iversen, T., Kirkevåg, A., Lamarque, J.-F., Richardson, T., Samset, B., Stjern, C., Takemura, T., and Smith, C.: Comparisonof Effective Radiative Forcing Calculations Using Multiple Methods, Drivers, and Models, J. Geophys. Res.-Atmos., 124, 4382-4394,735https://doi.org/10.1029/2018JD030188, https://agupubs.onlinelibrary.wiley.com/doi/abs/10.1029/2018JD030188, 2019.

Taylor, K., Crucifix, M., Braconnot, P., Hewitt, C., Doutriaux, C., Broccoli, A., Mitchell, J., and Webb, M.: Estimating shortwave radiativeforcing and response in climate models, J. Climate, 20, 2530-2543, 2007

Tokarska, K. B., Gillett, N. P., Arora, V. K., Lee, W. G., and Zickfeld, K., The influence of non-CO2 forcings on cumulative carbon emissions budgets. Environmental Research Letters, 13(3), 034039., 2018 
Tomassini, L., Geoffroy, O., Dufresne, J., Idelkadi, A., Cagnazzo, C., Block, K., Mauritsen, T., Giorgetta, M., and Quaas, J., The respective roles of surface temperature driven feedbacks and tropospheric adjustment to CO 2 in CMIP5 transient climate simulations. Climate Dynamics, 41(11-12), 3103-3126., 2013

Vial, J., Dufresne, J., and Bony, S., On the interpretation of inter-model spread in CMIP5 climate sensitivity estimates. Climate Dynamics, 41(11-12), 3339-3362., 2013

730 Watanabe, M.,Suzuki, T., O’ishi, R., Komuro, Y., Watanabe, S., Emori, S., Toshihiko T., Minoru C., Tomoo O., Miho S., Kumiko T., Dai Y., Tokuta Y., Toru N., Hiroyasu H., Hiroaki T., and Kimoto, M., Improved Climate Simulation by MIROC5. Journal of Climate, 23(23), 6312-6335. doi:10.1175/2010JCLI3679.1, 2010

Wilcox, L. J., Liu, Z., Samset, B. H., Hawkins, E., Lund, M. T., Nordling, K., Undorf, S., Bollasina, M., Ekman, A. M. L., Krishnan, S., Merikanto, J., and Turner, A. G.: Accelerated increases in global and Asian summer monsoon precipitation from future aerosol reductions, Atmos. Chem. Phys., 20, 11955-11977, https://doi.org/10.5194/acp-2011955-2020, 2020.

Zelinka, M. D., Myers, T. A., McCoy, D. T., Po-Chedley, S., Ca ldwell, P. M., Ceppi, P., Klein, S. A., a nd Ta ylor, K. E.: Ca uses of Higher Clima te Sensitivity in CMIP6 Models, Geophys. Res. Lett., 47, e2019GL085782, 10.1029/2019GL085782, 2020.

740 Zhao, M., Golaz, J.-C., Held, I., Ramaswamy, V., Lin, S.-J., Ming, Y., Ginoux, P., Wyman, B., Donner, L., Paynter, D., et al.: Uncertainty inmodel climate sensitivity traced to representations of cumulus precipitation microphysics, Journal of Climate, 29, 543-560, 2016 

FINNISH METEOROLOGICAL INSTITUTE

Erik Palménin aukio 1

P.O. Box 503

FI-00560 HELSINKI

tel. +358295391000

\section{WWW.FMI.FI}

FINNISH METEOROLOGICAL INSTITUTE CONTRIBUTIONS No. 176

ISSN 0782-6117

ISBN 978-952-336-143-O (paperback)

ISBN 978-952-336-142-3 (pdf)

https://doi.org/10.35614/isbn.9789523361423

Helsinki, 2021

Edita Prima Oy

$\because \because \because 8$

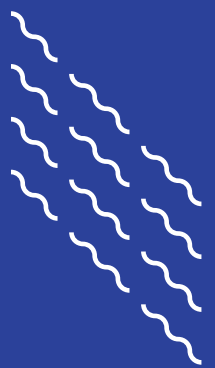

:००?

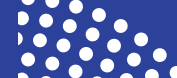

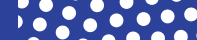

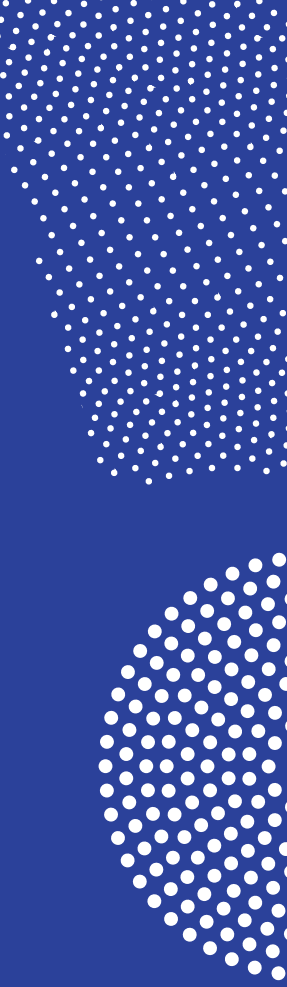

